INSTITUTO DE PESQUISAS ENERGÉTICAS E NUCLEARES

Autarquia associada à Universidade de São Paulo

\title{
ESTUDO DAS CARACTERÍSTICAS ELETROQUÍMICAS E MICROESTRUTURAIS DE ELETRODOS DE HIDRETO METÁLICO \\ À BASE DE LaNi COM ADIçÕES DE ELEMENTOS DE LIGA
}

\section{LIA MARIA CARLOTTI ZARPELON}

Tese apresentada como parte dos
requisitos para obtenção do Grau de
Doutor em Ciências na Área
de Tecnologia Nuclear - Materiais

Orientador:

Prof. Dr. Rubens Nunes de Faria Junior

Versão Corrigida

Versão Original disponível no IPEN

São Paulo

2016 
Aos meus amados pais

Helio Zarpelon (in memoriam)

Ruth Carlotti Zarpelon

e à minha querida

Dna. Cecília R. Almeida, exemplo vivo da caridade e da fé 


\section{AGRADECIMENTOS}

Ao Instituto de Pesquisas Energéticas e Nucleares pela oportunidade de realização deste trabalho.

Ao Dr. Rubens Nunes de Faria Junior pelo incentivo, orientação e assistência na execução deste trabalho.

À Fundação de Amparo à Pesquisa do Estado de São Paulo pelo apoio financeiro à execução do projeto 2004/12453-0 “Estudo da hidrogenação a alta temperatura para pulverização de ligas à base de LaPrMgAIMnCoNi“, de autoria do Dr. Rubens Nunes de Faria Junior, ao qual este trabalho esteve vinculado.

Aos integrantes do Laboratório de Microscopia e Microanálise do CCTM do IPEN pela viabilização das análises por microscopia eletrônica de varredura e espectroscopia por dispersão de energia de raios $\mathrm{X}$.

Aos integrantes do Laboratório de Difração de Raios X pelas análises realizadas.

À Dra. Vera Lúcia Ribeiro Salvador pelas contribuições ao trabalho, além do incentivo e amizade.

Ao Dr. Nelson Batista de Lima pelas contribuições ao trabalho e pelo empenho nas análises de difração de raios $X$ com refinamento por Rietveld.

Ao Dr. Luis Gallego Martinez pela colaboração inicial nas análises por difração de raios $X$.

À Dra. Isolda Costa e ao Dr. Everson do Prado Banczek pela realização e análise dos experimentos de resistência à corrosão das ligas consideradas neste estudo.

Ao Dr. Maurício David Martins das Neves pelo auxílio na interpretação dos aspectos morfológicos das ligas consideradas neste estudo.

Ao Dr. Julio César Serafim Casini pelos esclarecimentos na obtenção do carbono teflonado utilizado no preparo dos eletrodos de trabalho. 
À Msc. Ana Cláudia Martinelli Feher pela assistência e esclarecimentos prestados junto aos assuntos da Pós-Graduação, além de toda a paciência e amizade demonstradas.

Aos integrantes da Biblioteca do IPEN pelo empenho na obtenção de material bibliográfico e pela amizade.

Ao Dr. José Francisco Galves pelos cuidados médicos dispensados a mim e à minha família; por sua atenção, consideração e generosidade demonstradas ao longo de tantos anos.

Ao Alex da Silva Moraes por sua consideração por meus pais, sua amizade, e por tantas demonstrações de fraternidade para comigo, nos instantes de necessidade de auxílio e apoio.

A todos que direta ou indiretamente contribuíram para a realização deste trabalho, muito obrigada. 
“Estude sempre. A renovação das ideias favorece a evolução do espírito"

Extraído de Regras de Saúde de André Luiz, psicografia de Francisco Cândido Xavier 


\title{
ESTUDO DAS CARACTERÍSTICAS ELETROQUÍMICAS E MICROESTRUTURAIS DE ELETRODOS DE HIDRETO METÁLICO À BASE DE LaNi COM ADIÇÕES DE ELEMENTOS DE LIGA
}

\author{
Lia Maria Carlotti Zarpelon
}

\section{RESUMO}

Neste trabalho avaliou-se a ação positiva da substituição de lantânio por praseodímio e de lantânio por magnésio na performance eletroquímica de eletrodos de ligas de armazenamento de hidrogênio em estado bruto de fusão e com tratamento térmico. $\mathrm{O} \mathrm{La}$ foi substituído por $\mathrm{Mg}$ nas ligas $\mathrm{La}_{0,7-x} \mathrm{Mg}_{x} \mathrm{Pr}_{0,3} \mathrm{Al}_{0,3} \mathrm{Mn}_{0,4} \mathrm{Co}_{0,5} \mathrm{Ni}_{3,8} \quad(x=0,0-0,7) \quad$ e por $\mathrm{Pr}$ nas ligas $\mathrm{La}_{0,7-y} \mathrm{Pr}_{y} \mathrm{Mg}_{0,3} \mathrm{Al}_{0,3} \mathrm{Mn}_{0,4} \mathrm{Co}_{0,5} \mathrm{Ni}_{3,8} \quad(y=0,0-0,7)$. Os parâmetros eletroquímicos analisados foram ativação, capacidade de descarga, retenção da capacidade de descarga, autodescarga e alta taxa de descarga. As ligas apresentaram comportamento passivo em relação à corrosão. As análises por MEV/EDS e por DRX com refinamento por Rietveld revelaram a presença majoritária de fases similares às fases $\mathrm{LaNi}_{5}, \mathrm{PrNi}_{5}, \mathrm{LaMg}_{2} \mathrm{Ni}_{9}$ e $\mathrm{PrMg}_{2} \mathrm{Ni}_{9}$ em função das composições das ligas estudadas. Os parâmetros de rede e os volumes da célula unitária das fases diminuíram com a substituição crescente de La por Mg e de La por Pr. As capacidades de descarga máxima decresceram com a substituição crescente de La por Mg e de La por Pr, acompanhando o decréscimo da abundância da fase similar à fase $\mathrm{LaNi}_{5} \mathrm{e} O$ aumento da abundância da fase similar à fase $\mathrm{LaMg}_{2} \mathrm{Ni}_{\text {g }}$. Comparativamente, menores taxas de autodescarga e maior estabilidade cíclica foram observadas para o eletrodo da liga na condição $x=0,1$, ao passo que 0 eletrodo da liga na condição $y=0,0$ apresentou maiores valores de alta taxa de descarga, indicando melhor performance cinética.

Palavras-chave: ligas de armazenamento de hidrogênio; terras raras; eletrodo de hidreto metálico; propriedades eletroquímicas; microestrutura; baterias $\mathrm{Ni}-\mathrm{MH}$ 


\title{
STUDY OF ELECTROCHEMICAL AND MICROSTRUCTURAL CHARACTERISTICS OF LaNi-BASED METALLIC HYDRIDE ELECTRODES WITH ALLOYING ADDITIONS
}

\author{
Lia Maria Carlotti Zarpelon
}

\begin{abstract}
In this work, the positive action of the substitution of lanthanum by praseodymium and lanthanum by magnesium in the electrochemical performance of the as-cast and annealed hydrogen storage alloys electrodes had been evaluated. La was replaced by $\mathrm{Mg}$ in $\mathrm{La}_{0.7-x} \mathrm{Mg}_{x} \mathrm{Pr}_{0.3} \mathrm{Al}_{0.3} \mathrm{Mn}_{0.4} \mathrm{Co}_{0.5} \mathrm{Ni}_{3.8}(x=0.0-0.7)$ alloys and by $\operatorname{Pr}$ in $\mathrm{La}_{0.7-y} \mathrm{Pr}_{y} \mathrm{Mg}_{0.3} \mathrm{Al}_{0.3} \mathrm{Mn}_{0.4} \mathrm{Co}_{0.5} \mathrm{Ni}_{3.8} \quad(y=0.0-0.7)$ alloys. The electrochemical parameters analyzed were activation, discharge capacity, discharge capacity retention, self-discharge rate and high-rate dischargeability. The alloys showed a passive corrosion behavior. The analyses by SEM/EDS and XRD with Rietveld refinement revealed the majority presence of $\mathrm{LaNi}_{5}, \mathrm{PrNi}_{5}$, $\mathrm{LaMg}_{2} \mathrm{Ni}_{9}$ and $\mathrm{PrMg}_{2} \mathrm{Ni}_{9}$ similar reference phases depending on the compositions of the studied alloys. The lattice parameters and cell volumes of the component phases decreased with increasing substitution of La for $\mathrm{Mg}$ and with La for Pr. The maximum discharge capacity decreased with increasing substitution of $\mathrm{La}$ for $\mathrm{Mg}$ and with $\mathrm{La}$ for $\mathrm{Pr}$, following the decrease in the abundance of $\mathrm{LaNi}_{5}$ similar phase and the increase in the abundance of to the $\mathrm{LaMg}_{2} \mathrm{Ni}_{9}$ similar phase. Lower selfdischarge rates were observed for the alloy electrode when $x=0.1$, while higher high-rate dischargeability for the alloy electrode when $\mathrm{y}=0.0$ indicated better kinetic performance, comparatively.
\end{abstract}

Keywords: hydrogen storage alloys; rare earth-based alloys; metal hydride electrode; electrochemical properties; alloy structure; $\mathrm{Ni}-\mathrm{MH}$ battery 


\section{SUMÁRIO}

Página

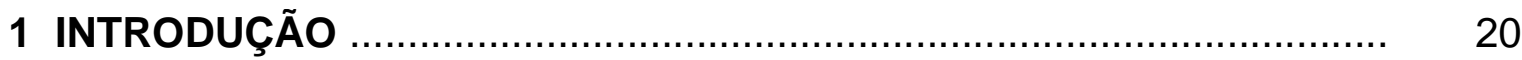

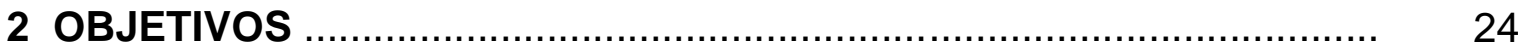

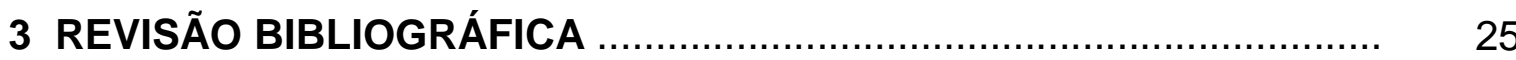

3.1 Princípios da bateria Ni-MH ......................................................... 25

3.2 Definições dos parâmetros eletroquímicos ............................................ 29

3.2.1 Capacidade de descarga …....................................................... 29

3.2.2 Ativação ............................................................................ 29

3.2.3 Retenção da capacidade de descarga .............................................. 29

3.2.4 Taxa de autodescarga ..............................................................

3.2.5 Alta taxa de descarga ............................................................. 30

3.3 Ligas de armazenamento de hidrogênio em baterias Ni-MH ................. 31

3.3.1 Aspectos termodinâmicos e cinéticos ................................................. 31

3.3.2 Resistência à corrosão ....................................................................... 32

3.3.3 Tratamentos e adições ................................................................. $\quad 35$

3.3.4 Sistemas utilizados .....................................................................

3.3.4.1 Ligas tipo $\mathrm{AB}_{5}$ à base de terras raras ............................................ 40

3.3.4.2 Ligas tipo R-Mg-Ni à base de terras raras-Mg-Ni ........................... 41

4 MATERIAIS E MÉTODOS ….............................................................. 52

4.1 Materiais e reagentes ...................................................................... 52

4.1.1 Ligas ........................................................................... 52

4.1.2 Demais materiais e reagentes ...................................................... 55

4.2 Métodos preparação/caracterização ................................................. 55

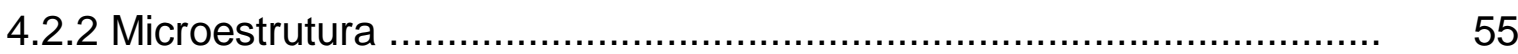

4.2.3 Resistência à corrosão ...................................................................... 55

4.3 Tratamento térmico …...................................................................... 56 
4.4 Estudo das propriedades eletroquímicas ………………………........ 57

4.4.1 Célula aberta de três eletrodos ........................................................ 57

4.4.1.1 Eletrodo de referência e contra-eletrodo ......................................... 58

4.4.1.2 Eletrodo de trabalho ................................................................... 58

4.4.2 Ciclos galvanostáticos de carga/descarga ....................................... 59

4.4.2.1 Detalhes experimentais ............................................................ 61

5 RESULTADOS E DISCUSSÃO ……………….................................... 64

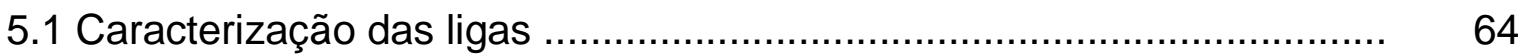

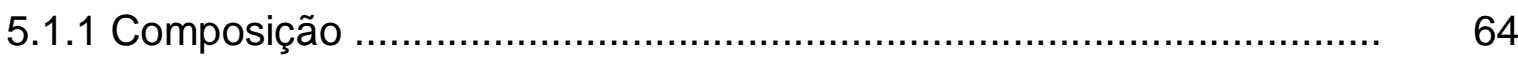

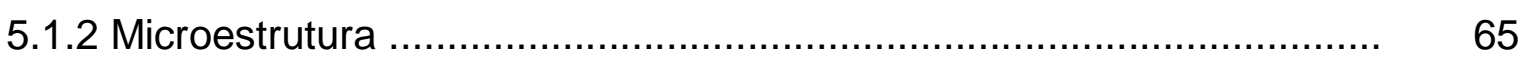

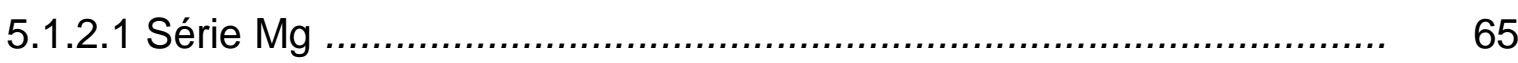

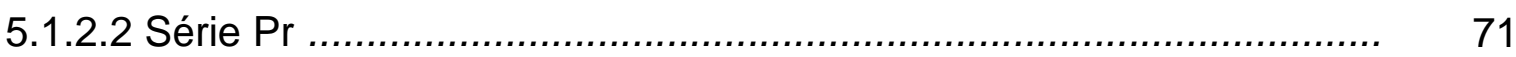

5.1.3 Estrutura cristalina ..................................................................

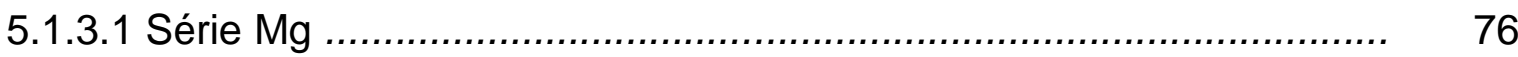

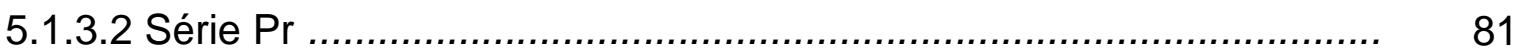

5.1.4 Resistência à corrosão ...................................................................... 86

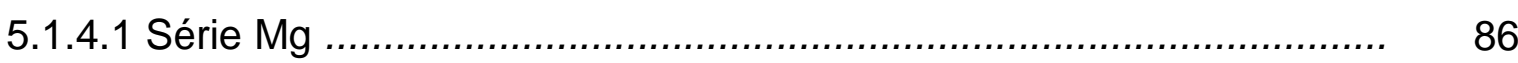

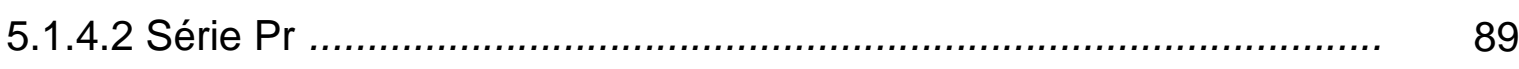

5.2 Propriedades eletroquímicas das ligas ............................................... 90

5.2.1 Efeito do teor de $\mathrm{Mg}$................................................................. 90

5.2.2 Efeito do teor de $\operatorname{Pr}$.................................................................... 97

5.2.3 Efeito do tratamento térmico ............................................................. 103

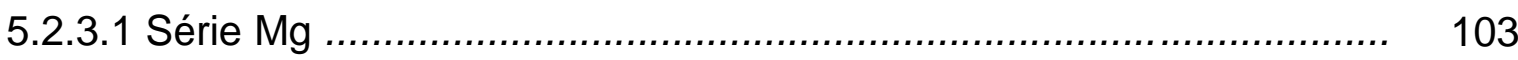

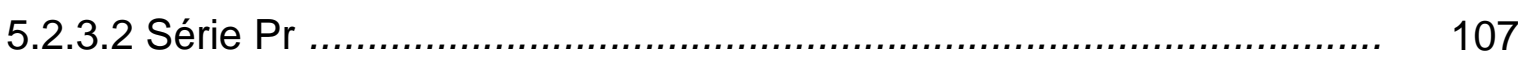

5.2.4 Efeito da densidade de corrente de descarga ................................ 112

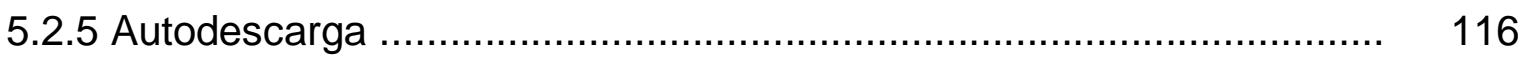

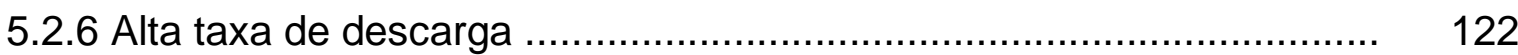

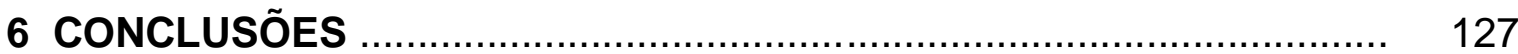

SUGESTÕES PARA TRABALHOS FUTUROS ……................................ 129

REFERÊNCIAS BIBLIOGRÁFICAS …………….............................. 130

PRODUÇÃO TÉCNICO-CIENTÍFICA ................................................... 142 


\section{LISTA DE TABELAS}

Página

TABELA 1 - Características dos principais tipos de ligas de armazenamento de hidrogênio desenvolvidas como material do eletrodo negativo para baterias $\mathrm{Ni}-\mathrm{MH}$.

TABELA 2 - Características estruturais e propriedades eletroquímicas de eletrodos de ligas à base de $\mathrm{R}-\mathrm{Mg}-\mathrm{Ni}$.

TABELA 3 - Composição em porcentagem de massa das ligas da Série $\mathrm{Mg}, \mathrm{La}_{0,7-x} \mathrm{Mg}_{x} \mathrm{Pr}_{0,3} \mathrm{Al}_{0,3} \mathrm{Mn}_{0,4} \mathrm{Co}_{0,5} \mathrm{Ni}_{3,8}(\mathrm{x}=0,0-0,7)$ - bruto de fusão.

TABELA 4 - Composição em porcentagem de massa das ligas da Série $\operatorname{Pr}, \mathrm{La}_{0,7-y} \mathrm{Pr}_{y} \mathrm{Mg}_{0,3} \mathrm{Al}_{0,3} \mathrm{Mn}_{0,4} \mathrm{Co}_{0,5} \mathrm{Ni}_{3,8}(y=0,0-0,7)$ - bruto de fusão.

TABELA 5 - Composições estequiométrica e atômica das ligas da Série $\mathrm{Mg}, \mathrm{La}_{0,7-x} \mathrm{Mg}_{x} \mathrm{Pr}_{0,3} \mathrm{Al}_{0,3} \mathrm{Mn}_{0,4} \mathrm{Co}_{0,5} \mathrm{Ni}_{3,8}(\mathrm{x}=0,0-0,7)$ - bruto de fusão.

TABELA 6 - Composições estequiométrica e atômica das ligas da Série $\operatorname{Pr}, \mathrm{La}_{0,7-y} \mathrm{Pr}_{y} \mathrm{Mg}_{0,3} \mathrm{Al}_{0,3} \mathrm{Mn}_{0,4} \mathrm{Co}_{0,5} \mathrm{Ni}_{3,8}(y=0,0-0,7)$ - bruto de fusão.

TABELA 7 - Sequência da parte experimental realizada para o estudo das características microestruturais e eletroquímicas dos eletrodos das ligas à base de LaNi.

TABELA 8 - Composições e massas molares das ligas da Série Mg, $\mathrm{La}_{0,7-x} \mathrm{Mg}_{x} \mathrm{Pr}_{0,3} \mathrm{Al}_{0,3} \mathrm{Mn}_{0,4} \mathrm{Co}_{0,5} \mathrm{Ni}_{3,8}(x=0,0-0,7)$ - bruto de fusão.

TABELA 9 - Composições e massas molares das ligas da Série $\operatorname{Pr}$, $\mathrm{La}_{0,7-y} \mathrm{Pr}_{y} \mathrm{Mg}_{0,3} \mathrm{Al}_{0,3} \mathrm{Mn}_{0,4} \mathrm{Co}_{0,5} \mathrm{Ni}_{3,8}(y=0,0-0,7)$

- bruto de fusão. 
Página

TABELA 10 - Composição da fase $M$ nas ligas da Série $M g$, $\mathrm{La}_{0,7-x} \mathrm{Mg}_{x} \mathrm{Pr}_{0,3} \mathrm{Al}_{0,3} \mathrm{Mn}_{0,4} \mathrm{Co}_{0,5} \mathrm{Ni}_{3,8}$, por EDS.

TABELA 11 - Composição da fase $G$ nas ligas da Série $M g$, $\mathrm{La}_{0,7-x} \mathrm{Mg}_{x} \mathrm{Pr}_{0,3} \mathrm{Al}_{0,3} \mathrm{Mn}_{0,4} \mathrm{Co}_{0,5} \mathrm{Ni}_{3,8}$, por EDS.

TABELA 12 - Composição da fase $D$ nas ligas da Série Mg, $\mathrm{La}_{0,7-x} \mathrm{Mg}_{x} \mathrm{Pr}_{0,3} \mathrm{Al}_{0,3} \mathrm{Mn}_{0,4} \mathrm{Co}_{0,5} \mathrm{Ni}_{3,8}$, por EDS.

TABELA 13 - Composição da fase $M$ nas ligas da Série Pr, $\mathrm{La}_{0,7-y} \mathrm{Pr}_{y} \mathrm{Mg}_{0,3} \mathrm{Al}_{0,3} \mathrm{Mn}_{0,4} \mathrm{Co}_{0,5} \mathrm{Ni}_{3,8}$, por EDS.

TABELA 14 - Composição da fase $G$ nas ligas da Série Pr, $\mathrm{La}_{0,7-y} \mathrm{Pr}_{y} \mathrm{Mg}_{0,3} \mathrm{Al}_{0,3} \mathrm{Mn}_{0,4} \mathrm{Co}_{0,5} \mathrm{Ni}_{3,8}$, por EDS.

TABELA 15 - Composição da fase $D$ nas ligas da Série $\operatorname{Pr}$, $\mathrm{La}_{0,7-y} \mathrm{Pr}_{y} \mathrm{Mg}_{0,3} \mathrm{Al}_{0,3} \mathrm{Mn}_{0,4} \mathrm{Co}_{0,5} \mathrm{Ni}_{3,8}$, por EDS.

TABELA 16 - Características das fases nas ligas da Série Mg, $\mathrm{La}_{0,7-x} \mathrm{Mg}_{x} \mathrm{Pr}_{0,3} \mathrm{Al}_{0,3} \mathrm{Mn}_{0,4} \mathrm{Co}_{0,5} \mathrm{Ni}_{3,8}(x=0,0-0,7)$.

TABELA 17 - Características das fases nas ligas da Série $\mathrm{Pr}$, $\mathrm{La}_{0,7-y} \mathrm{Pr}_{y} \mathrm{Mg}_{0,3} \mathrm{Al}_{0,3} \mathrm{Mn}_{0,4} \mathrm{Co}_{0,5} \mathrm{Ni}_{3,8}(y=0,0-0,7)$.

TABELA 18 - Propriedades eletroquímicas dos eletrodos das ligas da Série Mg, $\mathrm{La}_{0,7-x} \mathrm{Mg}_{x} \mathrm{Pr}_{0,3} \mathrm{Al}_{0,3} \mathrm{Mn}_{0,4} \mathrm{Co}_{0,5} \mathrm{Ni}_{3,8}$ sem tratamento térmico.

TABELA 19 - Propriedades eletroquímicas dos eletrodos das ligas da Série $\operatorname{Pr}, \mathrm{La}_{0,7-y} \mathrm{Pr}_{y} \mathrm{Mg}_{0,3} \mathrm{Al}_{0,3} \mathrm{Mn}_{0,4} \mathrm{Co}_{0,5} \mathrm{Ni}_{3,8}$ sem tratamento térmico.

TABELA 20 - Propriedades eletroquímicas dos eletrodos das ligas da Série Mg, $\mathrm{La}_{0,7-x} \mathrm{Mg}_{x} \mathrm{Pr}_{0,3} \mathrm{Al}_{0,3} \mathrm{Mn}_{0,4} \mathrm{Co}_{0,5} \mathrm{Ni}_{3,8}$ com tratamento térmico. 
Página

TABELA 21 - Propriedades eletroquímicas dos eletrodos das ligas da Série $\mathrm{Pr}, \mathrm{La}_{0,7-y} \mathrm{Pr}_{y} \mathrm{Mg}_{0,3} \mathrm{Al}_{0,3} \mathrm{Mn}_{0,4} \mathrm{Co}_{0,5} \mathrm{Ni}_{3,8}$ com tratamento térmico.

TABELA 22 - Propriedades eletroquímicas do eletrodo da liga $\mathrm{La}_{0,7} \mathrm{Pr}_{0,3} \mathrm{Al}_{0,3} \mathrm{Mn}_{0,4} \mathrm{Co}_{0,5} \mathrm{Ni}_{3,8}$ em função da densidade de corrente de descarga $\left(I_{D}\right)$.

TABELA 23 - Propriedades eletroquímicas dos eletrodos das ligas $\mathrm{La}_{0,7} \mathrm{Pr}_{0,3} \mathrm{Al}_{0,3} \mathrm{Mn}_{0,4} \mathrm{Co}_{0,5} \mathrm{Ni}_{3,8}, \mathrm{La}_{0,6} \mathrm{Mg}_{0,1} \mathrm{Pr}_{0,3} \mathrm{Al}_{0,3} \mathrm{Mn}_{0,4} \mathrm{Co}_{0,5} \mathrm{Ni}_{3,8}$ e $\mathrm{La}_{0,7} \mathrm{Mg}_{0,3} \mathrm{Al}_{0,3} \mathrm{Mn}_{0,4} \mathrm{Co}_{0,5} \mathrm{Ni}_{3,8}$ durante os experimentos de determinação de autodescarga $\left(I_{D}=200 \mathrm{~mA} \mathrm{~g}^{-1}\right)$. 


\section{LISTA DE FIGURAS}

Página

FIGURA 1 - Diagrama esquemático do processo eletroquímico de reação de carga/descarga

de uma bateria Ni-MH.

FIGURA 2 - Curvas de polarização das ligas $\mathrm{La}_{0,7-x} \mathrm{Pr}_{x} \mathrm{Mg}_{0,3} \mathrm{Al}_{0,3} \mathrm{Mn}_{0,4}$ $\mathrm{Co}_{0,5} \mathrm{Ni}_{3,8}(x=0,0 ; 0,1 ; 0,3 ; 0,5 ; 0,7)$ em solução de $\mathrm{KOH}$ $6,0 \mathrm{~mol} \mathrm{~L}^{-1}$ : (a) curvas de polarização anódica; (b) curvas de polarização catódica.

FIGURA 3 - Detalhe do sistema experimental adotado para os ciclos galvanostáticos de carga/descarga, mostrando a célula eletroquímica de três eletrodos, onde (1) corresponde ao contra-eletrodo, (2) ao eletrodo de referência, e (3) ao eletrodo de trabalho.

FIGURA 4 - Configuração para a montagem do eletrodo de referência, onde (1) corresponde à camisa interna e (2) à camisa externa.

FIGURA 5 - Micrografias de representação geral das ligas da Série Mg: (a) $\mathrm{La}_{0,7} \mathrm{Pr}_{0,3} \mathrm{Al}_{0,3} \mathrm{Mn}_{0,4} \mathrm{Co}_{0,5} \mathrm{Ni}_{3,8}$;

(b) $\mathrm{La}_{0,6} \mathrm{Mg}_{0,1} \mathrm{Pr}_{0,3} \mathrm{Al}_{0,3} \mathrm{Mn}_{0,4} \mathrm{Co}_{0,5} \mathrm{Ni}_{3,8}$;

(c) $\mathrm{La}_{0,4} \mathrm{Mg}_{0,3} \mathrm{Pr}_{0,3} \mathrm{Al}_{0,3} \mathrm{Mn}_{0,4} \mathrm{Co}_{0,5} \mathrm{Ni}_{3,8}$;

(d) $\mathrm{La}_{0,2} \mathrm{Mg}_{0,5} \mathrm{Pr}_{0,3} \mathrm{Al}_{0,3} \mathrm{Mn}_{0,4} \mathrm{Co}_{0,5} \mathrm{Ni}_{3,8}$;

(e) $\mathrm{Mg}_{0,7} \mathrm{Pr}_{0,3} \mathrm{Al}_{0,3} \mathrm{Mn}_{0,4} \mathrm{Co}_{0,5} \mathrm{Ni}_{3,8}$

(tensão 20,0 kV; ampliação 200x).

FIGURA 6 - Micrografias das ligas da Série Mg mostrando as fases

M, G e D: (a) $\mathrm{La}_{0,7} \mathrm{Pr}_{0,3} \mathrm{Al}_{0,3} \mathrm{Mn}_{0,4} \mathrm{Co}_{0,5} \mathrm{Ni}_{3,8}$;

(b) $\mathrm{La}_{0,6} \mathrm{Mg}_{0,1} \mathrm{Pr}_{0,3} \mathrm{Al}_{0,3} \mathrm{Mn}_{0,4} \mathrm{Co}_{0,5} \mathrm{Ni}_{3,8}$;

(c) $\mathrm{La}_{0,4} \mathrm{Mg}_{0,3} \mathrm{Pr}_{0,3} \mathrm{Al}_{0,3} \mathrm{Mn}_{0,4} \mathrm{Co}_{0,5} \mathrm{Ni}_{3,8}$;

(d) $\mathrm{La}_{0,2} \mathrm{Mg}_{0,5} \mathrm{Pr}_{0,3} \mathrm{Al}_{0,3} \mathrm{Mn}_{0,4} \mathrm{Co}_{0,5} \mathrm{Ni}_{3,8}$;

(e) $\mathrm{Mg}_{0,7} \mathrm{Pr}_{0,3} \mathrm{Al}_{0,3} \mathrm{Mn}_{0,4} \mathrm{Co}_{0,5} \mathrm{Ni}_{3,8}$

(tensão 20,0 kV; ampliação 800x). 
Página

FIGURA 7 - Micrografias de representação geral das ligas da Série Pr: (a) $\mathrm{La}_{0,7} \mathrm{Mg}_{0,3} \mathrm{Al}_{0,3} \mathrm{Mn}_{0,4} \mathrm{Co}_{0,5} \mathrm{Ni}_{3,8}$;

(b) $\mathrm{La}_{0,6} \mathrm{Pr}_{0,1} \mathrm{Mg}_{0,3} \mathrm{Al}_{0,3} \mathrm{Mn}_{0,4} \mathrm{Co}_{0,5} \mathrm{Ni}_{3,8}$;

(c) $\mathrm{La}_{0,4} \mathrm{Pr}_{0,3} \mathrm{Mg}_{0,3} \mathrm{Al}_{0,3} \mathrm{Mn}_{0,4} \mathrm{Co}_{0,5} \mathrm{Ni}_{3,8}$;

(d) $\mathrm{La}_{0,2} \mathrm{Pr}_{0,5} \mathrm{Mg}_{0,3} \mathrm{Al}_{0,3} \mathrm{Mn}_{0,4} \mathrm{Co}_{0,5} \mathrm{Ni}_{3,8}$;

(e) $\mathrm{Pr}_{0,7} \mathrm{Mg}_{0,3} \mathrm{Al}_{0,3} \mathrm{Mn}_{0,4} \mathrm{Co}_{0,5} \mathrm{Ni}_{3,8}$

(tensão 20,0 kV; ampliação 200x).

FIGURA 8 - Micrografias das ligas da Série $\operatorname{Pr}$ mostrando as fases

M, G e D: (a) $\mathrm{La}_{0,7} \mathrm{Mg}_{0,3} \mathrm{Al}_{0,3} \mathrm{Mn}_{0,4} \mathrm{Co}_{0,5} \mathrm{Ni}_{3,8}$;

(b) $\mathrm{La}_{0,6} \mathrm{Pr}_{0,1} \mathrm{Mg}_{0,3} \mathrm{Al}_{0,3} \mathrm{Mn}_{0,4} \mathrm{Co}_{0,5} \mathrm{Ni}_{3,8}$;

(c) $\mathrm{La}_{0,4} \mathrm{Pr}_{0,3} \mathrm{Mg}_{0,3} \mathrm{Al}_{0,3} \mathrm{Mn}_{0,4} \mathrm{Co}_{0,5} \mathrm{Ni}_{3,8}$;

(d) $\mathrm{La}_{0,2} \mathrm{Pr}_{0,5} \mathrm{Mg}_{0,3} \mathrm{Al}_{0,3} \mathrm{Mn}_{0,4} \mathrm{Co}_{0,5} \mathrm{Ni}_{3,8}$;

(e) $\mathrm{Pr}_{0,7} \mathrm{Mg}_{0,3} \mathrm{Al}_{0,3} \mathrm{Mn}_{0,4} \mathrm{Co}_{0,5} \mathrm{Ni}_{3,8}$

(tensão 20,0 kV; ampliação 800x).

FIGURA 9 - Espectros de difração de Raios $X$ das ligas da Série $M g$,

$\mathrm{La}_{0,7-x} \mathrm{Mg}_{x} \mathrm{Pr}_{0,3} \mathrm{Al}_{0,3} \mathrm{Mn}_{0,4} \mathrm{Co}_{0,5} \mathrm{Ni}_{3,8}(x=0,0-0,7)$.

FIGURA 10 - Parâmetros de rede e volumes de célula unitária das ligas da Série Mg, La $0_{0,7-x} \mathrm{Mg}_{x} \mathrm{Pr}_{0,3} \mathrm{Al}_{0,3} \mathrm{Mn}_{0,4} \mathrm{Co}_{0,5} \mathrm{Ni}_{3,8}(x=0,0-0,7)$ :

(a) fases $\mathrm{LaNi}_{5}, \mathrm{PrNi}_{5}$ e (La,Pr) $\mathrm{Ni}_{5}$; (b) fases (La, $\left.\mathrm{Pr}\right) \mathrm{Mg}_{2} \mathrm{Ni}_{9}$ e $\mathrm{PrMg}_{2} \mathrm{Ni}_{9}$.

FIGURA 11 - Abundância de fases nas ligas da Série Mg, $\mathrm{La}_{0,7-x} \mathrm{Mg}_{x} \mathrm{Pr}_{0,3} \mathrm{Al}_{0,3} \mathrm{Mn}_{0,4} \mathrm{Co}_{0,5} \mathrm{Ni}_{3,8}(x=0,0-0,7)$, onde $M=$ fase matriz; $G$ = fase cinza; $D=$ fase escura. 80

FIGURA 12 - Espectros de difração de Raios $X$ das ligas da Série $\operatorname{Pr}$, $\mathrm{La}_{0,7-y} \mathrm{Pr}_{y} \mathrm{Mg}_{0,3} \mathrm{Al}_{0,3} \mathrm{Mn}_{0,4} \mathrm{Co}_{0,5} \mathrm{Ni}_{3,8}(y=0,0-0,7)$.

FIGURA 13 - Parâmetros de rede e volumes de célula unitária das ligas da Série $\operatorname{Pr}, \mathrm{La}_{0,7-y} \mathrm{Pr}_{y} \mathrm{Mg}_{0,3} \mathrm{Al}_{0,3} \mathrm{Mn}_{0,4} \mathrm{Co}_{0,5} \mathrm{Ni}_{3,8}(y=0,0-0,7)$ :

(a) fases $\mathrm{LaNi}_{5}, \mathrm{PrNi}_{5}$ e (La,Pr) $\mathrm{Ni}_{5}$; (b) fases $\mathrm{LaMg}_{2} \mathrm{Ni}_{9}$, (La, $\mathrm{Pr}) \mathrm{Mg}_{2} \mathrm{Ni}_{9}$ e $\mathrm{PrMg}_{2} \mathrm{Ni}_{9}$. 
Página

FIGURA 14 - Abundância de fases nas ligas da Série $\mathrm{Pr}$,

$\mathrm{La}_{0,7-y} \mathrm{Pr}_{y} \mathrm{Mg}_{0,3} \mathrm{Al}_{0,3} \mathrm{Mn}_{0,4} \mathrm{Co}_{0,5} \mathrm{Ni}_{3,8}(y=0,0-0,7)$,

onde $M=$ fase matriz; $G$ = fase cinza; $D=$ fase escura.

FIGURA 15 - Curvas de polarização anódica das ligas da Série Mg,

$\mathrm{La}_{0,7-x} \mathrm{Mg}_{x} \mathrm{Pr}_{0,3} \mathrm{Al}_{0,3} \mathrm{Mn}_{0,4} \mathrm{Co}_{0,5} \mathrm{Ni}_{3,8}(x=0,0-0,7)$

em solução $\mathrm{KOH} 6,0 \mathrm{~mol} \mathrm{~L}^{-1}$.

86

FIGURA 16 - Diagramas de Nyquist das ligas da Série Mg,

$\mathrm{La}_{0,7-x} \mathrm{Mg}_{x} \mathrm{Pr}_{0,3} \mathrm{Al}_{0,3} \mathrm{Mn}_{0,4} \mathrm{Co}_{0,5} \mathrm{Ni}_{3,8}(x=0,0-0,7)$

testadas em solução $\mathrm{KOH} 6,0 \mathrm{~mol} \mathrm{~L}^{-1}$.

FIGURA 17 - Diagramas de ângulo de fase de Bode das ligas da

Série Mg, La ${ }_{0,7-x} \mathrm{Mg}_{x} \mathrm{Pr}_{0,3} \mathrm{Al}_{0,3} \mathrm{Mn}_{0,4} \mathrm{Co}_{0,5} \mathrm{Ni}_{3,8}(x=0,0-0,7)$

testadas em solução $\mathrm{KOH} 6,0 \mathrm{~mol} \mathrm{~L}^{-1}$.

FIGURA 18 - Perfis de ativação dos eletrodos das ligas da Série Mg,

$\mathrm{La}_{0,7-x} \mathrm{Mg}_{x} \mathrm{Pr}_{0,3} \mathrm{Al}_{0,3} \mathrm{Mn}_{0,4} \mathrm{Co}_{0,5} \mathrm{Ni}_{3,8}(x=0,0-0,7)$

sem tratamento térmico.

FIGURA 19 - Capacidade de descarga máxima $\left(\mathrm{C}_{\text {máx }}\right)$ em função das abundâncias relativas de fases $\mathrm{LaNi}_{5}, \mathrm{PrNi}_{5} \mathrm{e}(\mathrm{La}, \mathrm{Pr}) \mathrm{Ni}_{5}$ para a Série Mg, La $0,7-x \mathrm{Mg}_{x} \mathrm{Pr}_{0,3} \mathrm{Al}_{0,3} \mathrm{Mn}_{0,4} \mathrm{Co}_{0,5} \mathrm{Ni}_{3,8}$ $(x=0,0-0,7)$.

FIGURA 20 - (a) Capacidade de descarga das ligas da Série Mg, $\mathrm{La}_{0,7-x} \mathrm{Mg}_{x} \mathrm{Pr}_{0,3} \mathrm{Al}_{0,3} \mathrm{Mn}_{0,4} \mathrm{Co}_{0,5} \mathrm{Ni}_{3,8}(x=0,0-0,7)$ sem tratamento térmico vs. número do ciclo; (b) Retenção da capacidade de descarga das ligas da Série Mg sem tratamento térmico para $x=0,0 ; x=0,1$ e $x=0,3$.

FIGURA 21 - Curvas de potencial de descarga dos eletrodos das ligas da Série Mg, La $0_{0,7-x} \mathrm{Mg}_{x} \mathrm{Pr}_{0,3} \mathrm{Al}_{0,3} \mathrm{Mn}_{0,4} \mathrm{Co}_{0,5} \mathrm{Ni}_{3,8}(x=0,0-0,7)$ sem tratamento térmico. 


\section{Página}

FIGURA 22 - Perfis de ativação dos eletrodos das ligas da Série $\mathrm{Pr}$, $\mathrm{La}_{0,7-y} \mathrm{Pr}_{y} \mathrm{Mg}_{0,3} \mathrm{Al}_{0,3} \mathrm{Mn}_{0,4} \mathrm{Co}_{0,5} \mathrm{Ni}_{3,8}(y=0,0-0,7)$ sem tratamento térmico.

FIGURA 23 - Capacidade de descarga máxima $\left(\mathrm{C}_{\text {máx }}\right)$ em função das abundâncias relativas de fases $\mathrm{LaNi}_{5}, \mathrm{PrNi}_{5} \mathrm{e}(\mathrm{La}, \mathrm{Pr}) \mathrm{Ni}_{5}$ para a Série $\operatorname{Pr}, \mathrm{La}_{0,7-y} \mathrm{Pr}_{y} \mathrm{Mg}_{0,3} \mathrm{Al}_{0,3} \mathrm{Mn}_{0,4} \mathrm{Co}_{0,5} \mathrm{Ni}_{3,8}$ $(y=0,0-0,7)$.

FIGURA 24 - (a) Capacidade de descarga das ligas da Série $\operatorname{Pr}$, $\mathrm{La}_{0,7-y} \mathrm{Pr}_{y} \mathrm{Mg}_{0,3} \mathrm{Al}_{0,3} \mathrm{Mn}_{0,4} \mathrm{Co}_{0,5} \mathrm{Ni}_{3,8}(y=0,0-0,7)$ sem tratamento térmico vs. número do ciclo; (b) Retenção da capacidade de descarga das ligas da Série Pr sem tratamento térmico para $y=0,0 ; y=0,1$ e $y=0,3$.

FIGURA 25 - Curvas de potencial de descarga dos eletrodos das ligas da Série $\operatorname{Pr}, \mathrm{La}_{0,7-y} \mathrm{Pr}_{y} \mathrm{Mg}_{0,3} \mathrm{Al}_{0,3} \mathrm{Mn}_{0,4} \mathrm{Co}_{0,5} \mathrm{Ni}_{3,8}(y=0,0-0,7)$ sem tratamento térmico.

FIGURA 26 - Perfis de ativação dos eletrodos das ligas da Série Mg, $\mathrm{La}_{0,7-x} \mathrm{Mg}_{x} \mathrm{Pr}_{0,3} \mathrm{Al}_{0,3} \mathrm{Mn}_{0,4} \mathrm{Co}_{0,5} \mathrm{Ni}_{3,8}(x=0,0-0,7) \mathrm{com}$ tratamento térmico.

FIGURA 27 - (a) Capacidade de descarga das ligas da Série Mg, $\mathrm{La}_{0,7-x} \mathrm{Mg}_{x} \mathrm{Pr}_{0,3} \mathrm{Al}_{0,3} \mathrm{Mn}_{0,4} \mathrm{Co}_{0,5} \mathrm{Ni}_{3,8}(x=0,0-0,7) \mathrm{com}$ tratamento térmico vs. número do ciclo; (b) Retenção da capacidade de descarga das ligas da Série Mg com tratamento térmico para $x=0,0 ; x=0,1$ e $x=0,3$.

FIGURA 28 - Curvas de potencial de descarga dos eletrodos das ligas da Série Mg, $\mathrm{La}_{0,7-x} \mathrm{Mg}_{x} \mathrm{Pr}_{0,3} \mathrm{Al}_{0,3} \mathrm{Mn}_{0,4} \mathrm{Co}_{0,5} \mathrm{Ni}_{3,8}(x=0,0-0,7)$ com tratamento térmico.

FIGURA 29 - Perfis de ativação dos eletrodos das ligas da Série $\operatorname{Pr}$, $\mathrm{La}_{0,7-y} \mathrm{Pr}_{y} \mathrm{Mg}_{0,3} \mathrm{Al}_{0,3} \mathrm{Mn}_{0,4} \mathrm{Co}_{0,5} \mathrm{Ni}_{3,8}$ ( $(y=0,0-0,7) \mathrm{com}$ tratamento térmico. 
Página

FIGURA 30 - (a) Capacidade de descarga das ligas da Série $\mathrm{Pr}$, $\mathrm{La}_{0,7-y} \mathrm{Pr}_{y} \mathrm{Mg}_{0,3} \mathrm{Al}_{0,3} \mathrm{Mn}_{0,4} \mathrm{Co}_{0,5} \mathrm{Ni}_{3,8}(y=0,0-0,7) \mathrm{com}$ tratamento térmico vs. número do ciclo; (b) Retenção da capacidade de descarga das ligas da Série Pr com tratamento térmico para $y=0,0 ; y=0,1$ e $y=0,3$.

FIGURA 31 - Curvas de potencial de descarga dos eletrodos das ligas da Série $\operatorname{Pr}, \mathrm{La}_{0,7-y} \mathrm{Pr}_{y} \mathrm{Mg}_{0,3} \mathrm{Al}_{0,3} \mathrm{Mn}_{0,4} \mathrm{Co}_{0,5} \mathrm{Ni}_{3,8}(y=0,0-0,7)$ com tratamento térmico.

FIGURA 32 - Capacidade de descarga do eletrodo da liga $\mathrm{La}_{0,7} \mathrm{Pr}_{0,3} \mathrm{Al}_{0,3} \mathrm{Mn}_{0,4} \mathrm{Co}_{0,5} \mathrm{Ni}_{3,8}$ em função da densidade de corrente de descarga $\left(I_{D}=10,100,200\right.$ e $\left.500 \mathrm{~mA} \mathrm{~g}^{-1}\right)$.

FIGURA 33 - Retenção da capacidade de descarga do eletrodo da liga $\mathrm{La}_{0,7} \mathrm{Pr}_{0,3} \mathrm{Al}_{0,3} \mathrm{Mn}_{0,4} \mathrm{Co}_{0,5} \mathrm{Ni}_{3,8}$ em função da densidade de corrente de descarga: (a) $10 \mathrm{~mA} \mathrm{~g}^{-1}$, (b) $100 \mathrm{~mA} \mathrm{~g}^{-1}$,

(c) $200 \mathrm{~mA} \mathrm{~g}^{-1} \mathrm{e}$ (d) $500 \mathrm{~mA} \mathrm{~g}^{-1}$.

FIGURA 34 - Capacidade de descarga dos eletrodos das ligas

$\mathrm{La}_{0,7} \mathrm{Pr}_{0,3} \mathrm{Al}_{0,3} \mathrm{Mn}_{0,4} \mathrm{Co}_{0,5} \mathrm{Ni}_{3,8}$,

$\mathrm{La}_{0,6} \mathrm{Mg}_{0,1} \mathrm{Pr}_{0,3} \mathrm{Al}_{0,3} \mathrm{Mn}_{0,4} \mathrm{Co}_{0,5} \mathrm{Ni}_{3,8} \mathrm{e}$

$\mathrm{La}_{0,7} \mathrm{Mg}_{0,3} \mathrm{Al}_{0,3} \mathrm{Mn}_{0,4} \mathrm{Co}_{0,5} \mathrm{Ni}_{3,8}$ durante os

experimentos de determinação de autodescarga

$\left(\mathrm{I}_{\mathrm{D}}=200 \mathrm{~mA} \mathrm{~g}^{-1}\right)$.

FIGURA 35 - Taxa de autodescarga dos eletrodos das ligas

$\mathrm{La}_{0,7} \mathrm{Pr}_{0,3} \mathrm{Al}_{0,3} \mathrm{Mn}_{0,4} \mathrm{Co}_{0,5} \mathrm{Ni}_{3,8}$,

$\mathrm{La}_{0,6} \mathrm{Mg}_{0,1} \mathrm{Pr}_{0,3} \mathrm{Al}_{0,3} \mathrm{Mn}_{0,4} \mathrm{Co}_{0,5} \mathrm{Ni}_{3,8} \mathrm{e}$

$\mathrm{La}_{0,7} \mathrm{Mg}_{0,3} \mathrm{Al}_{0,3} \mathrm{Mn}_{0,4} \mathrm{Co}_{0,5} \mathrm{Ni}_{3,8}\left(\mathrm{I}_{\mathrm{D}}=200 \mathrm{~mA} \mathrm{~g}^{-1}\right)$.

FIGURA 36 - Retenção da capacidade de descarga dos eletrodos das ligas (a) $\mathrm{La}_{0,7} \mathrm{Pr}_{0,3} \mathrm{Al}_{0,3} \mathrm{Mn}_{0,4} \mathrm{Co}_{0,5} \mathrm{Ni}_{3,8}$,

(b) $\mathrm{La}_{0,6} \mathrm{Mg}_{0,1} \mathrm{Pr}_{0,3} \mathrm{Al}_{0,3} \mathrm{Mn}_{0,4} \mathrm{Co}_{0,5} \mathrm{Ni}_{3,8} \mathrm{e}$

(c) $\mathrm{La}_{0,7} \mathrm{Mg}_{0,3} \mathrm{Al}_{0,3} \mathrm{Mn}_{0,4} \mathrm{Co}_{0,5} \mathrm{Ni}_{3,8}$ durante as medidas de autodescarga indicadas $\left(\mathrm{I}_{\mathrm{D}}=200 \mathrm{~mA} \mathrm{~g}^{-1}\right)$. 
Página

FIGURA 37 - Alta taxa de descarga dos eletrodos das ligas

$\mathrm{La}_{0,6} \mathrm{Mg}_{0,1} \mathrm{Pr}_{0,3} \mathrm{Al}_{0,3} \mathrm{Mn}_{0,4} \mathrm{Co}_{0,5} \mathrm{Ni}_{3,8} \mathrm{e}$

$\mathrm{La}_{0,7} \mathrm{Mg}_{0,3} \mathrm{Al}_{0,3} \mathrm{Mn}_{0,4} \mathrm{Co}_{0,5} \mathrm{Ni}_{3,8}$ em função da

densidade de corrente de descarga $\left(\mathrm{I}_{\mathrm{D}}=250\right.$,

300, 400, 500 e $750 \mathrm{~mA} \mathrm{~g}^{-1}$ ).

FIGURA 38 - Perfis de descarga dos eletrodos das ligas

$\mathrm{La}_{0,6} \mathrm{Mg}_{0,1} \mathrm{Pr}_{0,3} \mathrm{Al}_{0,3} \mathrm{Mn}_{0,4} \mathrm{Co}_{0,5} \mathrm{Ni}_{3,8}$
(a) $I_{D}=250-750 \mathrm{~mA} \mathrm{~g}^{-1}$ e (b) $I_{D}=60 / 250-750 \mathrm{~mA} \mathrm{~g}^{-1} \mathrm{e}$
$\mathrm{La}_{0,7} \mathrm{Mg}_{0,3} \mathrm{Al}_{0,3} \mathrm{Mn}_{0,4} \mathrm{Co}_{0,5} \mathrm{Ni}_{3,8}$
(c) $I_{D}=250-750 \mathrm{~mA} \mathrm{~g}^{-1}$ e (d) $I_{D}=60 / 250-750 \mathrm{~mA} \mathrm{~g}^{-1}$ ).

FIGURA 39 - Abundância de fases nas ligas

(1) $\mathrm{La}_{0,6} \mathrm{Mg}_{0,1} \mathrm{Pr}_{0,3} \mathrm{Al}_{0,3} \mathrm{Mn}_{0,4} \mathrm{Co}_{0,5} \mathrm{Ni}_{3,8} \mathrm{e}$

(2) $\mathrm{La}_{0,7} \mathrm{Mg}_{0,3} \mathrm{Al}_{0,3} \mathrm{Mn}_{0,4} \mathrm{Co}_{0,5} \mathrm{Ni}_{3,8}$ 


\section{LISTA DE ABREVIATURAS E SIGLAS}

BSE Elétrons retroespalhados - Backscattering electron

C Capacidade de descarga - Discharge capacity

CCTM Centro de Ciência e Tecnologia de Materiais

$\mathrm{C}_{\text {máx }} \quad$ Capacidade de descarga máxima - Maximum discharge capacity

DRX Difração de raios $X$

EDS Energy Dispersive X-ray Spectroscopy

EIE Espectroscopia de impedância eletroquímica

FAPESP Fundação de Amparo à Pesquisa do Estado de São Paulo

GSAS General Structure Analysis System

H/M Massa de hidrogênio/massa de hidreto formado

HRD Alta taxa de descarga - High-rate dischargeability

ICP-AES Espectroscopia de emissão atômica por plasma induzido

IPEN Instituto de Pesquisas Energéticas e Nucleares

MEV Microscopia eletrônica de varredura

MM Massa molar

Mm; Ml Mischmetal

$\mathrm{Na}_{\mathrm{a}} \quad$ Número de ciclos necessários para ativar o eletrodo

Ni-MH Níquel-hidreto metálico

PCA Potencial de circuito aberto

PTFE Politetrafluoroetileno

SDR Taxa de autodescarga - Self-discharge rate

$\mathrm{S}_{\mathrm{n}} \quad$ Retenção da capacidade de descarga - Discharge capacity retention 


\section{INTRODUÇÃO}

A busca por métodos eficientes de armazenamento de energia elétrica compatíveis à demanda acompanha o uso dessa forma de energia desde sua descoberta. Para atender as novas exigências e avanços tecnológicos, a indústria de armazenamento de energia permanece em contínua evolução, em consonância à necessidade de otimização da gestão do fornecimento de energia, visando economia de custos e eficiência no propósito energético.

Entre os sistemas de armazenamento eletroquímico, situam-se as baterias denominadas secundárias ou recarregáveis que, em função de suas aplicações, são disponibilizadas em dimensionamentos e combinações químicas diferentes (ESA, 2015). Os tipos mais comuns são as baterias recarregáveis de chumbo-ácido, níquel-cádmio, íon lítio, lítio-polímero, e as de níquel-hidreto metálico (Ni-MH) (Liu et al., 2011b).

Inicialmente direcionadas ao uso em eletrônicos portáteis, as aplicações das baterias de Ni-MH evoluíram para novos desafios, como sistemas estacionários e veículos elétricos híbridos (Young e Nei, 2013).

Com estrutura similar às baterias de níquel-cádmio, as baterias de $\mathrm{Ni}-\mathrm{MH}$ apresentam, comparativamente, uma série de características significativamente superiores.

Entre as vantagens do uso de baterias $\mathrm{Ni}-\mathrm{MH}$, estão: alta densidade de potência ou alta taxa de capacidade; células de tamanhos flexíveis de $30 \mathrm{mAh}$ a $350 \mathrm{Ah}$; operação segura a alta voltagem; facilidade de aplicação em linhas em série e em série/paralelo; segurança nos processos de carga e de descarga, com tolerância superior a sobrecarga/sobredescarga elevados; ciclos de vida longos; ausência de efeito memória; manutenção dispensável; propriedades térmicas excelentes; circuito eletrônico de controle de carga simples e de baixo custo; maior compatibilidade ao meio ambiente e uso de materiais recicláveis (Liu et al., 2016; Liu et al., 2011b). 
Tais características conferem às baterias $\mathrm{Ni}-\mathrm{MH}$ a preferência quanto a aplicações em sistemas de alta voltagem - como as baterias utilizadas em veículos elétricos. Embora as baterias de íon lítio apresentem valores superiores de densidade de energia gravimétrica (110-160 $\mathrm{Wh} \mathrm{kg}^{-1}$ ) em relação às de $\mathrm{Ni}-\mathrm{MH}$ (60-120 Wh kg-1), fatores como custo e segurança operacional persistem como desafios a serem superados para sua aplicação em veículos (Battery University, 2015; Liu et al., 2011b).

As baterias $\mathrm{Ni}-\mathrm{MH}$ estão inseridas na classe de dispositivos de armazenamento de hidrogênio em materiais sólidos, no caso, hidretos recarregáveis, por meio da utilização de ligas e intermetálicos que constituem o principal material dos eletrodos negativos desses dispositivos (Riis et al., 2006).

Essencialmente, a performance das baterias $\mathrm{Ni}-\mathrm{MH}$ é avaliada em função de parâmetros como capacidade, durabilidade (tempo de vida em função dos ciclos de carga e de descarga) e taxa de descarga (cinética) que são, por sua vez, dependentes de propriedades e/ou características da liga de armazenamento de hidrogênio utilizada no eletrodo negativo. Nesse contexto exercem profunda influência o tipo de liga ou intermetálico considerado, a natureza e quantidade de cada elemento presente na composição, como também a microestrutura apresentada (Feng et al., 2001; Liu et al., 2011a, 2011b).

Entre os tipos ou sistemas de ligas pesquisados e representativos do ponto de vista comercial, destacam-se as ligas tipo $A_{5}$ à base de terras raras, as ligas tipo $A B_{2}$ fase de Laves à base de titânio e zircônio e as ligas tipo $A B_{3}, A_{2} B_{7}$ ou $\mathrm{A}_{5} \mathrm{~B}_{19}$ à base de terras raras-magnésio-níquel (R-Mg-Ni) (Liu et al., 2016; Liu et al., 2011a, 2011b).

Para a otimização da performance eletroquímica dos diferentes tipos de ligas, são considerados procedimentos como substituições e/ou adições de elementos tanto no lado A como no lado B, o uso de sistemas não estequiométricos, além de tratamentos térmico e de superfície, entre outros (Liu et al., 2011a, 2011b).

Nos sistemas de ligas à base de terras raras, as substituições e/ou adições de elementos do lado $A$ estão vinculadas, geralmente, à absorção de hidrogênio e à estabilidade estrutural das fases presentes, propriedades relacionadas ao aumento da capacidade de descarga e da estabilidade cíclica do eletrodo, respectivamente (Feng et al., 2001; Liu et al., 2011a, 2011b). 
À adição de praseodímio em substituição ao lantânio nas ligas à base de terras raras tipos $A_{5}$ e $\mathrm{R}-\mathrm{Mg}-\mathrm{Ni}$ foram reportados resultados vantajosos em relação a parâmetros eletroquímicos como ativação, taxa de descarga e, principalmente, sobre a estabilidade cíclica do eletrodo negativo - esta favorável à vida útil da bateria Ni-MH. Para as ligas tipo $A_{5}$, as referências são mais remotas (Chen et al., 1996; Chen et al., 1995); para as ligas tipo R-Mg-Ni, são disponibilizados um maior número de estudos correntes (Li, Y. et al., 2009; Liu et al., 2011b; Liu, J. et al., 2015a, Pan et al., 2007; Yan et al., 2009; Zhang, Y. et al., 2009, 2012a, 2013, 2014).

$O$ magnésio foi adicionado no lado $B$ das ligas tipo $A B_{5}$ à base de terras raras em substituição ao cobalto, em composições de ligas hipo e hiperestequiométricas, gerando redução de custos, maior potência e durabilidade às baterias Ni-MH (Cuscueta et al., 2008; Li, M. et al., 2006; Ozaki et al., 2006; Zhang, P. et al., 2005). Nas ligas à base de terras raras tipo R-Mg-Ni, o magnésio é fundamental para a formação das superestruturas relacionadas ao aumento da absorção de hidrogênio e consequente elevação da capacidade de descarga das ligas (Dong et al., 2008b; Liao et al., 2004b, 2003; Liu et al., 2011b; Wei et al., 2012; Tian et al., 2016).

No presente trabalho propôs-se a substituição crescente de lantânio por praseodímio e de lantânio por magnésio em ligas à base de LaNi de composições ainda não testadas, como procedimento para a avaliação da melhora da performance dos eletrodos correspondentes, a partir da determinação de parâmetros eletroquímicos fundamentais.

A determinação do tema deste trabalho esteve vinculada ao Projeto FAPESP 2004/12453-0 intitulado "Estudo da hidrogenação a alta temperatura para pulverização de ligas à base de LaPrMgAIMnCoNi”, de autoria do Dr. Rubens Nunes de Faria Junior. Logo, a execução de todo o estudo aqui apresentado figurou como atividade entre as metas estabelecidas do referido projeto.

Cumpre ainda considerar que no Laboratório de Baterias e Supercapacitores do Centro de Ciência e Tecnologia de Materiais (CCTM) do IPEN, coordenado pelo referido pesquisador, foram realizados vários estudos abordando a absorção de hidrogênio por ligas à base de terras raras para 
utilização em eletrodo negativo de baterias Ni-MH (Casini, 2011, 2015; Ferreira, 2013; Galdino, 2011).

Como diferencial, no presente trabalho são apresentados os estudos pertinentes às características microestruturais e propriedades eletroquímicas de eletrodos de ligas à base de LaNi - especificamente, os experimentos em que se fez uso de um sistema de medidas padrão composto por célula de três eletrodos para as medidas eletroquímicas realizadas.

O sistema de célula de três eletrodos é relatado por reunir características adequadas à determinação de propriedades eletroquímicas fundamentais do material em estudo (Hsia, 2013). Consequentemente, a avaliação dos parâmetros eletroquímicos aqui realizada acompanhou a sistemática reconhecidamente adotada em tais estudos. 


\section{OBJETIVOS}

O objetivo deste trabalho correspondeu à avaliação da ação positiva da substituição de lantânio por magnésio e de lantânio por praseodímio na performance eletroquímica de eletrodos de ligas à base de LaNi.

$O$ enfoque original do estudo realizado vinculou-se à substituição crescente e total de lantânio por magnésio e de lantânio por praseodímio na composição das ligas, correlacionando o comportamento eletroquímico resultante com as características composicionais e estruturais observadas.

Eletrodos das ligas foram submetidos a ciclos galvanostáticos de carga/descarga, sendo analisados parâmetros como ativação, capacidade de descarga máxima, estabilidade cíclica, autodescarga e alta taxa de descarga.

Considerando a forte dependência dos parâmetros eletroquímicos frente às características do material a compor o eletrodo, adicionalmente à microestrutura e à composição (uso das técnicas microscopia eletrônica de varredura/espectroscopia por dispersão de energia de raios $\mathrm{X}$ ), a caracterização das ligas incluiu estudos referentes à estrutura cristalina (por difração de raios $X$ com refinamento por Rietveld) e à resistência à corrosão (por polarização poteciométrica e espectroscopia de impedância eletroquímica).

Em complementação, avaliou-se, no presente trabalho, a influência do tratamento térmico na capacidade de descarga das ligas estudadas. 


\section{REVISÃO BIBLIOGRÁFICA}

\subsection{Princípios da bateria $\mathrm{Ni}-\mathrm{MH}$}

$\mathrm{O}$ princípio de funcionamento de uma bateria $\mathrm{Ni}-\mathrm{MH}$ baseia-se na capacidade de determinados metais, ligas ou intermetálicos (M) em absorver hidrogênio de forma reversível, segundo reações eletroquímicas de carga/descarga. A bateria de $\mathrm{Ni}-\mathrm{MH}$ resulta, então, da combinação entre um eletrodo negativo de uma liga de armazenamento de hidrogênio e de um eletrodo positivo de hidróxido de níquel, operando em presença de um separador e em solução aquosa de eletrólito alcalino.

Na FIG. 1 está representado o processo eletroquímico que ocorre na bateria $\mathrm{Ni}-\mathrm{MH}$.

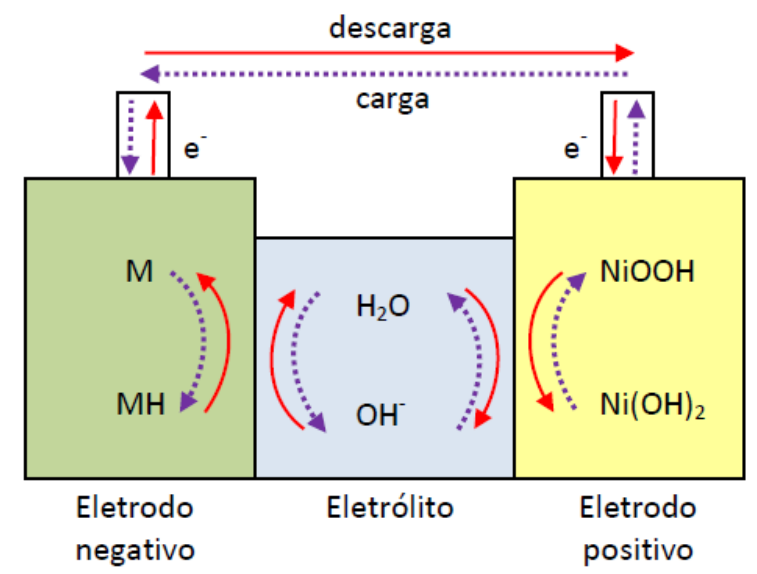

FIGURA 1 - Diagrama esquemático do processo eletroquímico de reação de carga/descarga de uma bateria Ni-MH (reproduzido de Liu et al., 2011b). 
As reações eletroquímicas que ocorrem nos eletrodos e a reação total da bateria são expressas por:

eletrodo positivo: $\quad \mathrm{Ni}(\mathrm{OH})_{2}+\mathrm{OH}^{-} \underset{\text { descarga }}{\stackrel{\text { carga }}{\rightleftarrows}} \mathrm{NiOOH}+\mathrm{H}_{2} \mathrm{O}+\mathrm{e}^{-}$

eletrodo negativo: $\quad \mathrm{M}+\mathrm{H}_{2} \mathrm{O}+\mathrm{e}^{-} \underset{\text { descarga }}{\stackrel{\text { carga }}{\rightleftarrows}} \mathrm{MH}+\mathrm{OH}^{-}$

reação total: $\quad \mathrm{Ni}(\mathrm{OH})_{2}+\mathrm{M} \underset{\text { descarga }}{\stackrel{\mathrm{t}}{\rightleftarrows}} \mathrm{NiOOH}+\mathrm{MH}$

Durante a carga, a liga de armazenamento de hidrogênio no eletrodo negativo reage com água para formar o hidreto metálico $(\mathrm{MH})$ e íons hidroxila, enquanto que no eletrodo positivo o hidróxido de níquel é oxidado a óxi-hidróxido de níquel II (NiOOH). No processo de descarga, as reações nos eletrodos ocorrem em sentido oposto à carga. Basicamente, o mecanismo de carga/descarga numa bateria $\mathrm{Ni}-\mathrm{MH}$ corresponde ao movimento de hidrogênio entre os eletrodos. Observa-se que tanto a quantidade total de água e de íons hidroxila, bem como a concentração da solução eletrolítica permanecem inalterados durante o processo de carga/descarga, uma vez que aparentemente a água não contribui na reação total da bateria (Feng et al., 2001; Inoue e Higuchi, 2015; Liu et al., 2011a).

A este princípio relativamente simples de carga/descarga, estão associados, verdadeiramente, processos importantes que ocorrem na interface eletrodo/eletrólito e de transporte de massa. As reações que descrevem tais processos, no sentido da carga da bateria, ou seja, de formação do hidreto metálico no eletrodo da liga de armazenamento de hidrogênio, podem ser representadas por (Notten e Hokkeling, 1991):

(a) difusão dos reagentes do interior (i) do eletrólito para a interface (s) eletrodo/eletrólito (equação 4):

$$
\mathrm{H}_{2} \mathrm{O}_{(\mathrm{i})} \rightleftarrows \mathrm{H}_{2} \mathrm{O}_{(\mathrm{s})}
$$


(b) reação de transferência de carga na interface eletrodo/eletrólito, com a adsorção (ad) de hidrogênio na superfície do eletrodo (equação 5):

$$
\mathrm{M}+\mathrm{H}_{2} \mathrm{O}_{(\mathrm{s})}+\mathrm{e}^{-} \rightleftarrows \mathrm{M}-\mathrm{H}_{(\mathrm{ad})}+\mathrm{OH}_{(\mathrm{s})}^{-}
$$

(c) difusão da espécie $\mathrm{M}-\mathrm{H}_{(\mathrm{ad})}$ para o interior da liga, ou seja, absorção do hidrogênio adsorvido na superfície do eletrodo, com a formação de uma solução sólida (fase $\alpha$ ) (equação 6):

$$
\mathrm{M}-\mathrm{H}_{(\mathrm{ad})} \rightleftarrows \mathrm{M}-\mathrm{H}_{(\mathrm{ab}(\mathrm{\alpha}))}
$$

(d) transporte dos ions $\mathrm{OH}^{-}$para o interior do eletrólito (equação 7):

$$
\mathrm{OH}_{(\mathrm{s})}^{-} \rightleftarrows \mathrm{OH}_{(\mathrm{i})}^{-}
$$

(e) difusão do hidrogênio absorvido no interior da liga de armazenamento de hidrogênio para a formação de uma fase $\beta$ de hidreto metálico enquanto um equilíbrio estático é estabelecido (equação 8):

$$
\mathrm{M}-\mathrm{H}_{(\mathrm{ab}(\alpha))} \rightleftarrows \mathrm{M}-\mathrm{H}_{(\mathrm{ab}(\beta))}
$$

No processo de descarga da bateria, ou seja, de decomposição eletroquímica do hidreto metálico, a sequência das reações ocorre de maneira reversa. Notadamente, no processo de formação/decomposição do hidreto metálico via reação eletroquímica de transferência de carga na interface metal/eletrólito, tem-se a participação ativa da superfície da liga.

Processos de sobrecarga e de sobredescarga são previstos em baterias comerciais $\mathrm{Ni}-\mathrm{MH}$ e, nestas, o eletrodo negativo da liga absorvedora de hidrogênio exibe uma capacidade de carga aproximadamente $50 \%$ maior que a correspondente ao eletrodo positivo de $\mathrm{Ni}(\mathrm{OH})_{2}$ (Inoue e Higuchi, 2015). Essa medida visa neutralizar a evolução de gases que ocorre durante o processo de carga/descarga, impedindo, portanto, o aumento da pressão interna na bateria. 
Especificamente, no processo de sobrecarga, ocorre a liberação de oxigênio no eletrodo positivo mediante a reação (equação 9):

eletrodo positivo: $\quad 2 \mathrm{OH}^{-} \rightleftarrows \mathrm{H}_{2} \mathrm{O}+1 / 2 \mathrm{O}_{2}+2 \mathrm{e}^{-}$

O oxigênio difunde para o eletrodo negativo através do separador, sendo a carga reserva consumida em reação com o oxigênio gerado segundo a reação (equação 10):

eletrodo negativo: $\quad \mathrm{MH}+1 / 2 \mathrm{O}_{2} \rightleftarrows 2 \mathrm{M}+\mathrm{H}_{2} \mathrm{O}$

No processo de sobredescarga, o hidrogênio é liberado no eletrodo positivo como é mostrado na reação (equação 11):

eletrodo positivo: $\quad 2 \mathrm{H}_{2} \mathrm{O}+2 \mathrm{e}^{-} \rightleftarrows \mathrm{H}_{2}+2 \mathrm{OH}^{-}$

O hidrogênio difunde para o eletrodo negativo através do separador, inicialmente ocorrendo sua dissociação atômica com a formação do hidreto metálico segundo a reação (equação 12):

eletrodo negativo: $\quad \mathrm{H}_{2}+2 \mathrm{M} \rightleftarrows 2 \mathrm{MH}$

Na sequência, ainda no eletrodo negativo, ocorre uma reação de transferência de carga (equação 13):

$$
2 \mathrm{OH}^{-}+2 \mathrm{MH} \rightleftarrows 2 \mathrm{M}+2 \mathrm{H}_{2} \mathrm{O}+2 \mathrm{e}^{-}
$$

Esse mecanismo de proteção à sobredescarga durante o processo de carga/descarga constitui um diferencial das baterias de $\mathrm{Ni}-\mathrm{MH}$, traduzindo-se numa grande vantagem para baterias de voltagem elevada direcionadas à aplicação em veículos elétricos (Inoue e Higuchi, 2015). 


\subsection{Definições dos parâmetros eletroquímicos}

\subsubsection{Capacidade de descarga}

A capacidade de descarga $C$ é definida como a carga elétrica em número de àmperes-hora $(A h)$ que pode ser retirada da célula por massa de material ativo (liga de armazenamento de hidrogênio) presente no eletrodo negativo:

$$
C=\frac{i \times t}{m}
$$

onde $i$ é a intensidade de corrente ( $\mathrm{mA})$, $t$ é o tempo de medida ( $\mathrm{h}$ ) e $m$ é a massa da liga (g). Parâmetros de descarga como densidade de corrente, potencial de corte ("cut-off") - que deve ser especificado - e a temperatura exercem influência sobre a capacidade de descarga (Faria et al., 2014; Kiehne e Raudszus, 2003).

\subsubsection{Ativação}

A facilidade de ativação é indispensável para o eletrodo da liga aplicada na bateria $\mathrm{Ni}-\mathrm{MH}$. A ativação do eletrodo corresponde ao número de ciclos de carga/descarga $\left(N_{\mathrm{a}}\right)$ necessários para que seja atingido o valor de

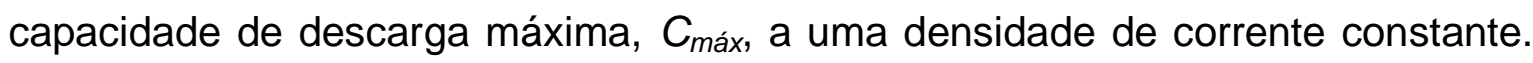

Basicamente, o processo de ativação é associado à redução do tamanho de partícula e reconstrução da superfície da liga (Adzic et al., 1997; Zhang, Y. et al., 2012b).

\subsubsection{Retenção da capacidade de descarga}

A taxa de retenção da capacidade de descarga, $S_{n}$, é definida como:

$$
S_{n}(\%)=\frac{C_{n}}{C_{\text {máx }}} \times 100
$$

onde $C_{\text {máx }}$ é a capacidade de descarga máxima atingida e $\mathrm{C}_{\mathrm{n}}$ é a capacidade de descarga no $n_{\text {ésimo }}$ ciclo de carga/descarga a determinada corrente de descarga. 
A retenção da capacidade de descarga é o parâmetro utilizado para caracterizar a estabilidade cíclica do eletrodo negativo que, por sua vez, atua diretamente na vida útil da bateria. A estabilidade cíclica constitui, portanto, um fator decisivo na avaliação da liga de armazenamento de hidrogênio a ser utilizada no eletrodo, sendo um dos maiores indicadores de sua performance (Zhang, Y. et al., 2012a; 2015).

\subsubsection{Taxa de autodescarga}

A taxa de autodescarga ("Self-discharge rate", $S D R$ ) é relacionada à estabilidade dos hidretos formados, sendo considerada um dos maiores parâmetros na estimativa da performance das baterias. No presente trabalho, a taxa de autodescarga foi calculada por:

$$
\operatorname{SDR}(\%)=\left(1-\frac{2 C_{b}}{C_{a}+C_{c}}\right) \times 100
$$

onde $C_{a}$ corresponde à capacidade de descarga no ciclo imediatamente anterior ao período de descanso (rest); $C_{b}$ à capacidade de descarga medida no ciclo considerando-se o período de descanso, e $C_{c}$ corresponde à capacidade de descarga no ciclo de carga/descarga imediatamente posterior ao ciclo de medida de $C_{b}$ (Yang et al., 2011).

\subsubsection{Alta taxa de descarga}

A alta taxa de descarga ("high-rate dischargeability", $H R D$ ) simboliza todas as propriedades cinéticas da liga de armazenamento de hidrogênio, sendo considerada um parâmetro chave na avaliação da mesma. No presente trabalho, a alta taxa de descarga foi calculada segundo a fórmula:

$$
\operatorname{HRD}(\%)=\left(\frac{C_{d}}{C_{d}+C_{60}}\right) \times 100
$$


onde $C_{d}$ é a capacidade de descarga à densidade de corrente de descarga $I_{d}$ considerada, e $C_{60}$ corresponde à capacidade de descarga residual à densidade de corrente de descarga $I=60 \mathrm{~mA} \mathrm{~g}^{-1}$ ) (Pan et al., 2007; Yan et al., 2009).

\subsection{Ligas de armazenamento de hidrogênio em baterias $\mathrm{Ni}-\mathrm{MH}$}

\subsubsection{Aspectos termodinâmicos e cinéticos}

A quantidade de hidrogênio que o material pode absorver determinará a capacidade de armazenamento eletroquímico do eletrodo negativo e, consequentemente, a capacidade de armazenamento de energia da bateria $\mathrm{Ni}-\mathrm{MH}$. É desejável, portanto, que haja uma elevada capacidade de armazenamento por parte do material a compor o eletrodo negativo, e que essa capacidade seja reversível eletroquimicamente. Às ligas candidatas a constituir o eletrodo negativo das baterias $\mathrm{Ni}-\mathrm{MH}$ são requisitadas, então, determinadas propriedades termodinâmicas e cinéticas. A capacidade de armazenamento de hidrogênio (relação $\mathrm{H} / \mathrm{M}$ em massa) deve ser alta. A estabilidade dos hidretos formados, por sua vez, deve ser moderada, correspondendo a uma faixa de pressão de desorção de hidrogênio entre 0,1 a 1 atm à temperatura ambiente, assegurando que uma grande quantidade de hidrogênio possa ser completamente liberada. Ainda, para assegurar a reversibilidade eletroquímica do armazenamento de hidrogênio, a força da ligação metal-hidrogênio $(M-H)$ deve estar entre 25 e $50 \mathrm{~kJ} \mathrm{~mol}^{-1}$. Geralmente, são utilizados isotermas de pressãocomposição (P-C-T) na análise dessas propriedades (Feng et al. 2001; Liu et al., 2011b).

Para assegurar uma alta taxa de descarga à bateria $\mathrm{Ni}-\mathrm{MH}$, é desejável, também, que para a liga esteja associada uma cinética adequada, tanto em relação à reação de transferência de carga na interface liga/eletrólito, como à difusão do hidrogênio do interior da liga para a superfície (vide item 3.1, equações 4 a 8).

A atividade eletrocatalítica para a reação de transferência de carga na superfície do eletrodo da liga é caracterizada pela densidade de corrente de troca, que é inversamente proporcional à resistência à polarização. Portanto, quanto maior a resistência à transferência de carga, menor a densidade de corrente de troca e, consequentemente, a cinética da reação de transferência de carga na 
interface metal/eletrólito será menor, o que comprometerá o parâmetro HRD. Adicionalmente, deverá ser observada uma dependência linear entre o parâmetro HRD e a densidade de corrente de troca se a reação eletroquímica na superfície da liga constituir o fator determinante para a velocidade da reação. Já, se a difusão do hidrogênio do interior da liga responder por tal fator, o parâmetro HRD permanecerá constante em função do aumento da densidade de corrente de troca (Faria et al., 2014; Yang et al., 2011; Zhang, W. et al., 2009).

No processo de difusão do hidrogênio, curvas de polarização anódica são utilizadas para caracterizar a velocidade de difusão do hidrogênio no interior da liga. O valor máximo atingido para a densidade de corrente na curva corresponde à densidade de corrente limitante que, por sua vez, guarda uma relação diretamente proporcional à velocidade de difusão do hidrogênio - quanto maior a velocidade de difusão, maior será a cinética do eletrodo. Logo, a comparação de valores da densidade de corrente limitante medidos é utilizada na análise das velocidades de difusão do hidrogênio associadas (Zhang, W. et al., 2009).

\subsubsection{Resistência à corrosão}

A bateria Ni-MH opera em um meio extremamente oxidante composto por eletrólito alcalino altamente concentrado, o que impõe, à liga candidata a compor o eletrodo negativo, uma alta resistência à corrosão. Dependendo da composição da liga, a resistência à corrosão dos eletrodos pode ser beneficiada pela formação de densas camadas de óxidos ou hidróxidos em sua superfície. A presença dessas camadas protetoras confere um caráter passivo à superfície da liga e, consequentemente, maior resistência às futuras oxidações as quais a liga estará sujeita durante o processo da absorção/desorção do hidrogênio.

Exemplificando estudo relacionado à resistência à corrosão de ligas com substituição de La por Pr, são reproduzidas, na FIG. 2, as curvas de polarização anódica e catódica das ligas $\mathrm{La}_{0,7-x} \mathrm{Pr}_{x} \mathrm{Mg}_{0,3} \mathrm{Al}_{0,3} \mathrm{Mn}_{0,4} \mathrm{Co}_{0,5} \mathrm{Ni}_{3,8}$ $(x=0,0-0,7)$ (Banczek et al., 2009). 


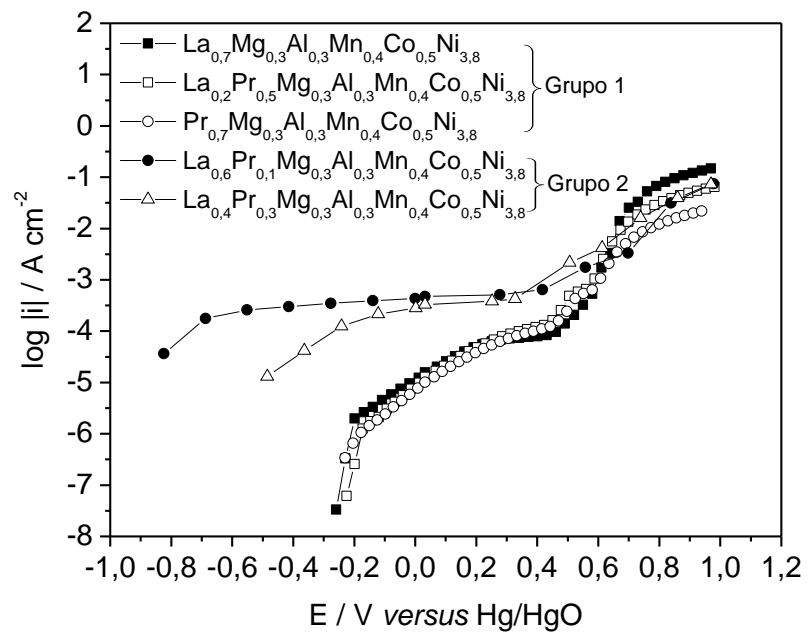

(a)

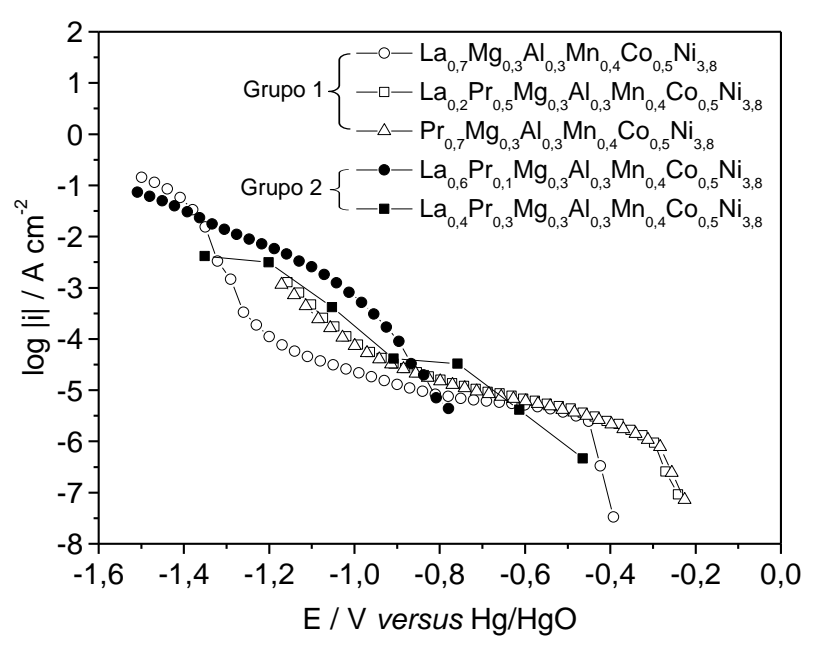

(b)

FIGURA 2 - Curvas de polarização das ligas $\mathrm{La}_{0,7-x} \mathrm{Pr}_{x} \mathrm{Mg}_{0,3} \mathrm{Al}_{0,3} \mathrm{Mn}_{0,4} \mathrm{Co}_{0,5} \mathrm{Ni}_{3,8}$ $(\mathrm{x}=0,0 ; 0,1 ; 0,3 ; 0,5 ; 0,7)$ em solução de $\mathrm{KOH} 6,0 \mathrm{~mol} \mathrm{~L}^{-1}$ : (a) curvas de polarização anódica; (b) curvas de polarização catódica (Reproduzido de Banczek et al., 2009).

As ligas foram agrupadas em dois grupos, segundo o comportamento de polarização apresentado. Verificou-se que a liga sem $\operatorname{Pr}$ ou aquelas com maiores teores de $\operatorname{Pr}$ apresentaram melhor performance frente à corrosão, em comparação às demais ligas. Aparentemente, tal comportamento relacionou-se com a cobertura da superfície das ligas por bolhas devido a elevada sobrevoltagem de hidrogênio em determinada fase presente na estrutura das ligas. Como descrito no estudo em referência, a maioria das ligas mostrou um caráter passivo, com densidades de corrosão muito baixas numa ampla faixa de 
potencial. Adicionalmente, em meio mais agressivo, a corrosão deu-se preferencialmente em fase rica em magnésio. Da avaliação realizada concluiu-se que a resistência à corrosão não constituiria uma propriedade limitante ao uso dessas ligas na composição do eletrodo negativo em experimentos de ciclagem (Banczek et al., 2009).

Outro fator determinante da performance do eletrodo frente à corrosão corresponde à magnitude da variação de volume da liga devido à formação do hidreto metálico $(\mathrm{MH})$. O volume molar de hidrogênio na fase hidreto governa a expansão/contração da liga durante o processo de carga/descarga do eletrodo negativo, sendo aceito que a mudança de volume de uma liga durante a hidretação é proporcional à quantidade de hidrogênio absorvido. Grandes variações de volume aumentam a ação do eletrólito por entre os poros e microtrincas presentes no eletrodo a cada ciclo de carga/descarga, aumentando a pulverização da liga. Como consequência, eleva-se a taxa de contato entre a superfície da liga com eletrólito fresco, aumentando a taxa de corrosão (Reilly, 1999; Willems, 1984). Deduz-se, portanto, que substituições composicionais nas ligas podem diminuir a taxa de corrosão das mesmas, seja pela possível passivação da superfície e/ou pela menor variação de volume a que estão sujeitas durante o processo de carga/descarga - favorecendo, nesse caso, a estabilidade cíclica do eletrodo negativo. Em contrapartida, esses dois fatores tendem a diminuir a capacidade de descarga do eletrodo. A passivação da superfície da liga atua desfavoravelmente à reação de transferência de carga na interface eletrodo/eletrólito, enquanto que um menor volume da fase $\mathrm{MH}$ está associado a menores cavidades no retículo cristalino e mais baixo armazenamento de hidrogênio.

Estudos relacionados à resistência à corrosão em eletrodos negativos de ligas tipo $A_{5}$ à base de terras raras incluem a substituição de La por Ce em ligas $\mathrm{La}_{1-\mathrm{x}} \mathrm{Ce}_{x} \mathrm{Ni}_{3,55} \mathrm{Co}_{0,75} \mathrm{Mn}_{0,4} \mathrm{Al}_{0,3}(\mathrm{x}=0,0-1,0)$ (Adzic et al., 1995), de Ni por Co em ligas $\mathrm{LaNi}_{4,3-x} \mathrm{Co}_{x} \mathrm{Mn}_{0,4} \mathrm{Al}_{0,3}$ e $\mathrm{MmNi}_{4,3-x} \mathrm{Co}_{x} \mathrm{Mn}_{0,4} \mathrm{Al}_{0,3} \quad(\mathrm{x}=0,0-0,75)$ (Adzic et al., 1997) e de Co por Al em ligas $\operatorname{LaNi}_{2,0} \mathrm{Co}_{2,5-x} \mathrm{M}_{x}(\mathrm{x}=0,1 ; \mathrm{M}=\mathrm{Al}$ ou Si) (Sakai et al., 1990). As interpretações para a melhora na resistência à corrosão nas ligas, em virtude das substituições feitas, foram baseadas na passivação e menor variação de volume (efeito do cério); na supressão da oxidação do níquel na superfície ou pela supressão do transporte de manganês à superfície, impedindo sua rápida 
oxidação (efeito do cobalto); e na formação de camada de óxido na superfície da liga (efeito do alumínio).

Ligas tipo $\mathrm{R}-\mathrm{Mg}-\mathrm{Ni}$ à base de terras raras-Mg-Ni a constituir o eletrodo negativo das baterias $\mathrm{Ni}-\mathrm{MH}$ necessitam melhorar sua resistência à corrosão, aumentando a durabilidade cíclica do eletrodo no meio eletrólito alcalino. Os principais fatores responsáveis pela rápida degradação da capacidade são a pulverização e a oxidação/corrosão dos componentes ativos ( $\mathrm{La}$ e Mg) durante os ciclos de carga/descarga (Liu et al., 2011b). No estágio inicial da ciclagem da bateria ocorre a oxidação e pulverização do $\mathrm{Mg}$; num segundo momento tem-se oxidação do La e do Mg; na sequência, ocorre a oxidação-passivação da superfície da liga, adicionalmente à sua desintegração (Liu et al., 2005a).

Comparativamente às ligas tipo $\mathrm{AB}_{5}$, as ligas tipo La-Mg-Ni sofrem uma pulverização mais drástica durante a ciclagem, com uma diminuição da média do tamanho de partícula muito mais acentuada durante os ciclos do que a observada para as ligas tipo $\mathrm{AB}_{5}$ (Li et al., 2012; Liu, J. et al., 2015b, 2013).

O estudo de Liu, J. et al. (2015c), a respeito do mecanismo da degradação da capacidade de ligas ternárias tipo La-Mg-Ni, mostrou que tensões intermoleculares constituem o principal fator do processo. Resultantes da diferença nas propriedades de expansão/contração entre as subunidades constituintes $\left[\mathrm{LaNi}_{5}\right]$ e [ $\left.\mathrm{LaMgNi}_{4}\right]$ durante o processo de carga/descarga, essas tensões poderiam ser aliviadas mediante ajuste da razão entre as subunidades. Segundo o estudo, tal ajuste conduziria à diminuição da pulverização e da oxidação, beneficiando a estabilidade cíclica do eletrodo.

\subsubsection{Tratamentos e adições}

Vários procedimentos tem sido avaliados para a melhora das propriedades eletroquímicas das ligas e, consequentemente, da performance do eletrodo negativo da bateria $\mathrm{Ni}-\mathrm{MH}$.

O tratamento térmico da liga confere homogeneidade e atua na morfologia obtida, influenciando diversos parâmetros eletroquímicos. Exemplificando, no estudo de Pan et al. (2005a), o tratamento térmico a 900, 1000 , e $1100{ }^{\circ} \mathrm{C}$ em liga de composição $\mathrm{La}_{0,7} \mathrm{Mg}_{0,3} \mathrm{Ni}_{2,45} \mathrm{Co}_{0,75} \mathrm{Mn}_{0,1} \mathrm{Al}_{0,2}$ revelou que o aumento na temperatura de recozimento promoveu tanto a expansão do volume da célula unitária como variações na abundância de fases constituintes. 
Os estudos eletroquímicos revelaram que na liga tratada a $900{ }^{\circ} \mathrm{C}$ deu-se 0 máximo de capacidade de descarga $\left(370,0 \mathrm{mAh}^{-1}\right)$, e que o tratamento a $1100{ }^{\circ} \mathrm{C}$ proporcionou uma melhora significativa na estabilidade cíclica do eletrodo negativo. Em contrapartida, a cinética do eletrodo foi deteriorada, com valores decrescentes para o parâmetro HRD a partir da realização do tratamento térmico e da temperatura adotada. Além de promover homogeneização da composição, o tratamento térmico diminui as tensões e os defeitos no retículo cristalino, suprimindo a pulverização e aumentando a resistência à transferência de carga na liga. Adicionalmente, a velocidade de difusão do hidrogênio do interior da liga para a superfície é diminuída. Vários outros exemplos de estudos tratando da influência do tratamento térmico em propriedades eletroquímicas como ativação, capacidade de descarga, estabilidade cíclica e alta taxa de descarga são reportados na literatura (Gao et al., 2012; Li, F. et al., 2009; Peng e Zhu, 2004; Song et al., 2008).

$\mathrm{A}$ adição de ligas à base de Ti-V via moagem por bolas (Chu et al., 2008a), ou mais recentemente, a adição de grafeno via moagem por plasma (Ouyang et al., 2014), à ligas tipo La-Mg-Ni exemplificam procedimento para a obtenção de eletrodos compósitos que apresentaram melhorias em características eletroquímicas como ativação, capacidade de descarga, estabilidade cíclica e cinética.

Interessante mencionar que, em estudo recente de Lim et al. (2016), foi avaliada a melhora da estabilidade cíclica de ligas tipo La-Mg-Ni via método compósito a partir de adições de liga tipo $\mathrm{AB}_{5}$ de composição comercial. Pós da liga $\mathrm{La}_{0,65} \mathrm{Ca}_{1,03} \mathrm{Mg}_{1,32} \mathrm{Ni}_{9}$ receberam adições crescentes de pós da liga tipo $\mathrm{AB}_{5}$ $\mathrm{La}_{0,80} \mathrm{Ce}_{0,20} \mathrm{Ni}_{4,82} \mathrm{Mo}_{0,10} \mathrm{Al}_{0,08} \quad(0$ a $100 \%$ em massa). As ligas resultantes (compósitos sintetizados por mistura física dos pós da liga La-Mg-Ni e da liga $A_{5}$ ) foram compostas pela fase majoritária $\mathrm{AB}_{3}$ (estrutura tipo $\mathrm{PuNi}_{3}$ ), seguida da fase $\mathrm{AB}_{5}$ (estrutura tipo $\mathrm{CaCu}_{5}$ ) e, e em menor abundância, pela fase $\mathrm{A}_{2} \mathrm{~B}_{7}$ (estrutura tipo $\mathrm{Ce}_{2} \mathrm{Ni}_{7}$ ). Os resultados obtidos indicaram que, em termos de capacidade de armazenamento de hidrogênio e estabilidade cíclica, a composição ótima correspondeu ao compósito obtido por adição de $50 \%$ da liga tipo $\mathrm{AB}_{5}$. Adicionalmente, nessa composição foi verificada uma redução de custo de $20 \%$ em comparação ao correspondente à liga tipo $A_{5}$ pura. 
Segundo Xiao et al. (2008), a modificação da superfície da liga $\mathrm{La}_{0,7} \mathrm{Mg}_{0,3} \mathrm{Ni}_{2,4} \mathrm{Co}_{0,6}$ por tratamento com solução de $\mathrm{KBH}_{4}$ trouxe benefícios à estabilidade cíclica e à cinética do eletrodo. Já no estudo de Shen et al. (2012), a modificação da superfície das partículas da liga $\mathrm{La}_{0,80} \mathrm{Mg}_{0,20} \mathrm{Ni}_{2,70} \mathrm{Mn}_{0,10} \mathrm{Co}_{0,55} \mathrm{Al}_{0,10}$ por recobrimento com polianilina (PANI) proporcionou aumento da estabilidade cíclica e da cinética do eletrodo, com decréscimo da resistência à transferência de carga e aumento na taxa de absorção de hidrogênio.

As modificações e/ou otimizações composicionais, procedimentos de grande importância e extensivamente pesquisados, serão considerados nos itens 3.3.4.1 e 3.3.4.2.

\subsubsection{Sistemas utilizados}

Os sistemas de ligas intensamente pesquisados para composição do eletrodo negativo em baterias Ni-MH incluem ligas tipo $A B_{5}$ à base de terras raras, ligas $A B_{2}$ à base de $T i$ e $Z r$, ligas tipo $A B_{3}$ ou $A_{2} B_{7}$ à base de terras rarasmagnésio, ligas multifásicas à base de Ti- $\mathrm{V}$, e ligas amorfas e nanocristalinas à base de Mg (Inoue e Higuchi, 2015; Liu et al., 2011b).

Na TAB. 1 são apresentados, sucintamente, exemplos de ligas dos diferentes tipos e características. Analisando as informações expostas na referida tabela, percebe-se o direcionamento dos sistemas de ligas e das modificações composicionais na busca pelo aumento na capacidade de descarga, visando melhora e adequação do desempenho das baterias Ni-MH.

Comercialmente, as baterias $\mathrm{Ni}-\mathrm{MH}$ foram introduzidas no mercado nos anos 1990, com eletrodo negativo constituído de ligas tipo $A B_{5}$ à base de terras raras, substituindo o uso de baterias de níquel-cádmio em eletrônicos portáteis (Liu et al., 2011a).

Em termos históricos, as ligas tipo $\mathrm{AB}_{5}$ remetem ao composto $\mathrm{LaNi}_{5}$ que, no início da década de 1970, despertou grande interesse por suas favoráveis propriedades de absorção de hidrogênio, tornando-se um material atrativo para o setor energético (Buschow e Mal, 1972; Mal et al., 1974; Vucht et al., 1970). Desde então, uma grande variedade de elementos de liga foi incorporada às ligas tipo $A_{5}$, no esforço de otimizar sua composição com vistas à redução de custos, maior durabilidade e aumento na performance eletroquímica da baterias $\mathrm{Ni}-\mathrm{MH}$. Essa performance, no entanto, tem sido limitada à capacidade de descarga em 
torno de $320 \mathrm{mAh} \mathrm{g}^{-1}$, não satisfazendo demandas recentes por maiores valores de densidade de energia - caso das novas gerações dos eletrônicos portáteis e dos veículos elétricos híbridos (Liu et al., 2011b; Zhang, Y. et al., 2015).

$\mathrm{Na}$ última década, o sistema de ligas à base de terras raras-magnésioníquel (R-Mg-Ni), precisamente ligas tipo $\mathrm{A}_{2} \mathrm{~B}_{7}$ à base de La-Mg-Ni, revelou-se como promissor para atender a demanda por baterias $\mathrm{Ni}-\mathrm{MH}$ comerciais de performance superior. Ligas desse sistema apresentam capacidade de descarga mais alta (380-410 mAh g ${ }^{-1}$ ), além de menores custos de produção. A melhoria na estabilidade cíclica dos eletrodos constitui o principal desafio para a aplicação dessas ligas.

Em vista da maior proximidade composicional às ligas consideradas no presente estudo, são apresentadas, a seguir, maiores considerações a respeito das ligas tipo $\mathrm{AB}_{5}$ à base de terras raras e das ligas tipo $\mathrm{R}-\mathrm{Mg}-\mathrm{Ni}$ à base de terras raras-Mg-Ni. 
TABELA 1 - Características dos principais tipos de ligas de armazenamento de hidrogênio desenvolvidas como material do eletrodo negativo para baterias $\mathrm{Ni}-\mathrm{MH}$ (Liu et al., 2011a, 2011b).

\begin{tabular}{|c|c|c|c|c|}
\hline Tipo de liga & Descrição ou exemplo & Estrutura cristalina & $\begin{array}{c}\text { Capacidade } \\
\left(\mathrm{mAh}^{-1}\right)\end{array}$ & Comentários \\
\hline $\begin{array}{l}\mathrm{AB}_{5} \\
\text { à base de terras } \\
\text { raras }\end{array}$ & $\begin{array}{l}A=\text { terras raras } \\
B=\mathrm{Ni}, \mathrm{Co}, \mathrm{Mn}, \mathrm{Al}, \mathrm{Sn}, \mathrm{Fe}\end{array}$ & $\begin{array}{l}\text { hexagonal } \\
\text { tipo } \mathrm{CaCu}_{5}\end{array}$ & $300-320$ & $\begin{array}{l}\text { Amplamente adotada na atualidade; } \\
\text { capacidade limitada. Composição } \\
\text { comercializada: } \mathrm{MmNi}_{3,55} \mathrm{Co}_{0,75} \mathrm{Mn}_{0,4} \mathrm{Al}_{0,3} \\
\mathrm{Mm}=\mathrm{La}_{0,62} \mathrm{Ce}_{0,27} \mathrm{Pr}_{0,03} \mathrm{Nd}_{0,08}\end{array}$ \\
\hline $\begin{array}{l}\mathrm{AB}_{2} \\
\text { à base de } \mathrm{Ti} \text { e } \mathrm{Zr}\end{array}$ & $\begin{array}{l}\mathrm{A}=\mathrm{Zr}, \mathrm{Ti} \\
\mathrm{B}=\mathrm{V}, \mathrm{Ni}, \mathrm{Cr}, \mathrm{Co}, \mathrm{Mn}, \mathrm{Al}, \mathrm{Fe}\end{array}$ & $\begin{array}{l}\text { fases de Laves } \\
\text { hexagonal } \mathrm{C} 14\left(\mathrm{MgZn}_{2}\right) \\
\text { cúbico } \mathrm{C} 15\left(\mathrm{MgCu}_{2}\right)\end{array}$ & $370-450$ & $\begin{array}{l}\text { Segunda geração de ligas devido maior } \\
\text { densidade de energia. Composição } \\
\text { comercializada: } \operatorname{Ti}_{0,51} Z \mathrm{Zr}_{0,49} \mathrm{~V}_{0,70} \mathrm{Ni}_{1,18} \mathrm{Cr}_{0,12}\end{array}$ \\
\hline $\begin{array}{l}\mathrm{R}-\mathrm{Mg}-\mathrm{Ni} \\
\text { à base de terras } \\
\text { raras-Mg-Ni }\end{array}$ & $\begin{array}{l}\text { Ex: } \\
\mathrm{La}_{0,7} \mathrm{Mg}_{0,3}\left(\mathrm{Ni}_{0,85} \mathrm{Co}_{0,15}\right)_{3,5}\end{array}$ & $\begin{array}{l}\text { romboédrica tipo } \mathrm{PuNi}_{3} \\
\text { e hexagonal tipo } \mathrm{CaCu}_{5} \\
\text { (estrutura relativa ao } \\
\text { exemplo dado) }\end{array}$ & 396 & $\begin{array}{l}\text { Maior expectativa para aplicação na } \\
\text { próxima geração de baterias de alta } \\
\text { energia e potência; necessidade de } \\
\text { melhoria na estabilidade cíclica }\end{array}$ \\
\hline $\begin{array}{l}\text { Amorfas e } \\
\text { nanocristalinas } \\
\text { à base de } \mathrm{Mg}\end{array}$ & Ex.: $\mathrm{Mg}_{50} \mathrm{Ni}_{50}$ & amorfa/nanocristalina & 500 & $\begin{array}{l}\text { Uso promissor devido capacidade de } \\
\text { descarga alta, baixo custo e abundância } \\
\text { de recursos; estabilidade cíclica ainda } \\
\text { insatisfatória para comercialização }\end{array}$ \\
\hline
\end{tabular}




\subsubsection{Ligas tipo $A B_{5}$ à base de terras raras}

Nas ligas tipo $A B_{5}$ à base de terras raras, o lado $A$ consiste de um ou mais elementos de terras raras como $\mathrm{La}, \mathrm{Ce}, \mathrm{Pr}$ e $\mathrm{Nd}$ e o lado B corresponde a metais de transição como $\mathrm{Ni}$, Co, $\mathrm{Mn}$ e Fe, além de outros metais como $\mathrm{Al}$ e $\mathrm{Sn}$. Tendo por protótipo a liga $\mathrm{LaNi}_{5}$, as ligas tipo $\mathrm{AB}_{5}$ apresentam estrutura hexagonal tipo $\mathrm{CaCu}_{5}$, com o hidrogênio ocupando preferencialmente os sítios tetraédricos da estrutura. Considerando o hidreto $\mathrm{LaNi}_{5} \mathrm{H}_{6}$, com absorção máxima de 6 átomos de hidrogênio por unidade, a capacidade de descarga correspondente equivale a $367 \mathrm{mAh} \mathrm{g}^{-1}$. Na prática, problemas como baixa estabilidade do hidreto formado e corrosão limitaram em muito o valor obtido para a capacidade de descarga do eletrodo de $\mathrm{LaNi}_{5}$, enviabilizando seu uso nas baterias Ni-MH (Reilly, 1999; Liu et al., 2011b).

Em relação às funções dos elementos adicionados às ligas tipo $A B_{5}$, os constituintes do lado $\mathrm{A}$ como $\mathrm{La}, \mathrm{Ce}, \mathrm{Pr}$ e $\mathrm{Nd}$ promovem a absorção de hidrogênio. No lado $B$, o $\mathrm{Ni}$ age como catalisador da velocidade da reação de carga/descarga para níveis apropriados; Co, $\mathrm{Mn}$ e $\mathrm{Sn}$ melhoram a atividade superficial da liga, e Al e Fe aumentam a resistência à corrosão (Feng et al., 2001; Liu et al., 2011b). Dos elementos de liga citados, o cobalto é o mais oneroso, podendo responder por até $50 \%$ do custo de uma liga tipo $A B_{5}$, apesar de sua participação na composição da liga ser, tipicamente, da ordem de 10\% em massa (ou 12,5 at.\%) (Liu et al., 2011b).

$A$ adição de pequenas quantidades de $M g$ às ligas tipo $A B_{5}$, com 0 intuito de diminuir a concentração de Co e consequente redução de custos, mostrou-se bastante satisfatória.

$\mathrm{Na}$ liga de composição hiperestequiométrica $\mathrm{Mm}_{0,96} \mathrm{Mg}_{0,04} \mathrm{Ni}_{4,2} \mathrm{Co}_{0,3} \mathrm{Mn}_{0,4} \mathrm{Al}_{0,3}\left(\mathrm{AB}_{5,2}\right)$, a presença de magnésio é de apenas 0,65 at.\% e, a de Co, 4,84 at.\% - esta, por sinal, bem inferior aos 12,5 at.\% (aproximadamente $61,3 \%$ a menos) de Co presente na composição da liga tipo $\mathrm{AB}_{5}$ comercializada, $\mathrm{MmNi}_{3,5} \mathrm{Co}_{0,75} \mathrm{Mn}_{0,4} \mathrm{Al}_{0,3}$, citada na TAB. 1. A presença de $\mathrm{Mg}$ em tais condições proporcionou características como baixo custo, maior potência e durabilidade às baterias Ni-MH testadas (Ozaki et al., 2006).

As composições hipoestequiométricas $\mathrm{Ml}_{0,95} \mathrm{Mg}_{0,05} \mathrm{Ni}_{3,8} \mathrm{Co}_{0,3} \mathrm{Mn}_{0,3} \mathrm{Al}_{0,4}$ $\left(\mathrm{AB}_{4,8}\right)$ e $\mathrm{Ml}_{0,95} \mathrm{Mg}_{0,05} \mathrm{Ni}_{3,6} \mathrm{Co}_{0,3} \mathrm{Mn}_{0,3} \mathrm{Al}_{0,4} \quad\left(\mathrm{AB}_{4,6}\right)$ (Zhang, P. et al., 2005), $\mathrm{RE}_{0,93} \mathrm{Mg}_{0,07} \mathrm{Ni}_{2,96} \mathrm{Co}_{0,60} \mathrm{Mn}_{0,37} \mathrm{Al}_{0,17} \quad\left(\mathrm{AB}_{4,1}\right) \quad(\mathrm{Li}, \quad \mathrm{M}$. et al., 2006) e 
$\mathrm{La}_{0,85} \mathrm{Mg}_{0,15} \mathrm{Ni}_{3,8} \mathrm{Co}_{0,3} \mathrm{Mn}_{0,3} \mathrm{Al}_{0,4}\left(\mathrm{AB}_{4,8}\right)$ (Cuscueta et al., 2008) constituem demais exemplos de ligas com pequenas adições de $\mathrm{Mg}$ visando a redução de Co e melhora da estabilidade cíclica.

Não obstante, é dada ênfase, mais uma vez, à limitação da capacidade de descarga fornecida pelas ligas tipo $\mathrm{AB}_{5}$, inviabilizando seu uso em baterias $\mathrm{Ni}-\mathrm{MH}$ de maior performance, como nos veículos elétricos híbridos (Liu et al., 2011b; Zhang, Y. et al., 2015). Estudos recentes de ligas tipo $A_{5}$ atestam a continuidade da limitação da capacidade de descarga máxima, como na adição de Mo por substituição ao Co (Yang et al., 2011) e na adição de Mn em substituição ao Ni (Zhong et al., 2011), com valores de descarga máxima de $320 \mathrm{mAh} \mathrm{g}^{-1}$ e 268,8 $\mathrm{mAh} \mathrm{g}^{-1}$, respectivamente.

\subsubsection{Ligas tipo $\mathrm{R}-\mathrm{Mg}-\mathrm{Ni}$ à base de terras raras-Mg-Ni}

Historicamente, os primeiros compostos ternários $\mathrm{La}_{1-x} \mathrm{Mg}_{\mathrm{x}} \mathrm{Ni}_{2}$ $(x=0-0,67)$ com estrutura tipo C15 foram preparados em 1980. Hidretos formados com composição rica em $\mathrm{Mg}\left(\mathrm{La}_{0,33} \mathrm{Mg}_{0,67} \mathrm{Ni}_{2} \mathrm{H}_{2,2}\right)$ mostraram capacidade de liberar hidrogênio à temperatura ambiente, mas com velocidade de desorção extremamente baixa, em virtude da elevada estabilidade dos mesmos (Oesterreicher e Bittner, 1980). A síntese de novos sistemas de ligas ternárias de armazenamento de hidrogênio, como $\mathrm{RMg}_{2} \mathrm{Ni}_{9}$, onde $\mathrm{R}=\mathrm{La}, \mathrm{Ce}, \mathrm{Pr}, \mathrm{Nd}$, Sm ou $\mathrm{Gd}$ (Kadir et al., 1997) e La $\mathrm{MgNi}_{9}, \mathrm{La}_{5} \mathrm{Mg}_{2} \mathrm{Ni}_{23}$ e $\mathrm{La}_{3} \mathrm{MgNi}_{14}$ (Kohno et al., 2000) fundamentou a posição do sistema de ligas R-Mg-Ni como promissor para uso no eletrodo negativo das baterias Ni-MH (Zhang, Y. et al., 2015).

No sistema de ligas R-Mg-Ni, a introdução de $\mathrm{Mg}$ como constituinte no lado $A$ em composições $A B_{3,0-5,0}$ à base de terras raras facilita a formação da fase ( $\mathrm{La}, \mathrm{Mg}) \mathrm{Ni}_{3}$ com estrutura romboédrica tipo $\mathrm{PuNi}_{3}$, ou da fase $(\mathrm{La}, \mathrm{Mg})_{2} \mathrm{Ni}_{7}$ com estrutura hexagonal tipo $\mathrm{Ce}_{2} \mathrm{Ni}_{7}$. As superestruturas apresentadas por essas fases, combinando subunidades $A B_{5}$ (estrutura tipo $C_{a C u_{5}}$ ) e $A B_{2}$ (estrutura tipo fase de Laves), permitem uma capacidade de absorção de hidrogênio maior e, consequentemente, seu maior armazenamento. Ainda, a presença de $\mathrm{Mg}$ nas fases $\mathrm{LaNi}_{3}$ e $\mathrm{La}_{2} \mathrm{Ni}_{7}$ é citada como fator eliminador de fases amorfas dos hidretos correspondentes, assegurando maior reversibilidade eletroquímica aos mesmos (Liu et al., 2011b). 
Por outro lado, La e Mg são relacionados à degradação da estabilidade cíclica e redução da capacidade de descarga do eletrodo em meio alcalino, mediante os processos de pulverização e oxidação/corrosão aos quais estão associados. Na superfície das partículas da liga, La e Mg são oxidados, respectivamente, a $\mathrm{La}(\mathrm{OH})_{3}$ e $\mathrm{Mg}(\mathrm{OH})_{2}$, promovendo a formação de camadas passivas na superfície. Essas camadas, não somente comprometem a atividade eletrocatalítica na superfície e a difusão do hidrogênio do interior da liga, como também decrescem a quantidade de $\mathrm{La}$ e $\mathrm{Mg}$ disponível à absorção de hidrogênio, reduzindo a capacidade de armazenamento de hidrogênio da liga. Adicionalmente, a substituição entre La e Mg promove uma elevada taxa de expansão/contração do volume da célula unitária durante a absorção/desorção do hidrogênio nos ciclos de carga/descarga, acelerando a corrosão dos componentes ativos (Liao et al., 2004b; Liu et al., 2011b).

Modificações composicionais constituem, ao lado de formação de compósitos e tratamentos térmico e de superfície, métodos para otimizar as propriedades eletroquímicas dos eletrodos das ligas R-Mg-Ni (Liu et al., 2011b). Algumas das propriedades de elementos adicionados são relacionadas a seguir.

- Lantânio: aumento do volume da célula unitária; aumento da capacidade de descarga, ativação fácil e alta taxa de descarga considerável (Liao et al. 2004a, 2003).

- Magnésio: eliminação da amorfização dos hidretos; decréscimo do volume da célula unitária e da estabilidade do hidreto; aumento da capacidade de descarga, da alta taxa de descarga e da estabilidade cíclica (Liu et al., 2005b; Tang et al., 2006; Zhang, F. et al., 2007).

- Praseodímio: decréscimo dos parâmetros de rede e dos volumes de célula das fases constituintes; decréscimo da capacidade de descarga máxima; melhora da estabilidade cíclica e da alta taxa de descarga (Pan et al., 2007).

- Cobalto: aumento dos parâmetros de rede e dos volumes de célula; aumento da capacidade de armazenamento de hidrogênio; melhora efetiva da estabilidade cíclica devido à menor variação do volume da célula e ao aumento da passivação da superfície; aumento da cinética eletroquímica em virtude das excelentes performances catalítica e condutora (Liu et al., 2004a, 2004b; Wang et al., 2006; Zhang, F. et al., 2006). 
- Manganês: aumento dos parâmetros de rede e dos volumes de célula; facilitação da formação da fase $\mathrm{LaNi}_{5}$; aumento da capacidade de descarga máxima e da cinética eletroquímica; melhora da estabilidade cíclica (Liao et al., 2004a; Liu et al., 2004c, 2004d; Pan et al., 2004c).

- Alumínio: aumento dos parâmetros de rede e dos volumes de célula; melhora significativa da estabilidade cíclica devido à formação de densa camada de óxido na superfície da liga; decréscimo da capacidade de descarga máxima e da alta taxa de descarga (Chu et al., 2008b; Li, B. et al., 2006; Liao et al., 2005; Liu et al., 2008, 2005c; Pan et al., 2005b).

- Molibdênio: decréscimo da capacidade de descarga máxima; aumento da estabilidade cíclica e da alta taxa de descarga conferindo à superfície da liga propriedades desejáveis e aumento das condutividades eletrônica e iônica (Zhang, X. et al., 2006).

- Níquel: aumento da atividade catalítica proporcionando velocidades apropriadas às reações de carga e descarga (Feng et al., 2001; Kleperis et al., 2001).

As informações expostas revelam a dualidade dos efeitos das adições, como no caso dos elementos supracitados $\mathrm{La}$ e $\mathrm{Mg}$, associados a melhorias na cinética dos eletrodos, em contrapartida a outras propriedades nem sempre benéficas, como já comentado. Verifica-se também que ao Pr está vinculada a melhora na estabilidade cíclica e na cinética de descarga, além do decréscimo na capacidade de descarga máxima. Não obstante, segundo Ozaki et al. (2007), a liga $\mathrm{La}_{0,6} \mathrm{Pr}_{0,2} \mathrm{Mg}_{0,2} \mathrm{Ni}_{3,2} \mathrm{Co}_{0,3}(\mathrm{MnAl})_{0,2}$, na qual o La foi parcialmente substituído por $\operatorname{Pr}$ apresentou, em comparação à liga $\mathrm{La}_{0,8} \mathrm{Mg}_{0,2} \mathrm{Ni}_{3,2} \mathrm{Co}_{0,3}(\mathrm{MnAl})_{0,2}$, maiores valores tanto para a capacidade de descarga máxima como para a retenção da capacidade.

llustrando a dependência da performance eletroquímica das ligas frente às condições definidas de composição, método de preparação, fases presentes e método das medidas eletroquímicas, são apresentados alguns exemplos na TAB. 2. As ligas $\mathrm{La}_{0,7} \mathrm{Mg}_{0,3} \mathrm{Ni}_{2,45} \mathrm{Mn}_{0,1} \mathrm{Co}_{0,75} \mathrm{Al}_{0,2}$ (Pan et al., 2005b) e $\mathrm{La}_{0,55} \mathrm{Pr}_{0,15} \mathrm{Mg}_{0,3} \mathrm{Ni}_{2,45} \mathrm{Co}_{0,75} \mathrm{Mn}_{0,1}$ (Pan et al., 2007), citadas na referida tabela, integram estudos sistemáticos de adição de elementos realizados nos anos 2000 por Pan e colaboradores, predominando a relação $A B_{3,5}$ e presença de $\mathrm{Mg}$ em porcentagem atômica significativa $(6,67$ at.\%) nas composições (Pan et al., 2004a, 2004b, 2004c, 2003, 2006, 2005c). 
TABELA 2 - Características estruturais e propriedades eletroquímicas de eletrodos de ligas à base de R-Mg-Ni.

\begin{tabular}{|c|c|c|c|c|c|c|c|c|}
\hline Liga & $\begin{array}{l}\text { Método de } \\
\text { Preparação }\end{array}$ & $\begin{array}{l}\text { Estrutura } \\
\text { tipo/fase }\end{array}$ & $\begin{array}{l}\text { Sistema } \\
\text { de } \\
\text { medida }\end{array}$ & $\begin{array}{l}\mathrm{I}_{\mathrm{D}}^{\mathrm{b}} \\
\text { carga/ } \\
\text { descarga } \\
\left(\mathrm{mA} \mathrm{g}^{-1}\right)\end{array}$ & $\begin{array}{l}\mathrm{C}_{\text {máx }}{ }^{\mathrm{c}} \\
\left(\mathrm{mA} \mathrm{g}^{-1}\right)\end{array}$ & $\begin{array}{c}\mathrm{HRD}_{\mathrm{ID}}{ }^{\mathrm{d}} \\
(\%)\end{array}$ & $\begin{array}{l}S^{e} \\
(\%)\end{array}$ & Referência \\
\hline $\mathrm{LaCaMgNi}_{9}$ & $\mathrm{~S}$ & $\mathrm{PuNi}_{3}$ & $\begin{array}{l}\text { dois } \\
\text { eletrodos }\end{array}$ & $150 / 150$ & 356 & - & - & $\begin{array}{l}\text { Chen et al., } \\
2000\end{array}$ \\
\hline $\mathrm{La}_{2} \mathrm{MgNi}_{9}$ & $S$ & $\mathrm{PuNi}_{3}$ & $\begin{array}{l}\text { três } \\
\text { eletrodos }\end{array}$ & $300 / 100$ & 397,5 & $\begin{array}{l}\mathrm{HRD}_{1200} \\
= \\
52,7\end{array}$ & $\begin{array}{l}S_{100} \\
= \\
60,6\end{array}$ & $\begin{array}{l}\text { Liao et al., } \\
2004 b\end{array}$ \\
\hline $\mathrm{La}_{0,7} \mathrm{Mg}_{0,3} \mathrm{Ni}_{2,45} \mathrm{Mn}_{0,1} \mathrm{Co}_{0,75} \mathrm{Al}_{0,2}$ & FLMV & $\begin{array}{l}(\mathrm{La}, \mathrm{Mg}) \mathrm{Ni}_{3} \\
\mathrm{LaNi}_{5}\end{array}$ & $\begin{array}{l}\text { três } \\
\text { eletrodos }\end{array}$ & $100 / 60$ & 370 & $\begin{array}{l}\mathrm{HRD}_{1000} \\
= \\
71,3\end{array}$ & $\begin{array}{l}S_{100} \\
= \\
71,3\end{array}$ & $\begin{array}{l}\text { Pan et al., } \\
2005 b\end{array}$ \\
\hline $\mathrm{La}_{0,7} \mathrm{Mg}_{0,3} \mathrm{Ni}_{2,9}\left(\mathrm{Al}_{0,5} \mathrm{Mo}_{0,5}\right)_{0,6}$ & $\mathrm{FV}+\mathrm{R}$ & $\begin{array}{l}\mathrm{La}(\mathrm{La}, \mathrm{Mg})_{2} \mathrm{Ni}_{9} \\
\mathrm{LaNi}_{5} \\
\mathrm{LaNi}\end{array}$ & $\begin{array}{l}\text { três } \\
\text { eletrodos }\end{array}$ & $60 / 60$ & 397,6 & $\begin{array}{l}\mathrm{HRD}_{1200} \\
= \\
70,5\end{array}$ & $\begin{array}{l}S_{70} \\
= \\
70,8\end{array}$ & $\begin{array}{l}\text { Zhang, X. } \\
\text { et al., } 2006\end{array}$ \\
\hline $\mathrm{La}_{0,55} \mathrm{Pr}_{0,15} \mathrm{Mg}_{0,3} \mathrm{Ni}_{2,45} \mathrm{Co}_{0,75} \mathrm{Mn}_{0,1}$ & FLMV & $\begin{array}{l}(\mathrm{La}, \mathrm{Mg}) \mathrm{Ni}_{3} \\
\mathrm{LaNi}_{5}\end{array}$ & $\begin{array}{l}\text { três } \\
\text { eletrodos }\end{array}$ & $100 / 60$ & 356,8 & $\begin{array}{l}\mathrm{HRD}_{1000} \\
= \\
78,9\end{array}$ & $\begin{array}{l}\mathrm{S}_{80} \\
= \\
79,4\end{array}$ & $\begin{array}{l}\text { Pan et al., } \\
2007\end{array}$ \\
\hline $\mathrm{La}_{0,7} \mathrm{Mg}_{0,3} \mathrm{Ni}_{3,5}$ & $\begin{array}{l}S L \\
(1200 \mathrm{~W})\end{array}$ & $\begin{array}{l}\mathrm{Ce}_{2} \mathrm{Ni}_{7} \\
\mathrm{LaNi}_{5} \\
\mathrm{LaMgNi}_{4}\end{array}$ & $\begin{array}{l}\text { três } \\
\text { eletrodos }\end{array}$ & $100 / 50$ & 352,8 & $\begin{array}{l}\mathrm{HRD}_{800} \\
= \\
79,4\end{array}$ & $\begin{array}{l}S_{100} \\
= \\
58,4\end{array}$ & $\begin{array}{l}\text { Si et al., } \\
2008\end{array}$ \\
\hline $\mathrm{La}_{0,80} \mathrm{Mg}_{0,20} \mathrm{Ni}_{3,75}$ & SPP & $\begin{array}{l}(\mathrm{La}, \mathrm{Mg})_{2} \mathrm{Ni}_{7} \\
\mathrm{LaNi}_{5}\end{array}$ & $\begin{array}{l}\text { três } \\
\text { eletrodos }\end{array}$ & $60 / 60$ & 368,2 & $\begin{array}{l}\mathrm{HRD}_{900} \\
= \\
60,75\end{array}$ & $\begin{array}{l}S_{150} \\
= \\
58,4\end{array}$ & $\begin{array}{l}\text { Dong et al., } \\
2008 a\end{array}$ \\
\hline $\mathrm{La}_{0,7} \mathrm{Mg}_{0,3}\left(\mathrm{Ni}_{0,9} \mathrm{Co}_{0,1}\right)_{3,5}$ & $\mathrm{FLI}+\mathrm{R}$ & $\begin{array}{l}(\mathrm{La}, \mathrm{Mg}) \mathrm{Ni}_{3} \\
(\mathrm{La}, \mathrm{Mg})_{2} \mathrm{Ni}_{7}\end{array}$ & $\begin{array}{l}\text { dois } \\
\text { eletrodos }\end{array}$ & $60 / 60$ & 392,1 & - & $\begin{array}{l}S_{100} \\
= \\
93,5\end{array}$ & $\begin{array}{l}\text { Cheng et } \\
\text { al., } 2008\end{array}$ \\
\hline
\end{tabular}


TABELA 2 - Características estruturais e propriedades eletroquímicas de eletrodos de ligas à base de R-Mg-Ni. (continuação)

\begin{tabular}{|c|c|c|c|c|c|c|c|c|}
\hline $\mathrm{La}_{0,7} \mathrm{Mg}_{0,3} \mathrm{Ni}_{3,4}\left(\mathrm{MnAl}_{2}\right)_{0,1}$ & FLMV & $\begin{array}{l}(\mathrm{La}, \mathrm{Mg}) \mathrm{Ni}_{3} \\
\mathrm{LaNi}_{5}\end{array}$ & $\begin{array}{l}\text { três } \\
\text { eletrodos }\end{array}$ & $300 / 100$ & 355,2 & $\begin{array}{l}\mathrm{HRD}_{800} \\
= \\
79\end{array}$ & $\begin{array}{l}S_{100} \\
= \\
43,7\end{array}$ & $\begin{array}{l}\text { Chu et al., } \\
2008 b\end{array}$ \\
\hline $\begin{array}{l}\mathrm{La}_{0,7} \mathrm{Mg}_{0,3} \mathrm{Ni}_{3,5^{-}} \\
40 \% \mathrm{Ti}_{0,17} \mathrm{Zr}_{0,08} \mathrm{~V}_{0,35} \mathrm{Cr}_{0,1} \mathrm{Ni}_{0,3}\end{array}$ & MB & $\begin{array}{l}(\mathrm{La}, \mathrm{Mg}) \mathrm{Ni}_{3} \\
\mathrm{LaNi}_{5} \\
\mathrm{LaNi} \\
\text { CCC } \\
\text { Laves C14 }\end{array}$ & $\begin{array}{l}\text { três } \\
\text { eletrodos }\end{array}$ & $300 / 100$ & 335,2 & - & $\begin{array}{l}S_{70} \\
= \\
63\end{array}$ & $\begin{array}{l}\text { Chu et al., } \\
2008 a\end{array}$ \\
\hline $\mathrm{La}_{0,60} \mathrm{Nd}_{0,20} \mathrm{Mg}_{0,20}(\mathrm{NiCoMnAl})_{3,5}$ & $\mathrm{FI}$ & $\begin{array}{l}\mathrm{LaNi}_{5} \\
\mathrm{La}_{2} \mathrm{Ni}_{7}\end{array}$ & $\begin{array}{l}\text { três } \\
\text { eletrodos }\end{array}$ & $60 / 60$ & 370 & $\begin{array}{l}\mathrm{HRD}_{1200} \\
= \\
44,3\end{array}$ & $\begin{array}{l}S_{100} \\
= \\
93,2\end{array}$ & $\begin{array}{l}\text { Li, Y. et al., } \\
2009\end{array}$ \\
\hline $\mathrm{La}_{2,1} \mathrm{Mg}_{0,9}(\mathrm{NiCoMn})_{9,3}$ & FLMV & $\begin{array}{l}\mathrm{LaNi}_{5} \\
\mathrm{LaMg}_{2} \mathrm{Ni}_{9} \\
\mathrm{La}_{4} \mathrm{MgNi}_{19}\end{array}$ & $\begin{array}{l}\text { três } \\
\text { eletrodos }\end{array}$ & $100 / 60$ & 366,8 & $\begin{array}{l}\mathrm{HRD}_{300} \\
= \\
92,69\end{array}$ & $\begin{array}{l}S_{100} \\
= \\
73,8\end{array}$ & $\begin{array}{l}\text { Wei et al., } \\
2012\end{array}$ \\
\hline $\mathrm{La}_{0,65} \mathrm{Gd}_{0,2} \mathrm{Mg}_{0,15} \mathrm{Ni}_{3,1} \mathrm{Co}_{0,3} \mathrm{Al}_{0,1}$ & $\mathrm{Fl}+\mathrm{R}$ & $\begin{array}{l}\mathrm{Ce}_{2} \mathrm{Ni}_{7} \\
\mathrm{~A}_{2} \mathrm{~B}_{7} \\
\mathrm{CaCu}_{5} \\
\mathrm{PuNi}_{3}\end{array}$ & $\begin{array}{l}\text { três } \\
\text { eletrodos }\end{array}$ & $60 / 300$ & 391,4 & $\begin{array}{l}\mathrm{HRD}_{900} \\
= \\
70,1\end{array}$ & $\begin{array}{l}S_{100} \\
= \\
92,0\end{array}$ & $\begin{array}{l}\text { Gao et al., } \\
2013\end{array}$ \\
\hline $\mathrm{La}_{0,60} \mathrm{Nd}_{0,15} \mathrm{Mg}_{0,25} \mathrm{Ni}_{3,3}$ & $\mathrm{FI}$ & $\begin{array}{l}\mathrm{Ce}_{2} \mathrm{Ni}_{7} \\
\mathrm{Gd}_{2} \mathrm{Ni}_{7} \\
\mathrm{LaNi}_{5}\end{array}$ & $\begin{array}{l}\text { três } \\
\text { eletrodos }\end{array}$ & $60 / 60$ & 376 & $\begin{array}{l}\mathrm{HRD}_{1440} \\
= \\
67,7\end{array}$ & $\begin{array}{l}S_{100} \\
= \\
76,7\end{array}$ & $\begin{array}{l}\text { Wang et al., } \\
2014\end{array}$ \\
\hline $\mathrm{La}_{0,80} \mathrm{Mg}_{0,20} \mathrm{Ni}_{2,95} \mathrm{Co}_{0,55} \mathrm{Al}_{0,15}$ & $\mathrm{FI}$ & $\begin{array}{l}(\mathrm{La}, \mathrm{Mg})_{2} \mathrm{Ni}_{7} \\
\mathrm{LaNi}_{5}\end{array}$ & $\begin{array}{l}\text { três } \\
\text { eletrodos }\end{array}$ & $60 / 60$ & 381 & $\begin{array}{l}\mathrm{HRD}_{1500} \\
= \\
95,7\end{array}$ & $\begin{array}{l}S_{150} \\
= \\
81,3 \\
\end{array}$ & $\begin{array}{l}\text { Liu, J. et al., } \\
2015 b\end{array}$ \\
\hline
\end{tabular}

${ }^{a}$ S, sinterização; FLMV, fusão por levitação magnética a vácuo; FA, fusão a vácuo; R, recozimento; SL, sinterização a laser; SPP, sinterização por plasma pulsado; FLI, fusão por levitação induzida; MB, moagem por bolas; FI, fusão por indução; ${ }^{b}$ Densidade de corrente; ${ }^{\mathrm{C}} \mathrm{Capacidade}$ de descarga máxima; ${ }^{d}$ Alta taxa de descarga em determinada densidade de corrente de descarga; ${ }^{e}$ Retenção da capacidade de descarga. 
Estudos da relação $\mathrm{La} / \mathrm{Mg}$ em sistemas ternários $\mathrm{La}_{x} \mathrm{Mg}_{3-x} \mathrm{Ni}_{9}$ $(x=1,0-2,0)$ e $\operatorname{La}_{x} \mathrm{Mg}_{3-x} \mathrm{Ni}_{9} \quad(\mathrm{x}=1,6-2,2)$, com estrutura hexagonal tipo $\mathrm{PuNi}_{3}$, revelaram que ligas ricas em La formam hidretos mais estáveis e promovem 0 aumento do volume da célula unitária, elevando o número de sítios disponíveis ao armazenamento de hidrogênio. Os eletrodos das ligas $\mathrm{La}_{1,8} \mathrm{Mg}_{1,2} \mathrm{Ni}_{9}$ e $\mathrm{La}_{2} \mathrm{MgNi}_{9}$ exibiram o valor mais elevado de capacidade de descarga máxima (cerca de $400 \mathrm{mAh} \mathrm{g}^{-1}$ ), além de ativação rápida e elevada alta taxa de descarga. Os valores de estabilidade cíclica, porém, mostraram-se pouco satisfatórios (Liao et al. 2004b, 2003).

Já no estudo de Dong et al. (2008b), as ligas $\mathrm{La}_{0,75+x} \mathrm{Mg}_{0,25-\mathrm{x}} \mathrm{Ni}_{3,5}$ $(x=0-0,1)$ foram compostas pelas fases $\mathrm{LaNi}_{5},(\mathrm{La}, \mathrm{Mg})_{2} \mathrm{Ni}_{7}$ e em menor quantidade $\mathrm{LaNi}_{2}$. Para a relação $\mathrm{La} / \mathrm{Mg}$ maior que 3 revelou-se a presença da fase LaNi e em abundância crescente com o aumento da relação La/Mg. O eletrodo da liga $\mathrm{La}_{0,75} \mathrm{Mg}_{0,25} \mathrm{Ni}_{3,5}$ exibiu o maior valor para a capacidade de descarga máxima, 343,7 mAh $\mathrm{g}^{-1}$, enquanto que a liga $\mathrm{La}_{0,85} \mathrm{Mg}_{0,15} \mathrm{Ni}_{3,5}$ apresentou melhores resultados de estabilidade cíclica.

O estudo de Denys e Yartys (2011) revelou a influência do magnésio na estrutura cristalina e na absorção/desorção de hidrogênio em ligas $\mathrm{La}_{3-x} \mathrm{Mg}_{x} \mathrm{Ni}_{9}$ $(x=0,5-2,0)$. A principal fase de cada liga correspondeu ao tipo $\mathrm{PuNi}_{3}$ formada pelo empilhamento de estruturas $\mathrm{LaNi}_{5}$ tipo $\mathrm{CaCu}_{5}$ e $\mathrm{La}_{2-x} \mathrm{Mg}_{x} \mathrm{Ni}_{4}$ tipo fase de Laves $M g Z n_{2}$ ao longo do eixo trigonal (001). A medida em que a relação La/Mg diminuiu, a estabilidade termodinâmica dos hidretos decresceu, ao passo que a reversibilidade na capacidade de armazenamento aumentou.

Ainda para sistemas ternários, o estudo sistemático de Zhang, Y. et al. (2015) a respeito da influência da relação $\mathrm{La} / \mathrm{Mg}$ no comportamento dos eletrodos das ligas $\mathrm{La}_{0,8+x} \mathrm{Mg}_{0,2-\mathrm{x}} \mathrm{Ni}_{3,5}(\mathrm{x}=0-0,05)$ tipo $\mathrm{A}_{2} \mathrm{~B}_{7}$ - em estado bruto de fusão $\mathrm{e}$ tratadas termicamente - revelou vários aspectos interessantes. Todas as ligas foram compostas pelas fases $(\mathrm{La}, \mathrm{Mg})_{2} \mathrm{Ni}_{7}$ (majoritária) e $\mathrm{LaNi}_{5}$, além da fase residual $\mathrm{LaNi}_{3}$. Nas ligas em estado bruto de fusão, a abundância da fase $\mathrm{LaNi}_{5}$ mostrou-se um pouco mais elevada que o observado nas tratadas termicamente. A medida em que a relação $\mathrm{La} / \mathrm{Mg}$ aumentou, a abundância da fase $\left(\mathrm{La}, \mathrm{Mg}{ }_{2} \mathrm{Ni}_{7}\right.$ diminuiu, com o consequente aumento da abundância das fases $\mathrm{LaNi}_{5}$ e $\mathrm{LaNi}_{3}$, tanto para as ligas tratadas como as não tratadas termicamente. Adicionalmente, 
verificou-se uma redução significativa da capacidade de descarga máxima para todas as ligas. Em contrapartida, foram aumentadas tanto a estabilidade cíclica como a cinética dos eletrodos de todas as ligas. Em termos relativos, o tratamento térmico mostrou-se desvantajoso em relação à cinética, com valores de HRD menores para os eletrodos das ligas tratadas termicamente.

Em sistemas R-Mg-Ni multicomponentes, a adição de magnésio exemplificou, no estudo de Tang et al. (2006), o possível aumento da capacidade de descarga e da cinética dos eletrodos. Nas ligas $\mathrm{Ml}_{1-x} \mathrm{Mg}_{x} \mathrm{Ni}_{2,4} \mathrm{Co}_{0,6} \quad(x=0-0,6)$ tratadas termicamente, revelou-se a presença principal da fase $\mathrm{LaNi}_{3}$ (estrutura romboédrica tipo $\mathrm{PuNi}_{3}$ ), e as fases $\mathrm{LaNi}_{5}$ e $\mathrm{LaNi}_{2}$ como impurezas. A adição de Mg provocou a diminuição da célula unitária e a redução da estabilidade dos hidretos formados. A liga $\mathrm{Ml}_{0,6} \mathrm{Mg}_{0,4} \mathrm{Ni}_{2,4} \mathrm{Co}_{0,6}$ apresentou os valores mais elevados de $\mathrm{H} / \mathrm{M}\left(1,75 \%\right.$ em massa), de capacidade de descarga máxima (326 mAh $\mathrm{g}^{-1}$ ) e estabilidade cíclica. A cinética do processo de carga e descarga também foi favorecida pela substituição crescente do mischmetal por magnésio, com a liga $\mathrm{Ml}_{0,4} \mathrm{Mg}_{0,6} \mathrm{Ni}_{2,4} \mathrm{Co}_{0,6}$ apresentando os maiores valores de HRD.

No estudo de Zhang, Z. et al. (2007) a respeito da adição de magnésio às ligas $\mathrm{Ml}_{1-x} \mathrm{Mg}_{\mathrm{x}} \mathrm{Ni}_{3,0} \mathrm{Mn}_{0,10} \mathrm{Co}_{0,55} \mathrm{Al}_{0,10}(\mathrm{x}=0,05-0,30)$, também submetidas a tratamento térmico, as variações nas propriedades eletroquímicas foram atribuídas às mudanças estruturais observadas. A abundância das duas fases detectadas, $\mathrm{LaNi}_{5}$ e ( $\left.\mathrm{La}, \mathrm{Mg}\right) \mathrm{Ni}_{3}$, variou em função de $\mathrm{x}$, com a presença da fase $\mathrm{LaNi}_{5}$ diminuindo com o aumento da adição de $\mathrm{Mg}$ (e o consequente aumento da presença da fase $\left.(\mathrm{La}, \mathrm{Mg}) \mathrm{Ni}_{3}\right)$. O comportamento dessas fases frente à capacidade de armazenamento de hidrogênio, as variações de volume de suas células unitárias e o princípio da oxidação/pulverização pela presença do magnésio foram utilizados nas interpretações dos resultados obtidos. $O$ maior valor de capacidade de descarga máxima (363 $\mathrm{mAh}^{-1}$ ) foi obtido para a condição $x=0,20$; os valores mais elevados para HRD foram verificados na condição $\mathrm{X}=0$,15. A retenção da capacidade decresceu com o teor de $\mathrm{Mg}$ crescente, indicando queda na estabilidade cíclica dos eletrodos ao longo das condições de substituição $x=0,05-0,30$. Os melhores valores foram obtidos para as condições $x=0,05$ e $x=0,10$ (em torno de $75 \%$ de retenção de capacidade).

A relação entre mudanças estruturais e propriedades eletroquímicas também foi verificada no estudo de Wei et al. (2012) relacionado à variação do 
teor de $\mathrm{Mg}$ nas ligas $\mathrm{La}_{1,7+x} \mathrm{Mg}_{1,3-x}\left(\mathrm{NiCoMn}_{9,3}(x=0-0,4)\right.$ tratadas termicamente. As fases detectadas foram $\mathrm{LaNi}_{5}, \mathrm{LaMg}_{2} \mathrm{Ni}_{9}$ ( estrutura tipo $\mathrm{PuNi}_{3}$ ) e $\mathrm{La}_{4} \mathrm{MgNi}_{19}$ (estrutura tipo $\mathrm{Ce}_{5} \mathrm{Co}_{19}+\mathrm{Pr}_{5} \mathrm{Co}_{19}$ ). Da condição $\mathrm{x}=0$ para $\mathrm{x}=0,2$, a abundância da fase $\mathrm{LaNi}_{5}$ aumentou, e a abundância da fase $\mathrm{LaMg}_{2} \mathrm{Ni}_{9}$ diminuiu, para se extinguir na condição $x=0,4$. Nesta, aparece a fase $\mathrm{La}_{4} \mathrm{MgNi}_{19}$ e em condição majoritária, com a fase $\mathrm{LaNi}_{5}$ em menor proporção. A capacidade de descarga máxima aumentou segundo os valores de 330,9 mAh $\mathrm{g}^{-1}(\mathrm{x}=0), 337,2 \mathrm{mAh} \mathrm{g}^{-1}$ $(\mathrm{x}=0,2)$ e $366,8 \mathrm{mAh} \mathrm{g}^{-1}(\mathrm{x}=0,4)$, com interpretações dos resultados baseadas nas propriedades de capacidade de armazenamento de hidrogênio das fases presentes, entre outras. Os valores de HRD e a estabilidade cíclica apresentaram ligeiro declínio na condição $\mathrm{x}=0,4$, sendo tais comportamentos atribuídos, respectivamente, a menor atividade catalítica na superfície da liga e a maior expansão/contração de volume da fase $\mathrm{La}_{4} \mathrm{MgNi}_{19}$ presente nessa condição.

Já o estudo de Tian et al. (2016) exemplifica a pesquisa a respeito da prevenção de perda de magnésio durante o processo de obtenção das ligas. Após preparação por fusão a arco, pós da liga $\mathrm{La}_{0,70} \mathrm{Ni}_{2,45} \mathrm{Co}_{0,75} \mathrm{Al}_{0,30}$ foram misturados com pó de magnésio segundo as adições $\mathrm{La}_{0,70} \mathrm{Mg}_{\mathrm{x}} \mathrm{Ni}_{2,45} \mathrm{Co}_{0,75} \mathrm{Al}_{0,30}(\mathrm{x}=0,30 ; 0,33$; 0,36 e 0,39), e submetidos ao processo de moagem vibratória de alta energia. $\mathrm{Na}$ sequência, os pós resultantes foram tratados termicamente. A liga $\mathrm{La}_{0,70} \mathrm{Ni}_{2,45} \mathrm{Co}_{0,75} \mathrm{Al}_{0,30}$ em estado bruto de fusão foi composta somente pela fase $\mathrm{LaNi}_{5}$, enquanto que as ligas $\mathrm{La}_{0,70} \mathrm{Mg}_{x} \mathrm{Ni}_{2,45} \mathrm{Co}_{0,75} \mathrm{Al}_{0,30}$ apresentaram a fase $\mathrm{LaNi}$ e a fase $(\mathrm{La}, \mathrm{Mg})_{2} \mathrm{Ni}_{7}$ em abundância crescente no sentido das adições de $\mathrm{Mg}$ às ligas. Com a adição de $\mathrm{Mg}$, a capacidade de descarga máxima aumentou (maior valor 313,5 mAh $\mathrm{g}^{-1}$ em $\left.\mathrm{x}=0,36\right)$, para em seguida diminuir $(\mathrm{x}=0,39)$. Nessas duas condições foram observados melhores comportamentos de ativação; já na condição $\mathrm{x}=0,33$, verificou-se melhor estabilidade cíclica do eletrodo da liga correspondente. Nas interpretações dos resultados obtidos foram considerados fatores como a proporção das fases presentes influenciando na capacidade de armazenamento e na cinética de absorção/desorção de hidrogênio, variação do volume da célula unitária pela introdução de $\mathrm{Mg}$, pulverização e oxidação das ligas, e os efeitos dos métodos de preparação utilizados.

$\mathrm{A}$ adição de praseodímio às ligas multicomponentes $\mathrm{R}-\mathrm{Mg}-\mathrm{Ni}$ ilustra a busca pelo aumento da estabilidade cíclica e da cinética dos eletrodos das ligas desse sistema. No estudo de Pan et al. (2007), as ligas 
$\mathrm{La}_{0,7-\mathrm{x}} \mathrm{Pr}_{\mathrm{x}} \mathrm{Mg}_{0,3} \mathrm{Ni}_{2,45} \mathrm{Co}_{0,75} \mathrm{Mn}_{0,1} \mathrm{Al}_{0,2} \quad(\mathrm{x}=0,00-0,30)$ foram tratadas termicamente, revelando-se a presença das fases ( $\mathrm{La}, \mathrm{Mg}) \mathrm{Ni}_{3}$ e $\mathrm{LaNi}_{5}$, com as respectivas abundâncias diminuindo e aumentando à medida da substituição crescente de La por Pr. O comportamento de ativação das ligas não foi afetado com a adição de Pr, enquanto que a capacidade de descarga máxima decresceu da condição $x=0,00$ para $x=0,30$. O parâmetro HRD aumentou para depois diminuir, com valor máximo sendo atingido na condição $x=0,15$, indicando melhora na cinética de aborção/desorção de hidrogênio nessa condição. A estabilidade cíclica também foi favorecida com a substituição de La por Pr, com valores crescentes de $x=0,00$ para $x=0,30$. Os resultados obtidos foram interpretados considerando a relação de abundância das fases ( $\mathrm{La}, \mathrm{Mg}) \mathrm{Ni}_{3}$ e $\mathrm{LaNi}_{5}$ e a variação dos volumes de célula unitária em função do teor de Pr presente na composição das ligas.

Efeito benéfico pela substituição de La por Pr na cinética do eletrodo também foi observado no estudo de Yan et al. (2009) das ligas $\mathrm{La}_{0,65-x} \mathrm{Pr}_{\mathrm{x}} \mathrm{Nd}_{0,12} \mathrm{Mg}_{0,23} \mathrm{Ni}_{3,4} \mathrm{Al}_{0,1} \quad(\mathrm{x}=0,0 ; 0,10 ; 0,15$ e 0,20$)$. Na condição da substituição $x=0,15$ foram observados bons valores de HRD e de estabilidade cíclica, ao passo que a capacidade de descarga máxima decresceu a partir da adição de $\operatorname{Pr}$ nas ligas. Nas condições $x \leq 0,10$ foram detectadas três fases, $(\mathrm{La}, \mathrm{Mg})_{2}(\mathrm{Ni}, \mathrm{Al})_{7}, \mathrm{La}(\mathrm{Ni}, \mathrm{Al})_{5}$ e $(\mathrm{La}, \mathrm{Mg})_{2} \mathrm{Ni}_{4}$; para $\mathrm{x} \geq 0,15$, detectou-se uma quarta fase, a saber, $(\mathrm{La}, \mathrm{Mg})(\mathrm{Ni}, \mathrm{Al})_{3}$.

São comentados, a seguir, os estudos sistemáticos da substituição de La por Pr realizados por Zhang, Y. e colaboradores entre os anos de 2009 e 2014.

Visando uma performance eletroquímica superior, no estudo das ligas $\mathrm{La}_{0,75-x} \mathrm{Pr}_{\mathrm{x}} \mathrm{Mg}_{0,25} \mathrm{Ni}_{3,2} \mathrm{Co}_{0,2} \mathrm{Al}_{0,1} \quad(\mathrm{x}=0-0.4) \quad$ (Zhang, Y. et al., 2009), e das ligas $\mathrm{La}_{0,75-x} \mathrm{M}_{x} \mathrm{Mg}_{0,25} \mathrm{Ni}_{3,2} \mathrm{Co}_{0,2} \mathrm{Al}_{0,1}$ (M=Pr ou Zr; $\mathrm{x}=0,0 ; 0,2$ ) (Zhang, Y. et al., 2012a), parte de todas as ligas preparadas por fusão por indução a vácuo foi submetida à solidificação rápida por melt spinning, comparando-se as propriedades eletroquímicas das ligas em estado bruto de fusão com aquelas obtidas pelo método citado. Em ambos os estudos, todas as ligas preparadas, independente do método de preparação e composição, apresentaram como fases majoritárias $(\mathrm{La}, \mathrm{Mg})_{2} \mathrm{Ni}_{7}$ e $\mathrm{LaNi}_{5}$, e a fase $\mathrm{LaNi}_{2}$ como residual. No estudo de 2009, verificouse o aumento da estabilidade cíclica com a substituição de La por Pr tanto para as ligas em estado bruto de fusão como para as submetidas à solidificação rápida, sendo que esse método de preparação mostrou-se eficaz na obtenção de maiores 
resultados de estabilidade. Com a adição crescente de $\operatorname{Pr}$, a abundância da fase $\mathrm{LaNi}_{5}$ diminuiu, com o consequente aumento da abundância da fase ( $\left.\mathrm{La}, \mathrm{Mg}\right)_{2} \mathrm{Ni}_{7}$. A capacidade de descarga aumentou para depois diminuir, sendo os maiores valores obtidos na condição $\mathrm{x}=0,1\left(392,4 \mathrm{mAh} \mathrm{g}^{-1}\right.$ e $397,9 \mathrm{mAh} \mathrm{g}^{-1}$, para as ligas em estado bruto de fusão e solidificadas rapidamente, respectivamente).

Já no estudo realizado nas ligas $\mathrm{La}_{0,8-\mathrm{x}} \operatorname{Pr}_{\mathrm{x}} \mathrm{Mg}_{0,2} \mathrm{Ni}_{3,35} \mathrm{Al}_{0,1} \mathrm{Si}_{0,05} \quad(\mathrm{x}=0,0$; $0,1 ; 0,2 ; 0,3 ; 0,4)$ em estado bruto de fusão e tratadas termicamente (Zhang, Y. et al., 2013), foi detectada a presença das fases $(\mathrm{La}, \mathrm{Mg})_{2} \mathrm{Ni}_{7}$ e $\mathrm{LaNi}_{5}$, e a fase $\mathrm{LaNi}_{3}$ como residual em todas as ligas. Com a substituição de La por Pr, a abundância da fase ( $\mathrm{La}, \mathrm{Mg})_{2} \mathrm{Ni}_{7}$ diminuiu e a da fase $\mathrm{LaNi}_{5}$ aumentou, não sendo observadas mudanças estruturais significativas entre as ligas em estado bruto de fusão e as tratadas termicamente. Ainda para as ligas nessas duas condições observou-se que a capacidade de descarga e os valores de HRD aumentaram e depois diminuiram com a adição crescente de $\operatorname{Pr}$ às ligas. Os maiores valores de capacidade de descarga máxima foram obtidos para a condição $x=0,3$, a saber, $363,1 \mathrm{mAh} \mathrm{g}^{-1}$ para as ligas em estado bruto de fusão e 389,7 $\mathrm{mAh} \mathrm{g}^{-1}$ para as ligas tratadas termicamente. Melhores valores de HRD para todas as ligas foram verificados para a condição $x=0,2$. A estabilidade cíclica foi beneficiada no sentido da adição crescente de $\operatorname{Pr}$, com maiores resultados para a condição $x=0,4$, observando-se que, relativamente, as ligas tratadas termicamente apresentaram melhores resultados que as em estado bruto de fusão. O tratamento térmico mostrou-se, por sua vez, prejudicial à cinética dos eletrodos das ligas. As interpretações dos resultados obtidos tiveram por base os efeitos de fatores como a presença de estrutura multifásica, a abundância relativa das fases e suas propriedades catalíticas, a redução dos volumes das células unitárias e a homogeneização resultante do tratamento térmico, entre outros.

Em estudo de ligas de composição análoga ao citado anteriormente, mas com o objetivo de comparar o efeito de adições de samário, neodímio ou praseodímio, ligas $\mathrm{La}_{0,8-\mathrm{x}} \mathrm{M}_{\mathrm{x}} \mathrm{Mg}_{0,2} \mathrm{Ni}_{3,35} \mathrm{Al}_{0,1} \mathrm{Si}_{0,05}(\mathrm{M}=\mathrm{Sm}, \mathrm{Nd}, \mathrm{Pr} ; \mathrm{x}=0,0 ; 0,1 ; 0,2$; $0,3 ; 0,4)$ foram preparadas e analisadas em estado bruto de fusão e após tratamento térmico (Zhang, Y. et al., 2014). Os maiores valores de capacidade de descarga foram obtidos com $\mathrm{M}=\operatorname{Pr}$ para a liga em estado bruto de fusão $\left(363,1 \mathrm{mAh} \mathrm{g}^{-1}\right)$ e para $\mathrm{M}=\mathrm{Sm}$ para a liga tratada termicamente. A estabilidade cíclica da liga $\mathrm{M}=\mathrm{Sm}$ foi a mais elevada entre as ligas em estado bruto de fusão, 
seguida da liga contendo $\mathrm{Pr}$; das tratadas termicamente, a de composição com $\mathrm{Pr}$ apresentou o maior resultado, seguida daquela com Sm. Valores mais elevados para o parâmetro HRD foram observados para as ligas com substituição em comparação às ligas sem adição de $\mathrm{M}=\mathrm{Sm}, \mathrm{Nd}$ ou Pr. Adicionalmente, os valores de HRD para as ligas em estado bruto de fusão e tratadas termicamente aumentaram e depois diminuiram com a adição crescente de M. Similar ao reportado no estudo citado anteriormente, o tratamento térmico elevou a capacidade de descarga e a estabilidade cíclica, mas mostrou-se desfavorável à cinética eletroquímica dos eletrodos das ligas estudadas.

$\mathrm{Na}$ busca pelo melhor entendimento de como o praseodímio atua no favorecimento da estabilidade cíclica, foi realizado, por Liu, J. et al. (2015a), o estudo das ligas $\mathrm{La}_{0,8-\mathrm{x}} \mathrm{Pr}_{\mathrm{x}} \mathrm{Mg}_{0,2} \mathrm{Ni}_{3,4} \mathrm{Al}_{0,1}(\mathrm{x}=0,0 ; 0,1 ; 0,2$ e 0,3$)$ tratadas termicamente. As principais fases presentes foram as super-redes $(\mathrm{La}, \mathrm{Mg})_{2} \mathrm{Ni}_{7} \mathrm{e}$ $(\mathrm{La}, \mathrm{Mg})_{5} \mathrm{Ni}_{19}$ (formadas pelas subunidades $\left[\mathrm{AB}_{5}\right]$ e $\left[\mathrm{A}_{2} \mathrm{~B}_{4}\right]$ ), além da fase $\mathrm{LaNi}_{5} \mathrm{em}$ menor abundância. Verificou-se que com a adição crescente de $\mathrm{Pr}$, a abundância da fase super-rede $(\mathrm{La}, \mathrm{Mg})_{2} \mathrm{Ni}_{7}$ diminuiu e a da fase super-rede (La,Mg) ${ }_{5} \mathrm{Ni}_{19}$ aumentou, sendo que na condição $x=0,3$, a abundância da fase $\mathrm{LaNi}_{5}$ aumentou significativamente. Constatou-se que o Pr tendeu a ocupar o sítio do La na subunidade $\left[\mathrm{AB}_{5}\right]$ preferencialmente ao correspondente à subunidade $\left[\mathrm{A}_{2} \mathrm{~B}_{4}\right]$, com a fase super-rede ( $\mathrm{La}, \mathrm{Mg})_{5} \mathrm{Ni}_{19}$ apresentando uma relação entre as subunidades $\left[A B_{5}\right] /\left[A_{2} B_{4}\right]$ elevada, preferencialmente à relação entre as mesmas subunidades na fase super-rede $(\mathrm{La}, \mathrm{Mg})_{2} \mathrm{Ni}_{7}$. O praseodímio atuou positivamente na estabilidade estrutural das fases super-redes $(\mathrm{La}, \mathrm{Mg})_{5} \mathrm{Ni}_{19}$, aumentando a resistência à pulverização das ligas e ainda desfavorecendo o aparecimento de fases amorfas resultantes de maiores variações de volume das células unitárias durante o processo de absorção/desorção do hidrogênio. A estabilidade cíclica dos eletrodos das ligas e o parâmetro HRD aumentaram com a adição de Pr até a condição $x=0,2$, para depois diminuírem em $x=0,3$. Nessa última condição, $a$ relativa diminuição da abundância das fases super-redes ( $\mathrm{La}, \mathrm{Mg}{ }_{5} \mathrm{Ni}_{19}$ em função da maior abundância da fase $\mathrm{LaNi}_{5}$ justificou o comportamento observado. 


\section{MATERIAIS E MÉTODOS}

\subsection{Materiais e reagentes}

\subsubsection{Ligas}

As ligas utilizadas neste estudo foram preparadas pela empresa Less Common Metals Ltd. (UK) em bateladas de $5 \mathrm{~kg}$ por fusão em forno de indução a vácuo com solidificação em molde de cobre refrigerado a água.

Em vista de sua composições, as ligas foram reunidas em dois grupos, doravante denominados "Série Mg" e "Série Pr", de acordo com as substituições efetuadas em relação ao metal La presente.

De maneira crescente, o La foi substituído por $\mathrm{Mg}$ nas ligas da Série Mg, La ${ }_{0,7-x} \mathrm{Mg}_{x} \mathrm{Pr}_{0,3} \mathrm{Al}_{0,3} \mathrm{Mn}_{0,4} \mathrm{Co}_{0,5} \mathrm{Ni}_{3,8}(x=0,0,0,1,0,3,0,5$ e 0,7) e por Pr nas ligas da Série $\operatorname{Pr}, \mathrm{La}_{0,7-y} \mathrm{Pr}_{y} \mathrm{Mg}_{0,3} \mathrm{Al}_{0,3} \mathrm{Mn}_{0,4} \mathrm{Co}_{0,5} \mathrm{Ni}_{3,8}$ ( $y=0,0,0,1,0,3,0,5$ e 0,7).

Nas TAB. 3 e 4 estão reunidos os resultados de análise por espectroscopia de emissão atômica por plasma induzido (ICP-AES) fornecidos pelo fabricante. Como especificado pelas análises, as ligas contêm enxofre, oxigênio e nitrogênio (<10 ppm) como impurezas; o teor de carbono presente é especificado nas tabelas em referência.

Nas TAB. 5 e 6 são apresentadas as composições estequiométrica e atômica correspondentes, com boa concordância entre os valores nominais e analisados. Observou-se a existência de uma liga comum às duas séries na condição $x=y=0,3$, ou seja, $\mathrm{La}_{0,4} \mathrm{Mg}_{0,3} \mathrm{Pr}_{0,3} \mathrm{Al}_{0,3} \mathrm{Mn}_{0,4} \mathrm{Co}_{0,5} \mathrm{Ni}_{3,8}$. 
TABELA 3 - Composição em porcentagem de massa das ligas da Série Mg, $\mathrm{La}_{0,7-x} \mathrm{Mg}_{x} \mathrm{Pr}_{0,3} \mathrm{Al}_{0,3} \mathrm{Mn}_{0,4} \mathrm{Co}_{0,5} \mathrm{Ni}_{3,8}$ ( $\left.x=0,0-0,7\right)$ - bruto de fusão.

\begin{tabular}{ccccccccc}
\hline \multirow{2}{*}{$x$} & \multicolumn{7}{c}{ Composição planejada e analisada (\% massa) } \\
\cline { 2 - 9 } & $\mathrm{La}$ & $\mathrm{Mg}$ & $\mathrm{Pr}$ & $\mathrm{Al}$ & $\mathrm{Mn}$ & $\mathrm{Co}$ & $\mathrm{Ni}$ & $\mathrm{C}^{*}$ \\
\hline \multirow{2}{*}{0,0} & 23,04 & - & 10,02 & 12,37 & 5,21 & 6,98 & 52,84 & - \\
& 22,50 & - & 8,93 & 11,99 & 5,28 & 7,32 & 53,92 & 96 \\
& 20,30 & 0,59 & 10,29 & 1,97 & 5,35 & 7,18 & 54,32 & - \\
0,1 & 19,75 & 0,80 & 9,34 & 1,75 & 4,86 & 6,61 & 56,79 & 106 \\
& 14,33 & 1,88 & 10,90 & 2,09 & 5,67 & 7,60 & 57,53 & - \\
0,3 & 13,63 & 1,77 & 10,90 & 2,06 & 5,55 & 7,72 & 58,28 & 97 \\
& 7,62 & 3,33 & 11,59 & 2,22 & 6,02 & 8,08 & 61,14 & - \\
0,5 & 7,44 & 2,82 & 11,86 & 2,09 & 5,65 & 8,22 & 61,81 & 76 \\
& - & 3,33 & 12,37 & 2,37 & 6,43 & 8,62 & 65,24 & - \\
0,7 & - & 2,82 & 11,99 & 2,16 & 6,38 & 8,61 & 66,53 & 69 \\
\hline
\end{tabular}

* impurezas (ppm)

Fonte: Less Common Metals Ltd.

TABELA 4 - Composição em porcentagem de massa das ligas da Série Pr, $\mathrm{La}_{0,7-y} \mathrm{Pr}_{y} \mathrm{Mg}_{0,3} \mathrm{Al}_{0,3} \mathrm{Mn}_{0,4} \mathrm{Co}_{0,5} \mathrm{Ni}_{3,8}$ (y=0,0-0,7) - bruto de fusão.

\begin{tabular}{ccccccccc}
\hline & \multicolumn{7}{c}{ Composição nominal e analisada (\% massa) } \\
\cline { 2 - 9 } & $\mathrm{La}$ & $\mathrm{Pr}$ & $\mathrm{Mg}$ & $\mathrm{Al}$ & $\mathrm{Mn}$ & $\mathrm{Co}$ & $\mathrm{Ni}$ & $\mathrm{C}^{*}$ \\
\hline \multirow{2}{*}{0,0} & 25,12 & - & 1,88 & 2,09 & 5,68 & 7,61 & 57,62 & - \\
& 24,57 & - & 1,62 & 1,90 & 5,58 & 7,67 & 58,55 & 62 \\
& 21,52 & 3,64 & 1,88 & 2,09 & 5,67 & 7,61 & 57,59 & - \\
0,1 & 21,01 & 3,88 & 1,71 & 2,03 & 5,57 & 7,77 & 57,93 & 94 \\
& 14,33 & 10,90 & 1,88 & 2,09 & 5,67 & 7,60 & 57,53 & - \\
0,3 & 13,63 & 10,90 & 1,77 & 2,06 & 5,55 & 7,72 & 58,28 & 97 \\
& 7,16 & 18,15 & 1,88 & 2,09 & 5,66 & 7,59 & 57,47 & - \\
0,5 & 6,82 & 18,18 & 1,70 & 2,00 & 5,63 & 7,64 & 57,93 & 73 \\
& - & 25,39 & 1,88 & 2,08 & 5,66 & 7,59 & 57,41 & - \\
0,7 & - & 23,98 & 1,54 & 2,12 & 5,62 & 7,92 & 58,73 & 90 \\
\hline
\end{tabular}

* impurezas (ppm)

Fonte: Less Common Metals Ltd. 
TABELA 5 - Composições estequiométrica e atômica das ligas da Série Mg, $\mathrm{La}_{0,7-x} \mathrm{Mg}_{x} \mathrm{Pr}_{0,3} \mathrm{Al}_{0,3} \mathrm{Mn}_{0,4} \mathrm{Co}_{0,5} \mathrm{Ni}_{3,8}(x=0,0-0,7)$ - bruto de fusão.

\begin{tabular}{|c|c|c|}
\hline \multirow{2}{*}{$x$} & \multicolumn{2}{|c|}{ Composição (nominal e analisada) } \\
\hline & Estequiométrica & Atômica (\%) \\
\hline \multirow{2}{*}{0,0} & $\mathrm{La}_{0,7} \mathrm{Pr}_{0,3} \mathrm{Al}_{0,3} \mathrm{Mn}_{0,4} \mathrm{Co}_{0,5} \mathrm{Ni}_{3,8}$ & $\mathrm{La}_{11,67} \mathrm{Pr}_{5} \mathrm{Al}_{5} \mathrm{Mn}_{6,67} \mathrm{Co}_{8,33} \mathrm{Ni}_{63,32}$ \\
\hline & $\mathrm{La}_{0,68} \mathrm{Pr}_{0,27} \mathrm{Al}_{0,3} \mathrm{Mn}_{0,43} \mathrm{Co}_{0,52} \mathrm{Ni}_{3,88}$ & $\mathrm{La}_{11,28} \mathrm{Pr}_{4,41} \mathrm{Al}_{5,03} \mathrm{Mn}_{6,69} \mathrm{Co}_{8,65} \mathrm{Ni}_{63,94}$ \\
\hline \multirow{2}{*}{0,1} & $\mathrm{La}_{0,6} \mathrm{Mg}_{0,1} \mathrm{Pr}_{0,3} \mathrm{Al}_{0,3} \mathrm{Mn}_{0,4} \mathrm{Co}_{0,5} \mathrm{Ni}_{3,8}$ & $\mathrm{La}_{10} \mathrm{Mg}_{1,66} \mathrm{Pr}_{5} \mathrm{Al}_{5} \mathrm{Mn}_{6,67} \mathrm{Co}_{8,34} \mathrm{Ni}_{63,33}$ \\
\hline & $\mathrm{La}_{0,58} \mathrm{Mg}_{0,14} \mathrm{Pr}_{0,27} \mathrm{Al}_{0,27} \mathrm{Mn}_{0,36} \mathrm{Co}_{0,56} \mathrm{Ni}_{3,97}$ & $\mathrm{La}_{9,64} \mathrm{Mg}_{2,23} \mathrm{Pr}_{4,5} \mathrm{Al}_{4,4} \mathrm{Mn}_{6} \mathrm{Co}_{7,61} \mathrm{Ni}_{65,62}$ \\
\hline \multirow{2}{*}{0,3} & $\mathrm{La}_{0,4} \mathrm{Mg}_{0,3} \mathrm{Pr}_{0,3} \mathrm{Al}_{0,3} \mathrm{Mn}_{0,4} \mathrm{Co}_{0,5} \mathrm{Ni}_{3,8}$ & $\mathrm{La}_{6,67} \mathrm{Mg}_{5} \mathrm{Pr}_{5} \mathrm{Al}_{5,01} \mathrm{Mn}_{6,67} \mathrm{Co}_{8,33} \mathrm{Ni}_{63,32}$ \\
\hline & $\mathrm{La}_{0,38} \mathrm{Mg}_{0,28} \mathrm{Pr}_{0,3} \mathrm{Al}_{0,3} \mathrm{Mn}_{0,39} \mathrm{Co}_{0,51} \mathrm{Ni}_{3,85}$ & $\mathrm{La}_{6,33} \mathrm{Mg}_{4,7} \mathrm{Pr}_{5} \mathrm{Al}_{4,91} \mathrm{Mn}_{6,52} \mathrm{Co}_{8,46} \mathrm{Ni}_{64,09}$ \\
\hline \multirow{2}{*}{0,5} & $\mathrm{La}_{0,2} \mathrm{Mg}_{0,5} \mathrm{Pr}_{0,3} \mathrm{Al}_{0,3} \mathrm{Mn}_{0,4} \mathrm{Co}_{0,5} \mathrm{Ni}_{3,8}$ & $\mathrm{La}_{3,34} \mathrm{Mg}_{8,33} \mathrm{Pr}_{5,01} \mathrm{Al}_{5} \mathrm{Mn}_{6,67} \mathrm{Co}_{8,33} \mathrm{Ni}_{63,32}$ \\
\hline & $\mathrm{La}_{0,2} \mathrm{Mg}_{0,42} \mathrm{Pr}_{0,31} \mathrm{Al}_{0,28} \mathrm{Mn}_{0,38} \mathrm{Co}_{0,51} \mathrm{Ni}_{3,84}$ & $\mathrm{La}_{3,3} \mathrm{Mg}_{7,13} \mathrm{Pr}_{5,18} \mathrm{Al}_{4,76} \mathrm{Mn}_{6,32} \mathrm{Co}_{8,58} \mathrm{Ni}_{64,74}$ \\
\hline \multirow{2}{*}{0,7} & $\mathrm{Mg}_{0,7} \mathrm{Pr}_{0,3} \mathrm{Al}_{0,3} \mathrm{Mn}_{0,4} \mathrm{Co}_{0,5} \mathrm{Ni}_{3,8}$ & $\mathrm{Mg}_{11,67} \mathrm{Pr}_{5} \mathrm{Al}_{5} \mathrm{Mn}_{6,67} \mathrm{Co}_{8,34} \mathrm{Ni}_{63,32}$ \\
\hline & $\mathrm{Mg}_{0,59} \mathrm{Pr}_{0,29} \mathrm{Al}_{0,27} \mathrm{Mn}_{0,4} \mathrm{Co}_{0,5} \mathrm{Ni}_{3,97}$ & $\mathrm{Mg}_{9,99} \mathrm{Pr}_{4,91} \mathrm{Al}_{4,62} \mathrm{Mn}_{6,7} \mathrm{Co}_{8,43} \mathrm{Ni}_{65,36}$ \\
\hline
\end{tabular}

TABELA 6 - Composições estequiométrica e atômica das ligas da Série $\operatorname{Pr}$, $\mathrm{La}_{0,7-y} \mathrm{Pr}_{y} \mathrm{Mg}_{0,3} \mathrm{Al}_{0,3} \mathrm{Mn}_{0,4} \mathrm{Co}_{0,5} \mathrm{Ni}_{3,8}$ (y=0,0-0,7) - bruto de fusão.

\begin{tabular}{|c|c|c|}
\hline \multirow{2}{*}{$y$} & \multicolumn{2}{|c|}{ Composição (nominal e analisada) } \\
\hline & Estequiométrica & Atômica (\%) \\
\hline \multirow{2}{*}{0,0} & $\mathrm{La}_{0,7} \mathrm{Mg}_{0,3} \mathrm{Al}_{0,3} \mathrm{Mn}_{0,4} \mathrm{Co}_{0,5} \mathrm{Ni}_{3,8}$ & $\mathrm{La}_{11,67} \mathrm{Mg}_{4,99} \mathrm{Al}_{5} \mathrm{Mn}_{6,67} \mathrm{Co}_{8,33} \mathrm{Ni}_{63,34}$ \\
\hline & $\mathrm{La}_{0,68} \mathrm{Mg}_{0,26} \mathrm{Al}_{0,27} \mathrm{Mn}_{0,39} \mathrm{Co}_{0,5} \mathrm{Ni}_{3,86}$ & $\mathrm{La}_{11,46} \mathrm{Mg}_{4,32} \mathrm{Al}_{4,56} \mathrm{Mn}_{6,58} \mathrm{Co}_{8,43} \mathrm{Ni}_{64,64}$ \\
\hline \multirow{2}{*}{0,1} & $\mathrm{La}_{0,6} \mathrm{Pr}_{0,1} \mathrm{Mg}_{0,3} \mathrm{Al}_{0,3} \mathrm{Mn}_{0,4} \mathrm{Co}_{0,5} \mathrm{Ni}_{3,8}$ & $\mathrm{La}_{10} \mathrm{Pr}_{1,67} \mathrm{Mg}_{5} \mathrm{Al}_{5} \mathrm{Mn}_{6,66} \mathrm{Co}_{8,33} \mathrm{Ni}_{63,34}$ \\
\hline & $\mathrm{La}_{0,59} \mathrm{Pr}_{0,11} \mathrm{Mg}_{0,27} \mathrm{Al}_{0,29} \mathrm{Mn}_{0,39} \mathrm{Co}_{0,51} \mathrm{Ni}_{3,82}$ & $\mathrm{La}_{9,80} \mathrm{Pr}_{1,78} \mathrm{Mg}_{4,56} \mathrm{Al}_{4,87} \mathrm{Mn}_{6,57} \mathrm{Co}_{8,53} \mathrm{Ni}_{63,90}$ \\
\hline \multirow{2}{*}{0,3} & $\mathrm{La}_{0,4} \mathrm{Pr}_{0,3} \mathrm{Mg}_{0,3} \mathrm{Al}_{0,3} \mathrm{Mn}_{0,4} \mathrm{Co}_{0,5} \mathrm{Ni}_{3,8}$ & $\mathrm{La}_{6,67} \operatorname{Pr}_{5} \mathrm{Mg}_{5} \mathrm{Al}_{5,01} \mathrm{Mn}_{6,67} \mathrm{Co}_{8,33} \mathrm{Ni}_{63,32}$ \\
\hline & $\mathrm{La}_{0,38} \mathrm{Pr}_{0,3} \mathrm{Mg}_{0,28} \mathrm{Al}_{0,3} \mathrm{Mn}_{0,39} \mathrm{Co}_{0,51} \mathrm{Ni}_{3,85}$ & $\mathrm{La}_{6,33} \mathrm{Pr}_{5} \mathrm{Mg}_{5,7} \mathrm{Al}_{4,91} \mathrm{Mn}_{6,52} \mathrm{Co}_{8,46} \mathrm{Ni}_{64,09}$ \\
\hline \multirow{2}{*}{0,5} & $\mathrm{La}_{0,2} \mathrm{Pr}_{0,5} \mathrm{Mg}_{0,3} \mathrm{Al}_{0,3} \mathrm{Mn}_{0,4} \mathrm{Co}_{0,5} \mathrm{Ni}_{3,8}$ & $\mathrm{La}_{3,33} \mathrm{Pr}_{8,33} \mathrm{Mg}_{5,01} \mathrm{Al}_{5,01} \mathrm{Mn}_{6,66} \mathrm{Co}_{8,33} \mathrm{Ni}_{63,33}$ \\
\hline & $\mathrm{La}_{0,19} \mathrm{Pr}_{0,5} \mathrm{Mg}_{0,27} \mathrm{Al}_{0,29} \mathrm{Mn}_{0,4} \mathrm{Co}_{0,5} \mathrm{Ni}_{3,83}$ & $\mathrm{La}_{3,19} \mathrm{Pr}_{8,37} \mathrm{Mg}_{4,54} \mathrm{Al}_{4,81} \mathrm{Mn}_{6,65} \mathrm{Co}_{8,41} \mathrm{Ni}_{64,04}$ \\
\hline \multirow{2}{*}{0,7} & $\operatorname{Pr}_{0,7} \mathrm{Mg}_{0,3} \mathrm{Al}_{0,3} \mathrm{Mn}_{0,4} \mathrm{Co}_{0,5} \mathrm{Ni}_{3,8}$ & $\mathrm{Pr}_{11,67} \mathrm{Mg}_{5,01} \mathrm{Al}_{4,99} \mathrm{Mn}_{6,67} \mathrm{Co}_{8,34} \mathrm{Ni}_{63,32}$ \\
\hline & $\operatorname{Pr}_{0,66} \mathrm{Mg}_{0,25} \mathrm{Al}_{0,31} \mathrm{Mn}_{0,4} \mathrm{Co}_{0,52} \mathrm{Ni}_{3,89}$ & $\mathrm{Pr}_{10,98} \mathrm{Mg}_{4,09} \mathrm{Al}_{5,07} \mathrm{Mn}_{6,60} \mathrm{Co}_{8,67} \mathrm{Ni}_{64,57}$ \\
\hline
\end{tabular}




\subsubsection{Demais materiais e reagentes}

- Mercúrio metálico: Hg 99,9\% PA ACS (Vetec).

- Óxido de mercúrio Il vermelho: HgO 99+\% (Sigma-Aldrich).

- Fio de platina: fio de Pt pura 99,95\% - certificação da empresa Umicore Brasil Ltda., diâmetro $0,50 \mathrm{~mm}$; produto importado.

- Tela de níquel: material retirado de baterias recarregáveis comerciais.

- Negro de fumo: Vulcan XC-72-R (Cabot Corporation).

- Politetrafluoroetileno: (PTFE) Teflon T30 (Daikin).

- Hidróxido de potássio: KOH PA (CAAL).

\subsection{Métodos preparação/caracterização}

\subsubsection{Microestrutura}

As amostras das ligas para as análises microestruturais foram preparadas segundo os métodos metalográficos convencionais (embutimento, lixamento e polimento). As microestruturas foram examinadas usando microscópio eletrônico de varredura (Philips XL30) com analisador por espectroscopia por dispersão de energia de raios $X$ integrado (MEV/EDS). Várias medidas independentes foram efetuadas de modo a obter médias dos resultados de composição. Amostras das ligas foram moídas ao ar em pós de malha 270 mesh $(<53 \mu \mathrm{m})$ tanto para os estudos eletroquímicos como para as análises por difração de raios X (DRX). Utilizou-se um difratômetro Rigaku DMAX-2000 com radiação Cu K $\mathrm{K}_{\alpha}(\lambda=0,154056 \mathrm{~nm})$ a $40 \mathrm{kV}$ e $20 \mathrm{~mA}$, com varreduras entre 10 e $80^{\circ}$ em $2 \Theta$ com intervalos de $0,2^{\circ}$ e tempo de leitura de $8 \mathrm{~s}$. Para o refinamento por Rietveld foi utilizado o programa GSAS (General Structure Analysis System) Rietveld Software.

\subsubsection{Resistência à corrosão}

A resistência à corrosão das ligas das Séries $\mathrm{Mg}$ e $\operatorname{Pr}$ no estado bruto de fusão foi avaliada por métodos eletroquímicos, especificamente, curvas de polarização potenciodinâmica (catódica e anódica, separadamente) e espectroscopia de impedância eletroquímica (EIE). Todas as medidas foram realizadas no Laboratório de Pesquisa Eletroquímica e Revestimentos Protetores 
do CCTM, sendo aqui descrita a metodologia adotada segundo estudo já publicado (Banczek et al., 2009).

Utilizou-se um sistema de célula de três eletrodos, com eletrodo de

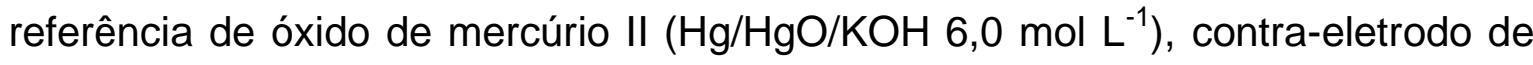
fio de $\mathrm{Pt}$, e os eletrodos de trabalho preparados por embutimento das amostras das ligas em resina epóxi com contato elétrico por fio de cobre. O comportamento eletroquímico foi avaliado utilizando-se um analisador de resposta de frequências (Gamry modelo EIS 300) acoplado a um potenciostato (Gamry modelo PCI4/300) em solução teste de $\mathrm{KOH} 6,0 \mathrm{~mol} \mathrm{~L}^{-1} \mathrm{a}(20 \pm 2){ }^{\circ} \mathrm{C}$. As amostras foram imersas na solução teste medindo-se o potencial de circuito aberto (PCA) em função do tempo. Os experimentos de espectroscopia de impedância eletroquímica (EIE) foram obtidos na faixa de $10 \mathrm{kHz}$ a $10 \mathrm{mHz}$, com uma amplitude de perturbação de $\pm 10 \mathrm{mV}$ (relativamente ao PCA), e com uma taxa de aquisição de dados de 10 pontos por década. Imediatamente após os ensaios de EIE, o PCA foi medido para avaliar a estabilidade do potencial. Em seguida, foram obtidas as curvas de polarização potenciodinâmica em velocidade de $30 \mathrm{mV} \mathrm{s}^{-1}$. Em consequência do elevado caráter passivo apresentado pelas ligas, foi impossibilitada a obtenção das curvas em velocidade de varredura menor. Para avaliar a reprodutibilidade das medidas, foram testadas 4 amostras de cada liga em estudo.

\subsection{Tratamento térmico}

No tratamento térmico realizado, cada amostra de liga fundida foi fragmentada manualmente em pedaços menores que $15 \mathrm{~mm}$ e colocada em uma retorta de aço inoxidável. Após a redução da pressão a $10^{-2}$ bar (vácuo mecânico), o sistema foi aquecido até a temperatura de tratamento adotada, correspondendo a $900{ }^{\circ} \mathrm{C}$ (Pan et al., 2005a; Zhang, Z. et al., 2007), permanecendo assim por 8 horas. Similarmente às amostras em estado bruto de fusão, as amostras tratadas termicamente foram preparadas para os estudos eletroquímicos. 


\subsection{Estudo das propriedades eletroquímicas}

\subsubsection{Célula aberta de três eletrodos}

Todas as medidas eletroquímicas realizadas nos ciclos de carga/descarga deste estudo foram conduzidas em um sistema de célula aberta composta por três eletrodos. O sistema de três eletrodos é reconhecidamente vantajoso para a avaliação das propriedades eletroquímicas fundamentais de um material em estudo. A presença de um contra-eletrodo de um material inerte como a Pt minimiza a passagem de corrente elétrica pelo eletrodo de referência, contribuindo para a não polarização do mesmo. $O$ eletrodo de referência viabiliza a medida precisa do potencial no eletrodo de trabalho, em relação a um referencial conhecido (Hsia, 2013; Oliveira, 2008).

No presente trabalho foi utilizada uma célula eletroquímica em " $\mathrm{H}$ " desenvolvida com base em modelo apresentado em estudo acadêmico publicado (Souza, 2006). Como mostrado na FIG. 3, o contra-eletrodo de Pt (1) é mantido separado dos demais. Essa configuração visa a preservação do ambiente entre o eletrodo de referência (2) e o de trabalho (3) livre de interferências como a possível evolução de hidrogênio a partir do contra-eletrodo de Pt.

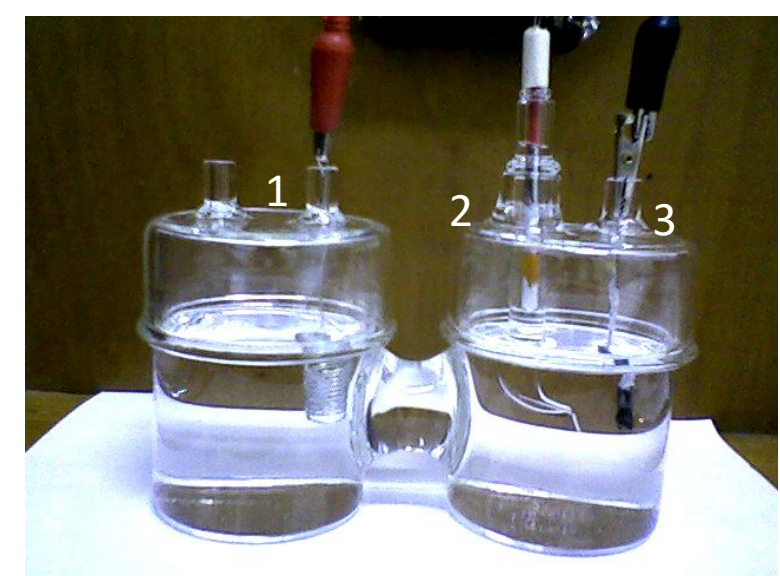

FIGURA 3 - Detalhe do sistema experimental adotado para os ciclos galvanostáticos de carga/descarga, mostrando a célula eletroquímica de três eletrodos, onde (1) corresponde ao contra-eletrodo, (2) ao eletrodo de referência, e (3) ao eletrodo de trabalho. 


\subsubsection{Eletrodo de referência e contra-eletrodo}

O eletrodo de referência de óxido de mercúrio II - $\mathrm{Hg} / \mathrm{HgO} / \mathrm{KOH}$ $6,0 \mathrm{~mol} \mathrm{~L}^{-1} ; \mathrm{E}^{0}=0,0977 \vee($ Bard e Faulkner, 2001) foi montado utilizando-se a configuração mostrada na FIG. 4, com base em modelo apresentado em estudo acadêmico publicado (Dall' Antonia, 1995). Na camisa interna (1) foram acomodadas, em sequência, camadas de lã de vidro, $\mathrm{HgO}, \mathrm{Hg}$ metálico e lã de vidro, com fio de Pt transpassado nas mesmas. Na camisa externa (2) é observado o contato de fio de Pt fixo; após o encaixe de (1) em (2), o volume entre as camisas foi preenchido com solução de $\mathrm{KOH} 6,0 \mathrm{~mol} \mathrm{~L}^{-1}$. O eletrodo de referência montado e em uso é mostrado na FIG. 3.

O contra-eletrodo de fio de Pt $(d=0,5 \mathrm{~mm} ;=300 \mathrm{~mm}$ ) foi montado em forma de espiral, como também mostrado na FIG. 3.

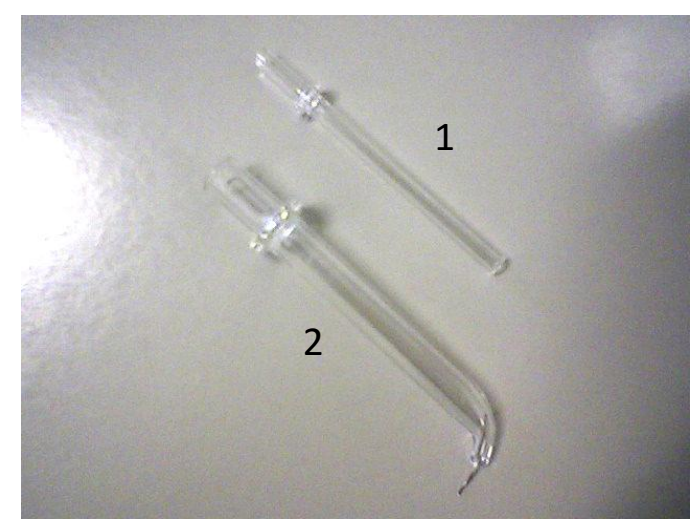

FIGURA 4 - Configuração para a montagem do eletrodo de referência, onde (1) corresponde à camisa interna e (2) à camisa externa.

\subsubsection{Eletrodo de trabalho}

Os eletrodos de trabalho (tipo botão) foram preparados a partir das ligas com e sem tratamento térmico, utilizando prensagem a frio de uma mistura de $0,1 \mathrm{~g}$ de pó de liga $(<53 \mu \mathrm{m}$ ) com carbono teflonado (Vulcan XC-72-R com 33 \% em massa de PTFE - politetrafluoroetileno), em razão de massa de 1:1 em ambos os lados de uma tela de níquel $(d=10 \mathrm{~mm})$. Fez-se uso de solda ponto para a junção entre a tela de níquel e o fio de platina usado para o contato do eletrodo de trabalho com os terminais do circuito. Na FIG. 3 tem-se uma vista em perfil do eletrodo de trabalho montado e em experimento. 


\subsubsection{Ciclos galvanostáticos de carga/descarga}

Ciclos galvanostáticos de carga/descarga consistem em carregar o eletrodo submetendo-o a uma corrente catódica constante por um certo período de tempo - até que esteja completamente carregado, utilizando-se, por segurança, um excesso de carga. Posteriormente, inverte-se o sentido da corrente para que o eletrodo seja descarregado até que ser atingido o potencial de corte, o que indica que o eletrodo está completamente descarregado. A cada ciclo, inverte-se o sentido da corrente para que o eletrodo seja carregado e descarregado continuamente (Ambrosio e Ticianelli, 2001). Esse procedimento viabiliza a obtenção da capacidade de descarga do eletrodo como produto da multiplicação entre o valor da corrente anódica e o tempo de descarga transcorrido em cada ciclo, normalizando-se o resultado obtido pela massa da liga utilizada no eletrodo. São obtidas, então, as curvas de capacidade de descarga dos eletrodos em função do número de ciclos de carga/descarga realizados (Souza, 2006).

No presente trabalho os ciclos galvanostáticos de carga/descarga foram realizados no equipamento para testes de baterias Arbin BT-4 (4 canais) a temperatura ambiente. A partir desses experimentos foram obtidos dados referentes à variação da capacidade de descarga dos eletrodos negativos das ligas em estudo em função das condições impostas.

Como mencionado no item 4.4.1, as medidas eletroquímicas foram conduzidas em célula aberta de três eletrodos, consistindo de um eletrodo de trabalho (eletrodo da liga tipo botão), um eletrodo auxiliar (contra-eletrodo de fio de Pt $(d=0,5 \mathrm{~mm} ; \quad=300 \mathrm{~mm}))$, e um eletrodo de referência $\mathrm{Hg} / \mathrm{HgO}$

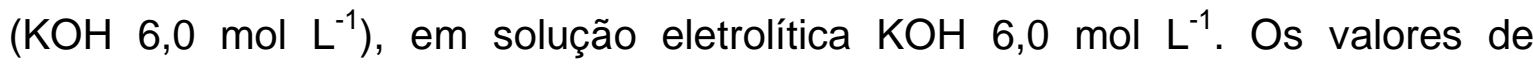
densidade de corrente de descarga $\left(I_{D}\right)$ variaram em função do parâmetro eletroquímico em estudo, mantendo-se constante a densidade de corrente de carga $\left(I_{C}=100 \mathrm{~mA} \mathrm{~g}^{-1}\right)$ e o potencial de corte $\left(V_{\text {corte }}=-0,6 \mathrm{~V}\right.$ versus eletrodo de referência $\mathrm{Hg} / \mathrm{HgO}$ ) em todos os experimentos de ciclagem realizados.

$\mathrm{Na}$ TAB. 7 é apresentada, sumariamente, a parte experimental realizada no presente trabalho, incluindo a sequência das quatro etapas abordadas no estudo das propriedades eletroquímicas dos eletrodos das ligas. Detalhes experimentais dessas etapas são considerados no item a seguir. 
TABELA 7 - Sequência da parte experimental realizada para o estudo das características microestruturais e eletroquímicas dos eletrodos das ligas à base de LaNi.

\section{1 - CARACTERIZAÇÃO MICROESTRUTURAL (MEV/EDS; DR-X) E CORROSÃO (POLARIZ. POTENC.; EIE) \\ 2 - TRATAMENTO TÉRMICO $\left(900^{\circ} \mathrm{C}, 8 \mathrm{~h}\right)$ \\ 3 - ESTUDO DAS PROPRIEDADES ELETROQUÍMICAS - ETAPAS REALIZADAS}

Objetivo: investigar o comportamento de descarga dos eletrodos das ligas - Série Mg e Série Pr com e sem tratamento térmico.

1 a

Proced. Exp.: 50 ciclos de carga/descarga $\left(i_{c}=10 \mathrm{~mA} / 5 \mathrm{~h}\right) ;\left(i_{d}=5 \mathrm{~mA} / \mathrm{V}_{\text {corte }}=-0,6 \mathrm{~V}\right)$.

Critério de Análise: capacidade de descarga máxima $\left(C_{\text {máx }}\right)$; retenção da capacidade de descarga $\left(S_{n}\right)$

Resultado: definição da liga a ser adotada para a etapa seguinte.

Objetivo: avaliar a influência da densidade de corrente de descarga $\left(I_{D}\right)$ na performance do eletrodo da liga selecionada.

$\mathbf{2}^{\mathbf{a}}$

Proced. Exp.: amostras da liga selecionada submetidas à variação de $I_{D}\left(I_{D}=10,100,200\right.$ e $\left.500 \mathrm{~mA} \mathrm{~g}^{-1}\right)$.

Critério de Análise: $\mathrm{C}_{\text {máx }} ; \mathrm{S}_{\mathrm{n}}$; número de ciclos de operação $(\mathrm{n})$.

Resultado: definição da densidade de corrente de descarga a ser considerada na etapa seguinte.

Objetivo: avaliação da estabilidade do hidreto formado, por determinação da taxa de autodescarga (SDR).

$3^{\mathbf{a}}$

Proced. Exp.: amostras de ligas de 03 composições diferentes (maiores $\mathrm{C}_{\text {máx }}$ ) submetidas ao procedimento de autodescarga.

Critério de Análise: maior estabilidade do hidreto formado.

Resultado: definição das ligas a serem consideradas na etapa seguinte.

Objetivo: avaliar a cinética eletroquímica dos eletrodos, por determinação da alta taxa de descarga (HRD) em função de $I_{D}$.

$4^{\mathbf{a}}$

Proced. Exp.: duas ligas submetidas a diferentes $I_{D}\left(I_{D}=250-750 \mathrm{~mA} \mathrm{~g}^{-1}\right)$ no procedimento de determinação de HRD.

Critério de Análise: melhor cinética do eletrodo.

Resultado: comparação das performances dos eletrodos das ligas, segundo análise dos dados obtidos. 


\subsubsection{Detalhes experimentais}

Equipamentos como o do tipo utilizado nos ciclos galvanostáticos de carga/descarga realizados no presente trabalho possuem aplicação internacionalmente reconhecida em estudos eletroquímicos de materiais, eletrodos, células e baterias.

No presente estudo, os valores de capacidade de descarga, bem como os demais parâmetros calculados a partir dos dados de leitura, são apresentados considerando a primeira casa decimal. Tal resolução baseou-se tanto em cálculo estimado a partir das incertezas relativas das grandezas relacionadas (corrente, tempo e massa), como o observado na divulgação de resultados em publicações nacionais e internacionais aqui referenciados (para exemplos, vide TAB. 2).

A seguir são apresentados detalhes da metodologia adotada em cada etapa do estudo referente às propriedades eletroquímicas dos eletrodos das ligas estudadas.

1를 ETAPA: Investigação do comportamento de descarga dos eletrodos das ligas.

Cada eletrodo de todas as ligas da Série Mg e da Série Pr, com e sem tratamento térmico, foi submetido a 50 ciclos de carga e descarga.

Sequência de programação adotada:

(1) carga a $10 \mathrm{~mA}$ por $5 \mathrm{~h}\left(\mathrm{I}_{\mathrm{C}}=100 \mathrm{~mA} \mathrm{~g}^{-1}\right)$;

(2) descarga a $5 \mathrm{~mA}\left(\mathrm{I}_{\mathrm{D}}=50 \mathrm{~mA} \mathrm{~g}^{-1}\right)$;

(3) repetição dos passos (1) e (2);

(4) finalização da operação após 50 ciclos de carga/descarga.

2를 ETAPA: Avaliação da influência da densidade de corrente de descarga $\left(I_{D}\right)$ na performance do eletrodo da liga selecionada.

A diferença experimental da $2^{\underline{a}}$ ETAPA em relação à $1^{\underline{a}}$ correspondeu à realização de ciclos de carga/descarga de eletrodos de uma mesma liga segundo diferentes valores de densidade de corrente de descarga $\left(I_{D}=10,100,200\right.$ e $\left.500 \mathrm{~mA} \mathrm{~g}^{-1}\right)$. Adotou-se, como critério de finalização da ciclagem, para cada valor de densidade de corrente de descarga considerada, a capacidade de descarga correspondente à metade do valor da capacidade de descarga máxima atingida. 
Sequência de programação adotada - exemplo para $I_{D}=10 \mathrm{~mA} \mathrm{~g}^{-1}$ :

(1) carga a $10 \mathrm{~mA}$ por $5 \mathrm{~h}\left(\mathrm{I}_{\mathrm{C}}=100 \mathrm{~mA} \mathrm{~g}^{-1}\right)$;

(2) descarga a $1 \mathrm{~mA}\left(\mathrm{I}_{\mathrm{D}}=10 \mathrm{~mA} \mathrm{~g}^{-1}\right)$;

(3) repetição dos passos (1) e (2);

(4) finalização da operação após o valor da capacidade de descarga corresponder à metade do valor da capacidade de descarga máxima.

3. ETAPA: Avaliação da estabilidade do hidreto formado, por determinação da taxa de autodescarga (SDR).

As medidas de capacidade de descarga para o cálculo da taxa de autodescarga (SDR) foram realizadas ao longo de operações de ciclagem de cada eletrodo de liga selecionada à densidade de corrente de descarga de $200 \mathrm{~mA} \mathrm{~g}^{-1}$ $\left(\mathrm{I}_{\mathrm{D}}=200 \mathrm{~mA} \mathrm{~g}^{-1}\right)$.

Sequência de programação adotada:

(1) carga a $10 \mathrm{~mA}$ por $5 \mathrm{~h}\left(\mathrm{I}_{\mathrm{C}}=100 \mathrm{~mA} \mathrm{~g}^{-1}\right)$;

(2) descarga a $20 \mathrm{~mA}\left(I_{D}=200 \mathrm{~mA} \mathrm{~g}^{-1}\right)$;

(3) repetição da sequência de passos (1) e (2) até ativação da liga (ciclo de carga/descarga correspondente);

$\rightarrow 1^{\text {a }}$ medida de SDR:

(4) repetição da sequência de passos (1) e (2), então: medida de $\mathbf{C}_{\mathbf{a}}$;

(5) repetição do passo (1);

(6) rest por $24 \mathrm{~h}$;

(7) repetição do passo (2), então: medida de $\mathbf{C}_{\mathbf{b}}$;

(8) repetição da sequência dos passos (1) e (2), então: medida de $\mathbf{C}_{\mathbf{c}}$;

(9) repetição da sequência dos passos (1) e (2) por aproximadamente 21 a 26 ciclos de carga/descarga (5 a 6 dias de operação - intervalo entre as medidas de SDR);

$\rightarrow 2^{\mathrm{a}}$ medida de SDR:

(10) repetição do passo (4), então: medida de $\mathbf{C}_{\mathbf{a}}$;

(11) repetição dos passos (5), (6) e (7), então: medida de $\mathbf{C}_{\mathbf{b}}$;

(12) repetição do passo (8), então: medida de $\mathbf{C}_{\mathbf{c}}$;

(13) repetição dos passos de (9) a (12) para as medidas de SDR subsequentes; 
(14) finalização da operação após capacidade de descarga medida corresponder a aproximadamente $30 \%$ da capacidade de descarga máxima.

4⿳亠口冋 ETAPA: Avaliação da cinética eletroquímica dos eletrodos, por determinação da alta taxa de descarga (HRD).

As medidas de capacidade de descarga para o cálculo da alta taxa de descarga (HRD) foram realizadas ao longo de operações de ciclagem de cada eletrodo de liga selecionada. Cada operação envolveu a mudança sequencial na densidade de corrente de descarga $\left(I_{D}=250,300,400,500\right.$ e $\left.750 \mathrm{~mA} \mathrm{~g}^{-1}\right)$.

Sequência de programação adotada:

(1) carga a $10 \mathrm{~mA}$ por $5 \mathrm{~h}\left(\mathrm{I}_{\mathrm{C}}=100 \mathrm{~mA} \mathrm{~g}^{-1}\right)$;

(2) descarga a $5 \mathrm{~mA}\left(\mathrm{I}_{\mathrm{D}}=50 \mathrm{~mA} \mathrm{~g}^{-1}\right)$;

(3) repetição da sequência de passos (1) e (2) até ativação da liga (ciclo completo de carga/descarga correspondente);

(4) repetição do passo (1);

(5) descarga a $25 \mathrm{~mA}\left(\mathrm{I}_{\mathrm{D}}=250 \mathrm{~mA} \mathrm{~g}^{-1}\right)$, então: medida de $\mathrm{C}_{250}$;

(6) descarga a $6 \mathrm{~mA}\left(\mathrm{I}_{\mathrm{D}}=60 \mathrm{~mA} \mathrm{~g}{ }^{-1}\right)$, então: medida de $C_{60} / 250$;

(7) repetição da sequência de passos (1) e (2) até a estabilização do valor de capacidade de descarga;

(8) repetição do passo 1;

(9) descarga a $30 \mathrm{~mA}\left(\mathrm{I}_{\mathrm{D}}=300 \mathrm{~mA} \mathrm{~g}^{-1}\right)$ então: medida de $\mathrm{C}_{300}$;

(10) descarga a $6 \mathrm{~mA}\left(\mathrm{I}_{\mathrm{D}}=60 \mathrm{~mA} \mathrm{~g}{ }^{-1}\right)$ então: medida de $\mathrm{C}_{60} \mathrm{o}_{300}$;

(11) repetição da sequência de passos (7) e (8) e subsequentes descargas a 400/60 mA g ${ }^{-1}$ (medidas de $\mathbf{C}_{400}$ e $\mathbf{C}_{60 / 400}$ ); $500 / 60 \mathrm{~mA} \mathrm{~g}^{-1}$ (medidas de $\mathbf{C}_{500}$ e $\mathbf{C}_{60 / 500}$ ) e 750/60 mA g-1 (medidas de $\mathbf{C}_{750}$ e $\mathbf{C}_{60 / 750}$ );

(12) finalização da operação após as medidas de $C_{750}$ e $C_{60 / 750}\left(H R D_{750}\right)$. 


\section{RESULTADOS E DISCUSSÃO}

\subsection{Caracterização das ligas}

\subsubsection{Composição}

Com o objetivo de facilitar posteriores consultas em relação às ligas das Séries $\mathrm{Mg}$ e $\operatorname{Pr}$ estudadas no presente trabalho, são reproduzidas, respectivamente nas TAB. 8 e 9, dados referentes às composições e massas molares das mesmas.

TABELA 8 - Composições e massas molares das ligas da Série Mg, $\mathrm{La}_{0,7-x} \mathrm{Mg}_{x} \mathrm{Pr}_{0,3} \mathrm{Al}_{0,3} \mathrm{Mn}_{0,4} \mathrm{Co}_{0,5} \mathrm{Ni}_{3,8}$ (x=0,0-0,7) - bruto de fusão.

\begin{tabular}{|c|c|c|c|}
\hline$x$ & \multicolumn{2}{|c|}{ Composições estequiométrica e atômica (\% at.) } & $\begin{array}{c}\mathrm{MM} \\
\left(\mathrm{g} \mathrm{mol}^{-1}\right)\end{array}$ \\
\hline 0,0 & $\mathrm{La}_{0,7} \mathrm{Pr}_{0,3} \mathrm{Al}_{0,3} \mathrm{Mn}_{0,4} \mathrm{Co}_{0,5} \mathrm{Ni}_{3,8}$ & $\mathrm{La}_{11,67} \mathrm{Pr}_{5} \mathrm{Al}_{5} \mathrm{Mn}_{6,67} \mathrm{Co}_{8,33} \mathrm{Ni}_{63,32}$ & 422,102 \\
\hline 0,1 & $\mathrm{La}_{0,6} \mathrm{Mg}_{0,1} \mathrm{Pr}_{0,3} \mathrm{Al}_{0,3} \mathrm{Mn}_{0,4} \mathrm{Co}_{0,5} \mathrm{Ni}_{3,8}$ & $\mathrm{La}_{10} \mathrm{Mg}_{1,66} \mathrm{Pr}_{5} \mathrm{Al}_{5} \mathrm{Mn}_{6,67} \mathrm{Co}_{8,34} \mathrm{Ni}_{63,33}$ & 410,642 \\
\hline 0,3 & $\mathrm{La}_{0,4} \mathrm{Mg}_{0,3} \mathrm{Pr}_{0,3} \mathrm{Al}_{0,3} \mathrm{Mn}_{0,4} \mathrm{Co}_{0,5} \mathrm{Ni}_{3,8}$ & $\mathrm{La}_{6,67} \mathrm{Mg}_{5} \mathrm{Pr}_{5} \mathrm{Al}_{5,01} \mathrm{Mn}_{6,67} \mathrm{Co}_{8,33} \mathrm{Ni}_{63,32}$ & 387,721 \\
\hline 0,5 & $\mathrm{La}_{0,2} \mathrm{Mg}_{0,5} \mathrm{Pr}_{0,3} \mathrm{Al}_{0,3} \mathrm{Mn}_{0,4} \mathrm{Co}_{0,5} \mathrm{Ni}_{3,8}$ & $\mathrm{La}_{3,34} \mathrm{Mg}_{8,33} \mathrm{Pr}_{5,01} \mathrm{Al}_{5} \mathrm{Mn}_{6,67} \mathrm{Co}_{8,33} \mathrm{Ni}_{63,32}$ & 364,802 \\
\hline 0,7 & $\mathrm{Mg}_{0,7} \mathrm{Pr}_{0,3} \mathrm{Al}_{0,3} \mathrm{Mn}_{0,4} \mathrm{Co}_{0,5} \mathrm{Ni}_{3,8}$ & $\mathrm{Mg}_{11,67} \mathrm{Pr}_{5} \mathrm{Al}_{5} \mathrm{Mn}_{6,67} \mathrm{Co}_{8,34} \mathrm{Ni}_{63,32}$ & 341,882 \\
\hline
\end{tabular}

TABELA 9 - Composições e massas molares das ligas da Série $\operatorname{Pr}$, $\mathrm{La}_{0,7-y} \mathrm{Pr}_{y} \mathrm{Mg}_{0,3} \mathrm{Al}_{0,3} \mathrm{Mn}_{0,4} \mathrm{Co}_{0,5} \mathrm{Ni}_{3,8}$ ( $\left.y=0,0-0,7\right)$ - bruto de fusão.

\begin{tabular}{|c|c|c|c|}
\hline$y$ & \multicolumn{2}{|c|}{ Composições estequiométrica e atômica (\% at.) } & $\begin{array}{c}\mathrm{MM}^{-1} \\
\left(\mathrm{~g} \mathrm{~mol}^{-1}\right)\end{array}$ \\
\hline 0,0 & $\mathrm{La}_{0,7} \mathrm{Mg}_{0,3} \mathrm{Al}_{0,3} \mathrm{Mn}_{0,4} \mathrm{Co}_{0,5} \mathrm{Ni}_{3,8}$ & $\mathrm{La}_{11,67} \mathrm{Mg}_{4,99} \mathrm{Al}_{5} \mathrm{Mn}_{6,67} \mathrm{Co}_{8,33} \mathrm{Ni}_{63,34}$ & 387,121 \\
\hline 0,1 & $\mathrm{La}_{0,6} \mathrm{Pr}_{0,1} \mathrm{Mg}_{0,3} \mathrm{Al}_{0,3} \mathrm{Mn}_{0,4} \mathrm{Co}_{0,5} \mathrm{Ni}_{3,8}$ & $\mathrm{La}_{10} \mathrm{Pr}_{1,67} \mathrm{Mg}_{5} \mathrm{Al}_{5} \mathrm{Mn}_{6,66} \mathrm{Co}_{8,33} \mathrm{Ni}_{63,34}$ & 387,322 \\
\hline 0,3 & $\mathrm{La}_{0,4} \mathrm{Pr}_{0,3} \mathrm{Mg}_{0,3} \mathrm{Al}_{0,3} \mathrm{Mn}_{0,4} \mathrm{Co}_{0,5} \mathrm{Ni}_{3,8}$ & $\mathrm{La}_{6,67} \mathrm{Pr}_{5} \mathrm{Mg}_{5} \mathrm{Al}_{5,01} \mathrm{Mn}_{6,67} \mathrm{Co}_{8,33} \mathrm{Ni}_{63,32}$ & 387,721 \\
\hline 0,5 & $\mathrm{La}_{0,2} \mathrm{Pr}_{0,5} \mathrm{Mg}_{0,3} \mathrm{Al}_{0,3} \mathrm{Mn}_{0,4} \mathrm{Co}_{0,5} \mathrm{Ni}_{3,8}$ & $\mathrm{La}_{3,33} \mathrm{Pr}_{8,33} \mathrm{Mg}_{5,01} \mathrm{Al}_{5,01} \mathrm{Mn}_{6,66} \mathrm{Co}_{8,33} \mathrm{Ni}_{63,33}$ & 388,123 \\
\hline 0,7 & $\mathrm{Pr}_{0,7} \mathrm{Mg}_{0,3} \mathrm{Al}_{0,3} \mathrm{Mn}_{0,4} \mathrm{Co}_{0,5} \mathrm{Ni}_{3,8}$ & $\operatorname{Pr}_{11,67} \mathrm{Mg}_{5,01} \mathrm{Al}_{4,99} \mathrm{Mn}_{6,67} \mathrm{Co}_{8,34} \mathrm{Ni}_{63,32}$ & 388,623 \\
\hline
\end{tabular}




\subsubsection{Microestrutura}

\subsubsection{Série Mg}

Nas micrografias das FIG. 5 e 6 são apresentadas imagens obtidas por elétrons retroespalhados (BSE) - representações geral e detalhada (ampliações de 200x e 800x, respectivamente) - das ligas da Série Mg, $\mathrm{La}_{0,7-x} \mathrm{Mg}_{x} \mathrm{Pr}_{0,3} \mathrm{Al}_{0,3} \mathrm{Mn}_{0,4} \mathrm{Co}_{0,5} \mathrm{Ni}_{3,8} \quad(x=0,0,0,1,0,3,0,5,0,7)$ em estado bruto de fusão. Tal condição exerceu, seguramente, influência nas características microestruturais e morfológicas das ligas em estudo, como pode ser observado na FIG. 5.

A liga sem magnésio, $\mathrm{La}_{0,7} \mathrm{Pr}_{0,3} \mathrm{Al}_{0,3} \mathrm{Mn}_{0,4} \mathrm{Co}_{0,5} \mathrm{Ni}_{3,8}$, mostrou-se composta de uma fase matriz $(M)$ e de uma fase cinza $(G)$ nos contornos de grão, como é mostrado na FIG. 6 (a).

Ainda com o auxílio da FIG. 6 , observou-se que as demais ligas $(x=0,1$ a $x=0,7)$ foram compostas por três fases, a saber: $M, G$ e uma fase escura $(D)$. Visualmente, a proporção dessas três fases modificou-se pela presença e aumento do teor de Mg nas ligas. Exemplificando, com a total substituição de La por $M g$, a fase $M$ passou à condição minoritária na liga $\mathrm{Mg}_{0,7} \mathrm{Pr}_{0,3} \mathrm{Al}_{0,3} \mathrm{Mn}_{0,4} \mathrm{Co}_{0,5} \mathrm{Ni}_{3,8}$, sendo observada no interior da fase cinza da liga em referência, como é mostrado na FIG. 6 (e).

Uma comparação entre as microestruturas das ligas dessa série também revelou que a substituição de lantânio por magnésio resultou numa modificação na estrutura de grão das ligas. Como é mostrado na FIG. 5, as ligas com menor substituição de La por Mg apresentaram grãos com estrutura próxima à equiaxial, visivelmente mais grosseira. Relativamente, a liga sem La $(x=0,7)$ revelou uma estrutura agulhada, com proximidade à colunar, mais refinada. Tais observações permitiram inferir que, considerando as condições de solidificação das ligas segundo o método de preparação adotado, a substituição crescente de lantânio por magnésio contribuiu para uma modificação na morfologia dos grãos de uma condição mais grosseira, equiaxial, para uma menos grosseira, colunar. 


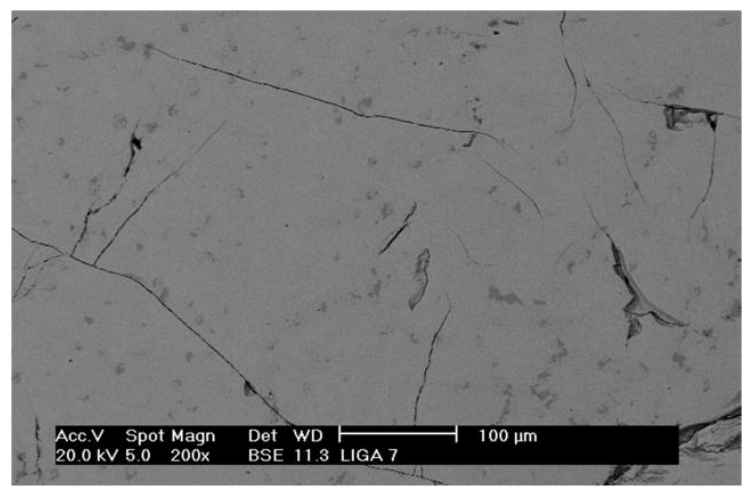

(a)

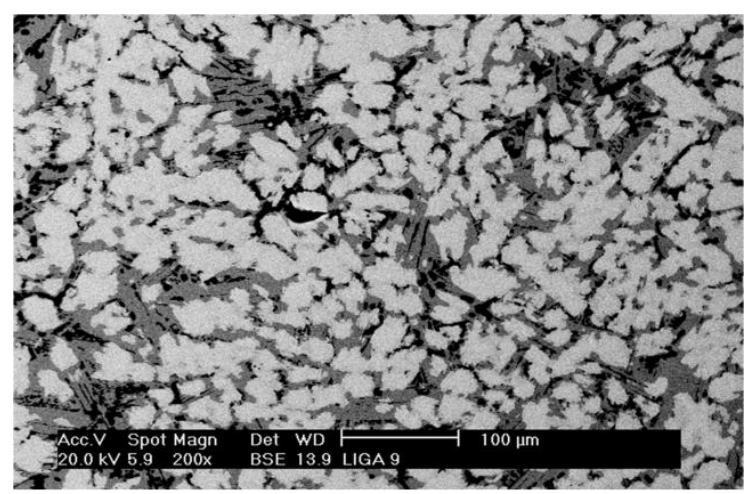

(c)

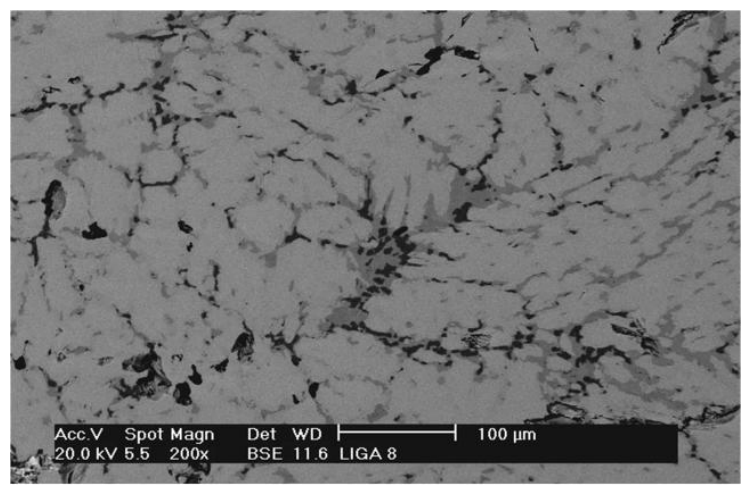

(b)

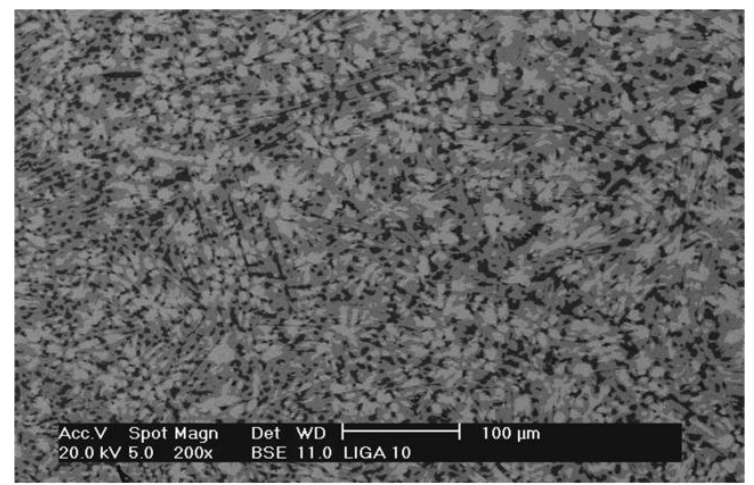

(d)

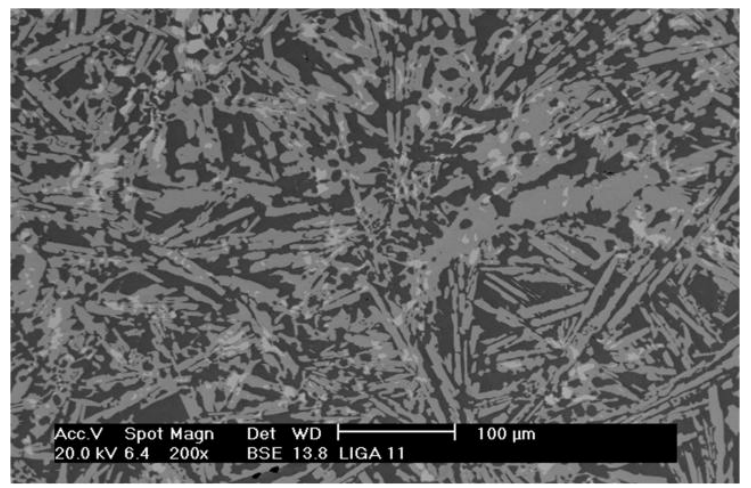

(e)

FIGURA 5 - Micrografias de representação geral das ligas da Série Mg: (a) $\mathrm{La}_{0,7} \mathrm{Pr}_{0,3} \mathrm{Al}_{0,3} \mathrm{Mn}_{0,4} \mathrm{Co}_{0,5} \mathrm{Ni}_{3,8} ;$ (b) $\mathrm{La}_{0,6} \mathrm{Mg}_{0,1} \mathrm{Pr}_{0,3} \mathrm{Al}_{0,3} \mathrm{Mn}_{0,4} \mathrm{Co}_{0,5} \mathrm{Ni}_{3,8}$; (c) $\mathrm{La}_{0,4} \mathrm{Mg}_{0,3} \mathrm{Pr}_{0,3} \mathrm{Al}_{0,3} \mathrm{Mn}_{0,4} \mathrm{Co}_{0,5} \mathrm{Ni}_{3,8} ;$ (d) $\mathrm{La}_{0,2} \mathrm{Mg}_{0,5} \mathrm{Pr}_{0,3} \mathrm{Al}_{0,3} \mathrm{Mn}_{0,4} \mathrm{Co}_{0,5}$ $\mathrm{Ni}_{3,8} ;$ (e) $\mathrm{Mg}_{0,7} \mathrm{Pr}_{0,3} \mathrm{Al}_{0,3} \mathrm{Mn}_{0,4} \mathrm{Co}_{0,5} \mathrm{Ni}_{3,8}$ (tensão $20,0 \mathrm{kV}$; ampliação 200x; BSE). 


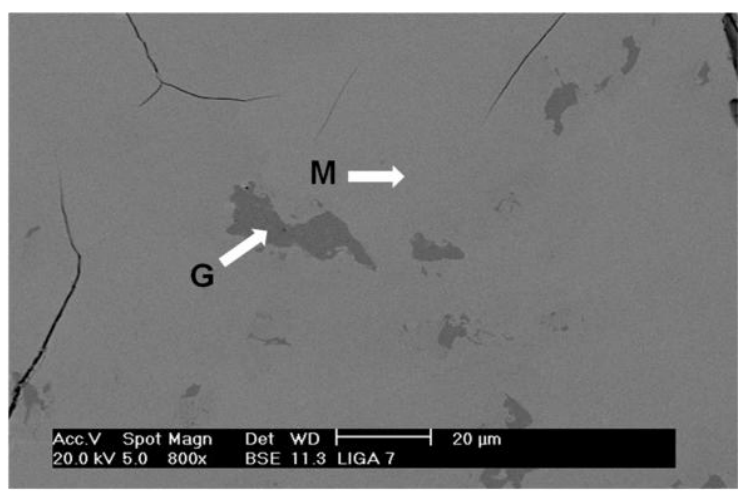

(a)

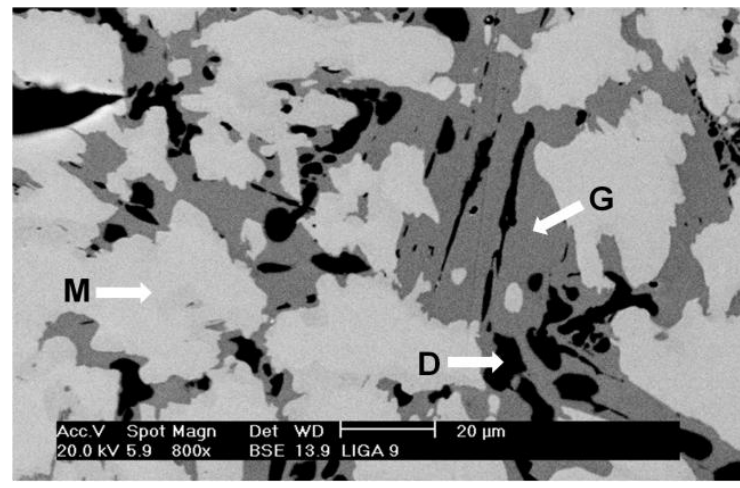

(c)

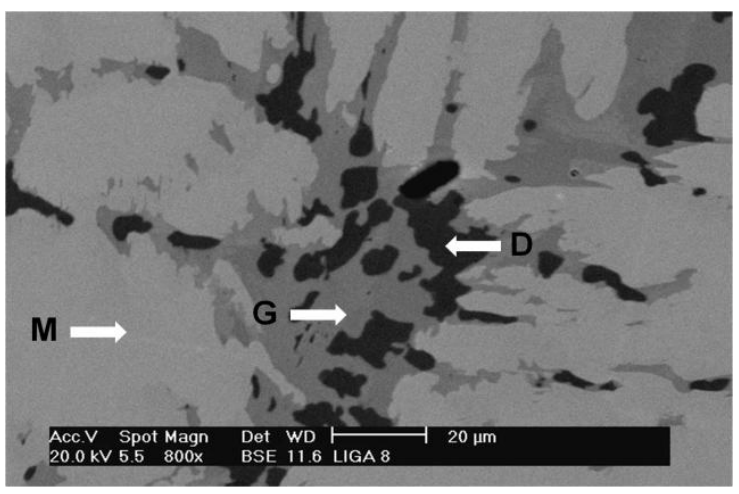

(b)

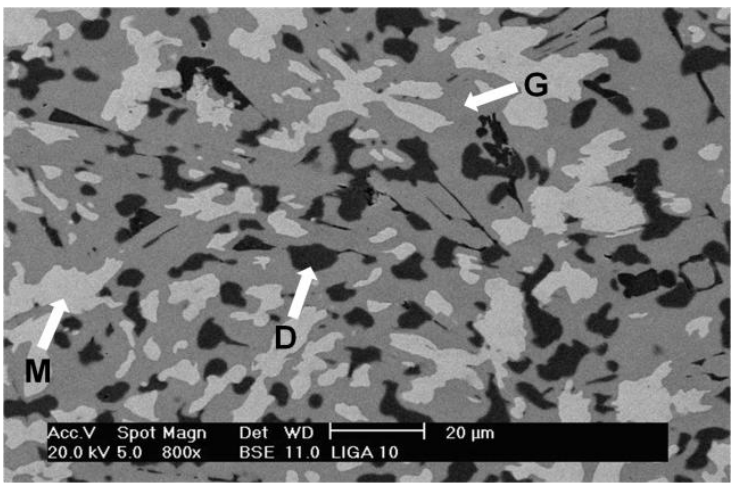

(d)

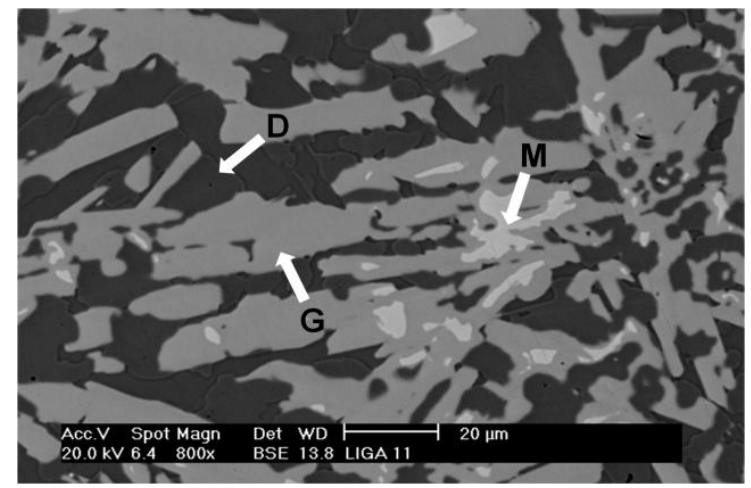

(e)

FIGURA 6 - Micrografias das ligas da Série $M g$ mostrando as fases $M, G$ e $D$ : (b) $\mathrm{La}_{0,7} \mathrm{Pr}_{0,3} \mathrm{Al}_{0,3} \mathrm{Mn}_{0,4} \mathrm{Co}_{0,5} \mathrm{Ni}_{3,8} ;$ (b) $\mathrm{La}_{0,6} \mathrm{Mg}_{0,1} \mathrm{Pr}_{0,3} \mathrm{Al}_{0,3} \mathrm{Mn}_{0,4} \mathrm{Co}_{0,5} \mathrm{Ni}_{3,8}$; (c) $\mathrm{La}_{0,4} \mathrm{Mg}_{0,3} \mathrm{Pr}_{0,3} \mathrm{Al}_{0,3} \mathrm{Mn}_{0,4} \mathrm{Co}_{0,5} \mathrm{Ni}_{3,8}$; (d) $\mathrm{La}_{0,2} \mathrm{Mg}_{0,5} \mathrm{Pr}_{0,3} \mathrm{Al}_{0,3} \mathrm{Mn}_{0,4} \mathrm{Co}_{0,5}$ $\mathrm{Ni}_{3,8}$; (e) $\mathrm{Mg}_{0,7} \mathrm{Prg}_{0,3} \mathrm{Al}_{0,3} \mathrm{Mn}_{0,4} \mathrm{Co}_{0,5} \mathrm{Ni}_{3,8}$ (tensão $20,0 \mathrm{kV}$; ampliação $800 x$; BSE). 
$\mathrm{Na}$ TAB. 10 é apresentada a composição química da fase $M$, determinada por EDS, para as ligas da Série Mg.

A fase $M$ na liga sem $M g$ revelou uma razão atômica (La,Pr) : $(\mathrm{Al}, \mathrm{Mn}, \mathrm{Co}, \mathrm{Ni})$ de 5,0, indicando tratar-se de uma fase $1: 5$. Esse resultado estaria em concordância com a fase matriz $\mathrm{LaNi}_{5}$ de ligas tipo $\mathrm{AB}_{5}$ (Liu et al. 2004d; Pan et al., 2005a, 2006; Zhang, P. et al., 2005).

TABELA 10 - Composição da fase $M$ nas ligas da Série $M g$, $\mathrm{La}_{0,7-x} \mathrm{Mg}_{x} \mathrm{Pr}_{0,3} \mathrm{Al}_{0,3} \mathrm{Mn}_{0,4} \mathrm{Co}_{0,5} \mathrm{Ni}_{3,8}$, por EDS.

\begin{tabular}{|c|c|c|c|c|c|c|c|c|}
\hline \multirow{2}{*}{$x$} & \multicolumn{7}{|c|}{ Composição (\% at.) } & \multirow{2}{*}{ Razão* } \\
\hline & $\mathrm{La}$ & $\operatorname{Pr}$ & $\mathrm{Mg}$ & Al & $\mathrm{Mn}$ & Co & $\mathrm{Ni}$ & \\
\hline 0,0 & $12,0 \pm 0,2$ & $4,7 \pm 0,4$ & - & $5,5 \pm 0,5$ & $5,8 \pm 1,4$ & $8,6 \pm 0,2$ & $63,4 \pm 1,3$ & 5,0 \\
\hline 0,1 & $11,0 \pm 0,5$ & $5,3 \pm 0,1$ & - & $3,6 \pm 1,1$ & $3,1 \pm 1,1$ & $7,7 \pm 0,2$ & $69,4 \pm 2,3$ & 5,1 \\
\hline 0,3 & $8,5 \pm 0,1$ & $7,0 \pm 0,4$ & - & $4,2 \pm 0,6$ & $3,1 \pm 0,9$ & $8,2 \pm 0,4$ & $68,0 \pm 1,5$ & 5,4 \\
\hline 0,5 & $5,9 \pm 0,2$ & $9,7 \pm 0,3$ & - & $3,6 \pm 0,4$ & $3,1 \pm 0,5$ & $8,0 \pm 0,4$ & $70,0 \pm 0,7$ & 5,4 \\
\hline 0,7 & - & $14,0 \pm 0,2$ & - & $3,4 \pm 0,4$ & $2,8 \pm 0,3$ & $7,6 \pm 0,3$ & $72,0 \pm 0,8$ & 6,1 \\
\hline
\end{tabular}

*(La,Pr)/(Al,Mn,Co,Ni)

Nas ligas de composição subsequente $(x>0,0)$, observou-se um aumento na razão atômica considerada devido à variação nas porcentagens dos elementos constituintes.

A substituição de La por $\mathrm{Mg}$ ainda influenciou na quantidade de terras raras presente na fase $M$, tendo sido observado um decréscimo de 16,7 \% at. para $14,0 \%$ at. - valor este correspondendo ao praseodímio contido na liga $\mathrm{Mg}_{0,7} \mathrm{Pr}_{0,3} \mathrm{Al}_{0,3} \mathrm{Mn}_{0,4} \mathrm{Co}_{0,5} \mathrm{Ni}_{3,8}$. Diferentemente, observou-se que o níquel contido na fase $M$ aumentou de 63,4 para $72,0 \%$ at. com tal substituição, ao passo que a quantidade de alumínio e de manganês nesta fase $(5,5 \%$ at. e 5,8 \% at., respectivamente) tendeu a decrescer com o aumento do magnésio contido. Para o cobalto, verificou-se uma composição média de aproximadamente 8,0 \% at. na fase $M$ para as ligas consideradas.

A composição química da fase cinza $G$ observada nas ligas desta série, também determinada por EDS, é mostrada na TAB. 11. 
TABELA 11 - Composição da fase $G$ nas ligas da Série $\mathrm{Mg}$, $\mathrm{La}_{0,7-x} \mathrm{Mg}_{x} \mathrm{Pr}_{0,3} \mathrm{Al}_{0,3} \mathrm{Mn}_{0,4} \mathrm{Co}_{0,5} \mathrm{Ni}_{3,8}$, por EDS.

\begin{tabular}{ccccccccc}
\hline \multicolumn{7}{c}{$x$} & \multicolumn{7}{c}{ Composição (\% at.) } & \multirow{2}{*}{ Razão* } \\
\cline { 2 - 7 } & $\mathrm{La}$ & $\mathrm{Pr}$ & $\mathrm{Mg}$ & $\mathrm{Al}$ & $\mathrm{Mn}$ & $\mathrm{Co}$ & $\mathrm{Ni}$ & \\
\hline 0,0 & $8,1 \pm 0,4$ & $2,3 \pm 0,4$ & - & $4,0 \pm 0,3$ & $21,8 \pm 1,4$ & $8,5 \pm 0,8$ & $55,3 \pm 1,3$ & - \\
0,1 & $6,4 \pm 0,3$ & $2,9 \pm 0,2$ & $10,9 \pm 0,4$ & $2,9 \pm 0,2$ & $10,3 \pm 0,4$ & $7,9 \pm 0,3$ & $58,7 \pm 0,5$ & $1: 2,3: 7,5$ \\
0,3 & $5,0 \pm 0,3$ & $4,3 \pm 0,2$ & $12,0 \pm 0,6$ & $3,7 \pm 0,1$ & $6,5 \pm 0,5$ & $7,4 \pm 0,2$ & $61,0 \pm 0,3$ & $1: 2,0: 8,0$ \\
0,5 & $3,5 \pm 0,2$ & $5,9 \pm 0,3$ & $12,4 \pm 0,4$ & $2,8 \pm 0,1$ & $4,8 \pm 0,5$ & $6,8 \pm 0,6$ & $63,8 \pm 0,2$ & $1: 1,8: 7,8$ \\
0,7 & - & $9,1 \pm 0,3$ & $12,5 \pm 0,5$ & $1,7 \pm 0,2$ & $3,8 \pm 0,3$ & $5,8 \pm 0,5$ & $67,0 \pm 0,7$ & $1: 1,8: 8,2$ \\
\hline$*(\mathrm{La}, \mathrm{Pr}) /(\mathrm{Mg}) /(\mathrm{Al}, \mathrm{Mn}, \mathrm{Co}, \mathrm{Ni})$ & & & & & &
\end{tabular}

Como observado anteriormente na fase $M$, o La contido na fase $G$ decresceu em função de sua substituição por $\mathrm{Mg}$, enquanto que o $\operatorname{Pr}$ contido aumentou nesta fase. A quantidade de terras raras na fase $G(9,1 \%$ at. a $10,4 \%$ at.) correspondeu em média a $64 \%$ do total observado na fase $M$, demonstrando uma distribuição relativamente equilibrada desses elementos nas duas fases consideradas.

Para o magnésio, a partir da condição de substituição $x \geq 0,1$, verificaram-se valores entre 10,9 e $12,5 \%$ at. na fase $G$, indicando uma concentração preferencial deste elemento nessa fase.

Semelhante ao observado na fase $M$, a quantidade de alumínio e de manganês na fase $G$ decresceu a medida em que o La foi substituído pelo $\mathrm{Mg}$. $O$ alumínio contido na fase $G(1,7 \%$ at. a $4,0 \%$ at.) foi menor que o verificado na fase $M(3,4 \%$ at. a $5,5 \%$ at. $)$.

Para a fase $G$ observada nos contornos de grão da liga $\mathrm{La}_{0,7} \operatorname{Pr}_{0,3} \mathrm{Al}_{0,3} \mathrm{Mn}_{0,4} \mathrm{Co}_{0,5} \mathrm{Ni}_{3,8} \quad(x=0,0)$, verificou-se um pico de concentração de manganês ( $22 \%$ at.), o que indicaria a presença de uma fase rica nesse elemento, mas de quantidade bastante reduzida, como observado na micrografia correspondente, mostrada na FIG. 6 (a). A detecção desse pico de concentração de $\mathrm{Mn}$ pode ser atribuída ao estado bruto de fusão das ligas. Exceto à liga nesta condição $(x=0,0)$, a fase cinza presente nas demais ligas revelou uma razão atômica ( $\mathrm{La}, \mathrm{Pr})$ : $\mathrm{Mg}:(\mathrm{Al}, \mathrm{Mn}, \mathrm{Co}, \mathrm{Ni})$ próxima a $1: 2$ : 9. Esta razão indicaria a 
presença de fases similares à fase $\mathrm{REMg}_{2} \mathrm{Ni}_{9}$, em concordância a sistemas estudados anteriormente (Kadir et al., 2000, 1997).

Adicionalmente, observou-se uma presença menor de alumínio contido na fase $G(1,7 \%$ at. a 4,0 \% at.) em relação à fase $M(3,4 \%$ at. a 5,5\% at.), enquanto que o manganês contido nas duas fases apresentou pouca variação (de $\sim 8 \%$ at. na fase $M$ para $\sim 7 \%$ at. na fase $G$ ).

Na TAB. 12 é apresentada a composição da fase escura $D$ presente nas ligas consideradas, sendo que a mesma não foi detectada na liga sem $\mathrm{Mg}$.

TABELA 12 - Composição da fase $D$ nas ligas da Série $\mathrm{Mg}$, $\mathrm{La}_{0,7-x} \mathrm{Mg}_{x} \mathrm{Pr}_{0,3} \mathrm{Al}_{0,3} \mathrm{Mn}_{0,4} \mathrm{Co}_{0,5} \mathrm{Ni}_{3,8}$, por EDS.

\begin{tabular}{ccccccccc}
\hline & \multicolumn{7}{c}{ Composição (\% at.) } & \multirow{2}{*}{ Razão* } \\
\cline { 2 - 7 } & La & Pr & Mg & Al & Mn & Co & Ni & \\
\hline 0,1 & $<1$ & $<1$ & $<1$ & $16-17$ & $23-24$ & $7-8$ & $49-50$ & 1,4 \\
0,3 & $<1$ & $<1$ & $<1$ & $10-11$ & $15-16$ & $15-16$ & $55-57$ & 2,8 \\
0,5 & $<1$ & $<1$ & $1-18$ & $3-11$ & $12-13$ & $15-16$ & $60-63$ & 3,1 \\
0,7 & - & $<1$ & $21-23$ & $1-2$ & $7-9$ & $5-13$ & $61-65$ & 2,0 \\
\hline
\end{tabular}

${ }^{*}(\mathrm{Mg}, \mathrm{Al}, \mathrm{Mn}) /(\mathrm{Co}, \mathrm{Ni})$

Aparentemente, o magnésio exerceu influência na microestrutura e também nas fases presentes nas ligas.

Na fase $D$, a composição de terras raras esteve próxima ou abaixo do limite de detecção (EDS), indicando a concentração preferencial desses elementos nas outras fases detectadas.

Para $x=0,1$, a fase $D$ apresentou-se rica em manganês e em alumínio, em contraste com os outros constituintes (exceto níquel).

Somente na liga sem La $(x=0,7)$ observou-se um pico de concentração de magnésio. A razão atômica entre $\mathrm{Mg}$ e $\mathrm{Ni}$ nesta condição sugeriu a presença de uma fase similar à fase $\mathrm{MgNi}_{2}$. Esta observação estaria em acordo com as observações feitas por Kadir et al. (1997) em estudo da síntese de ligas ternárias $\mathrm{RMg}_{2} \mathrm{Ni}_{9}$ por sinterização de pós de $\mathrm{MgNi}_{2}$ e $\mathrm{RNi}_{5}$ (R=La,Ce,Pr,Nd,Sm,Gd).

Exceto para $x=0,7$, observou-se a presença preferencial de alumínio na fase $D$, em comparação às concentrações nas fases $M$ e $G$. 
Para o manganês, após um pico de concentração na condição $x=0,1$, verificou-se um decréscimo nas demais composições. No caso do cobalto, foram observadas as maiores concentrações na fase $D$, comparativamente às verificadas nas demais fases $(M$ e $G$ ), para as condições $x=0,3$ e $x=0,5$. Deve-se considerar que a caracterização das ligas foi conduzida no estado bruto de fusão, e que alguns desvios nos resultados podem ser atribuídos à condição de heterogeneidade das mesmas. No presente estudo, as análises por EDS indicaram fases de composições próximas às fases $\mathrm{LaNi}_{5}$ na fase matriz, $(\mathrm{La}, \mathrm{Pr}) \mathrm{Mg}_{2} \mathrm{Ni}_{9}$ na fase cinza e $\mathrm{MgNi}_{2}$ na fase escura.

\subsubsection{Série $\operatorname{Pr}$}

Nas micrografias das FIG. 7 e 8 são apresentadas imagens obtidas por elétrons retroespalhados (BSE) - representações geral e detalhada (ampliações de 200x e 800x, respectivamente) - das ligas da Série Pr, $\mathrm{La}_{0,7-y} \mathrm{Pr}_{y} \mathrm{Mg}_{0,3} \mathrm{Al}_{0,3} \mathrm{Mn}_{0,4} \mathrm{Co}_{0,5} \mathrm{Ni}_{3,8}(y=0,0,0,1,0,3,0,5,0,7)$ em estado bruto de fusão. A microestrutura e os aspectos morfológicos observados para as ligas da Série Pr também foram influenciados por tal estado das ligas.

Pelas micrografias mostradas na FIG. 7, observou-se um aspecto dendrítico na morfologia dos grãos em todas as ligas dessa série. Evidenciou-se que, com a substituição crescente de lantânio por praseodímio, esse aspecto adquiriu maior notoriedade, principalmente nas condições de substituição $y=0,5 \mathrm{e}$ $y=0,7$, ligas $\mathrm{La}_{0,2} \mathrm{Pr}_{0,5} \mathrm{Mg}_{0,3} \mathrm{Al}_{0,3} \mathrm{Mn}_{0,4} \mathrm{Co}_{0,5} \mathrm{Ni}_{3,8}$ e $\mathrm{Pr}_{0,7} \mathrm{Mg}_{0,3} \mathrm{Al}_{0,3} \mathrm{Mn}_{0,4} \mathrm{Co}_{0,5} \mathrm{Ni}_{3,8}$, respectivamente. Observou-se, ainda, que tal aparência passou de uma condição mais grosseira, como a da liga sem praseodímio, mostrada na FIG. 7 (a), para uma mais refinada, à medida da substituição de lantânio por praseodímio.

Como mostrado na FIG. 8, em todas as ligas da Série Pr observou-se a presença de uma fase matriz $(M)$, além de outras duas fases secundárias nos contornos de grão - fase cinza $(G)$ e fase escura $(D)$. Visualmente, a substituição de La por $\operatorname{Pr}$ favoreceu a presença da fase $G$ em detrimento da fase $D$, principalmente como observado para as condições $y=0,1$ a $y=0,5$. Observou-se, também, que em todas as ligas a fase $M$ manteve-se como majoritária, diferentemente do verificado nas ligas da Série $M g$. As composições das fases $M$, $G$ e $D$ das ligas da Série $\operatorname{Pr}$, via EDS, estão apresentadas nas TAB. 13, 14 e 15, respectivamente. 


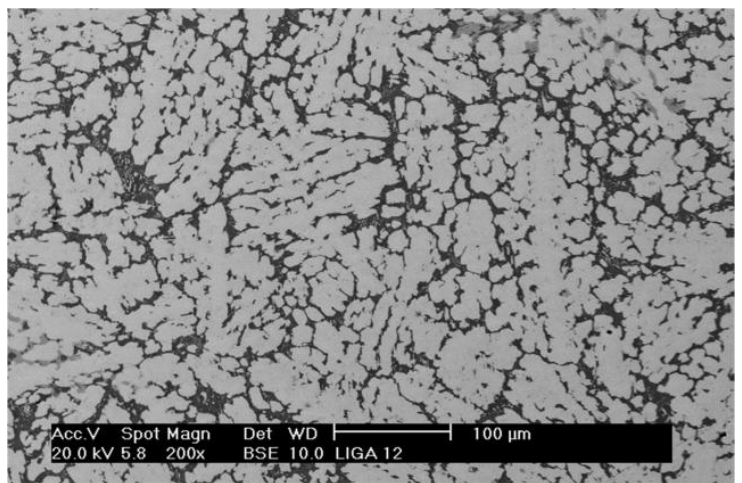

(a)

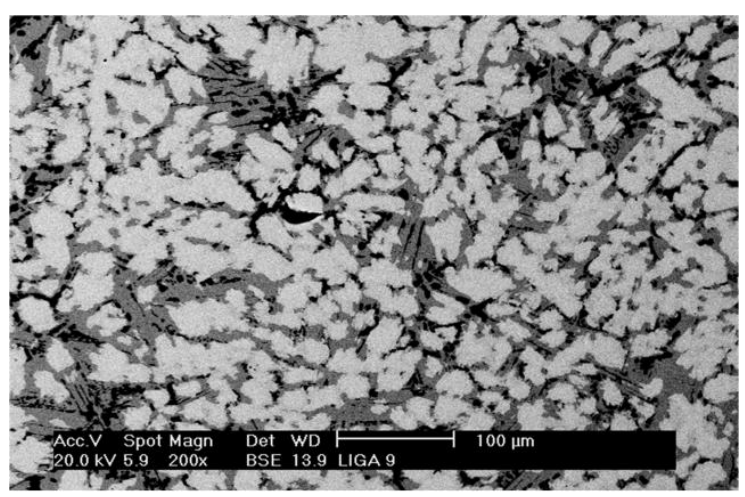

(c)

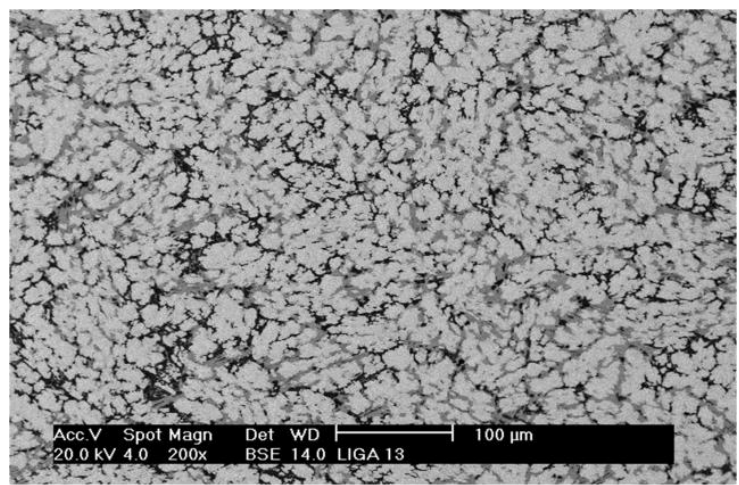

(b)

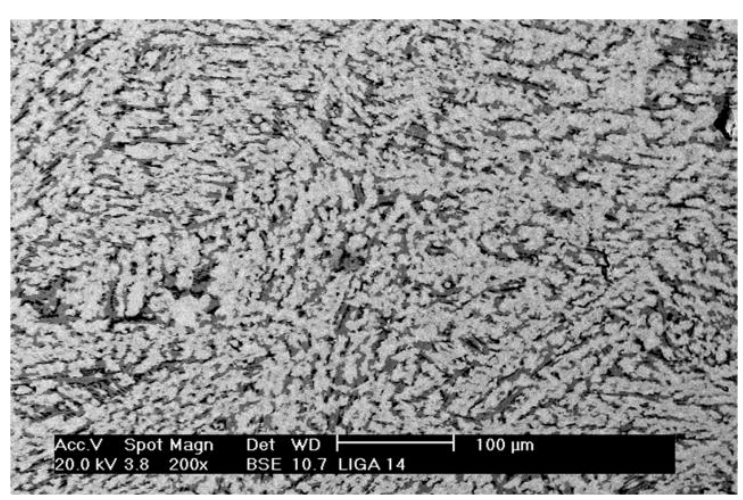

(d)

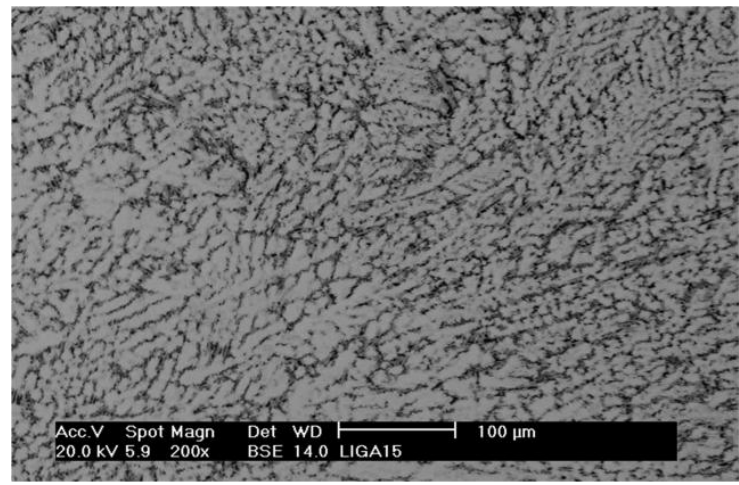

(e)

FIGURA 7 - Micrografias de representação geral das ligas da Série Pr: (a) $\mathrm{La}_{0,7} \mathrm{Mg}_{0,3} \mathrm{Al}_{0,3} \mathrm{Mn}_{0,4} \mathrm{Co}_{0,5} \mathrm{Ni}_{3,8} ;$ (b) $\mathrm{La}_{0,6} \mathrm{Pr}_{0,1} \mathrm{Mg}_{0,3} \mathrm{Al}_{0,3} \mathrm{Mn}_{0,4} \mathrm{Co}_{0,5} \mathrm{Ni}_{3,8}$; (c) $\mathrm{La}_{0,4} \mathrm{Pr}_{0,3} \mathrm{Mg}_{0,3} \mathrm{Al}_{0,3} \mathrm{Mn}_{0,4} \mathrm{Co}_{0,5} \mathrm{Ni}_{3,8}$; (d) $\mathrm{La}_{0,2} \mathrm{Pr}_{0,5} \mathrm{Mg}_{0,3} \mathrm{Al}_{0,3} \mathrm{Mn}_{0,4} \mathrm{Co}_{0,5}$ $\mathrm{Ni}_{3,8} ; \quad$ (e) $\mathrm{Pr}_{0,7} \mathrm{Mg}_{0,3} \mathrm{Al}_{0,3} \mathrm{Mn}_{0,4} \mathrm{Co}_{0,5} \mathrm{Ni}_{3,8}$ (tensão 20,0 kV; ampliação 200x; BSE). 


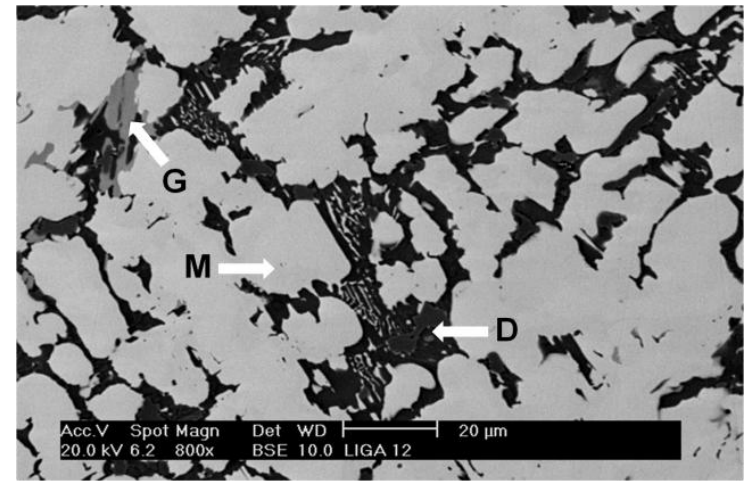

(a)

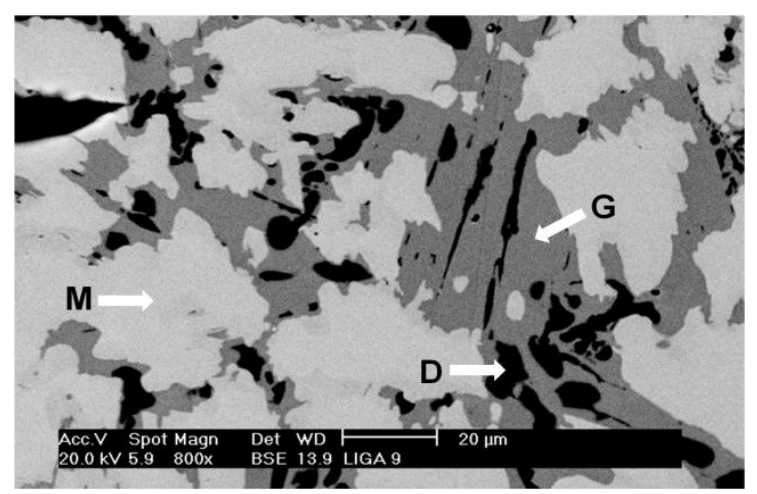

(c)

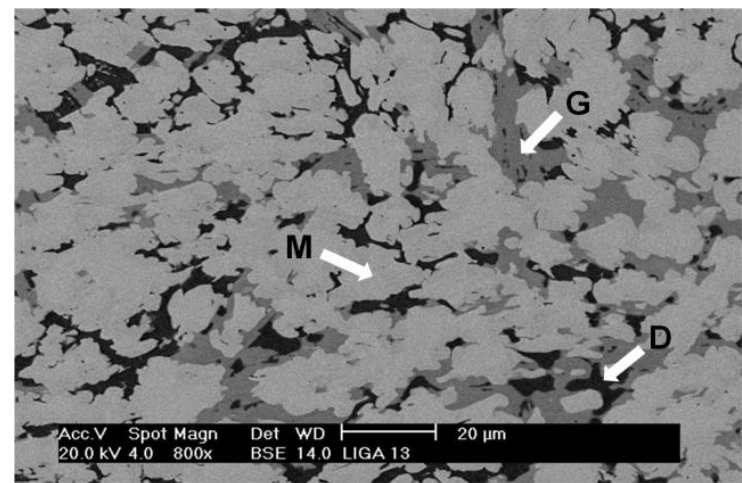

(b)

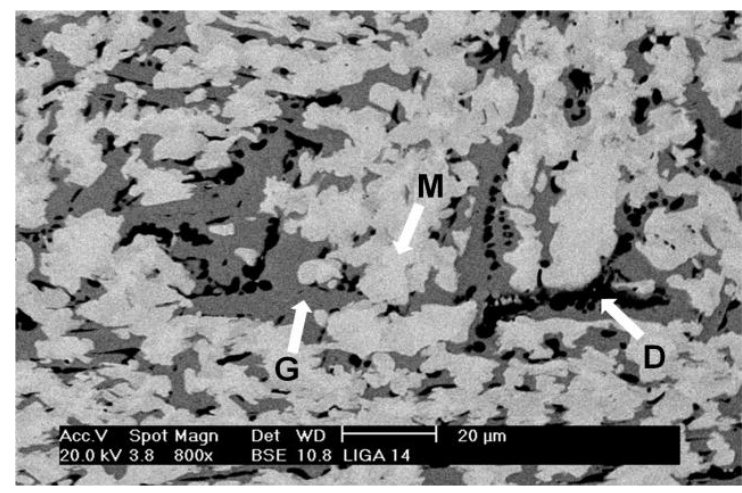

(d)

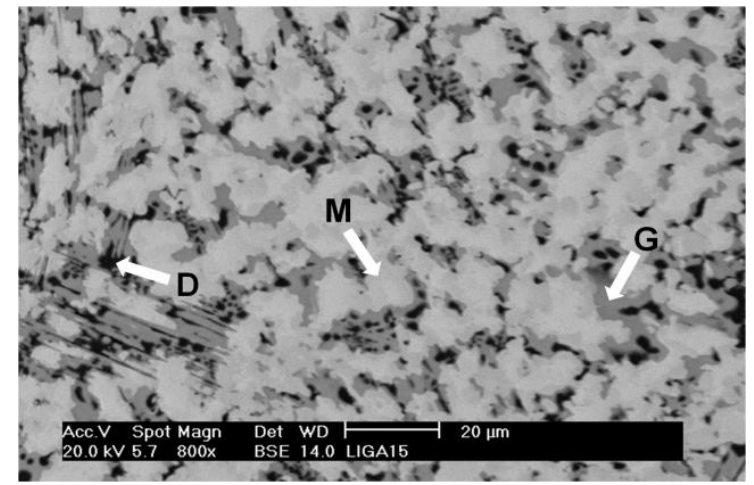

(e)

FIGURA 8 - Micrografias das ligas da Série $\operatorname{Pr}$ mostrando as fases $M, G$ e $D$ : (c) $\mathrm{La}_{0,7} \mathrm{Mg}_{0,3} \mathrm{Al}_{0,3} \mathrm{Mn}_{0,4} \mathrm{Co}_{0,5} \mathrm{Ni}_{3,8}$; (b) $\mathrm{La}_{0,6} \mathrm{Pr}_{0,1} \mathrm{Mg}_{0,3} \mathrm{Al}_{0,3} \mathrm{Mn}_{0,4} \mathrm{Co}_{0,5} \mathrm{Ni}_{3,8}$; (c) $\mathrm{La}_{0,4} \mathrm{Pr}_{0,3} \mathrm{Mg}_{0,3} \mathrm{Al}_{0,3} \mathrm{Mn}_{0,4} \mathrm{Co}_{0,5} \mathrm{Ni}_{3,8}$; (d) $\mathrm{La}_{0,2} \mathrm{Pr}_{0,5} \mathrm{Mg}_{0,3} \mathrm{Al}_{0,3} \mathrm{Mn}_{0,4} \mathrm{Co}_{0,5}$ $\mathrm{Ni}_{3,8} ; \quad$ (e) $\operatorname{Pr}_{0,7} \mathrm{Mg}_{0,3} \mathrm{Al}_{0,3} \mathrm{Mn}_{0,4} \mathrm{Co}_{0,5} \mathrm{Ni}_{3,8}$ (tensão $20,0 \mathrm{kV}$; ampliação $800 x$; BSE). 
TABELA 13 - Composição da fase $M$ nas ligas da Série $\operatorname{Pr}$, $\mathrm{La}_{0,7-y} \mathrm{Pr}_{y} \mathrm{Mg}_{0,3} \mathrm{Al}_{0,3} \mathrm{Mn}_{0,4} \mathrm{Co}_{0,5} \mathrm{Ni}_{3,8}$, por EDS.

\begin{tabular}{ccccccccc}
\hline & \multicolumn{7}{c}{ Composição (\% at.) } & \multirow{2}{*}{ Razão* } \\
\cline { 2 - 8 } & $\mathrm{La}$ & $\mathrm{Pr}$ & $\mathrm{Mg}$ & $\mathrm{Al}$ & $\mathrm{Mn}$ & $\mathrm{Co}$ & $\mathrm{Ni}$ & \\
\hline 0,0 & $15,4 \pm 0,6$ & - & $<1$ & $3,6 \pm 0,3$ & $3,6 \pm 0,6$ & $8,3 \pm 0,5$ & $68,4 \pm 1,2$ & 5,4 \\
0,1 & $13,1 \pm 0,3$ & $2,5 \pm 0,2$ & $<1$ & $4,2 \pm 0,5$ & $3,4 \pm 0,8$ & $8,2 \pm 0,3$ & $68,0 \pm 0,1$ & 5,4 \\
0,3 & $8,5 \pm 0,1$ & $7,0 \pm 0,4$ & $<1$ & $4,2 \pm 0,6$ & $3,1 \pm 0,9$ & $8,2 \pm 0,4$ & $68,0 \pm 1,5$ & 5,4 \\
0,5 & $4,1 \pm 0,1$ & $11,1 \pm 0,6$ & $<1$ & $4,4 \pm 0,6$ & $3,7 \pm 0,9$ & $8,4 \pm 0,3$ & $67,6 \pm 1,1$ & 5,5 \\
0,7 & - & $14,8 \pm 0,9$ & $1,1 \pm 0,7$ & $4,2 \pm 0,7$ & $3,5 \pm 1,2$ & $8,3 \pm 0,5$ & $68,0 \pm 1,4$ & 5,7 \\
\hline$*$ *(La,Pr)/(Al,Mn,Co,Ni) & & & & & &
\end{tabular}

Pela TAB. 13 verificou-se a crescente substituição de La por Pr na fase matriz, totalizando cerca de $15 \%$ at. de terras raras nesta fase. Os demais constituintes mantiveram composições relativamente constantes em todas as condições de substituição $(y=0,0$ a $y=0,7)$, estando o magnésio abaixo do limite de detecção do EDS (1\% at.).

Levando-se em consideração as prováveis substituições no retículo cristalino, as razões atômicas ( $\mathrm{La}, \mathrm{Pr})$ : $(\mathrm{Al}, \mathrm{Mn}, \mathrm{Co}, \mathrm{Ni})$ na fase $M$ indicaram a possibilidade de tratar-se de uma fase similar à fase LaNi $\mathrm{L}_{5}$. Esta fase já fora detectada em estudos de substituição de La por $\mathrm{Pr}$ em ligas $\mathrm{La}_{0,7-x} \mathrm{Pr}_{x} \mathrm{Mg}_{0,3} \mathrm{Ni}_{2,45} \mathrm{Co}_{0,75} \mathrm{Mn}_{0,1} \mathrm{Al}_{0,2}$ ( $x=0,0-0,3$ ), em condições de homogeneização das ligas (Pan et al., 2007).

Com o auxílio da TAB. 14, referente à composição da fase cinza nas ligas da Série $\operatorname{Pr}$, verificou-se que, novamente, o La foi substituído pelo Pr em todas as ligas. $O$ valor total de terras raras determinado $(8,2$ a $9,1 \%$ at.) correspondeu em média a $57 \%$ do verificado na fase matriz.

Alumínio e cobalto mantiveram teores próximos aos observados na fase matriz, enquanto que o manganês contido na fase $G$ representou mais que o dobro do teor desse componente na fase matriz. 
TABELA 14 - Composição da fase $G$ nas ligas da Série $\operatorname{Pr}$, $\mathrm{La}_{0,7-y} \mathrm{Pr}_{y} \mathrm{Mg}_{0,3} \mathrm{Al}_{0,3} \mathrm{Mn}_{0,4} \mathrm{Co}_{0,5} \mathrm{Ni}_{3,8}$, por EDS.

\begin{tabular}{ccccccccc}
\hline & \multicolumn{7}{c}{ Composição (\% at.) } & \multirow{2}{*}{ *Razão } \\
\cline { 2 - 7 } & $\mathrm{La}$ & $\mathrm{Pr}$ & $\mathrm{Mg}$ & $\mathrm{Al}$ & $\mathrm{Mn}$ & $\mathrm{Co}$ & $\mathrm{Ni}$ & \\
\hline 0,0 & $8,2 \pm 0,3$ & - & $10,9 \pm 0,2$ & $2,9 \pm 0,4$ & $9,5 \pm 1,8$ & $7,6 \pm 0,1$ & $60,9 \pm 1,7$ & $1: 1,3: 9,9$ \\
0,1 & $7,3 \pm 0,6$ & $1,2 \pm 0,2$ & $11,5 \pm 0,2$ & $3,1 \pm 0,3$ & $8,8 \pm 0,8$ & $8,3 \pm 0,3$ & $59,8 \pm 0,8$ & $1: 1,4: 9,4$ \\
0,3 & $5,0 \pm 0,3$ & $4,3 \pm 0,2$ & $12,0 \pm 0,6$ & $3,7 \pm 0,1$ & $6,5 \pm 0,5$ & $7,4 \pm 0,2$ & $61,0 \pm 0,3$ & $1: 1,3: 8,5$ \\
0,5 & $2,6 \pm 0,2$ & $6,4 \pm 0,4$ & $11,2 \pm 0,3$ & $3,0 \pm 0,5$ & $7,6 \pm 0,9$ & $8,1 \pm 0,3$ & $61,1 \pm 0,9$ & $1: 1,2: 8,9$ \\
0,7 & - & $9,1 \pm 1,2$ & $10,1 \pm 0,1$ & $3,4 \pm 0,4$ & $7,3 \pm 1,2$ & $7,6 \pm 0,9$ & $62,5 \pm 0,6$ & $1: 1,1: 8,9$ \\
\hline${ }^{*}(\mathrm{La}, \mathrm{Pr}) /(\mathrm{Mg}) /(\mathrm{Al}, \mathrm{Mn}, \mathrm{Co}, \mathrm{Ni})$ & & & & &
\end{tabular}

Evidenciou-se a concentração preferencial de magnésio na fase $G$, com um valor médio de $11,0 \%$ at., em contraste com os valores abaixo do limite de detecção verificados na fase matriz. Similarmente ao observado na fase cinza para as ligas da Série $\mathrm{Mg}$, a razão atômica ( $\mathrm{La}, \mathrm{Pr}): \mathrm{Mg}:(\mathrm{Al}, \mathrm{Mn}, \mathrm{Co}, \mathrm{Ni})$ na fase cinza para as ligas da Série $\operatorname{Pr}$ sugere uma proximidade à relação $1: 2: 9$, correspondendo à fase $\mathrm{RMg}_{2} \mathrm{Ni}_{9}$ (Kadir et al., 1997).

A composição química da fase escura $D$ para as diferentes ligas da Série $\operatorname{Pr}$, também determinada por EDS, é apresentada na TAB. 15. Praticamente, a presença de terras raras nesta fase deveu-se aos teores de $\mathrm{Pr}$ nas condições de substituição $y=0,5$ e $y=0,7$, uma vez que o teor de La contido manteve-se abaixo do limite de detecção em todas as ligas consideradas.

TABELA 15 - Composição da fase $D$ nas ligas da Série $\operatorname{Pr}$, $\mathrm{La}_{0,7-y} \mathrm{Pr}_{y} \mathrm{Mg}_{0,3} \mathrm{Al}_{0,3} \mathrm{Mn}_{0,4} \mathrm{Co}_{0,5} \mathrm{Ni}_{3,8}$, por EDS.

\begin{tabular}{cccccccc}
\hline & \multicolumn{7}{c}{ Composição (\% at.) } \\
\cline { 2 - 7 } & La & Pr & Mg & Al & Mn & Co & Ni \\
\hline 0,0 & $<1$ & - & $1-2$ & $9-10$ & 15 & $16-17$ & $56-57$ \\
0,1 & $<1$ & $<1$ & $1-5$ & $9-20$ & $15-19$ & $8-17$ & $50-57$ \\
0,3 & $<1$ & $<1$ & $<1$ & $10-11$ & $15-16$ & $15-16$ & $55-57$ \\
0,5 & $<1$ & $1-3$ & $1-4$ & $14-17$ & $16-21$ & $7-9$ & $49-53$ \\
0,7 & - & $4-8$ & $6-8$ & $4-7$ & $8-11$ & $8-10$ & $60-62$ \\
\hline
\end{tabular}


Confirmou-se, também, a concentração preferencial de $\mathrm{Mg}$ na fase cinza, com baixos teores observados na fase escura nas condições de substituição. Verificou-se a presença significativa de $\mathrm{Al}, \mathrm{Mn}$ e Co na fase $D$, indicando a provável presença de fases ricas nesses componentes. Ainda nessa fase, o níquel contido assumiu os menores valores em comparação às determinações anteriores, ou seja, nas fases matriz e cinza. Os resultados das análises revelaram maior heterogeneidade na fase escura, com variações consideráveis nos teores dos componentes. Esse comportamento pode ser atribuído ao estado bruto de fusão das ligas.

\subsubsection{Estrutura cristalina}

\subsubsection{Série $M g$}

Os espectros de difração de raios $X$ das ligas $\mathrm{La}_{0,7-x} \mathrm{Mg}_{x} \mathrm{Pr}_{0,3} \mathrm{Al}_{0,3} \mathrm{Mn}_{0,4} \mathrm{Co}_{0,5} \mathrm{Ni}_{3,8} \quad(x=0,0,0,1,0,3,0,5,0,7)$ no estado bruto de fusão estão mostrados na FIG. 9.

A identificação das fases por difração de raios $X$ teve por base os resultados obtidos por MEV/EDS. As fases identificadas, os parâmetros de rede, os volumes das células unitárias, além das abundâncias de fases obtidos pelo método de Rietveld estão listados na TAB. 16 e representados graficamente nas FIG. 10 e 11.

Pela FIG. 9 observou-se que os picos de difração foram deslocados para ângulos maiores devido à substituição do La (raio atômico 2,74 Á) pelo Mg (raio atômico 1,72 Á), notando-se, ainda, a presença constante de $\mathrm{Pr}$ (raio atômico 2,67 Á) em todas as composições. Tal conjuntura implicou no decréscimo dos parâmetros de rede e na subsequente contração dos volumes das células unitárias das fases presentes, como mostrado na TAB. 16 e na FIG. 10.

Foram identificadas fases com mesma simetria cristalina e grupo espacial das fases de referência $\mathrm{LaNi}_{5}, \mathrm{PrNi}_{5}, \mathrm{LaMg}_{2} \mathrm{Ni}_{9}, \mathrm{PrMg}_{2} \mathrm{Ni}_{9}, \mathrm{AlMnNi}_{6}$ e $\mathrm{MgNi}_{2}$. Entretanto, nos parâmetros de rede a e $c$ foram observadas variações em relação àqueles das fases de referência. Isto pode ser atribuído às possíveis substituições no retículo cristalino nos sítios do La ( $\mathrm{La}, \mathrm{Pr})$ e do $\mathrm{Ni}(\mathrm{Al}, \mathrm{Mn}, \mathrm{Co}, \mathrm{Ni})$, em consequência do estado bruto de fusão das ligas. Essa condição, além da 
substituição crescente de La por Mg, influenciaram na abundância relativa das fases, como mostrado na TAB. 16 e na FIG. 11. Nesta figura é também apresentada a correspondência com as fases matriz $(M)$, cinza $(G)$ e escura $(D)$, determinadas pelas análises por MEV/EDS para as ligas da Série Mg.

Com a adição de $M g$ (condição $x=0,0$ para $x=0,1$ ), a abundância da fase similar à fase $\mathrm{LaNi}_{5}$ decresceu de $74,2 \%$ para $43,0 \%$, ao passo que à correspondente à fase $\mathrm{PrNi}_{5}$ aumentou de 25,8\% para 45,5\%, além da detecção, na condição $x=0,1$, da fase similar à fase ( $\mathrm{La}, \mathrm{Pr}) \mathrm{Mg}_{2} \mathrm{Ni}_{9}(11,5 \%)$. A abundância desta fase mostrou-se crescente com o aumento do Mg contido ( $x=0,1$ a 0,5), com a detecção da fase $\mathrm{PrMg}_{2} \mathrm{Ni}_{9}$ na condição de substituição total de La por $\mathrm{Mg}$ $\left(\mathrm{Mg}_{0,7} \mathrm{Pr}_{0,3} \mathrm{Al}_{0,3} \mathrm{Mn}_{0,4} \mathrm{Co}_{0,5} \mathrm{Ni}_{3,8}\right)$.

A fase (La,Pr) $\mathrm{Ni}_{5}$ passou de abundância majoritária $(60,7 \%)$ na condição $x=0,3$ para minoritária $(5,8 \%)$ em $x=0,7$.

A partir de $x=0,3$, identificou-se, também, uma fase similar à fase AlMnNi ${ }_{6}$, em abundância crescente, atingindo $33,5 \%$ em $x=0,7$. Nesta condição, ou seja, na total substituição de La por Mg, detectou-se a presença de uma fase similar à fase $\mathrm{MgNi}_{2}(14,3 \%)$.

A identificação de fases presentes por meio das técnicas de DRX e MEV/EDS resultaram na seguinte associação: fase matriz $(M)$, correspondeu às fases similares às fases $\mathrm{LaNi}_{5}$ e $\mathrm{PrNi}_{5}$; fase cinza $(G)$, às fases similares às fases $\mathrm{LaMg}_{2} \mathrm{Ni}_{9}$ e $\mathrm{PrMg}_{2} \mathrm{Ni}_{9} \mathrm{e}$ a fase esdura (D), às fases similares às fases $\mathrm{MgNi}_{2} \mathrm{e}$ $\mathrm{AlMnNi}_{6}$. 


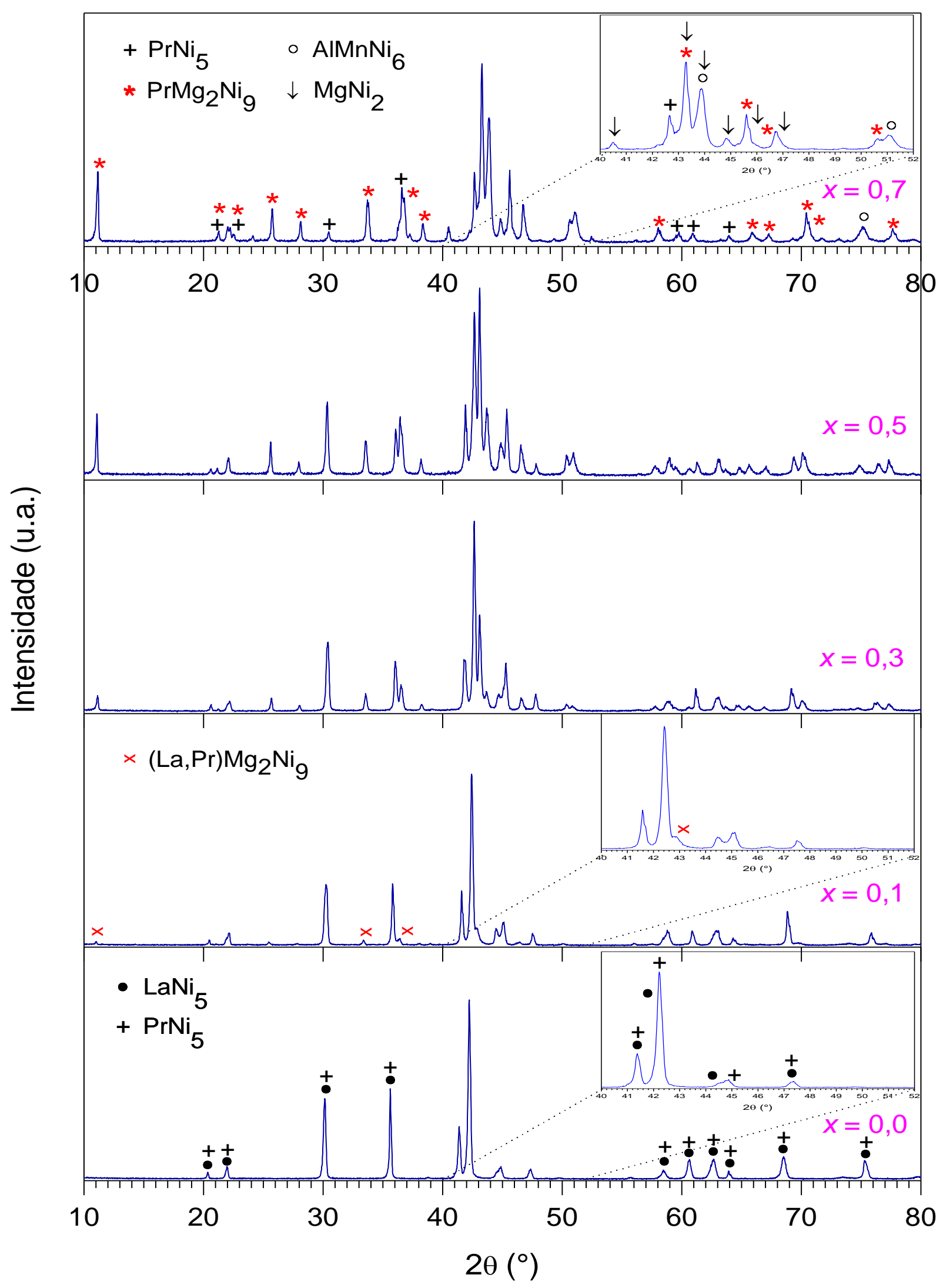

FIGURA 9 - Espectros de difração de raios $X$ das ligas da Série $M g$, $\mathrm{La}_{0,7-x} \mathrm{Mg}_{x} \mathrm{Pr}_{0,3} \mathrm{Al}_{0,3} \mathrm{Mn}_{0,4} \mathrm{Co}_{0,5} \mathrm{Ni}_{3,8}(x=0,0-0,7)$. 
TABELA 16 - Características das fases nas ligas da Série Mg, $\operatorname{La}_{0,7-x} \mathrm{Mg}_{x} \mathrm{Pr}_{0,3} \mathrm{Al}_{0,3} \mathrm{Mn}_{0,4} \mathrm{Co}_{0,5} \mathrm{Ni}_{3,8}(x=0,0-0,7)$.

\begin{tabular}{|c|c|c|c|c|c|c|c|}
\hline \multirow[t]{2}{*}{ Liga } & \multirow[t]{2}{*}{ Fases } & \multirow{2}{*}{$\begin{array}{l}\text { Grupo } \\
\text { espacial }\end{array}$} & \multirow{2}{*}{$\begin{array}{l}\text { Parâmetros } \\
\text { de ajuste }^{\mathrm{a}}\end{array}$} & \multirow{2}{*}{$\begin{array}{l}\text { Abundância } \\
\text { de fase (\%) }\end{array}$} & \multicolumn{2}{|c|}{ Parâmetros de rede $(\AA \hat{)})$} & \multirow{2}{*}{$\begin{array}{l}\text { Volume da } \\
\text { célula }\left(\AA^{3}\right)\end{array}$} \\
\hline & & & & & $a$ & $c$ & \\
\hline \multirow[t]{2}{*}{$x=0,0$} & $\mathrm{LaNi}_{5}$ & $\mathrm{P} 6 / \mathrm{mmm}$ & $R_{\mathrm{p}}=0,2660$ & 74,2 & 5,047 & 4,063 & $89,6 \pm 0,5$ \\
\hline & $\mathrm{PrNi}_{5}$ & $\mathrm{P} 6 / \mathrm{mmm}$ & $R_{\mathrm{wp}}=0,4664, \chi^{2}=2,757$ & 25,8 & 5,034 & 4,034 & $88,5 \pm 0,5$ \\
\hline \multirow[t]{3}{*}{$x=0,1$} & $\mathrm{LaNi}_{5}$ & $\mathrm{P} 6 / \mathrm{mmm}$ & $R_{\mathrm{p}}=0,2416$ & 43,0 & 5,017 & 4,062 & $88,5 \pm 0,5$ \\
\hline & $\mathrm{PrNi}_{5}$ & $\mathrm{P} 6 / \mathrm{mmm}$ & $R_{\mathrm{wp}}=0,4440, \chi^{2}=2,467$ & 45,5 & 5,020 & 4,019 & $87,7 \pm 0,5$ \\
\hline & $(\mathrm{La}, \mathrm{Pr}) \mathrm{Mg}_{2} \mathrm{Ni}_{9}$ & $\mathrm{R}-3 \mathrm{~m}$ & & 11,5 & 4,950 & 24,299 & $516 \pm 1$ \\
\hline \multirow[t]{3}{*}{$x=0,3$} & $(\mathrm{La}, \mathrm{Pr}) \mathrm{Ni}_{5}$ & $\mathrm{P} 6 / \mathrm{mmm}$ & $R_{\mathrm{p}}=0,2416$ & 60,7 & 4,996 & 4,051 & $87,6 \pm 0,5$ \\
\hline & $(\mathrm{La}, \mathrm{Pr}) \mathrm{Mg}_{2} \mathrm{Ni}_{9}$ & $\mathrm{R}-3 \mathrm{~m}$ & $R_{\mathrm{wp}}=0,4440, \chi^{2}=2,467$ & 29,3 & 4,936 & 24,104 & $509 \pm 1$ \\
\hline & $\mathrm{AIMnNi}_{6}$ & Pm3m & & 10,0 & 3,603 & 3,603 & $46,8 \pm 0,5$ \\
\hline \multirow[t]{3}{*}{$x=0,5$} & $(\mathrm{La}, \mathrm{Pr}) \mathrm{Ni}_{5}$ & $\mathrm{P} 6 / \mathrm{mmm}$ & $R_{\mathrm{p}}=0,2469$ & 32,6 & 4,981 & 4,041 & $86,8 \pm 0,5$ \\
\hline & $(\mathrm{La}, \mathrm{Pr}) \mathrm{Mg}_{2} \mathrm{Ni}_{9}$ & $\mathrm{R}-3 \mathrm{~m}$ & $R_{\mathrm{wp}}=0,6088, \chi^{2}=2,148$ & 42,6 & 4,932 & 23,993 & $505 \pm 1$ \\
\hline & $\mathrm{AIMnNi}_{6}$ & Pm3m & & 24,8 & 3,590 & 3,590 & $46,3 \pm 0,5$ \\
\hline \multirow[t]{4}{*}{$x=0,7$} & $\mathrm{PrNi}_{5}$ & $\mathrm{P} 6 / \mathrm{mmm}$ & $R_{\mathrm{p}}=0,2056$ & 5,8 & 4,943 & 4,028 & $85,2 \pm 0,5$ \\
\hline & $\mathrm{PrMg}_{2} \mathrm{Ni}_{9}$ & $\mathrm{R}-3 \mathrm{~m}$ & $R_{\mathrm{wp}}=0,3734, \chi^{2}=2,249$ & 46,4 & 4,918 & 23,906 & $501 \pm 1$ \\
\hline & $\mathrm{AIMnNi}_{6}$ & $\mathrm{Pm} 3 \mathrm{~m}$ & & 33,5 & 3,583 & 3,583 & $46,0 \pm 0,5$ \\
\hline & $\mathrm{MgNi}_{2}$ & $\mathrm{PG}_{3} / \mathrm{mmc}$ & & 14,3 & 4,834 & 15,824 & $320 \pm 1$ \\
\hline
\end{tabular}

${ }^{\text {a }} R_{\mathrm{p}}=$ fator padrão, $R_{\mathrm{wp}}=$ fator padrão ponderado, $\chi^{2}=$ índice de qualidade do refinamento. 


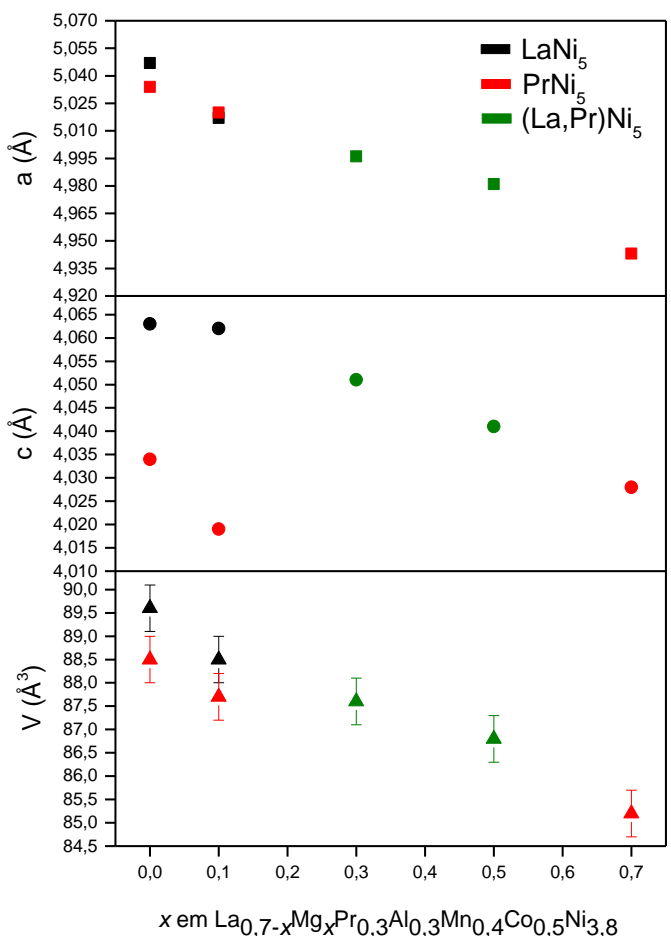

(a)

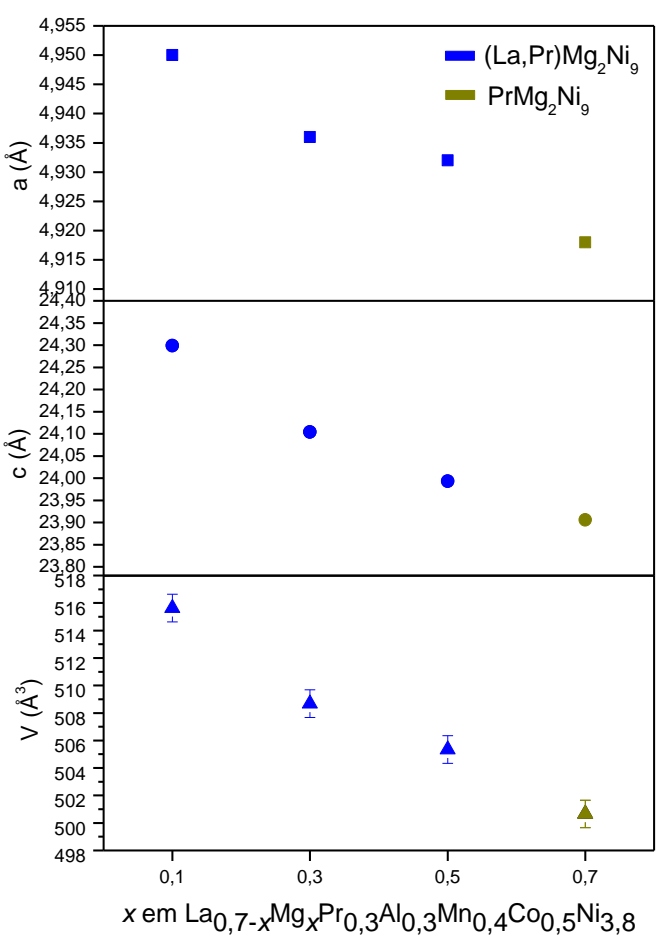

(b)

FIGURA 10 - Parâmetros de rede e volumes de célula unitária das ligas da Série Mg, $\mathrm{La}_{0,7-x} \mathrm{Mg}_{x} \mathrm{Pr}_{0,3} \mathrm{Al}_{0,3} \mathrm{Mn}_{0,4} \mathrm{Co}_{0,5} \mathrm{Ni}_{3,8}$ ( $\left.x=0,0-0,7\right)$ : (a) fases $\mathrm{LaNi}_{5}, \mathrm{PrNi}_{5}$ e (La,Pr)Nis; (b) fases (La,Pr)Mg $\mathrm{Ni}_{9}$ e $\mathrm{PrMg}_{2} \mathrm{Ni}_{9}$.

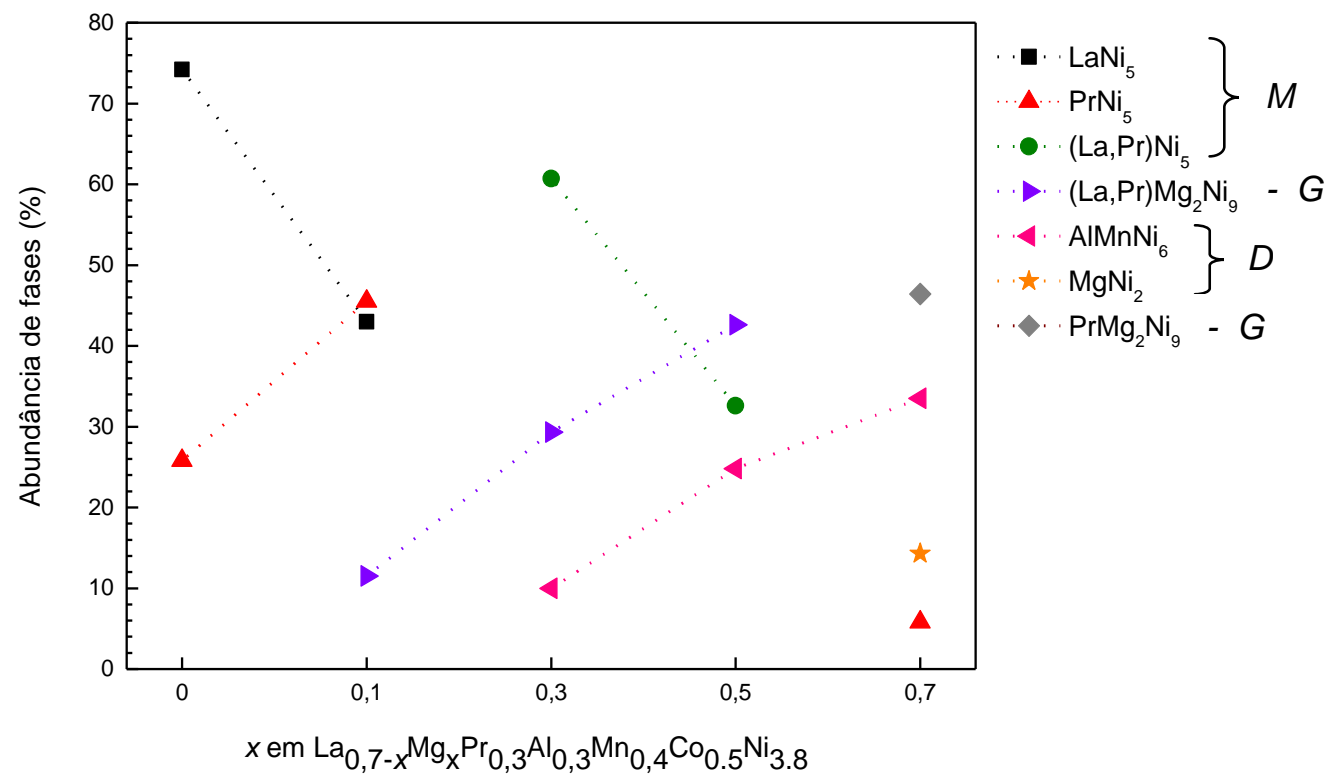

FIGURA 11 - Abundância de fases nas ligas da Série $\mathrm{Mg}$, $\mathrm{La}_{0,7-x} \mathrm{Mg}_{x} \mathrm{Pr}_{0,3} \mathrm{Al}_{0,3} \mathrm{Mn}_{0,4} \mathrm{Co}_{0,5} \mathrm{Ni}_{3,8}(x=0,0-0,7)$, onde $M=$ fase matriz; $G=$ fase cinza; $D=$ fase escura. 


\subsubsection{Série $\mathrm{Pr}$}

Os espectros de difração de raios $X$ das ligas $\mathrm{La}_{0,7-y} \mathrm{Pr}_{y} \mathrm{Mg}_{0,3} \mathrm{Al}_{0,3} \mathrm{Mn}_{0,4} \mathrm{Co}_{0,5} \mathrm{Ni}_{3,8} \quad(y=0,0,0,1,0,3,0,5,0,7)$ no estado bruto de fusão estão mostrados na FIG. 12.

A identificação das fases por difração de raios $X$ teve por base os resultados obtidos por MEV/EDS. As fases identificadas, os parâmetros de rede, os volumes das células unitárias e as abundâncias de fases obtidos pelo método de Rietveld estão listados na TAB. 17 e representados graficamente nas FIG. 13 e 14. Na FIG. 14 é também apresentada a correspondência com as fases matriz $(M)$, cinza $(G)$ e escura $(D)$, determinadas pelas análises por MEV/EDS para as ligas da Série Pr.

O deslocamento dos picos de difração para ângulos maiores para as ligas da Série $\operatorname{Pr}$ não foi tão pronunciado como o observado para as ligas da Série $\mathrm{Mg}$, devido a menor diferença entre os raios atômicos do La (raio atômico 2,74 Á) e do $\operatorname{Pr}$ (raio atômico 2,67 Á). Observou-se, portanto, menor contração dos volumes das células unitárias para as fases presentes nas ligas da Série Pr, em comparação à Série Mg.

Aparentemente, a presença constante de $\mathrm{Mg}$ em todas as composições das ligas da Série Pr contribuiu para as fases detectadas e suas abundâncias.

Observou-se que na liga sem $\operatorname{Pr}, \mathrm{La}_{0,7} \mathrm{Mg}_{0,3} \mathrm{Al}_{0,3} \mathrm{Mn}_{0,4} \mathrm{Co}_{0,5} \mathrm{Ni}_{3,8},(y=0,0)$, além da fase similar à fase $\mathrm{LaNi}_{5}$, foram identificadas as fases similares às fases $\mathrm{LaMg}_{2} \mathrm{Ni}_{9}, \mathrm{AlMnNi}_{6}$ e $\mathrm{AlMnNi}_{2}$. À exceção desta última, as demais foram detectadas nas ligas da Série $\mathrm{Mg}$ a partir da introdução de $\mathrm{Mg}$ nas ligas (vide TAB. 16, condições $x \geq 0,1)$.

Como é mostrado na TAB. 17 e na FIG. 14, a abundância da fase similar à fase $\mathrm{LaNi}_{5}$ na ausência de $\operatorname{Pr}$ foi de $78,1 \%$, decaindo mais suavemente nas condições de substituição de La por $\operatorname{Pr}$ seguintes $(y=0,1$ a $y=0,5)$, em comparação ao observado no estudo das ligas da Série Mg. As demais fases presentes na liga sem $\mathrm{Pr}$, similares às fases $\mathrm{LaMg}_{2} \mathrm{Ni}_{9}, \mathrm{AIMnNi}_{6}$ e $\mathrm{AIMnNi}_{2}$, apresentaram abundâncias de $11,1 \%, 5,7 \%$ e 5,1\%, respectivamente.

A fase ( $\mathrm{La}, \mathrm{Pr}) \mathrm{Mg}_{2} \mathrm{Ni}_{9}$ apresentou abundância crescente na condições subsequentes, atingindo $37 \%(y=0,5)$. Na condição de substituição total de La por $\operatorname{Pr}$, a fase similar à fase $\mathrm{PrMg}_{2} \mathrm{Ni}_{9}$ apresentou uma abundância de aproximadamente $33 \%$. 
A fase similar à fase $\mathrm{AlMnNi}_{2}$ foi detectada somente nas duas primeiras condições de substituição $(y=0,0$ e $y=0,1)$,ou seja, nas ligas com maiores teores de La.

Já a fase similar à fase $\mathrm{AlMnNi}_{6}$ esteve presente e em abundância crescente em todas as condições de substituição de La por $\operatorname{Pr}$, à exceção da liga $\mathrm{La}_{0,2} \mathrm{Pr}_{0,5} \mathrm{Mg}_{0,3} \mathrm{Al}_{0,3} \mathrm{Mn}_{0,4} \mathrm{Co}_{0,5} \mathrm{Ni}_{3,8}$ ( $\left.y=0,5\right)$. Considerando a relativa coerência nas identificações e abundâncias observadas para as demais fases, atribuiu-se essa ocorrência à condição de heterogeneidade das ligas analisadas.

A fase similar à fase $\mathrm{PrNi}_{5}$, presente na liga sem La $(y=0,7)$, $\mathrm{Pr}_{0,7} \mathrm{Mg}_{0,3} \mathrm{Al}_{0,3} \mathrm{Mn}_{0,4} \mathrm{Co}_{0,5} \mathrm{Ni}_{3,8}$, foi a mais abundante nesta condição (54,2\%), seguida das fases similares às fases $\mathrm{PrMg}_{2} \mathrm{Ni}_{9}$ (32,9\%) e $\mathrm{AlMnNi}_{6}$ (12,8\%). Verificou-se, ainda, a presença de uma fase majoritária em todas as ligas, ou seja, a fase similar à fase $\mathrm{LaNi}_{5}$, à exceção, obviamente, da liga $\mathrm{Pr}_{0,7} \mathrm{Mg}_{0,3} \mathrm{Al}_{0,3} \mathrm{Mn}_{0,4} \mathrm{Co}_{0,5} \mathrm{Ni}_{3,8}(y=0,7)$.

A identificação de fases presentes por meio das técnicas de DRX e MEV/EDS resultaram na seguinte associação: fase matriz $(M)$, correspondeu às fases similares às fases $\mathrm{LaNi}_{5}$ e $\mathrm{PrNi}_{5}$; fase cinza $(\mathrm{G})$, às fases similares às fases $\mathrm{LaMg}_{2} \mathrm{Ni}_{9}$ e $\mathrm{PrMg}_{2} \mathrm{Ni}_{9}$ e a fase esdura (D), às fases similares às fases $\mathrm{AlMnNi}_{6} \mathrm{e}$ $\mathrm{AlMnNi}_{2}$. 


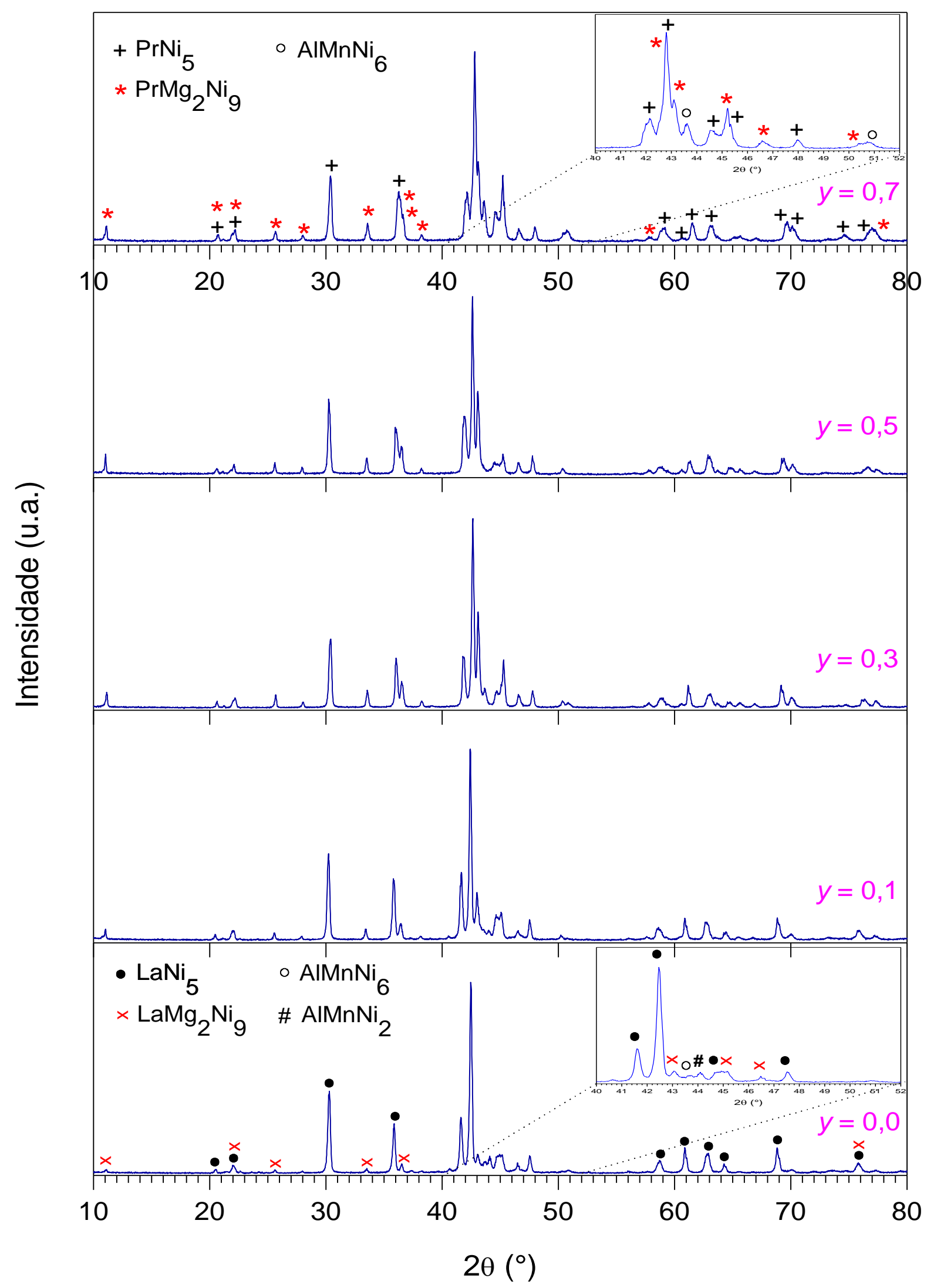

FIGURA 12 - Espectros de difração de raios $X$ das ligas da Série $\operatorname{Pr}$, $\mathrm{La}_{0,7-y} \mathrm{Pr}_{y} \mathrm{Mg}_{0,3} \mathrm{Al}_{0,3} \mathrm{Mn}_{0,4} \mathrm{Co}_{0,5} \mathrm{Ni}_{3,8}(y=0,0-0,7)$. 
TABELA 17 - Características das fases nas ligas da Série $\operatorname{Pr}, \operatorname{La}_{0,7-y} \operatorname{Pr}_{y} \mathrm{Mg}_{0,3} \mathrm{Al}_{0,3} \mathrm{Mn}_{0,4} \mathrm{Co}_{0,5} \mathrm{Ni}_{3,8}(y=0,0-0,7)$.

\begin{tabular}{|c|c|c|c|c|c|c|c|}
\hline \multirow[t]{2}{*}{ Liga } & \multirow[t]{2}{*}{ Fases } & \multirow[t]{2}{*}{ Grupo espacial } & \multirow{2}{*}{$\begin{array}{l}\text { Parâmetros de } \\
\text { ajuste (\%) }\end{array}$} & \multirow{2}{*}{$\begin{array}{l}\text { Abundância } \\
\text { de fase (\%) }\end{array}$} & \multicolumn{2}{|c|}{ Parâmetros de rede $(\AA \hat{)})$} & \multirow{2}{*}{$\begin{array}{c}\text { Volume da célula } \\
\qquad\left(\AA^{3}\right)\end{array}$} \\
\hline & & & & & $a$ & $c$ & \\
\hline \multirow[t]{4}{*}{$y=0,0$} & $\mathrm{LaNi}_{5}$ & $\mathrm{P} 6 / \mathrm{mmm}$ & $R_{\mathrm{p}}=0,1523$ & 78,1 & 5,024 & 4,048 & $88,5 \pm 0,5$ \\
\hline & $\mathrm{LaMg}_{2} \mathrm{Ni}_{9}$ & $\mathrm{R}-3 \mathrm{~m}$ & $R_{\mathrm{wp}}=0,2075, \chi^{2}=19,72$ & 11,1 & 4,942 & 24,131 & $511 \pm 1$ \\
\hline & $\mathrm{AIMnNi}_{6}$ & Pm3m & & 5,7 & 3,594 & 3,594 & $46,4 \pm 0,5$ \\
\hline & $\mathrm{AIMnNi}_{2}$ & Pm3m & & 5,1 & 5,811 & 5,811 & $196 \pm 1$ \\
\hline \multirow[t]{4}{*}{$y=0,1$} & $\mathrm{LaNi}_{5}$ & $\mathrm{P} 6 / \mathrm{mmm}$ & $R_{\mathrm{p}}=0,1854$ & 71,6 & 5,011 & 4,047 & $88,0 \pm 0,5$ \\
\hline & $(\mathrm{La}, \mathrm{Pr}) \mathrm{Mg}_{2} \mathrm{Ni}_{9}$ & $\mathrm{R}-3 \mathrm{~m}$ & $R_{\mathrm{wp}}=0,1088, \chi^{2}=25,66$ & 20,8 & 4,936 & 24,128 & $509 \pm 1$ \\
\hline & $\mathrm{AlMnNi}_{6}$ & Pm3m & & 5,6 & 3,599 & 3,599 & $46,6 \pm 0,5$ \\
\hline & $\mathrm{AIMnNi}_{2}$ & Pm3m & & 2,0 & 5,825 & 5,825 & $198 \pm 1$ \\
\hline \multirow[t]{3}{*}{$y=0,3$} & $(\mathrm{La}, \mathrm{Pr}) \mathrm{Ni}_{5}$ & $\mathrm{P} 6 / \mathrm{mmm}$ & $R_{\mathrm{p}}=0,2660$ & 60,7 & 4,996 & 4,051 & $87,6 \pm 0,5$ \\
\hline & $(\mathrm{La}, \mathrm{Pr}) \mathrm{Mg}_{2} \mathrm{Ni}_{9}$ & $\mathrm{R}-3 \mathrm{~m}$ & $R_{\mathrm{wp}}=0,4664, \chi^{2}=2,757$ & 29,3 & 4,936 & 24,104 & $509 \pm 1$ \\
\hline & $\mathrm{AlMnNi}_{6}$ & Pm3m & & 10,0 & 3,603 & 3,603 & $46,8 \pm 0,5$ \\
\hline \multirow[t]{2}{*}{$y=0,5$} & $(\mathrm{La}, \mathrm{Pr}) \mathrm{Ni}_{5}$ & $\mathrm{P} 6 / \mathrm{mmm}$ & $R_{\mathrm{p}}=0,1392$ & 63,0 & 4,983 & 4,065 & $87,4 \pm 0,5$ \\
\hline & $(\mathrm{La}, \mathrm{Pr}) \mathrm{Mg}_{2} \mathrm{Ni}_{9}$ & $\mathrm{R}-3 \mathrm{~m}$ & $R_{\mathrm{wp}}=0,1904, \chi^{2}=18,79$ & 37,0 & 4,927 & 24,059 & $506 \pm 1$ \\
\hline \multirow[t]{3}{*}{$y=0,7$} & $\mathrm{PrNi}_{5}$ & $\mathrm{P} 6 / \mathrm{mmm}$ & $R_{\mathrm{p}}=0,1644$ & 54,2 & 4,964 & 4,058 & $86,6 \pm 0,5$ \\
\hline & $\mathrm{PrMg}_{2} \mathrm{Ni}_{9}$ & $\mathrm{R}-3 \mathrm{~m}$ & $R_{\mathrm{wp}}=0,2271, \chi^{2}=7,617$ & 33,0 & 4,938 & 24,036 & $507 \pm 1$ \\
\hline & $\mathrm{AIMnNi}_{6}$ & Pm3m & & 12,8 & 3,601 & 3,601 & $46,7 \pm 0,5$ \\
\hline
\end{tabular}

${ }^{\text {a }} R_{\mathrm{p}}=$ fator padrão, $R_{\mathrm{wp}}=$ fator padrão ponderado, $\chi^{2}=$ índice de qualidade do refinamento. 


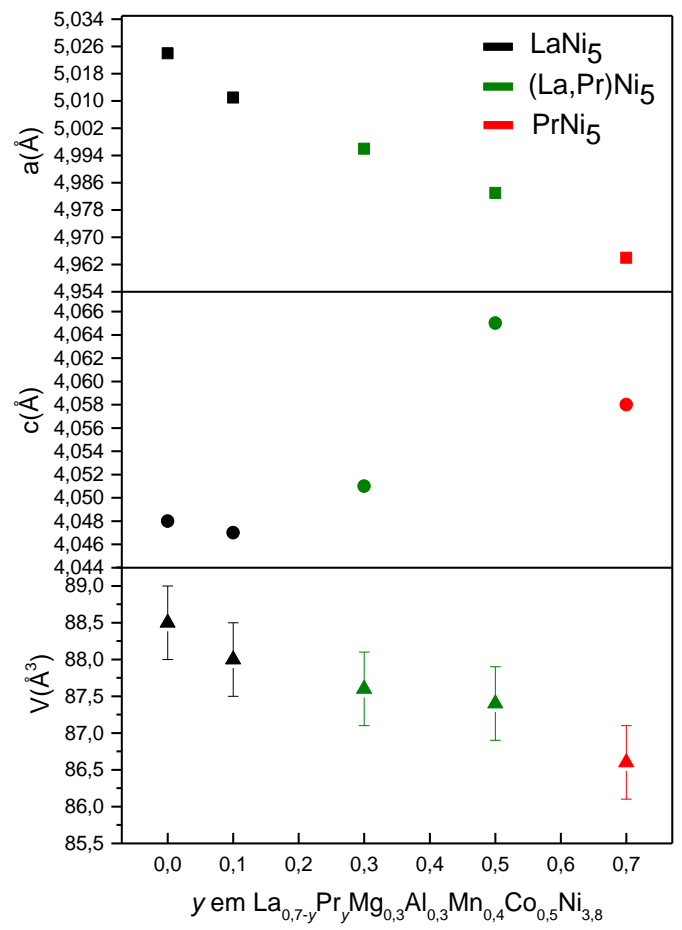

(a)

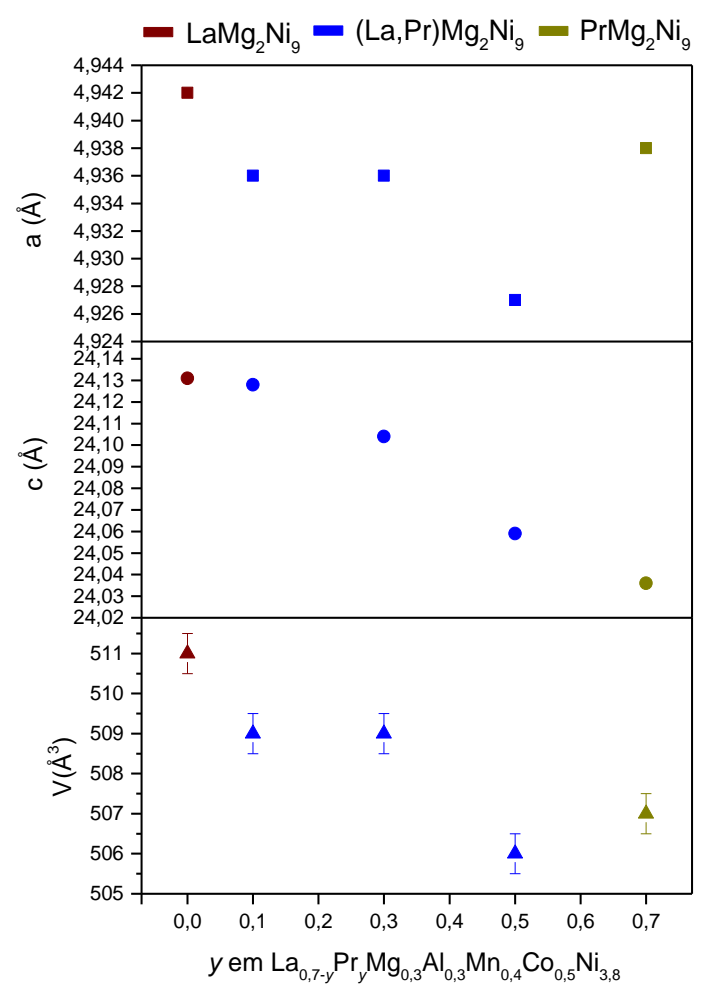

(b)

FIGURA 13 - Parâmetros de rede e volumes de célula unitária das ligas da Série Pr, $\mathrm{La}_{0,7-y} \mathrm{Pr}_{y} \mathrm{Mg}_{0,3} \mathrm{Al}_{0,3} \mathrm{Mn}_{0,4} \mathrm{Co}_{0,5} \mathrm{Ni}_{3,8} \quad(y=0,0-0,7)$ : (a) fases $\mathrm{LaNi}_{5}, \mathrm{PrNi}_{5}$ e (La,Pr)Ni $\mathrm{Ni}_{5}$ (b) fases LaMg ${ }_{2} \mathrm{Ni}_{9},(\mathrm{La}, \mathrm{Pr}) \mathrm{Mg}_{2} \mathrm{Ni}$ e $\mathrm{PrMg}_{2} \mathrm{Ni}_{9}$.

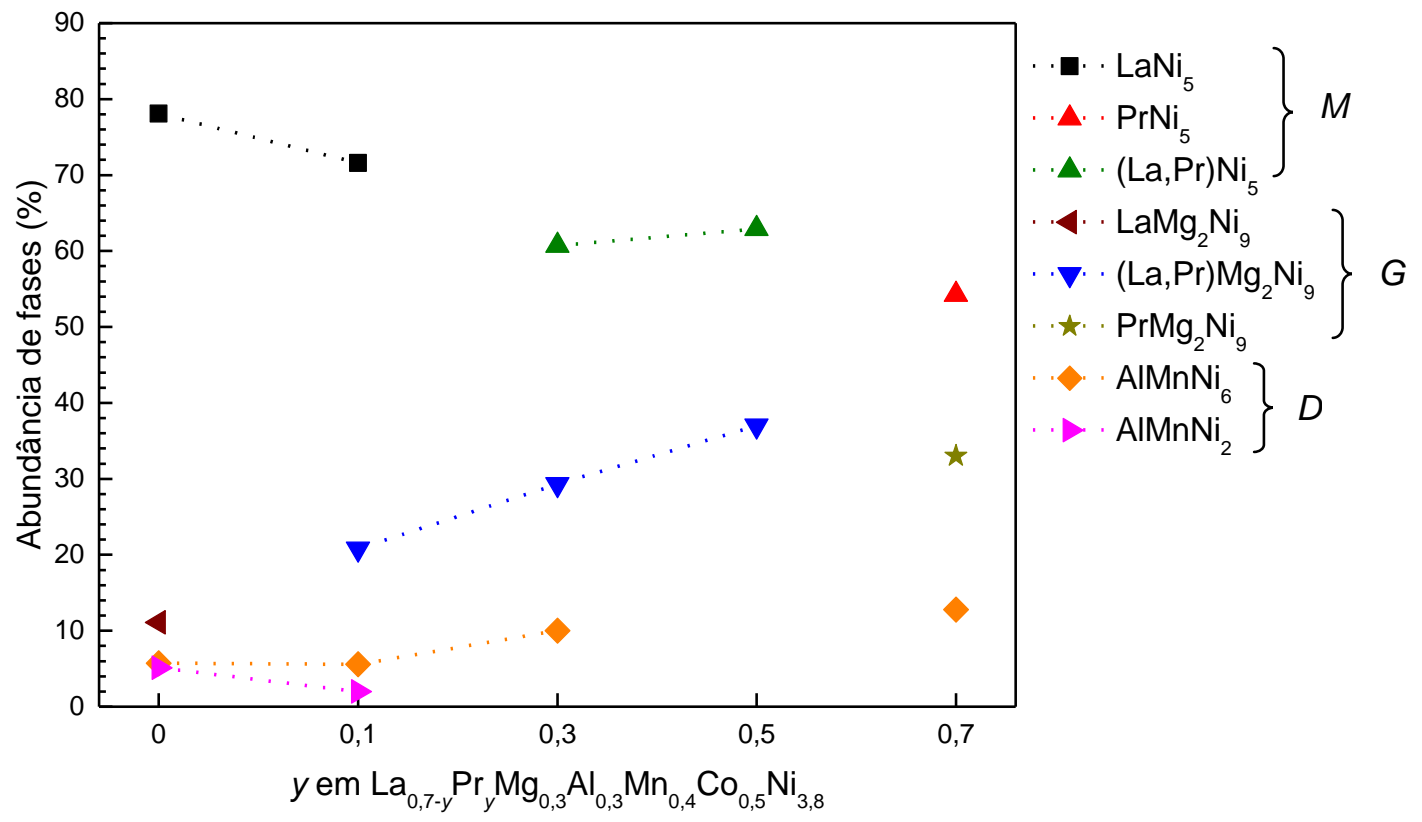

FIGURA 14 - Abundância de fases nas ligas da Série $\mathrm{Pr}$, $\mathrm{La}_{0,7-y} \mathrm{Pr}_{y} \mathrm{Mg}_{0,3} \mathrm{Al}_{0,3} \mathrm{Mn}_{0,4} \mathrm{Co}_{0,5} \mathrm{Ni}_{3,8}(y=0,0-0,7)$, onde $M=$ fase matriz; $G=$ fase cinza; $D=$ fase escura. 


\subsubsection{Resistência à corrosão}

\subsubsection{Série Mg}

Na FIG. 15 é mostrada a curva de polarização potenciodinâmica anódica para as ligas $\mathrm{La}_{0,7-x} \mathrm{Mg}_{x} \mathrm{Pr}_{0,3} \mathrm{Al}_{0,3} \mathrm{Mn}_{0,4} \mathrm{Co}_{0,5} \mathrm{Ni}_{3,8}(x=0,0,0,1,0,3,0,5,0,7)$. No potencial de corrosão, a maioria das ligas apresentou valores de densidade de corrente de corrosão muito baixos, da ordem de $10^{-5} \mathrm{~A} \mathrm{~cm}^{-2}$ a $10^{-6} \mathrm{~A} \mathrm{~cm}^{-2}$, típicos de materiais passivos. Os menores valores de densidade de corrente foram observados nas ligas com maior substituição de La por Mg, com destaque à liga sem La $(x=0,7)$, à qual estaria associado o filme passivo com maior resistência à corrosão. Para a liga sem $\operatorname{Mg}(x=0,0)$, a densidade de corrente aumentou substancialmente com o sobrepotencial, demonstrando que o filme passivo nesta liga apresentou a resistência à corrosão mais baixa em comparação às demais.

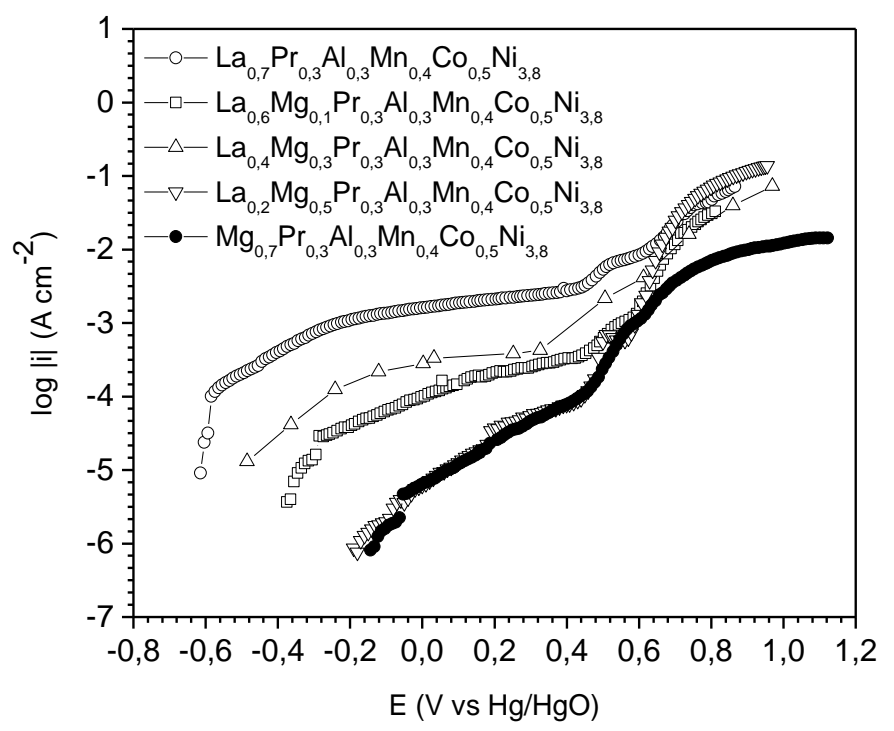

FIGURA 15 - Curvas de polarização anódica das ligas da Série Mg, $\mathrm{La}_{0,7-x} \mathrm{Mg}_{x} \mathrm{Pr}_{0,3} \mathrm{Al}_{0,3} \mathrm{Mn}_{0,4} \mathrm{Co}_{0,5} \mathrm{Ni}_{3,8} \quad(x=0,0-0,7)$ em solução $\mathrm{KOH}$ $6,0 \mathrm{~mol} \mathrm{~L}^{-1}$.

Os filmes passivos nas ligas de condições $x=0,1$ e $x=0,3$ mostraram resistências intermediárias entre os extremos da substituição de La por Mg. Os resultados indicaram que o comportamento das ligas frente à corrosão foi altamente dependente de suas microestruturas. Como mencionado no item 5.1.2.1, a substituição crescente de La por Mg conduziu a uma modificação na 
estrutura de grão, de uma condição equiaxial mais grosseira (condição $x=0,0$ ) para uma próxima à colunar, mais refinada (condição $x=0,7$ ). Essa mudança na estrutura traduziu-se num efeito benéfico à resistência à corrosão das ligas. Por outro lado, à maior abundância das fases similares às de referência $\mathrm{LaNi}_{5}$ e $\mathrm{PrNi}_{5}$, além da fase ( $\mathrm{La}, \mathrm{Pr}) \mathrm{Ni}_{5}$, foi associada resultados menos favoráveis à resistência à corrosão (ligas nas condições $x=0,0, x=0,1$ e $x=0,3$ ). A abundância crescente das fases similares à fase $\mathrm{RMg}_{2} \mathrm{Ni}_{9}\left(\mathrm{R}=\mathrm{La}\right.$ e ou $\mathrm{Pr}$ ) e à fase $\mathrm{AlMnNi}_{6}$ esteve, por sua vez, vinculada aos melhores resultados obtidos.

Ainda com o auxílio da FIG. 15, verificou-se o efeito marcante da composição das ligas e, consequentemente, da microestrutura apresentada, ao observar-se o comportamento das curvas de polarização para potenciais acima de $0,7 \mathrm{~V}$. Nas proximidades deste potencial, esteve associado um aumento na densidade de corrente para todas as ligas. Nos potenciais próximos a 0,8 V, verificou-se um comportamento similar às ligas com concentração de $\mathrm{Mg}$ crescente $(x=0,0$ a $x=0,5)$. Por outro lado, a liga com total substituição de La por Mg apresentou, não somente nas proximidades do potencial em questão, mas sim, em toda a faixa de potencial considerada, os menores valores de densidade de corrente em relação às outras ligas.

Os diagramas de Nyquist e de ângulo de fase de Bode para as ligas $\mathrm{La}_{0,7-x} \mathrm{Mg}_{x} \mathrm{Pr}_{0,3} \mathrm{Al}_{0,3} \mathrm{Mn}_{0,4} \mathrm{Co}_{0,5} \mathrm{Ni}_{3,8} \quad(x=0,0,0,1,0,3,0,5,0,7)$ são mostrados nas FIG. 16 e 17, respectivamente.

Os resultados de espectroscopia de impedância eletroquímica mostrados na FIG.16 revelaram elevadas impedâncias associadas às ligas com maior $\mathrm{Mg}$ contido $(x=0,5$ e $x=0,7)$, indicando um comportamento passivo para essas ligas. As impedâncias mais baixas foram associadas à liga sem $\mathrm{Mg}$, sustentando os resultados apresentados de polarização, quanto à mais baixa resistência à corrosão apresentada por esta liga.

Pelo diagrama de ângulo de fase de Bode mostrado na FIG. 17 verificou-se duas constantes de tempo para todas as ligas estudadas, com ângulos de fase mais baixos relacionados às ligas sem $\mathrm{Mg}$ ou com menor teor de Mg contido ( $x=0,1$ e $x=0,3)$. Para as ligas com maior teor de $\operatorname{Mg}(x=0,5$ ou $x=0,7)$, a constante de tempo a altas frequências foi observada a aproximadamente $1 \mathrm{kHz}$, enquanto que para as demais ligas esta constante ocorreu próxima a $0,1 \mathrm{kHz}$. 


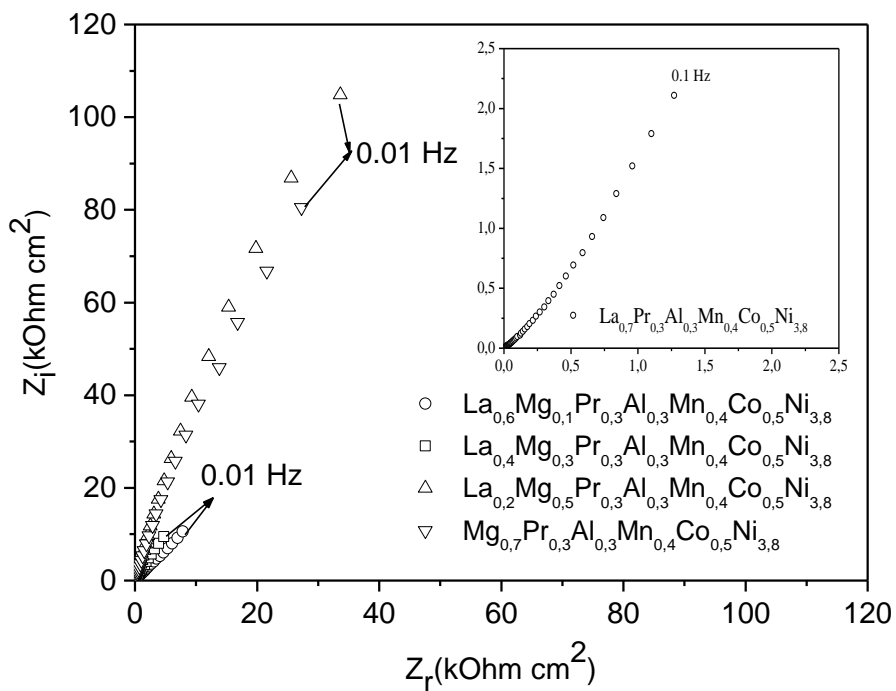

FIGURA 16 - Diagramas de Nyquist das ligas da Série Mg, $\mathrm{La}_{0,7-x} \mathrm{Mg}_{x} \mathrm{Pr}_{0,3} \mathrm{Al}_{0,3} \mathrm{Mn}_{0,4} \mathrm{Co}_{0,5} \mathrm{Ni}_{3,8} \quad(x=0,0-0,7)$ testadas em solução $\mathrm{KOH} 6,0 \mathrm{~mol} \mathrm{~L}^{-1}$.

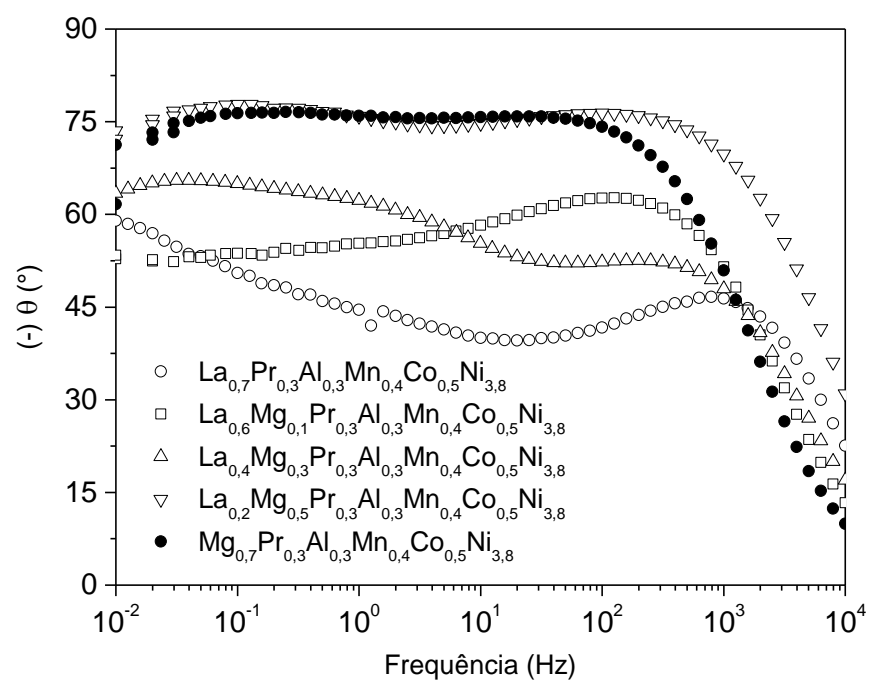

FIGURA 17 - Diagramas de ângulo de fase de Bode das ligas da Série Mg, $\mathrm{La}_{0,7-x} \mathrm{Mg}_{x} \mathrm{Pr}_{0,3} \mathrm{Al}_{0,3} \mathrm{Mn}_{0,4} \mathrm{Co}_{0,5} \mathrm{Ni}_{3,8}(x=0,0-0,7)$ testadas em solução $\mathrm{KOH} 6,0 \mathrm{~mol} \mathrm{~L}^{-1}$. 
A segunda constante de tempo para todas as ligas foi observada aproximadamente na mesma frequência, $0,1 \mathrm{~Hz}$. Constantes de tempo a frequências mais elevadas estão relacionadas à formação de filmes superficiais de óxido/hidróxido, enquanto que aquelas a frequências mais baixas são associadas a processos de transferência de carga. Portanto, os resultados indicaram que as ligas com teor de $\mathrm{Mg}$ elevado apresentaram maior formação de filmes superficiais de proteção. Devido ao baixo potencial de redução associado ao magnésio em meio alcalino $\left(E^{0}=-2,687\right.$ V) (Bard e Faulkner, 2001), filmes passivos de $\mathrm{Mg}(\mathrm{OH})_{2}$ são razoavelmente estáveis, corroborando a presença dos mesmos na superfície das ligas.

O comportamento passivo apresentado pelas ligas da Série Mg indicou que, isoladamente, a resistência à corrosão não constituiria uma propriedade proibitiva à avaliação das características eletroquímicas dos eletrodos dessas ligas.

\subsubsection{Série $\mathrm{Pr}$}

Os estudos eletroquímicos realizados nas ligas da Série $\mathrm{Pr}$, $\mathrm{La}_{0,7-y} \mathrm{Pr}_{y} \mathrm{Mg}_{0,3} \mathrm{Al}_{0,3} \mathrm{Mn}_{0,4} \mathrm{Co}_{0,5} \mathrm{Ni}_{3,8}$ ( $\left.y=0,0,0,1,0,3,0,5,0,7\right)$, constataram, segundo estudo publicado, a influência da microestrutura na resistência à corrosão das ligas (Banczek et al., 2009). Como descrito no artigo em referência, em geral, as ligas apresentaram comportamento típico de materiais passivos. Em termos estruturais, como apresentado no item 5.1.2.2, observou-se um padrão dendrítico em todas as ligas da Série $\operatorname{Pr}$, com destaque às condições de substituição $y=0,5$ e $y=0,7$, com maior refinamento. Ainda, de acordo com o comportamento de polarização obtido, as ligas associadas aos melhores resultados de resistência à corrosão foram aquelas das condições $y=0,0, y=0,5$ e $y=0,7$, como mostrado nas curvas de polarização reproduzidas na FIG. 2, constante do item 3.3.2. Como mencionado no artigo, tal comportamento associou-se, aparentemente, a maior cobertura da superfície dessas ligas por bolhas de hidrogênio que foram observadas após a imersão das ligas em $\mathrm{KOH} 6,0 \mathrm{~mol} \mathrm{~L}^{-1}$. A presença de determinadas fases nessas ligas, com elevado sobrepotencial para a reação de evolução de hidrogênio, pode ter contribuído para o comportamento observado. Estruturalmente, na condição $\mathrm{y}=0,0$ contou-se, diferentemente do verificado na condição $x=0,0$ da Série $\mathrm{Mg}$, com a presença das fases $\mathrm{LaMg}_{2} \mathrm{Ni}_{9}$ e $\mathrm{AlMnNi}_{6}$, 
associadas à condições com melhores resultados de resistência à corrosão. Essa constatação pode auxiliar na interpretação para o comportamento observado para a resistência à corrosão das ligas da Série Pr. A despeito das ligas nas condições de substituição do La por $\operatorname{Pr}$ em $y=0,1$ e $y=0,3$, que apresentaram densidades de corrosão mais altas, os resultados sugerem um comportamento passivo satisfatório. Como considerado para as ligas da Série Mg, a resistência à corrosão não seria uma propriedade limitante à avaliação dos eletrodos das ligas da Série Pr nos estudos eletroquímicos segundo o meio eletrolítico adotado (solução $\left.\mathrm{KOH} 6,0 \mathrm{~mol} \mathrm{~L}^{-1}\right)$.

\subsection{Propriedades eletroquímicas das ligas}

\subsubsection{Efeito do teor de $\mathrm{Mg}$}

Na FIG. 18 são apresentados os perfis de ativação dos eletrodos das ligas da Série Mg, $\mathrm{La}_{0,7-x} \mathrm{Mg}_{x} \mathrm{Pr}_{0,3} \mathrm{Al}_{0,3} \mathrm{Mn}_{0,4} \mathrm{Co}_{0,5} \mathrm{Ni}_{3,8}(x=0,0,0,1,0,3,0,5,0,7)$ sem tratamento térmico.

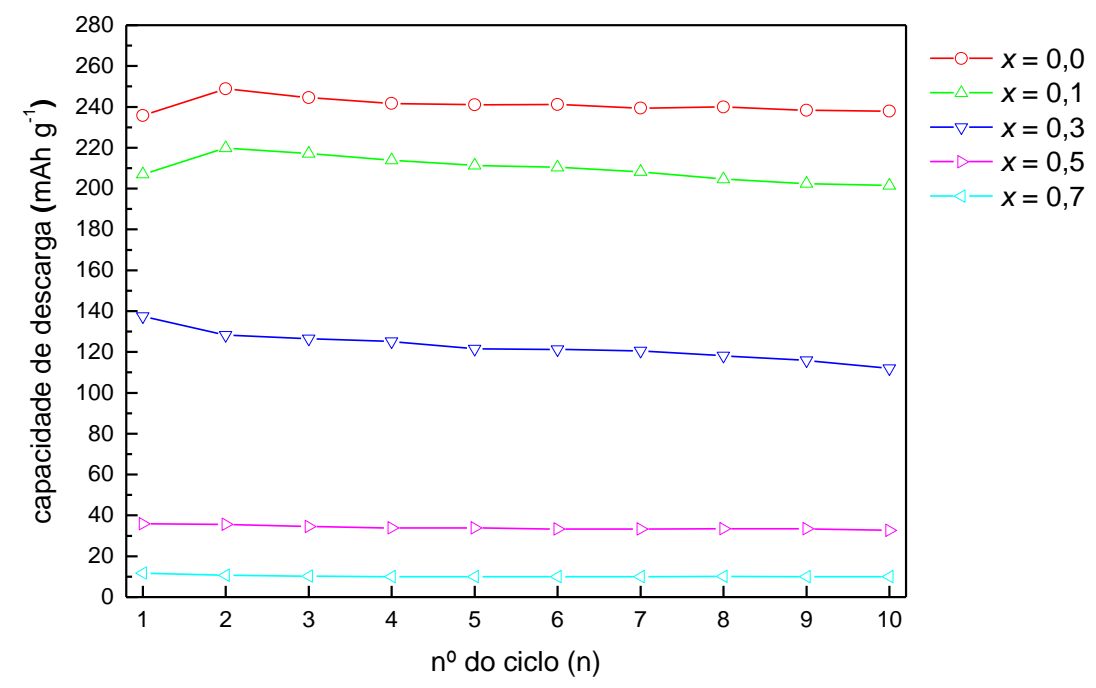

FIGURA 18 - Perfis de ativação dos eletrodos das ligas da Série Mg, $\mathrm{La}_{0,7-x} \mathrm{Mg}_{x} \mathrm{Pr}_{0,3} \mathrm{Al}_{0,3} \mathrm{Mn}_{0,4} \mathrm{Co}_{0,5} \mathrm{Ni}_{3,8} \quad(x=0,0-0,7)$ sem tratamento térmico. 
Com o auxílio da figura em referência, verificou-se que os eletrodos foram facilmente ativados para suas capacidades de descarga máxima $\left(C_{\text {máx }}\right)$ em dois ciclos, $N_{\mathrm{a}}=2$, (condições $x=0,0$ e $x=0,1$ ) e um ciclo, $N_{\mathrm{a}}=1$, (condições $x=0,3$, $x=0,5$ e $x=0,7)$. A capacidade de descarga máxima de maior valor foi obtida para a liga sem $\mathrm{Mg}$, ou seja, 248,8 $\mathrm{mAh}^{-1}$ na condição $x=0,0$. Com a introdução de $\mathrm{Mg}$ na liga $(x=0,1)$, foi obtido o valor de 219,8 $\mathrm{mAh} \mathrm{g}^{-1}$, que corresponde a um decréscimo de 11,66\% em relação à capacidade de descarga máxima da liga sem Mg. A continuidade da adição de Mg conduziu à deterioração da capacidade de descarga, verificando-se o valor máximo de $11,8 \mathrm{mAh} \mathrm{g}^{-1}$ para a condição de substituição total de $\mathrm{La}$ por $\mathrm{Mg}(x=0,7)$. Em análise conjunta à microestrutura, verificou-se que a queda na capacidade de descarga dos eletrodos acompanhou a modificação na estrutura de grão - próxima à equiaxial (mais grosseira) para um aspecto colunar (mais refinada) - observado pela adição de $\mathrm{Mg}$ nas ligas (vide FIG. 5). Ainda do ponto de vista estrutural (vide TAB. 16 e FIG. 11), à adição crescente de Mg esteve associado o aumento na abundância das fases similares às fases ( $\mathrm{La}, \mathrm{Pr}$ ) $\mathrm{Mg}_{2} \mathrm{Ni}_{9}, \mathrm{AlMnNi}_{6}$ e $\mathrm{MgNi}_{2}$, concomitantemente ao decréscimo na abundância das fases similares às fases $\mathrm{LaNi}_{5}$ e $\mathrm{PrNi}_{5}$. A diminuição da capacidade de descarga observada nas ligas com maior abundância das fases similares às fases ( $\mathrm{La}, \mathrm{Pr}) \mathrm{Mg}_{2} \mathrm{Ni}_{9}$ e $\mathrm{MgNi}_{2}$ está em acordo com o reportado na literatura (Kadir et al., 2000). No referido estudo, a capacidade de armazenamento de hidrogênio $(\mathrm{H} / \mathrm{M})$ determinada para a liga $\mathrm{LaMg}_{2} \mathrm{Ni}_{9}$ é baixa $(\sim 0,33 \%$ em massa), valor similar à capacidade correspondente à liga $\mathrm{MgNi}_{2}$, com tal proximidade sendo explicada com base nas investigações estruturais realizadas. Adicionalmente, no estudo do sistema $\mathrm{La}_{x} \mathrm{Mg}_{3-x} \mathrm{Ni}_{9}(x=1,0-2,0)$ realizado por Liao et al. (2003), foram associados à liga $\mathrm{LaMg}_{2} \mathrm{Ni}_{9}$ os piores resultados em termos de propriedades eletroquímicas em relação às demais ligas de armazenamento de hidrogênio investigadas. No presente estudo, nas três primeiras condições de substituição de La por $\operatorname{Mg}(x=0,0, x=0,1$ e $x=0,3)$, contou-se com maior abundância das fases similares às fases $\mathrm{LaNi}_{5}, \mathrm{PrNi}_{5}$ e (La,Pr) $\mathrm{Ni}_{5}$, sendo pertinente mencionar que a capacidade de armazenamento de hidrogênio $(H / M)$ para o composto $\mathrm{LaNi}_{5} \mathrm{H}_{6}$ é de 1,4\% em massa (Willems, 1984).

$\mathrm{Na}$ FIG. 19 está representada a relação entre a capacidade de descarga máxima $\left(\mathrm{C}_{\text {máx }}\right)$ obtida para os eletrodos das ligas da Série $\mathrm{Mg}$, $\mathrm{La}_{0.7-x} \mathrm{Mg}_{x} \mathrm{Pr}_{0,3} \mathrm{Al}_{0,3} \mathrm{Mn}_{0,4} \mathrm{Co}_{0,5} \mathrm{Ni}_{3,8}$ ( $\left.x=0,0-0,7\right)$, em função da abundância das fases 
$\mathrm{LaNi}_{5}, \mathrm{PrNi}_{5}$ e (La,Pr) $\mathrm{Ni}_{5}$ em cada condição considerada. Evidenciou-se que os maiores valores de capacidade de descarga máxima estiveram associados às condições em que a abundância das fases $\mathrm{LaNi}_{5}, \mathrm{PrNi}_{5}$ e (La,Pr) $\mathrm{Ni}_{5}$ mostraram-se majoritárias.

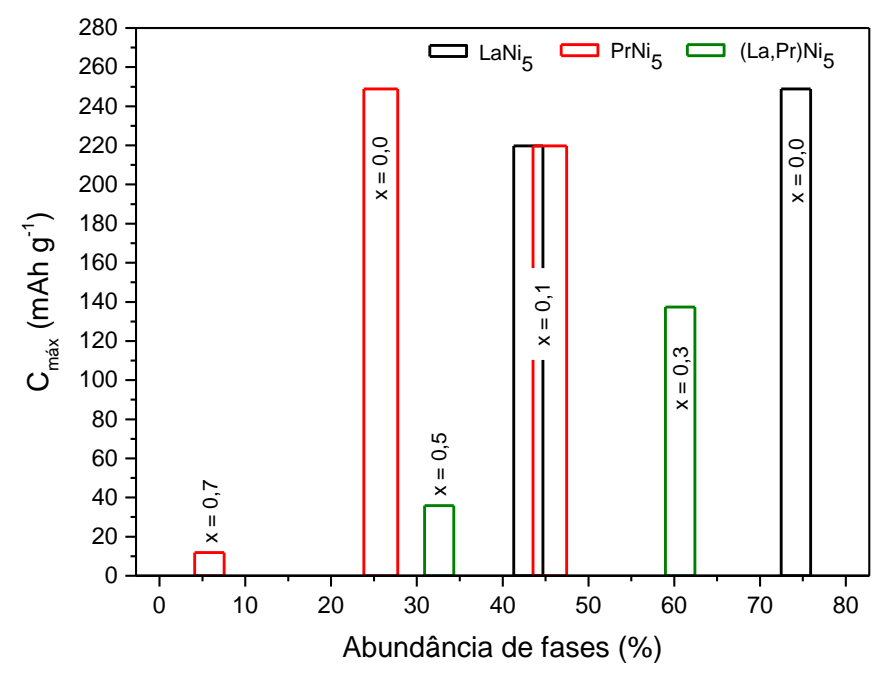

FIGURA 19 - Capacidade de descarga máxima $\left(C_{\text {máx }}\right)$ em função das abundâncias relativas de fases $\mathrm{LaNi}_{5}, \mathrm{PrNi}_{5}$ e (La,Pr) $\mathrm{Ni}_{5}$ para a Série $\mathrm{Mg}$, $\mathrm{La}_{0,7-x} \mathrm{Mg}_{x} \mathrm{Pr}_{0,3} \mathrm{Al}_{0,3} \mathrm{Mn}_{0,4} \mathrm{Co}_{0,5} \mathrm{Ni}_{3,8}(x=0,0-0,7)$.

Na FIG. 20 (a) são apresentadas as curvas de capacidade de descarga versus número do ciclo de carga/descarga para os eletrodos; na FIG. 20 (b) está representada a retenção da capacidade de descarga $\left(S_{n}\right)$ em função do ciclo considerado $\left(10^{\circ}, 20^{\circ}, 30^{\circ}, 40^{\circ}\right.$ e $\left.50^{\circ}\right)$, em relação à capacidade de descarga máxima das condições $x=0,0, x=0,1$ e $x=0,3$.

$\mathrm{Na}$ TAB. 18 estão reunidas, por sua vez, as propriedades eletroquímicas dos eletrodos das ligas da Série $\mathrm{Mg}$, $\mathrm{La}_{0.7-x} \mathrm{Mg}_{x} \mathrm{Pr}_{0,3} \mathrm{Al}_{0,3} \mathrm{Mn}_{0,4} \mathrm{Co}_{0,5} \mathrm{Ni}_{3,8}(x=0,0-0,7)$ sem tratamento térmico. 


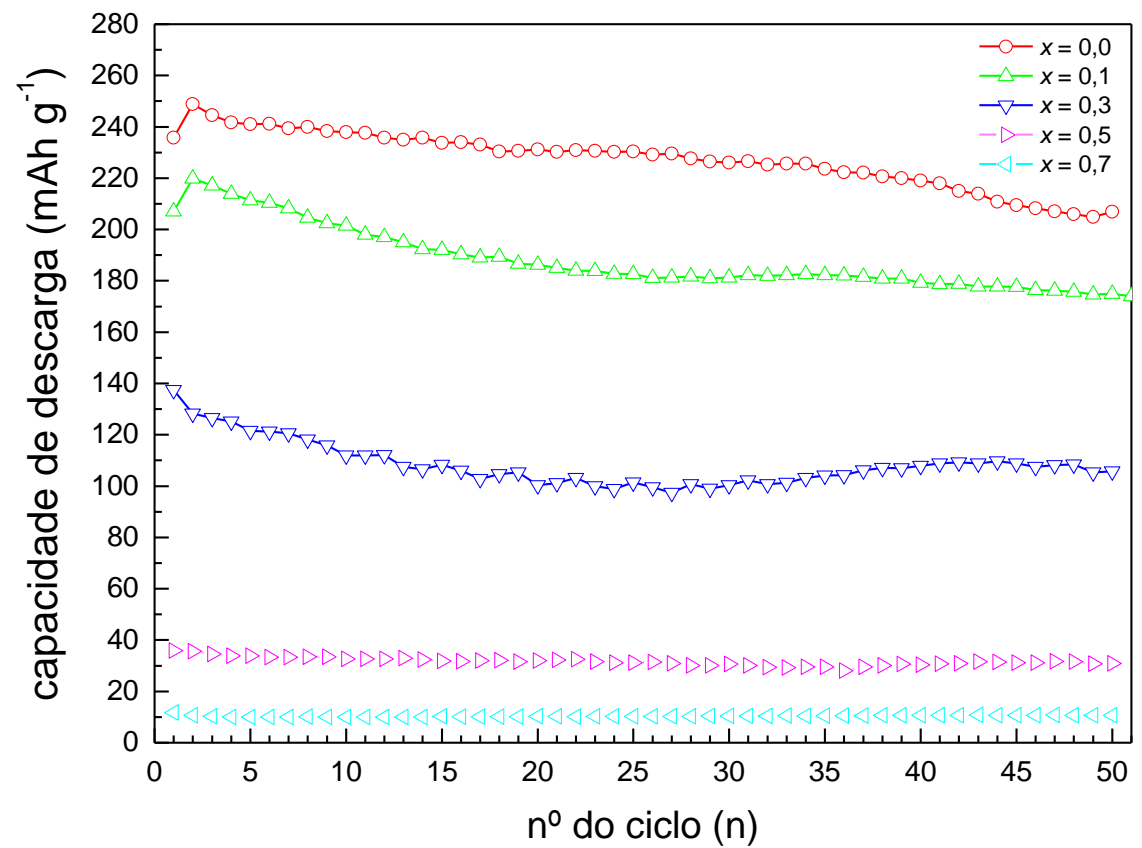

(a)

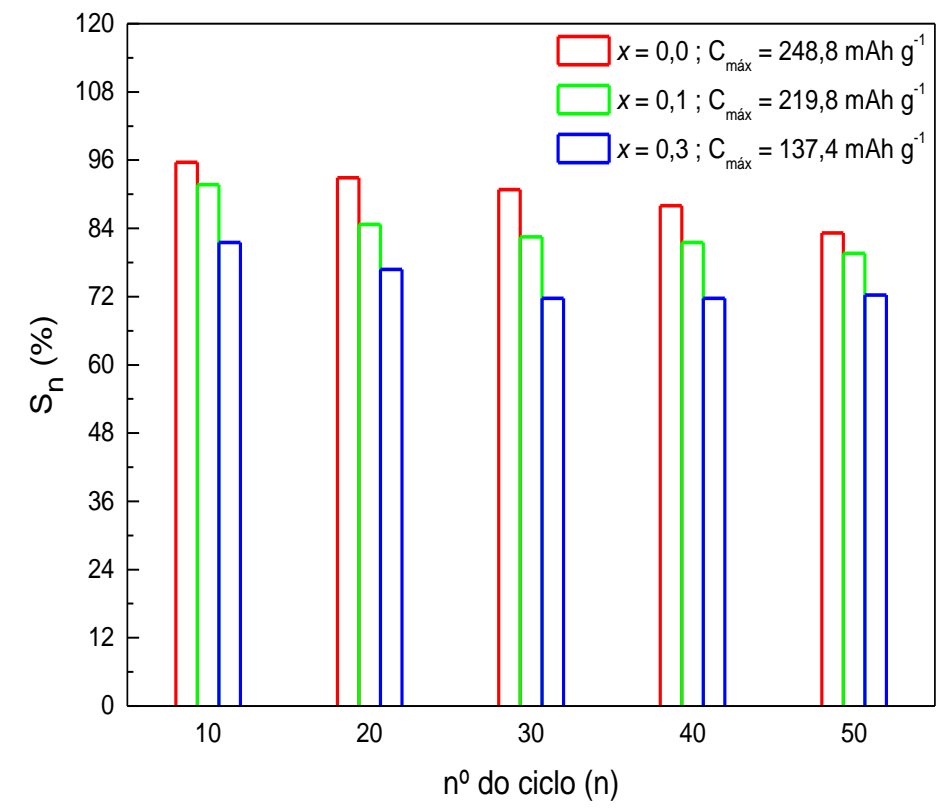

(b)

FIGURA 20 - (a) Capacidade de descarga das ligas da Série Mg, $\mathrm{La}_{0,7-x} \mathrm{Mg}_{x} \mathrm{Pr}_{0,3} \mathrm{Al}_{0,3} \mathrm{Mn}_{0,4} \mathrm{Co}_{0,5} \mathrm{Ni}_{3,8} \quad(x=0,0-0,7) \quad$ sem tratamento térmico vs. número do ciclo; (b) Retenção da capacidade de descarga das ligas da Série Mg sem tratamento térmico para $x=0,0 ; x=0,1$ e $x=0,3$. 
TABELA 18 - Propriedades eletroquímicas dos eletrodos das ligas da Série Mg, $\mathrm{La}_{0,7-x} \mathrm{Mg}_{x} \mathrm{Pr}_{0,3} \mathrm{Al}_{0,3} \mathrm{Mn}_{0,4} \mathrm{Co}_{0,5} \mathrm{Ni}_{3,8}$, sem tratamento térmico.

\begin{tabular}{cccccc}
\hline$x$ & $\mathrm{C}_{\text {máx }}\left(\mathrm{mAh} \mathrm{g}^{-1}\right)$ & $N_{\mathrm{a}}{ }^{a}$ & $\mathrm{~S}_{50}(\%)$ & $n_{\mathrm{H}}{ }^{\mathrm{b}}$ & $\mathrm{V}_{\text {met }}{ }^{\mathrm{c}}(\mathrm{V})$ \\
\hline 0,0 & 248,8 & 2 & 83,2 & 3,92 & 0,883 \\
0,1 & 219,8 & 2 & 79,6 & 3,37 & 0,867 \\
0,3 & 137,4 & 1 & 72,3 & 1,99 & 0,826 \\
0,5 & 35,9 & 1 & 86,1 & 0,49 & 0,776 \\
0,7 & 11,8 & 1 & 90,7 & 0,15 & 0,770 \\
\hline
\end{tabular}

${ }^{a}$ Número de ciclos necessários para ativar os eletrodos.

${ }^{\mathrm{b}}$ Número de átomos de hidrogênio por célula unitária.

cPotencial de descarga na metade da capacidade de descarga máxima.

$\mathrm{Na}$ refererida tabela constam os valores da retenção da capacidade de descarga $\left(\mathrm{S}_{50}\right)$ considerando $50^{\circ}$ ciclo de carga/descarga para todas as condições de substituição de La por Mg consideradas neste estudo. As curvas mostradas na FIG. 20 (a) evidenciaram que a liga sem Mg apresentou uma capacidade de descarga maior em relação às demais condições ao longo dos 50 ciclos de carga/descarga realizados. Com o auxílio da FIG. 20 (b) e TAB. 18, observou-se que o eletrodo da liga sem $\mathrm{Mg}$ exibiu a maior retenção da capacidade ao longo dos ciclos, traduzindo-se em uma maior estabilidade cíclica relativa $\left(S_{50}=83,2 \%\right)$, seguida da condição $x=0,1\left(S_{50}=79,6 \%\right)$. Uma queda brusca na capacidade de descarga e uma diminuição na retenção da capacidade foram observadas para a condição $x=0,3\left(S_{50}=72,3 \%\right)$. As condições $x=0,5$ e $x=0,7$ mostraram-se mais drásticas, com valores de capacidade de descarga extremamente reduzidos ao longo de toda a ciclagem realizada (vide FIG. 20 (a)). Ainda, na TAB. 18, estão listados os valores de hidrogênio contido no eletrodo carregado de cada liga considerada, expressos em número de átomos de hidrogênio, $n_{\mathrm{H}}$, por célula unitária, calculados via equação de Faraday (Reilly et al., 1999),

$$
n_{H}=e^{-}=\frac{3600}{9,65 \times 10^{7}}(M M)\left(C_{\text {máx }}\right)
$$


onde MM é a massa molar da liga em $\mathrm{g} \mathrm{mol}^{-1} \mathrm{e} \mathrm{C}_{\text {máx }}$ está expresso em mAh $\mathrm{g}^{-1}$. Verificou-se que o eletrodo da liga sem adição de $M g(x=0,0)$ exibiu o maior número de átomos de hidrogênio por célula unitária $(n=3,92)$, em correspondência ao maior valor de capacidade de descarga máxima obtido $\left(248,8 \mathrm{mAh} \mathrm{g}^{-1}\right)$. Para ligas tipo $A B_{5}$, o valor máximo do número de átomos de hidrogênio contido por célula unitária corresponde a 5,5 (Willems, 1984). Considerando esse valor, calculou-se, a partir da equação (18), a capacidade de descarga máxima teórica da liga $\mathrm{La}_{0,7} \mathrm{Pr}_{0,3} \mathrm{Al}_{0,3} \mathrm{Mn}_{0,4} \mathrm{Co}_{0,5} \mathrm{Ni}_{3,8}$ ( $\left.x=0,0\right)$, obtendo-se o valor de $349,25 \mathrm{mAh} \mathrm{g}^{-1}$. A redução para o valor medido experimentalmente $\left(248,8 \mathrm{mAh} \mathrm{g}^{-1}\right)$ correspondeu a $28,76 \%$, evidenciando a influência da composição e das características microestruturais das ligas na capacidade eletroquímica dos eletrodos correspondentes. Em adição, aspectos termodinâmicos relacionados à menor estabilidade dos hidretos formados podem ter influenciado na redução da capacidade de descarga observada.

Com a substituição crescente de La por Mg, o número de átomos de hidrogênio contido decresceu significativamente, seguindo a redução da capacidade de descarga máxima. Deve-se observar que a substituição de La (raio atômico 2,74 Á) por Mg (raio atômico 1,72 Á) impôs uma retração considerável no volume da célula unitária, com o consequente decréscimo de sítios disponíveis ao armazenamento de hidrogênio (Tang et al., 2006). O aumento da concentração de $\mathrm{Mg}$ é também relacionado à deterioração da estabilidade cíclica dos eletrodos pelos princípios de oxidação-pulverização. No meio aquoso do eletrólito alcalino $\mathrm{KOH}$, o magnésio pode ser oxidado para a forma $\mathrm{Mg}(\mathrm{OH})_{2}$, não impedindo o avanço na corrosão da liga por ação do eletrólito. A oxidação das partículas da liga no eletrólito conduz a uma redução da quantidade de materiais ativos e, consequentemente, à deterioração da capacidade do eletrodo. Quanto maior a presença de $\mathrm{Mg}$ na liga, maior sua tendência à oxidação, resultando no decréscimo da estabilidade cíclica do eletrodo e a perda de material ativo no meio (Zhang, Z. et al., 2007).

$\mathrm{Na}$ FIG. 21 estão representadas as curvas de potencial de descarga dos eletrodos das ligas da Série Mg sem tratamento térmico. 


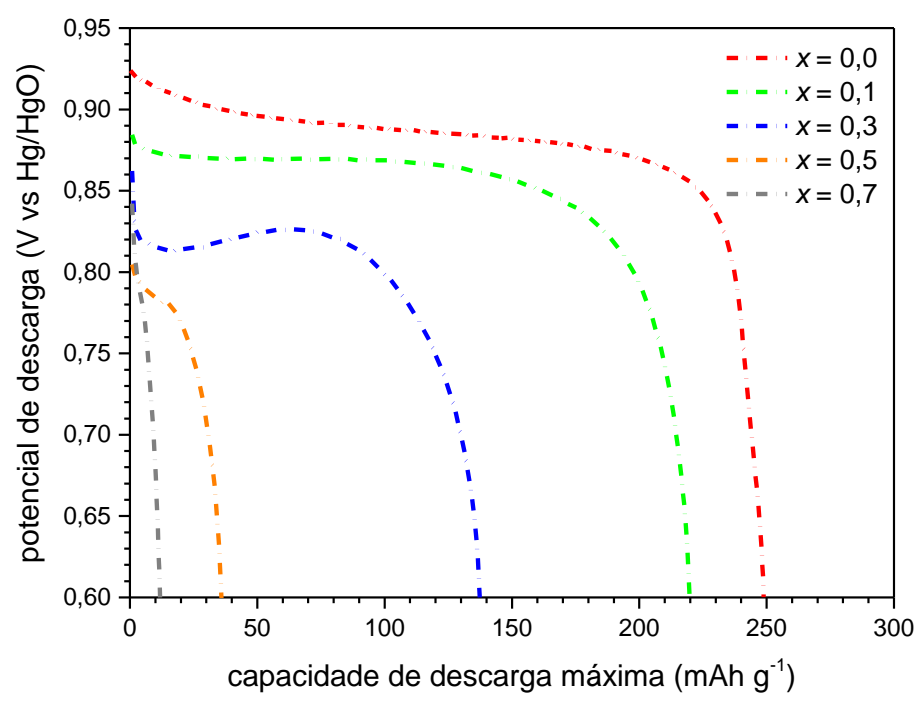

FIGURA 21 - Curvas de potencial de descarga dos eletrodos das ligas da Série $\mathrm{Mg}, \quad \mathrm{La}_{0,7-x} \mathrm{Mg}_{x} \mathrm{Pr}_{0,3} \mathrm{Al}_{0,3} \mathrm{Mn}_{0,4} \mathrm{Co}_{0,5} \mathrm{Ni}_{3,8} \quad(x=0,0-0,7)$ sem tratamento térmico.

Os potenciais de descarga correspondentes à metade do valor da capacidade de descarga máxima $\left(\mathrm{V}_{\text {met }}\right)$ estão também apresentados na TAB. 18. Pela FIG. 21 observou-se que, para as três primeiras condições de substituição de La por Mg ( $x=0,0 ; x=0,1$ e $x=0,3)$, puderam ser facilmente identificadas as duas regiões que comumente estão presentes nas curvas dos potenciais de descarga. A parte relativamente plana é denominada platô de potencial, correspondendo ao processo de descarga controlado pela transferência de carga. Já a parte em queda representa o abrupto decréscimo do potencial devido ao esgotamento de átomos de hidrogênio na superfície das ligas (Tian et al., 2016). O número de átomos de hidrogênio constantes na TAB. 18 calculados para as condições de substituição $x=0,5$ e $x=0,7$, e demais considerações realizadas em relação à elevada concentração de Mg presente, auxiliam na explicação do aspecto observado para as curvas de potencial dessas mesmas condições. Em contrapartida, como ainda observado pela TAB. 18, o eletrodo da liga $\mathrm{La}_{0,7} \mathrm{Pr}_{0,3} \mathrm{Al}_{0,3} \mathrm{Mn}_{0,4} \mathrm{Co}_{0,5} \mathrm{Ni}_{3,8}(x=0,0)$ apresentou o maior valor de $\mathrm{V}_{\text {met, }}$ com platô de potencial mais longo, indicando que nessa condição o processo de transferência de carga foi mais efetivo, relativamente às demais condições estudadas. 


\subsubsection{Efeito do teor de Pr}

Na FIG. 22 são apresentados os perfis de ativação dos eletrodos das ligas da Série $\operatorname{Pr}, \operatorname{La}_{0,7-y} \operatorname{Pr}_{y} \mathrm{Mg}_{0,3} \mathrm{Al}_{0,3} \mathrm{Mn}_{0,4} \mathrm{Co}_{0,5} \mathrm{Ni}_{3,8}(y=0,0,0,1,0,3,0,5,0,7)$ sem tratamento térmico.

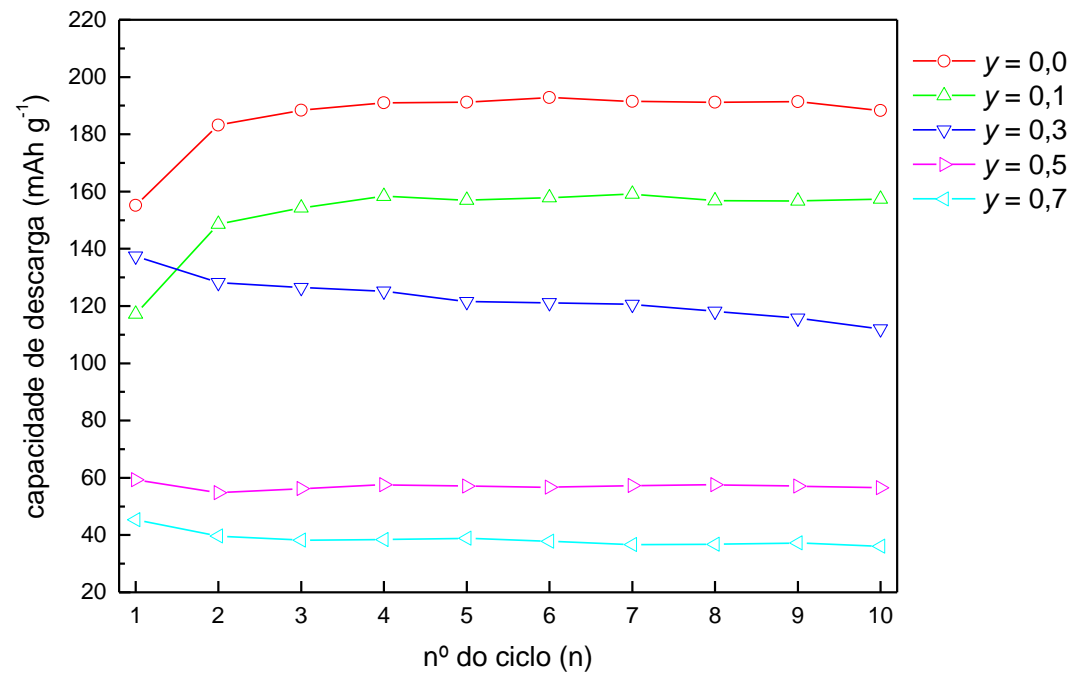

FIGURA 22 - Perfis de ativação dos eletrodos das ligas da Série Pr, $\mathrm{La}_{0,7-y} \mathrm{Pr}_{y} \mathrm{Mg}_{0,3} \mathrm{Al}_{0,3} \mathrm{Mn}_{0,4} \mathrm{Co}_{0,5} \mathrm{Ni}_{3,8} \quad(y=0,0-0,7)$ sem tratamento térmico.

Com auxílio da em referência observou-se que, para as condições de substituição de La por $\operatorname{Pr} y=0,0$ e $y=0,1$, a ativação deu-se de maneira gradual, ocorrendo de modo efetivo nos $6^{0}$ e $7^{0}$ ciclo, respectivamente. Para as demais condições, a ativação deu-se prontamente no $1^{0}$ ciclo de carga/descarga.

O maior valor para a capacidade de descarga máxima foi obtido para a liga sem adição de $\operatorname{Pr}(y=0,0)$, ou seja, 192,8 $\mathrm{mAh} \mathrm{g}^{-1}$ para a liga $\mathrm{La}_{0,7} \mathrm{Mg}_{0,3} \mathrm{Al}_{0,3} \mathrm{Mn}_{0,4} \mathrm{Co}_{0,5} \mathrm{Ni}_{3,8}$. Com a adição de $\operatorname{Pr}(y=0,1)$, obteve-se o valor de 159,1 $\mathrm{mAh} \mathrm{g}^{-1}$ para a capacidade de descarga máxima, correspondendo a um decréscimo de 17,48\% em relação à liga sem Pr. Verificou-se a continuidade da redução da capacidade de descarga em função do aumento do teor de $\operatorname{Pr}$ presente, obtendo-se o valor de 45,3 $\mathrm{mAh} \mathrm{g}^{-1}$ para a liga com substituição total de La por $\operatorname{Pr}$ (condição $y=0,7$ ).

Observou-se que o maior valor alcançado para a capacidade de descarga máxima para os eletrodos das ligas da Série $\operatorname{Pr}\left(192,8 \mathrm{mAh} \mathrm{g}^{-1}\right)$ mostrou-se abaixo do valor correspondente ao obtido na Série $\mathrm{Mg}$ 


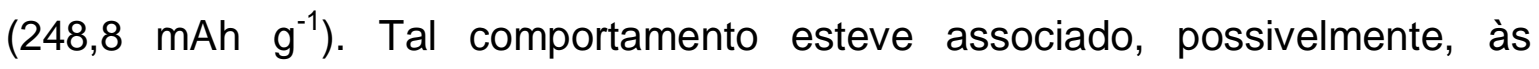
diferenças microestruturais, morfológicas e composicionais entre as ligas das duas séries. Estruturas de grãos grosseiras foram observadas tanto nas ligas da Série Mg como nas ligas da Série Pr. O aspecto equiaxial foi observado na substituição de La por Mg, ao passo que o aspecto dendrítico acompanhou a substituição de La por Pr. Adicionalmente, em todas as composições das ligas da Série $\mathrm{Pr}$, contou-se com a concentração de $\mathrm{Mg}$ de $5 \%$ at., o que pode ter contribuído para a deterioração mais acentuada dos eletrodos das ligas. Ainda assim, semelhante ao considerado para as ligas da Série Mg, a presença de uma fase similar à fase $\mathrm{LaNi}_{5}$ nas ligas das Série $\mathrm{Pr}$ favoreceu a capacidade de descarga dos eletrodos das mesmas. Contrariamente, fases similares às fases ( $\mathrm{La}, \mathrm{Pr}) \mathrm{Mg}_{2} \mathrm{Ni}_{9}$ foram associadas a valores menores de capacidade de descarga. Similarmente ao representado na FIG. 19, na FIG. 23 é visualizada, para as ligas da Série $\operatorname{Pr}, \quad \mathrm{La}_{0,7-y} \mathrm{Pr}_{y} \mathrm{Mg}_{0,3} \mathrm{Al}_{0,3} \mathrm{Mn}_{0,4} \mathrm{Co}_{0,5} \mathrm{Ni}_{3,8} \quad(y=0,0-0,7)$, a relação entre a capacidade de descarga máxima $\left(\mathrm{C}_{\text {máx }}\right)$ obtida em função da abundância das fases $\mathrm{LaNi}_{5}, \mathrm{PrNi}_{5}$ e ( $\left.\mathrm{La}, \mathrm{Pr}\right) \mathrm{Ni}_{5}$ em cada condição considerada. Observou-se que aos maiores valores de capacidade de descarga máxima estiveram associados valores elevados em abundância da fase $\mathrm{LaNi}_{5}$.

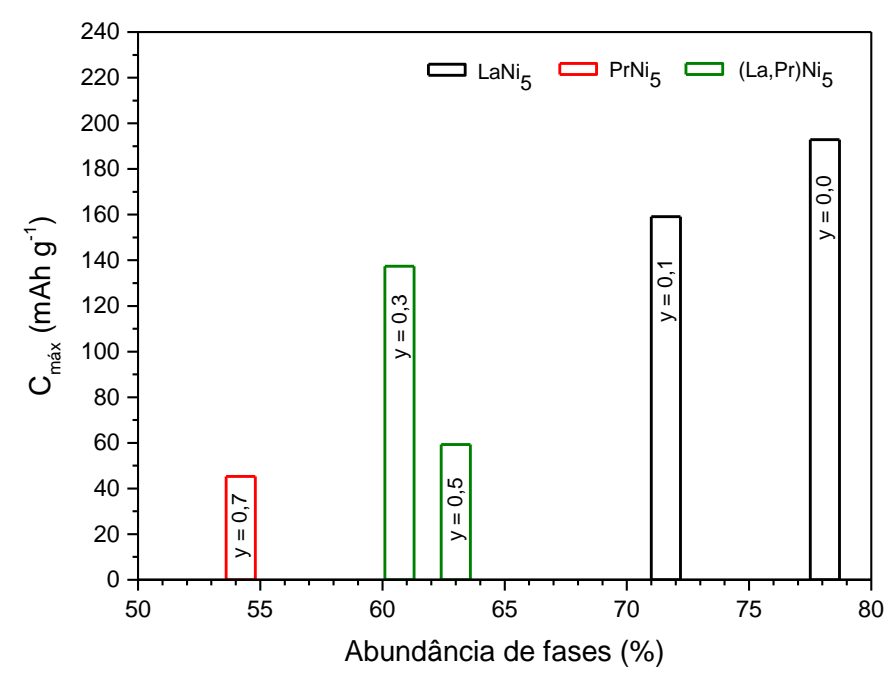

FIGURA 23 - Capacidade de descarga máxima $\left(C_{\text {máx }}\right)$ em função das abundâncias relativas de fases $\mathrm{LaNi}_{5}, \mathrm{PrNi}_{5}$ e $(\mathrm{La}, \mathrm{Pr}) \mathrm{Ni}_{5}$ para a Série $\operatorname{Pr}, \mathrm{La}_{0,7-y} \mathrm{Pr}_{y} \mathrm{Mg}_{0,3} \mathrm{Al}_{0,3} \mathrm{Mn}_{0,4} \mathrm{Co}_{0,5} \mathrm{Ni}_{3,8}(y=0,0-0,7)$. 
Apesar de diferenças na composição e no método de preparação adotado, a diminuição na capacidade de descarga de ligas de armazenamento de hidrogênio com substituição de La por Pr foi relatada na literatura. A abundância relativa e a capacidade de armazenamento de hidrogênio das fases foram os fatores considerados na interpretação do comportamento da capacidade de descarga das ligas estudadas (Pan et al., 2007; Yan et al., 2009).

Na FIG. 24 (a) são apresentadas as curvas de capacidade de descarga versus número do ciclo de carga/descarga para os eletrodos das ligas $\mathrm{La}_{0,7-y} \mathrm{Pr}_{y} \mathrm{Mg}_{0,3} \mathrm{Al}_{0,3} \mathrm{Mn}_{0,4} \mathrm{Co}_{0,5} \mathrm{Ni}_{3,8}$ ( $(y=0,0-0,7)$. Na FIG. 24 (b) está representada a retenção da capacidade de descarga $\left(S_{n}\right)$ em função do ciclo considerado $\left(10^{\circ}\right.$, $20^{\circ}, 30^{\circ}, 40^{\circ}$ e $\left.50^{\circ}\right)$, em relação à capacidade de descarga máxima das condições $y=0,0, y=0,1$ e $y=0,3$.

$\mathrm{Na}$ TAB. 19 estão listadas as propriedades eletroquímicas dos eletrodos de todas as ligas da Série $\operatorname{Pr}$ sem tratamento térmico, incluindo os valores da retenção da capacidade de descarga considerando $50^{\circ}$ ciclo de carga/descarga $\left(S_{50}\right)$ para todas as condições de substituição estudadas.

As curvas mostradas na FIG. 24 (a) evidenciaram que a liga sem adição de $\operatorname{Pr}(y=0,0)$ apresentou os maiores valores de capacidade de descarga nos 50 ciclos realizados, com as demais ligas apresentando capacidades de descarga decrescentes no sentido do aumento da adição de Pr. Já, com auxílio da FIG. 24 (b) e TAB. 19, verificou-se que para as três condições de substituição com maior capacidade de descarga máxima $(y=0,0, y=0,1$ e $y=0,3)$, os maiores valores de retenção de capacidade de descarga, ao longo dos ciclos realizados, foram observados para a condição $y=0,1$. Relativamente, para esta condição esteve associada uma maior estabilidade cíclica $\left(S_{50}=92,8 \%\right)$, seguida da liga sem adição de $\operatorname{Pr}$, ou seja, $y=0,0\left(S_{50}=85,1 \%\right)$. Uma diminuição considerável na capacidade de descarga e na retenção da capacidade foi observada na condição $y=0,3\left(S_{50}=72,3 \%\right)$ e, nas condições subsequentes ( $y=0,5$ e $\left.y=0,7\right)$, a capacidade de descarga assumiu valores ainda mais baixos. A melhora na estabilidade cíclica foi reportada em outros estudos de substituição de La por $\operatorname{Pr}$ em ligas de armazenamento de hidrogênio ( $\mathrm{Li}, \mathrm{Y}$. et al., 2009; Liu et al., 2011b; Pan et al., 2007). Nestes, o fenômeno foi correlacionado com a quantidade relativa das fases presentes e a variação nos volumes das células unitárias das mesmas durante os ciclos de carga/descarga dos eletrodos formados por ligas com diferentes adições 


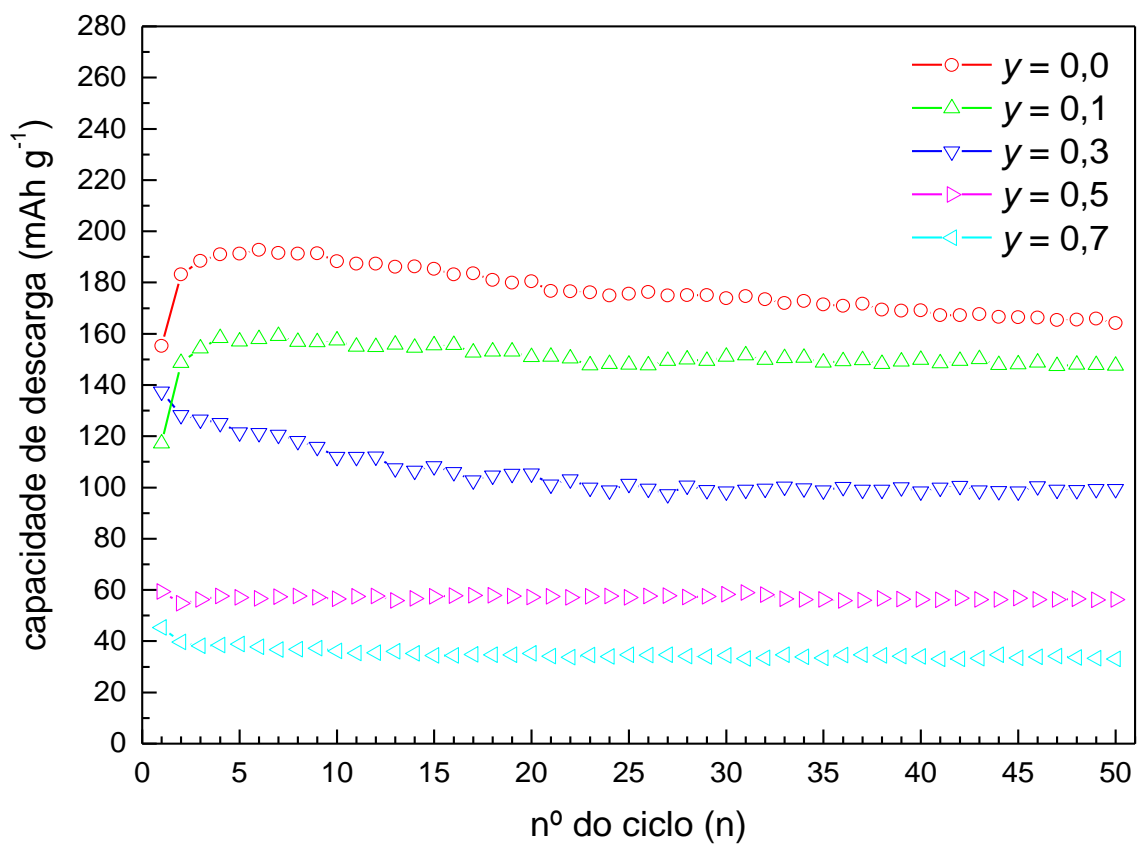

(a)

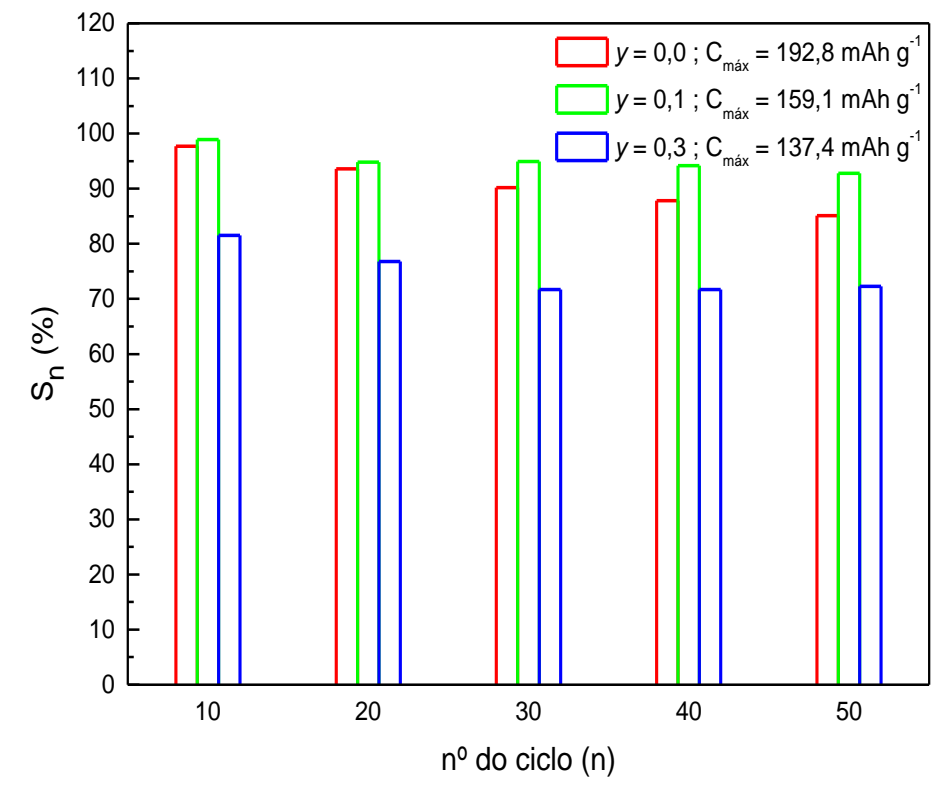

(b)

FIGURA 24 - (a) Capacidade de descarga das ligas da Série $\operatorname{Pr}$, $\mathrm{La}_{0,7-y} \mathrm{Pr}_{y} \mathrm{Mg}_{0,3} \mathrm{Al}_{0,3} \mathrm{Mn}_{0,4} \mathrm{Co}_{0,5} \mathrm{Ni}_{3,8} \quad(y=0,0-0,7) \quad$ sem tratamento térmico vs. número do ciclo; (b) Retenção da capacidade de descarga das ligas da Série $\operatorname{Pr}$ sem tratamento térmico para $y=0,0 ; y=0,1$ e $y=0,3$. 
TABELA 19 - Propriedades eletroquímicas dos eletrodos das ligas da Série $\mathrm{Pr}$, $\mathrm{La}_{0,7-y} \mathrm{Pr}_{y} \mathrm{Mg}_{0,3} \mathrm{Al}_{0,3} \mathrm{Mn}_{0,4} \mathrm{Co}_{0,5} \mathrm{Ni}_{3,8}$, sem tratamento térmico.

\begin{tabular}{cccccc}
\hline$y$ & $\mathrm{C}_{\text {máx }}\left(\mathrm{mAh} \mathrm{g}^{-1}\right)$ & $N_{\mathrm{a}}{ }^{\mathrm{a}}$ & $\mathrm{S}_{50}(\%)$ & $n_{\mathrm{H}}^{\mathrm{b}}$ & $\mathrm{V}_{\text {met }}{ }^{\mathrm{c}}(\mathrm{V})$ \\
\hline 0,0 & 192,8 & 6 & 85,1 & 2,78 & 0,895 \\
0,1 & 159,1 & 7 & 92,8 & 2,30 & 0,892 \\
0,3 & 137,4 & 1 & 72,3 & 1,99 & 0,826 \\
0,5 & 59,3 & 1 & 94,8 & 0,86 & 0,801 \\
0,7 & 45,3 & 1 & 72,8 & 0,66 & 0,793 \\
\hline
\end{tabular}

${ }^{a}$ Número de ciclos necessários para ativar os eletrodos.

${ }^{\mathrm{b}}$ Número de átomos de hidrogênio por célula unitária.

${ }^{c}$ Potencial de descarga na metade da capacidade de descarga máxima.

de $\operatorname{Pr}$. As interpretações foram baseadas na relação direta entre a variação de volume (expansão/contração) pela formação/decomposição do hidreto metálico, além da pulverização da liga.

Com o auxílio da equação (18) foram calculados os valores de hidrogênio contido no eletrodo carregado de cada liga da Série $\mathrm{Pr}$, sendo o número de átomos de hidrogênio correspondentes, $n_{\mathrm{H}}$, listados na TAB. 19. Verifcou-se, experimentalmente, que a liga sem $\operatorname{Pr}(y=0,0)$ apresentou o maior valor de hidrogênio contido por célula unitária, seguido de valores decrescentes, acompanhando a diminuição da capacidade de descarga máxima em função da adição de $\operatorname{Pr}$ às ligas. Apesar de menos pronunciada, a substituição de La (raio atômico 2,74 Á) por $\operatorname{Pr}$ (raio atômico 2,67 Á) também impôs, como na substituição de La por Mg, uma retração no volume da célula unitária, resultando no decréscimo de sítios disponíveis ao armazenamento de hidrogênio.

Evidenciou-se, mais uma vez, que a composição e as características microestruturais das ligas exerceram uma influência considerável no desempenho dos eletrodos. No presente estudo é interessante, ainda, comparar as abundâncias relativas, com o auxílio das TAB. 16 e 17, e as curvas de descarga representadas nas FIG. 20 (a) e 24 (a). Especificamente, ao serem consideradas as substituições de La por Mg e de La por $\operatorname{Pr}$ nas condições $x=y=0,5$ e $x=y=0,7$, verificou-se que para a Série $\mathrm{Pr}$, onde nessas condições as fases similares às fases $\mathrm{LaNi}_{5}$ e $\mathrm{PrNi}_{5}$ permaneceram majoritárias, a capacidade de descarga dos 
eletrodos das ligas foi maior que o observado para os eletrodos das ligas da Série $\mathrm{Mg}$ nestas mesmas condições. Tal constatação reforça, para o estudo realizado, a consideração que fases similares à fase $\mathrm{LaNi}_{5}$ contribuíram de forma positiva para o desempenho dos eletrodos das ligas das duas séries analisadas, bem como as fases similares à fase $\mathrm{LaMg}_{2} \mathrm{Ni}_{9}$ contribuíram para o efeito contrário.

Na FIG. 25 estão representadas as curvas de potencial de descarga dos eletrodos das ligas da Série Pr sem tratamento térmico.

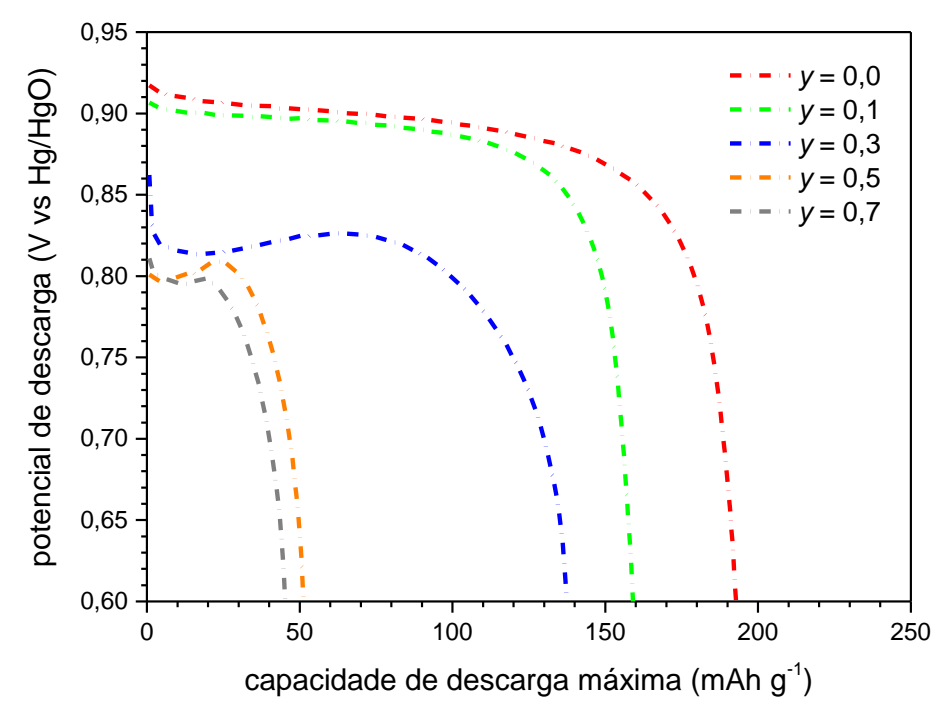

FIGURA 25 - Curvas de potencial de descarga dos eletrodos das ligas da Série $\operatorname{Pr}, \quad \mathrm{La}_{0,7-\mathrm{y}} \mathrm{Pr}_{y} \mathrm{Mg}_{0,3} \mathrm{Al}_{0,3} \mathrm{Mn}_{0,4} \mathrm{Co}_{0,5} \mathrm{Ni}_{3,8} \quad(y=0,0-0,7) \quad$ sem tratamento térmico.

Com o auxílio da FIG. 25 e dos valores de $\mathrm{V}_{\text {met }}$ mostrados na TAB. 19, observou-se a proximidade entre as regiões do platô de potencial dos eletrodos das condições $y=0,0$ e $y=0,1$, apresentando valores muito próximos de $V_{\text {met. }}$. Comparativamente, porém, na condição de substituição de La por $\operatorname{Pr}$ em $y=0,1$, o eletrodo da liga apresentou um decréscimo no potencial mais acentuado do que na condição da liga sem $\operatorname{Pr}$, indicando a maior exaustão de átomos de hidrogênio na superfície da liga em $y=0,1$. Nas demais condições de substituição, o aspecto das curvas de potencial de descarga sugeriu a baixa participação do processo de transferência de carga durante as descargas dos respectivos eletrodos, com valores de $V_{\text {met }}$ bem mais baixos em relação às outras condições. 


\subsubsection{Efeito do tratamento térmico}

\subsubsection{Série $\mathrm{Mg}$}

Na FIG. 26 são apresentados os perfis de ativação dos eletrodos das ligas $\mathrm{La}_{0,7-x} \mathrm{Mg}_{x} \mathrm{Pr}_{0,3} \mathrm{Al}_{0,3} \mathrm{Mn}_{0,4} \mathrm{Co}_{0,5} \mathrm{Ni}_{3,8}(x=0,0,0,1,0,3,0,5,0,7)$ com tratamento térmico.

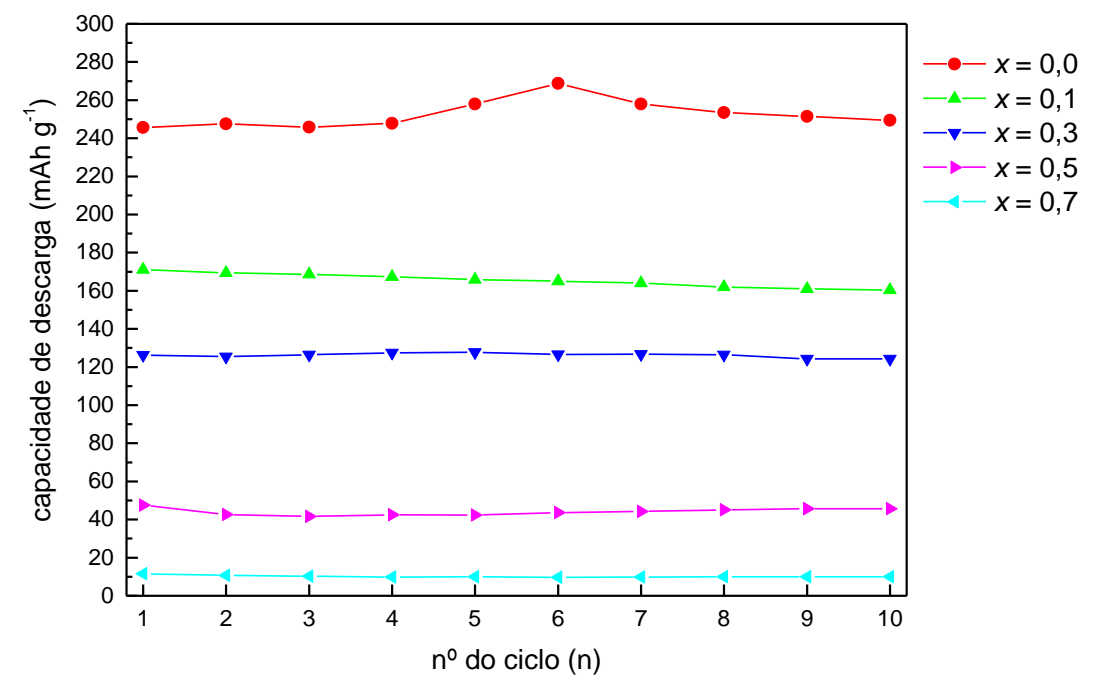

FIGURA 26 - Perfis de ativação dos eletrodos das ligas da Série Mg, $\mathrm{La}_{0,7-x} \mathrm{Mg}_{x} \mathrm{Pr}_{0,3} \mathrm{Al}_{0,3} \mathrm{Mn}_{0,4} \mathrm{Co}_{0,5} \mathrm{Ni}_{3,8} \quad(x=0,0-0,7) \quad$ com tratamento térmico.

Com o auxílio da figura em referência, observou-se uma diferença no comportamento de ativação das ligas, principalmente naquelas associadas aos maiores valores de capacidade de descarga máxima ( $x=0,0, x=0,1$ e $x=0,3)$. A liga sem adição de $\mathrm{Mg}(x=0,0)$ exibiu a maior capacidade de descarga máxima, $268,8 \mathrm{mAh} \mathrm{g}^{-1}$, com ativação no $6^{\circ}$ ciclo. Quanto à condição de substituição seguinte $(x=0,1)$, o valor de $171,1 \mathrm{mAh} \mathrm{g}^{-1}$ para a capacidade de descarga máxima obtida já no $1^{0}$ ciclo correspondeu a um decréscimo de $26,35 \%$ em relação àquela da liga sem $\mathrm{Mg}$. A liga da condição $x=0,3$ exibiu pouca variação nos valores de capacidade de descarga com ativação no $5^{\circ}$ ciclo, e a continuidade da adição de $\mathrm{Mg}$ conduziu à sequência da deterioração da capacidade de descarga das ligas. 
Na FIG. 27 (a) são apresentadas as curvas de capacidade de descarga versus número do ciclo de carga/descarga para os eletrodos das ligas $\mathrm{La}_{0,7-x} \mathrm{Mg}_{x} \mathrm{Pr}_{0,3} \mathrm{Al}_{0,3} \mathrm{Mn}_{0,4} \mathrm{Co}_{0,5} \mathrm{Ni}_{3,8}$ ( $\left.x=0,0-0,7\right)$ com tratamento térmico. Na FIG. 27 (b) está representada a retenção da capacidade de descarga $\left(S_{n}\right)$ em função do ciclo considerado $\left(10^{\circ}, 20^{\circ}, 30^{\circ}, 40^{\circ}\right.$ e $\left.50^{\circ}\right)$, em relação à capacidade de descarga máxima das condições $x=0,0, x=0,1$ e $x=0,3$.

$\mathrm{Na}$ TAB. 20 estão listadas as propriedades eletroquímicas dos eletrodos de todas as ligas da Série $\mathrm{Mg}$ com tratamento térmico, incluindo os valores da retenção da capacidade de descarga considerando $50^{\circ}$ ciclo de carga/descarga $\left(\mathrm{S}_{50}\right)$ para todas as condições de substituição estudadas.

Por intermédio da FIG. 27 (a) verificou-se que a liga sem adição de Mg destacou-se das demais, mantendo uma capacidade de descarga mais elevada ao longo de toda a ciclagem realizada.

Como mostrado na FIG. 27 (b) e na TAB. 20, para as ligas tratadas termicamente, a condição de substituição $x=0,3$ apresentou, dentre as ligas com maior capacidade de descarga, os maiores valores de retenção de capacidade ao longo da ciclagem realizada. Nesta condição, portanto, esteve associada uma maior estabilidade cíclica, embora no $50^{\circ}$ ciclo, os valores de retenção $\left(S_{50}\right)$ para as três primeiras condições $(x=0,0, x=0,1$ e $x=0,3)$ foram bastante próximos (82,5\%, $80,4 \%$ e $83,8 \%$, respectivamente).

Ainda, pela TAB. 20, verificou-se a elevada quantidade de hidrogênio contido no eletrodo carregado da liga sem adição de $\mathrm{Mg}$, em consonância com a maior capacidade de descarga máxima atingida após o tratamento térmico. 


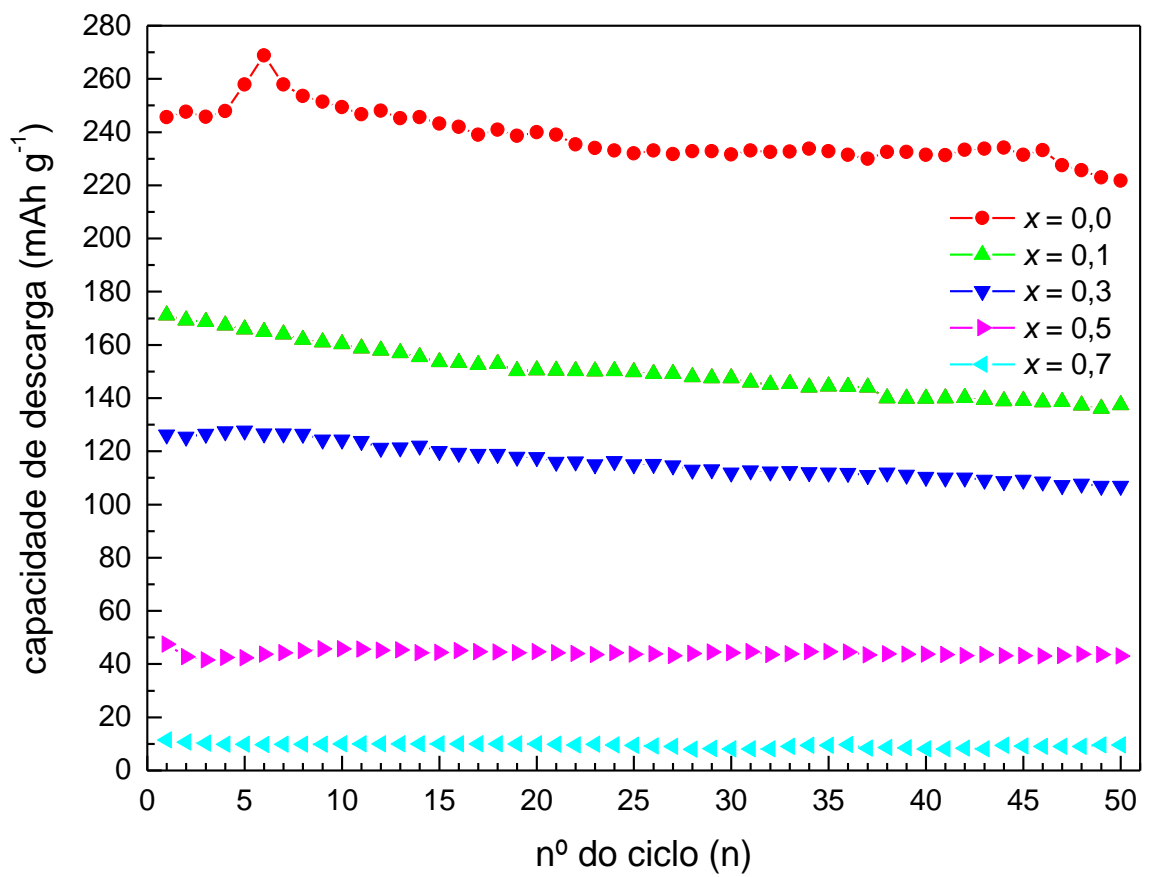

(a)

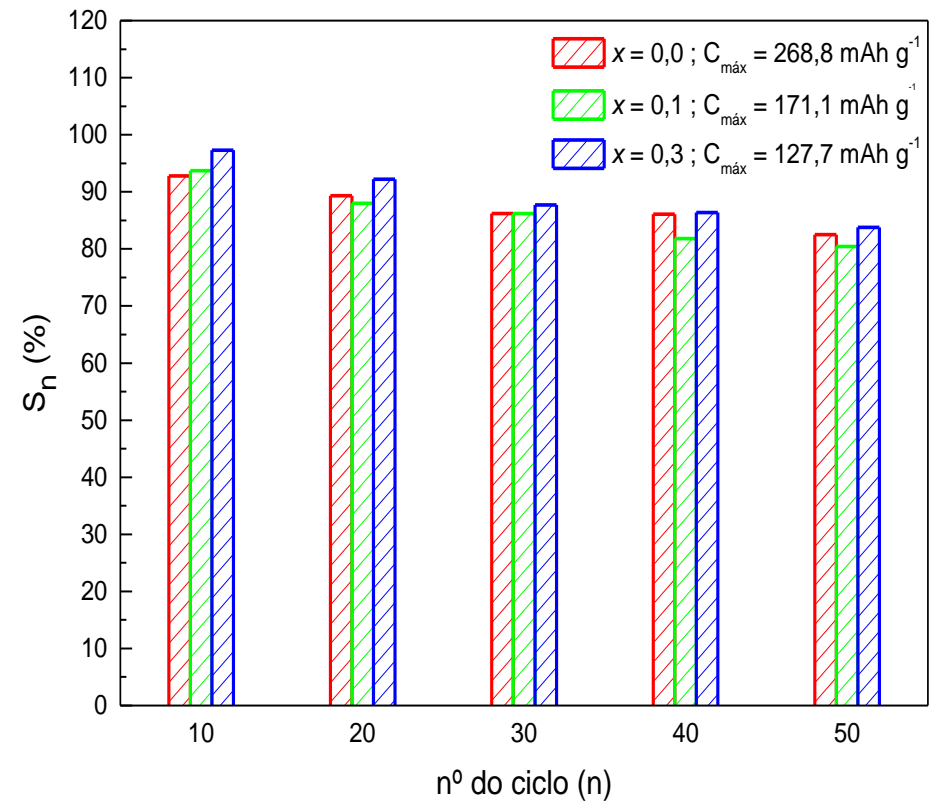

(b)

FIGURA 27 - (a) Capacidade de descarga das ligas da Série Mg, $\mathrm{La}_{0,7-x} \mathrm{Mg}_{x} \mathrm{Pr}_{0,3} \mathrm{Al}_{0,3} \mathrm{Mn}_{0,4} \mathrm{Co}_{0,5} \mathrm{Ni}_{3,8} \quad(x=0,0-0,7) \quad$ com tratamento térmico vs. número do ciclo; (b) Retenção da capacidade de descarga das ligas da Série Mg com tratamento térmico para $x=0,0 ; x=0,1$ e $x=0,3$. 
TABELA 20 - Propriedades eletroquímicas dos eletrodos das ligas da Série Mg, $\mathrm{La}_{0,7-x} \mathrm{Mg}_{x} \mathrm{Pr}_{0,3} \mathrm{Al}_{0,3} \mathrm{Mn}_{0,4} \mathrm{Co}_{0,5} \mathrm{Ni}_{3,8}$, com tratamento térmico.

\begin{tabular}{cccccc}
\hline$x$ & $\mathrm{C}_{\text {máx }}\left(\mathrm{mAhg}^{-1}\right)$ & $N_{\mathrm{a}}{ }^{\mathrm{a}}$ & $\mathrm{S}_{50}(\%)$ & $n_{\mathrm{H}}{ }^{\mathrm{b}}$ & $\mathrm{V}_{\text {met }}{ }^{\mathrm{c}}(\mathrm{V})$ \\
\hline 0,0 & 268,8 & 6 & 82,5 & 4,23 & 0,907 \\
0,1 & 171,1 & 1 & 80,4 & 2,62 & 0,876 \\
0,3 & 127,7 & 5 & 83,8 & 1,85 & 0,881 \\
0,5 & 47,5 & 1 & 90,5 & 0,65 & 0,828 \\
0,7 & 11,5 & 1 & 83,5 & 0,15 & 0,780 \\
\hline
\end{tabular}

${ }^{a}$ Número de ciclos necessários para ativar os eletrodos.

${ }^{\mathrm{b}}$ Número de átomos de hidrogênio por célula unitária.

${ }^{c}$ Potencial de descarga na metade da capacidade de descarga máxima.

Na FIG. 28 estão representadas as curvas de potencial de descarga dos eletrodos das ligas da Série Mg com tratamento térmico.

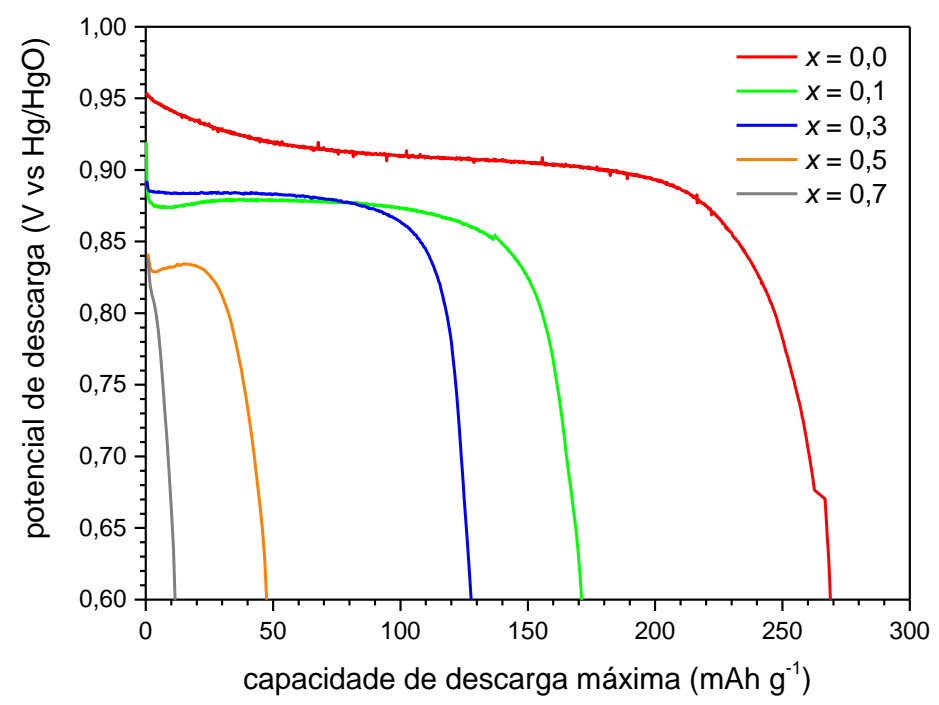

FIGURA 28 - Curvas de potencial de descarga dos eletrodos das ligas da Série $\mathrm{Mg}, \quad \mathrm{La}_{0,7-x} \mathrm{Mg}_{x} \mathrm{Pr}_{0,3} \mathrm{Al}_{0,3} \mathrm{Mn}_{0,4} \mathrm{Co}_{0,5} \mathrm{Ni}_{3,8} \quad(x=0,0-0,7) \quad$ com tratamento térmico.

Os valores de $V_{\text {met }}$ listados na TAB. 20 e as curvas de potencial de descarga mostradas na FIG. 28 confirmaram as performances eletroquímicas dos eletrodos das ligas com tratamento térmico, com destaque à condição sem substituição de La por Mg, com o platô de potencial mais extenso que as demais. 
Comparando, por sua vez, os perfis do potencial de descarga dos eletrodos das ligas na condição $x=0,1$ sem tratamento térmico (vide FIG. 21) e com tratamento térmico (vide FIG. 28), evidenciou-se o desfavorecimento do tratamento térmico na performance eletroquímica dos eletrodos das ligas quando da introdução de Mg às mesmas.

\subsubsection{Série $\mathrm{Pr}$}

Na FIG. 29 são apresentados os perfis de ativação dos eletrodos das ligas $\mathrm{La}_{0,7-y} \mathrm{Pr}_{y} \mathrm{Mg}_{0,3} \mathrm{Al}_{0,3} \mathrm{Mn}_{0,4} \mathrm{Co}_{0,5} \mathrm{Ni}_{3,8}(y=0,0,0,1,0,3,0,5,0,7)$ com tratamento térmico.

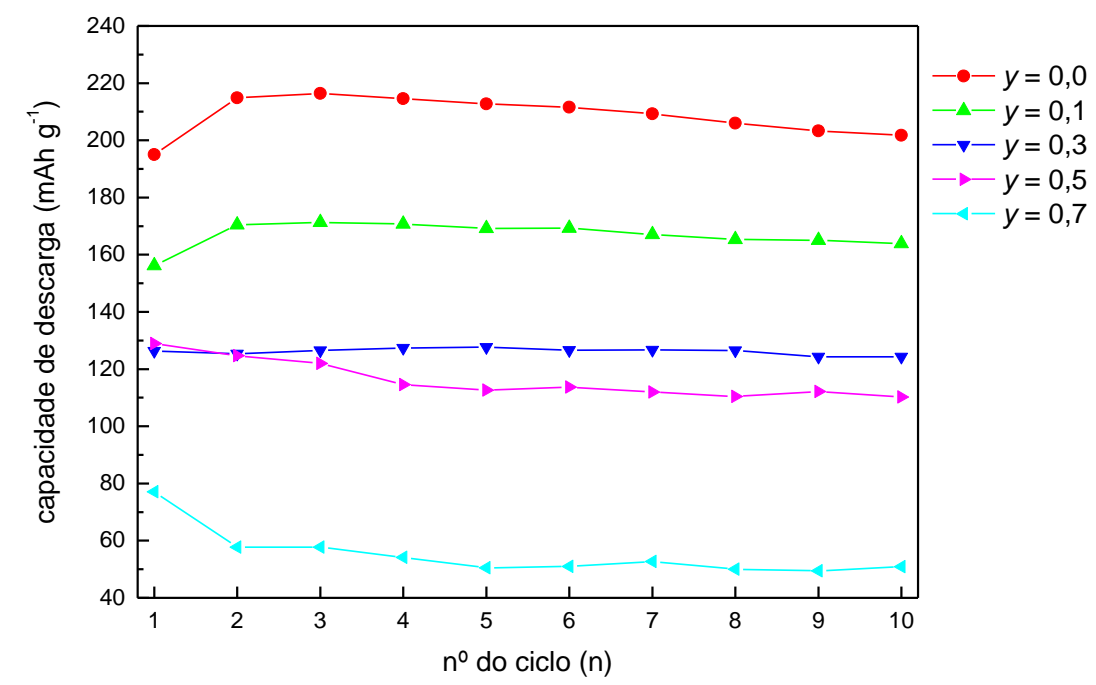

FIGURA 29 - Perfis de ativação dos eletrodos das ligas da Série $\operatorname{Pr}$, $\mathrm{La}_{0,7-y} \mathrm{Pr}_{y} \mathrm{Mg}_{0,3} \mathrm{Al}_{0,3} \mathrm{Mn}_{0,4} \mathrm{Co}_{0,5} \mathrm{Ni}_{3,8} \quad(y=0,0-0,7) \quad$ com tratamento térmico.

Como mostrado na figura em referência, foram necessários três ciclos para a ativação dos eletrodos das ligas com tratamento térmico para $y=0,0 \mathrm{e}$ $y=0,1$; já para $y=0,3$ necessitou-se cinco, e para as demais condições, um ciclo apenas. Novamente, a liga sem adição de Pr apresentou a maior capacidade de descarga máxima $\left(216,4 \mathrm{mAh} \mathrm{g}^{-1}\right)$, com a condição de adição $(y=0,1)$ conduzindo a uma diminuição de $20,84 \%$ do valor $\left(171,3 \mathrm{mAh} \mathrm{g}^{-1}\right)$. Observou-se, ainda, uma proximidade em relação aos valores de capacidade de descarga máxima nas condições $y=0,3$ e $y=0,5$ (127,7 $\mathrm{mAh} \mathrm{g}^{-1}$ e 128,9 $\mathrm{mAh} \mathrm{g}^{-1}$, respectivamente), com 
esta última sendo ativada mais rapidamente. A adição crescente de $\operatorname{Pr}$ foi associada, também para as ligas tratadas, à deterioração da capacidade de descarga das ligas.

Na FIG. 30 (a) são apresentadas as curvas de capacidade de descarga versus número do ciclo de carga/descarga para os eletrodos das ligas $\mathrm{La}_{0,7-y} \mathrm{Pr}_{y} \mathrm{Mg}_{0,3} \mathrm{Al}_{0,3} \mathrm{Mn}_{0,4} \mathrm{Co}_{0,5} \mathrm{Ni}_{3,8}(y=0,0-0,7)$ com tratamento térmico.

Na FIG. 30 (b) está representada a retenção da capacidade $\left(S_{n}\right)$ de descarga em função do ciclo considerado $\left(10^{\circ}, 20^{\circ}, 30^{\circ}, 40^{\circ}\right.$ e $\left.50^{\circ}\right)$, em relação à capacidade de descarga máxima das condições $y=0,0, y=0,1$ e $y=0,3$.

$\mathrm{Na}$ TAB. 21 estão listadas as propriedades eletroquímicas dos eletrodos de todas as ligas da Série $\operatorname{Pr}$ com tratamento térmico, incluindo os valores da retenção da capacidade de descarga considerando $50^{\circ}$ ciclo de carga/descarga $\left(\mathrm{S}_{50}\right)$ para todas as condições de substituição estudadas.

As curvas mostradas na FIG. 30 (a) evidenciaram o destaque da liga sem $\mathrm{Pr}$, que apresentou a maior capacidade de descarga ao longo de toda a ciclagem realizada.

Similarmente ao observado para as ligas da Série Mg, com o auxílio da FIG. 30 (b) verificou-se que a condição de substituição de La por $\operatorname{Pr}$ em $y=0,3$ exibiu os maiores valores de retenção de capacidade ao longo dos ciclos de carga/descarga realizados, associando-se à mesma uma maior estabilidade cíclica em comparação às demais.

O valor de retenção de capacidade no $50^{\circ}$ ciclo $\left(S_{50}\right)$ para a condição de substituição $y=0,3(83,8 \%)$ mostrou-se maior que para as condições $y=0,0$ e $y=0,1(74,6 \%$ e $81,1 \%$, respectivamente). Na Série $\mathrm{Mg}$, para as ligas tratadas termicamente, essas diferenças foram bem menos pronunciadas.

Como observado pela TAB. 21, os valores de hidrogênio contido no eletrodo carregado acompanharam a performance de capacidade de descarga dos eletrodos, com a liga sem Pr apresentando a maior quantidade de hidrogênio associada. 


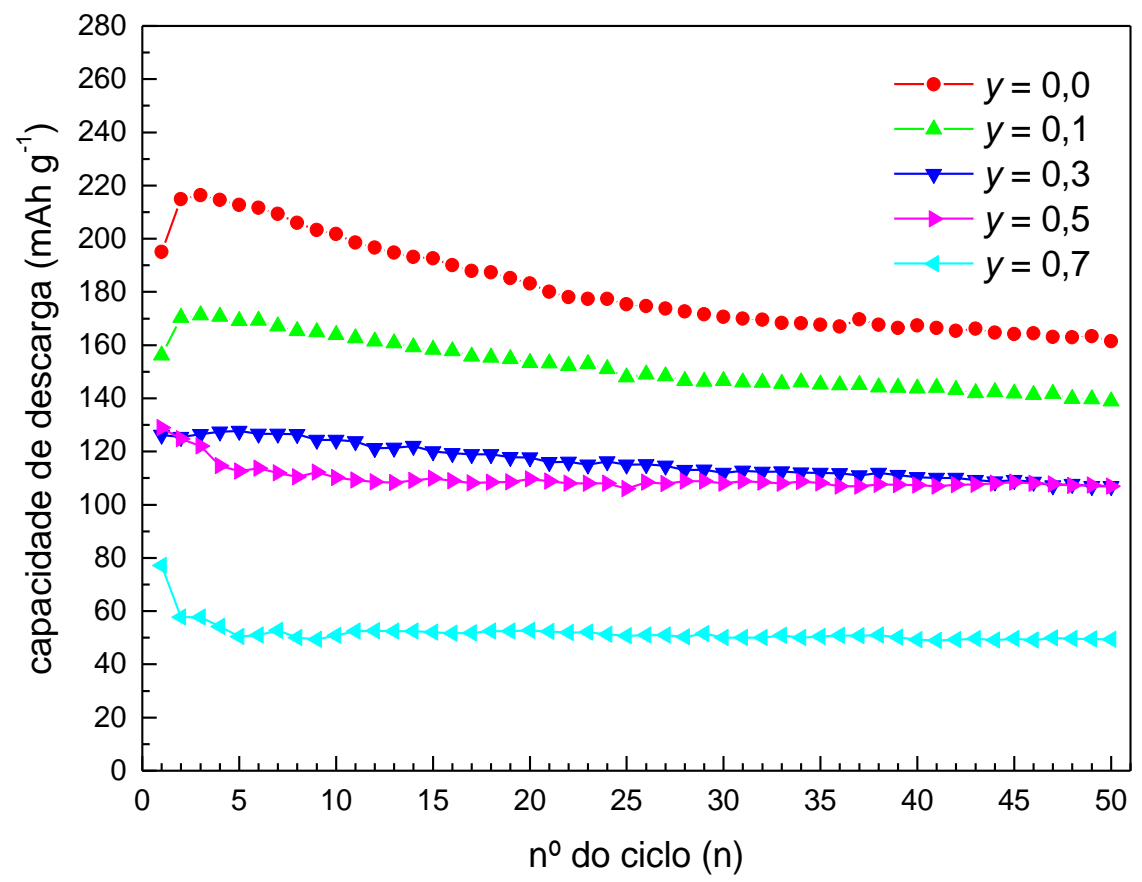

(a)

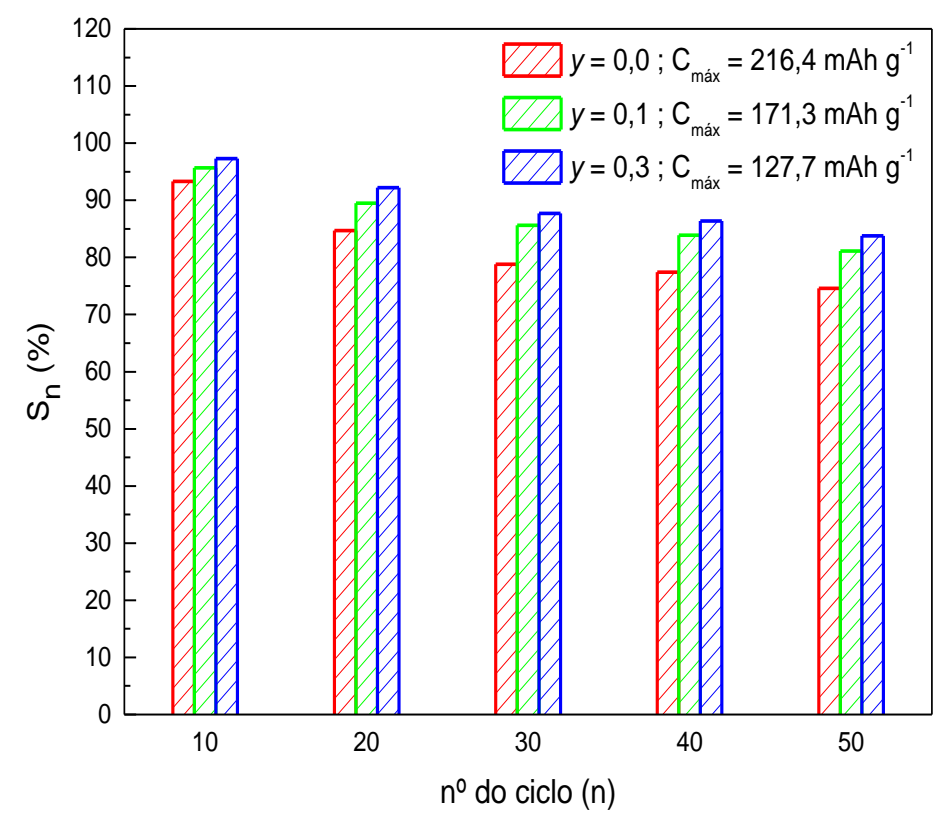

(b)

FIGURA 30 - (a) Capacidade de descarga das ligas da Série Pr, $\mathrm{La}_{0,7-y} \mathrm{Pr}_{y} \mathrm{Mg}_{0,3} \mathrm{Al}_{0,3} \mathrm{Mn}_{0,4} \mathrm{Co}_{0,5} \mathrm{Ni}_{3,8} \quad(y=0,0-0,7) \quad$ com tratamento térmico vs. número do ciclo; (b) Retenção da capacidade de descarga das ligas da Série $\operatorname{Pr}$ com tratamento térmico para $y=0,0 ; y=0,1$ e $y=0,3$. 
TABELA 21 - Propriedades eletroquímicas dos eletrodos das ligas da Série $\mathrm{Pr}$, $\mathrm{La}_{0,7-y} \mathrm{Pr}_{y} \mathrm{Mg}_{0,3} \mathrm{Al}_{0,3} \mathrm{Mn}_{0,4} \mathrm{Co}_{0,5} \mathrm{Ni}_{3,8}$, com tratamento térmico.

\begin{tabular}{cccccc}
\hline$y$ & $\mathrm{C}_{\text {máx }}\left(\mathrm{mAhg}^{-1}\right)$ & $N_{\mathrm{a}}{ }^{\mathrm{a}}$ & $\mathrm{S}_{50}(\%)$ & $n_{\mathrm{H}}{ }^{\mathrm{b}}$ & $\mathrm{V}_{\text {met }}{ }^{\mathrm{c}}(\mathrm{V})$ \\
\hline 0,0 & 216,4 & 3 & 74,6 & 3,13 & 0,879 \\
0,1 & 171,3 & 3 & 81,1 & 2,48 & 0,879 \\
0,3 & 127,7 & 5 & 83,8 & 1,85 & 0,881 \\
0,5 & 128,9 & 1 & 83,0 & 1,87 & 0,804 \\
0,7 & 77,1 & 1 & 63,9 & 1,12 & 0,836 \\
\hline
\end{tabular}

${ }^{a}$ Número de ciclos necessários para ativar os eletrodos.

${ }^{\mathrm{b}}$ Número de átomos de hidrogênio por célula unitária.

${ }^{c}$ Potencial de descarga na metade da capacidade de descarga máxima.

Na FIG. 31 estão representadas as curvas de potencial de descarga dos eletrodos das ligas da Série Pr com tratamento térmico.

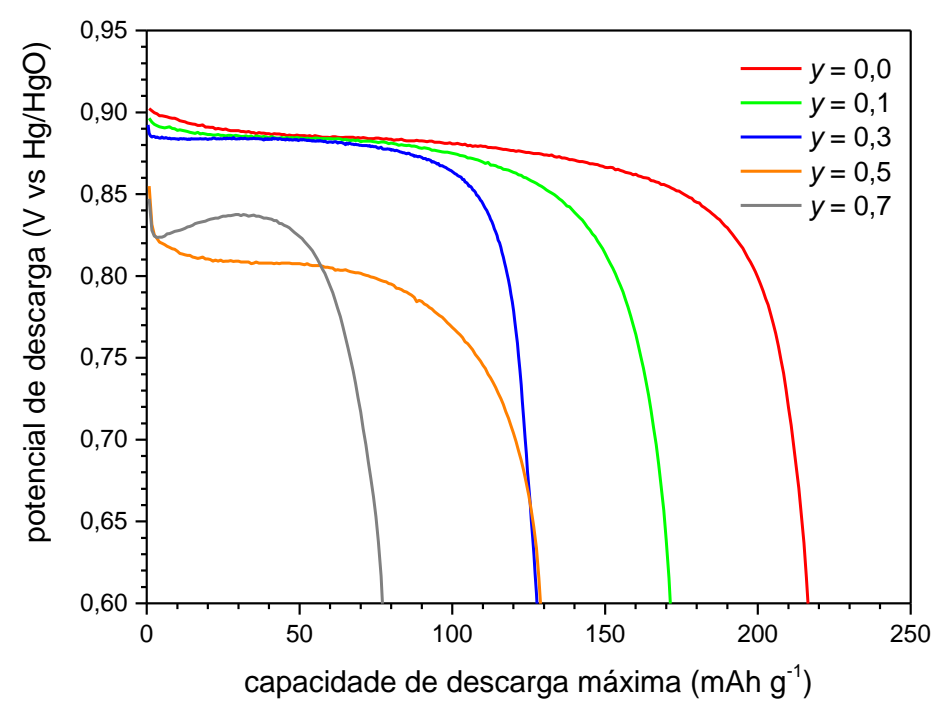

FIGURA 31 - Curvas de potencial de descarga dos eletrodos das ligas da Série $\operatorname{Pr}, \quad \mathrm{La}_{0,7-y} \mathrm{Pr}_{y} \mathrm{Mg}_{0,3} \mathrm{Al}_{0,3} \mathrm{Mn}_{0,4} \mathrm{Co}_{0,5} \mathrm{Ni}_{3,8} \quad(y=0,0-0,7) \quad$ com tratamento térmico.

Os perfis de potencial de descarga apresentados na FIG. 31 e os valores de $V_{\text {met }}$ mostrados na TAB. 21 atestaram o comportamento dos eletrodos das ligas da Série $\mathrm{Pr}$ com tratamento térmico. O eletrodo da liga sem $\mathrm{Pr}$ apresentou o maior platô de potencial, em correspondência ao maior valor de capacidade de descarga máxima atingido nessa condição. Observou-se, também, 
determinada similaridade entre os perfis de descarga dos eletrodos das ligas quando da introdução de $\operatorname{Pr}$ às mesmas (condição $y=0,1$ ), sem tratamento térmico (vide FIG. 25) e com tratamento térmico (vide FIG. 31). Fixando essa condição de substituição de La por $M g$ e por $\operatorname{Pr}(x=y=0,1)$, e analisando os perfis dos potenciais de descarga, verificou-se que o efeito do tratamento térmico na Série Pr foi menos prejudicial do que o observado para a Série Mg.

Em complemento às análises dos resultados obtidos, verificou-se a influência do tratamento térmico realizado nos valores de capacidade máxima obtidos para as duas séries de ligas estudadas. Em concordância a vários estudos reportados na literatura, as ligas tratadas termicamente exibiram, em geral, maiores valores de capacidade de descarga máxima. Tal comportamento tem sido atribuído à variação na abundância das fases presentes após o tratamento térmico (Fetcenko, 2002; Li, F. et al., 2009; Ma et al., 2002; Pan et al., 2005a).

O aumento na estabilidade cíclica também é citado frequentemente como decorrência de tratamentos térmicos impostos às ligas ( $L i$, R. et al., 2004; Pan et al., 2005a; Zhang, F. et al., 2005; Zhou et al., 2010). Para as composições e condições de tratamento adotadas no presente estudo, não foi percebida uma melhora significativa para esta propriedade eletroquímica, em comparação aos resultados obtidos para as ligas sem tratamento térmico.

Analisando os comportamentos e resultados das ligas das Séries Mg e Pr sem e com tratamento térmico, dispostos nas FIG. 18 a 31 e TAB. 18 a 21, verificou-se que a primeira liga da Série $\mathrm{Mg}$ com tratamento térmico, a saber, $\mathrm{La}_{0,7} \mathrm{Pr}_{0,3} \mathrm{Al}_{0,3} \mathrm{Mn}_{0,4} \mathrm{Co}_{0,5} \mathrm{Ni}_{3,8}$ (condição $x=0,0$ ), exibiu o maior valor de capacidade de descarga máxima $\left(268,8 \mathrm{mAh}^{-1}\right)$, seguida da mesma liga sem tratamento térmico (248,8 mAh $\left.\mathrm{g}^{-1}\right)$. O aumento do valor na capacidade de descarga máxima da liga tratada para a não tratada correspondeu a 7,44\%. Economicamente, é fato que a introdução de uma etapa de tratamento térmico significa custo adicional a qualquer processamento.

Em conformidade ao caráter tecnológico do presente estudo, a diferença entre os valores das capacidades de descarga dos eletrodos das ligas tratadas termicamente para as não tratadas foi considerado insuficiente para justificar a inclusão desta etapa no tocante à continuidade dos experimentos. Essa interpretação, além da análise dos perfis de ativação, dos valores de 
capacidade de descarga ao longo dos 50 ciclos realizados, e dos valores de retenção de capacidade obtidos, direcionaram a opção pela liga $\mathrm{La}_{0,7} \mathrm{Pr}_{0,3} \mathrm{Al}_{0,3} \mathrm{Mn}_{0,4} \mathrm{Co}_{0,5} \mathrm{Ni}_{3,8}$ sem tratamento térmico a ser considerada para a $2^{\mathrm{a}}$ etapa dos experimentos propostos - estudo da variação da densidade de corrente de descarga.

\subsubsection{Efeito da densidade de corrente de descarga}

Na FIG. 32 são apresentadas as curvas de capacidade de descarga do eletrodo da liga $\mathrm{La}_{0,7} \mathrm{Pr}_{0,3} \mathrm{Al}_{0,3} \mathrm{Mn}_{0,4} \mathrm{Co}_{0,5} \mathrm{Ni}_{3,8}$ em função de diferentes densidades de corrente de descarga $\left(I_{D}=10,100,200\right.$ e $\left.500 \mathrm{~mA} \mathrm{~g}^{-1}\right)$.

$\mathrm{Na}$ TAB. 22 estão listadas propriedades eletroquímicas e demais dados utilizados no critério de análise dos resultados.

Na FIG. 33 é ilustrado o comportamento da retenção da capacidade de descarga do eletrodo em referência também em função das densidades de corrente de descarga consideradas.

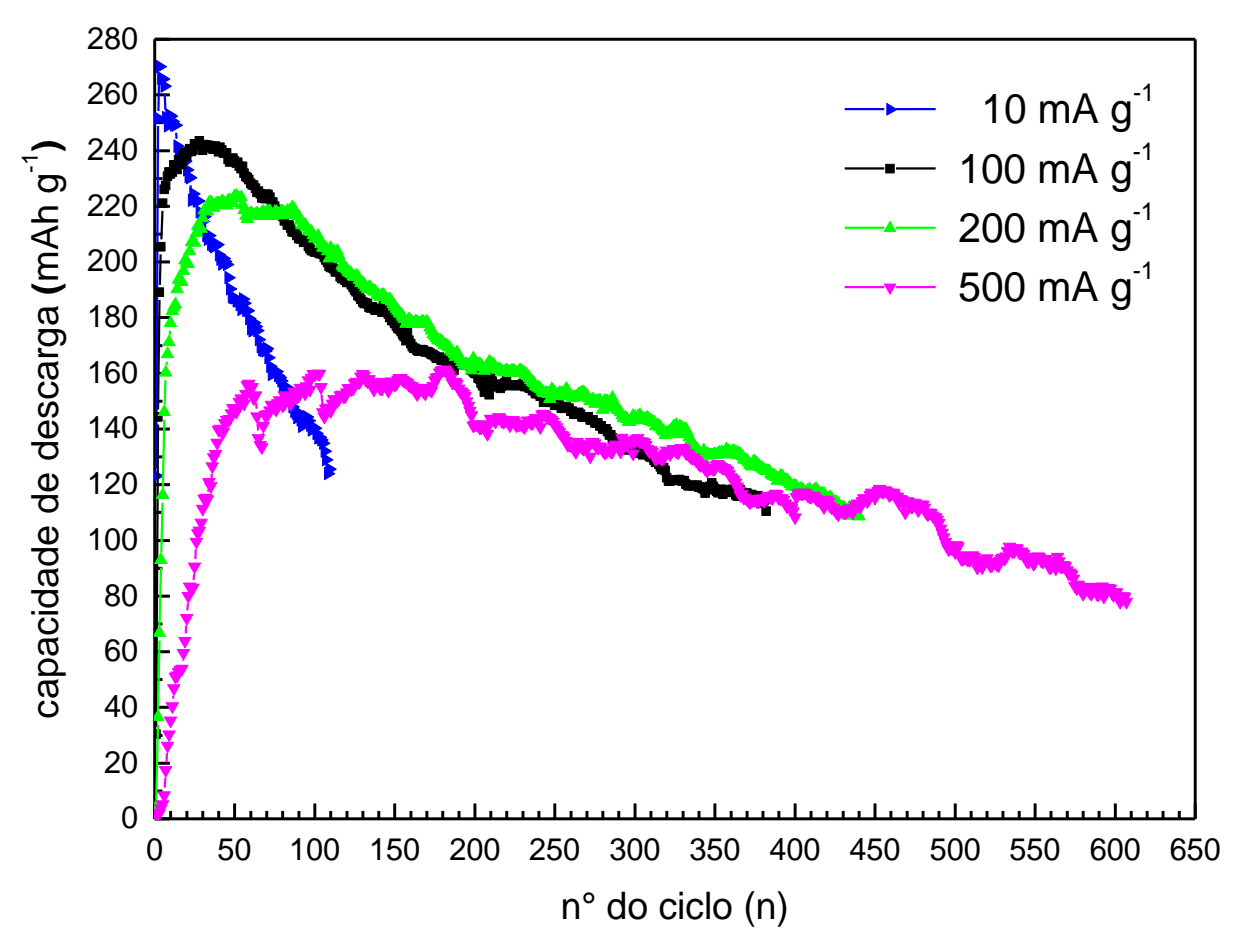

FIGURA 32 - Capacidade de descarga do eletrodo da liga $\mathrm{La}_{0,7} \mathrm{Pr}_{0,3} \mathrm{Al}_{0,3} \mathrm{Mn}_{0,4} \mathrm{Co}_{0,5} \mathrm{Ni}_{3,8}$ em função da densidade de corrente de descarga $\left(I_{D}=10,100,200\right.$ e $\left.500 \mathrm{~mA} \mathrm{~g}^{-1}\right)$. 
TABELA 22 - Propriedades eletroquímicas do eletrodo da liga $\mathrm{La}_{0,7} \mathrm{Pr}_{0,3} \mathrm{Al}_{0,3} \mathrm{Mn}_{0,4} \mathrm{Co}_{0,5} \mathrm{Ni}_{3,8}$ em função da densidade de corrente de descarga $\left(I_{D}\right)$.

\begin{tabular}{ccccccc}
\hline $\begin{array}{c}\mathrm{I}_{\mathrm{D}} \\
\left(\mathrm{mA} \mathrm{g}^{-1}\right)\end{array}$ & $\begin{array}{c}\mathrm{C}_{\text {máx }} \\
\left(\mathrm{mAh} \mathrm{g}^{-1}\right)\end{array}$ & $\begin{array}{c}\mathrm{t}_{\text {desc }} \mathrm{em} \\
\mathrm{C}_{\text {máx }}(\mathrm{h})\end{array}$ & $N_{\mathrm{a}}{ }^{(\mathrm{a})}$ & $\begin{array}{c}\mathrm{S}_{100} \\
(\%)\end{array}$ & $\mathrm{n}_{\text {Cmax/2 }}{ }^{(\mathrm{b})}$ & $\mathrm{n}_{\mathrm{op}}{ }^{(\mathrm{c})}$ \\
\hline 10 & 270,2 & 27,016 & 3 & 51,9 & 105 & $105-3=102$ \\
100 & 243,4 & 2,434 & 28 & 83,6 & 325 & $325-28=297$ \\
200 & 223,7 & 1,119 & 51 & 93,1 & 430 & $430-51=379$ \\
500 & 161,5 & 0,323 & 181 & 98,8 & 580 & $580-181=399$ \\
\hline
\end{tabular}

(a) Número de ciclos necessários para ativar os eletrodos.

(b) Número do ciclo em $\mathrm{C}_{\text {máx }} / 2\left(S_{n}=50 \%\right)$.

(c) Número de ciclos de operação entre $C_{\text {máx }}$ e $C_{\text {máx }} / 2$.

Com o auxílio da FIG. 32 e da TAB. 22, observou-se que quanto menor a densidade de corrente $\left(I_{D}\right)$ imposta, maior o valor da capacidade de descarga máxima $\left(\mathrm{C}_{\text {máx }}\right)$ obtida, além de maior o tempo de descarga, como ilustrado pelos valores em horas ( $t_{\text {desc. }}$ em $C_{\text {máx }}$ ) mostrados na tabela em referência.

Em contrapartida, como pode ser observado pelos dados da TAB. 22 e FIG. 33, relações diretamente proporcionais foram verificadas entre a densidade de corrente de descarga e a ativação $\left(N_{\mathrm{a}}\right)$, bem como em relação à estabilidade cíclica do eletrodo, esta traduzida pela retenção da capacidade de descarga após 100 ciclos de operação $\left(S_{100}\right)$.

Considerando como plausível para viabilidade de operação a redução à metade da capacidade de descarga máxima atingida, na última coluna da TAB. 22 estão listados o número de ciclos de operação correspondentes a este intervalo, descontado o número de ciclos necessários para a ativação dos eletrodos.

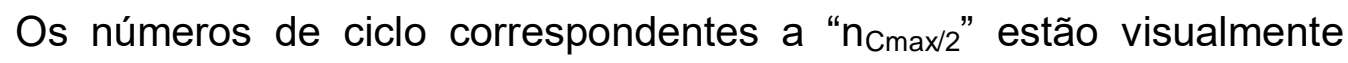
identificados na FIG. 33. Verificou-se que na condição de $I_{D}=500 \mathrm{~mA} \mathrm{~g}^{-1}$, foi obtido o maior número de ciclos no intervalo considerado $\left(\mathrm{n}_{\mathrm{op}}=399\right)$. Nessa condição, obteve-se também, o maior valor de retenção de capacidade de descarga $\left(S_{100}=98,8 \%\right)$, associado ao menor valor de capacidade de descarga máxima $\left(\mathrm{C}_{\text {máx }}=161,5 \mathrm{mAh} \mathrm{g}^{-1}\right)$.

Ainda referente à condição de $I_{D}=500 \mathrm{~mA} \mathrm{~g}^{-1}$, observou-se, durante toda a operação de ciclagem, flutuações significativas nas medidas de 
capacidade de descarga, como pode ser verificado na FIG. 32. Tal comportamento refletiu na dificuldade em se identificar a ativação do eletrodo, bem como no tempo maior de operação (aproximadamente 142 dias) para identificação do número do ciclo correspondente a $\mathrm{C}_{\text {máx }} / 2$.

Para fins de seleção de determinada densidade de corrente de descarga a ser considerada na fase seguinte dos experimentos (3 $3^{\text {a }}$ etapa autodescarga), ponderou-se que o comportamento de descarga na condição de $I_{D}=500 \mathrm{~mA} \mathrm{~g}^{-1}$ pudesse eventualmente mostrar-se inadequado para a natureza das medidas a serem realizadas.

Optou-se, para a etapa seguinte dos experimentos, a condição de densidade de corrente de descarga correspondente a $200 \mathrm{~mA} \mathrm{~g}^{-1}$. Como critério de escolha, foram considerados - preferencialmente ao valor de capacidade de descarga máxima atingido $\left(C_{\text {máx }}=223,7 \mathrm{mAh} \mathrm{g}^{-1}\right)$ - o valor de retenção de capacidade de descarga apresentado $\left(S_{100}=93,1 \%\right)$ e o no de ciclos de operação entre $C_{\text {máx }}$ e $C_{\text {máx }} / 2\left(n_{o p}=379\right)$. 


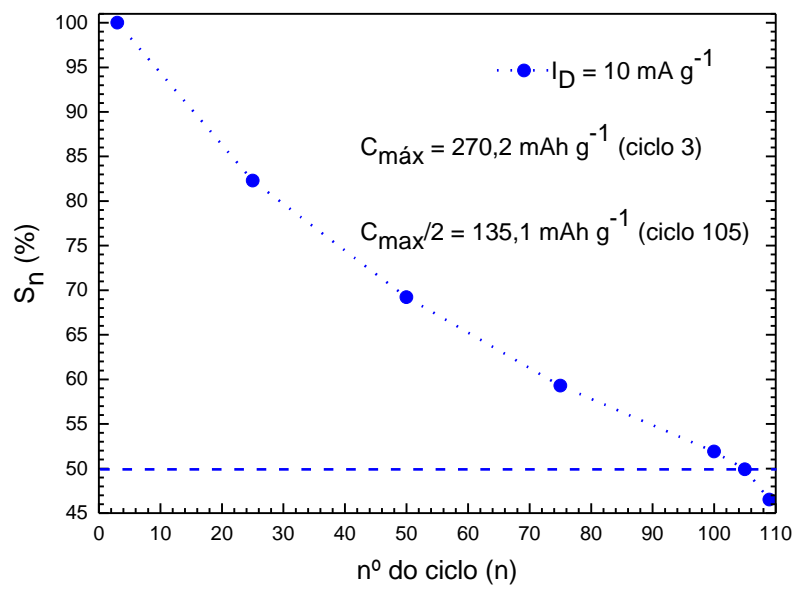

(a)

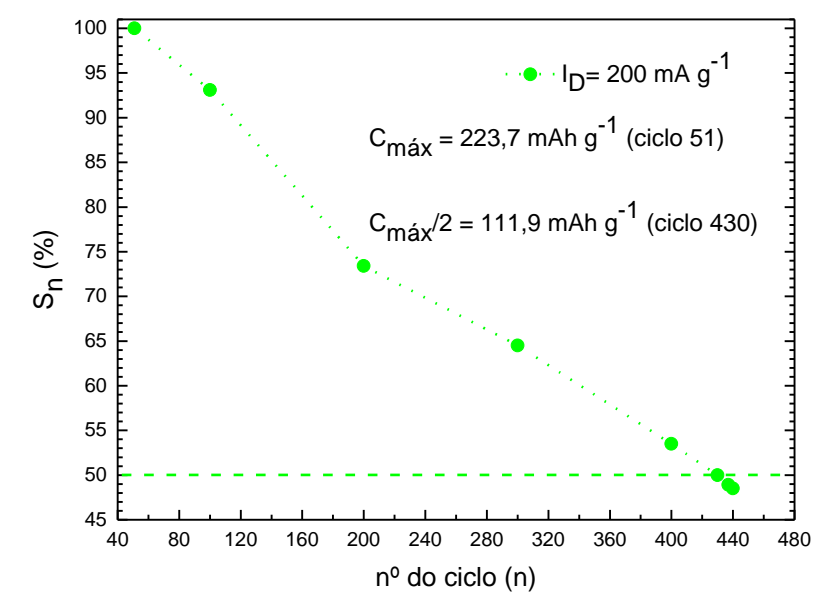

(c)

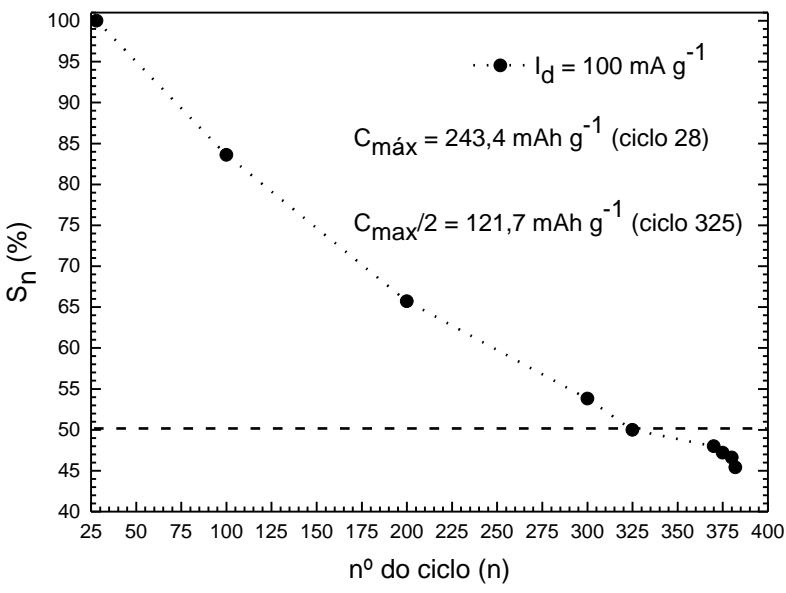

(b)

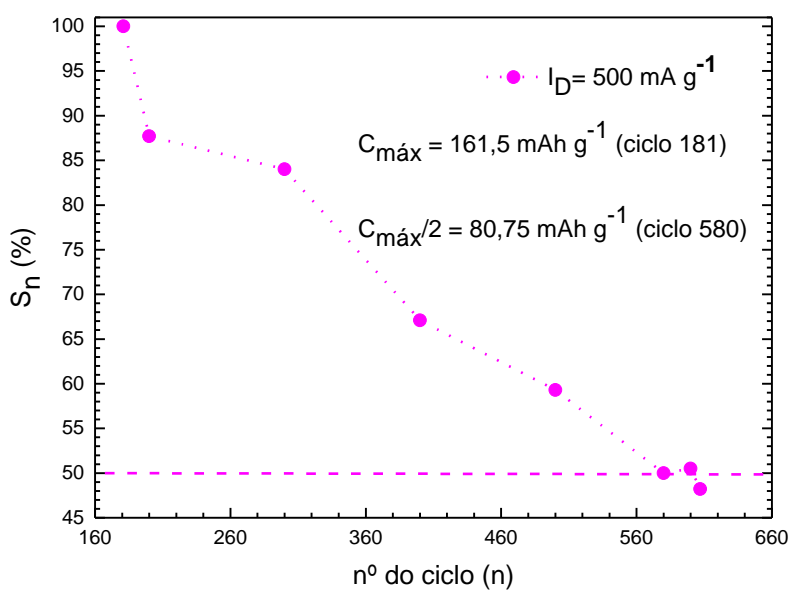

(d)

FIGURA 33 - Retenção da capacidade de descarga do eletrodo da liga $\mathrm{La}_{0,7} \mathrm{Pr}_{0,3} \mathrm{Al}_{0,3} \mathrm{Mn}_{0,4} \mathrm{Co}_{0,5} \mathrm{Ni}_{3,8}$ em função da densidade de corrente de descarga: (a) $10 \mathrm{~mA} \mathrm{~g}^{-1}$, (b) $100 \mathrm{~mA} \mathrm{~g}^{-1}$, (c) $200 \mathrm{~mA} \mathrm{~g}^{-1}$ e (d) $500 \mathrm{~mA} \mathrm{~g}^{-1}$. 


\subsubsection{Autodescarga}

Em adição à definição da densidade de corrente de descarga a ser considerada no estudo de autodescarga dos eletrodos, selecionaram-se três composições de ligas para esta etapa. Como critério de escolha, foram considerados os maiores valores de capacidade de descarga máxima, sendo então designadas as ligas da Série $M g$ das condições $x=0,0$ e $x=0,1$, $\mathrm{La}_{0,7} \mathrm{Pr}_{0,3} \mathrm{Al}_{0,3} \mathrm{Mn}_{0,4} \mathrm{Co}_{0,5} \mathrm{Ni}_{3,8}$, e $\mathrm{La}_{0,6} \mathrm{Mg}_{0,1} \mathrm{Pr}_{0,3} \mathrm{Al}_{0,3} \mathrm{Mn}_{0,4} \mathrm{Co}_{0,5} \mathrm{Ni}_{3,8}$, respectivamente, além da liga da Série Pr na condição $y=0,0, \mathrm{La}_{0,7} \mathrm{Mg}_{0,3} \mathrm{Al}_{0,3} \mathrm{Mn}_{0,4} \mathrm{Co}_{0,5} \mathrm{Ni}_{3,8}$.

Na FIG. 34 são apresentadas as curvas de capacidade de descarga versus número do ciclo de carga/descarga para os eletrodos das referidas ligas durante os experimentos de determinação das taxas de autodescarga correspondentes, à densidade de corrente de descarga de $200 \mathrm{~mA} \mathrm{~g}^{-1}$. No eixo $x$ superior é apresentado o tempo de operação decorrido.

$\mathrm{Na}$ TAB. 23 estão listadas propriedades eletroquímicas dos referidos eletrodos, como capacidade de descarga máxima $\left(\mathrm{C}_{\text {máx }}\right)$, número de ciclos necessários para ativar os eletrodos $\left(N_{\mathrm{a}}\right)$, e retenção da capacidade de descarga em relação aos $100^{\circ}$ s, $220^{\circ}$ S e $420^{\circ}$ s ciclos de operação $\left(S_{100}, S_{220}\right.$ e $\left.S_{420}\right)$, respectivamente.

Analogamente ao observado na $1^{\underline{a}}$ etapa dos estudos realizados neste trabalho - investigação do comportamento de descarga das ligas à densidade de corrente de descarga de $50 \mathrm{~mA} \mathrm{~g}^{-1}$ (vide TAB. 18 e 19) - o eletrodo da liga sem $\mathrm{Mg}, \mathrm{La}_{0,7} \mathrm{Pr}_{0,3} \mathrm{Al}_{0,3} \mathrm{Mn}_{0,4} \mathrm{Co}_{0,5} \mathrm{Ni}_{3,8}$ apresentou, como verificado na FIG. 34 e na TAB. 23, o maior valor de capacidade de descarga máxima (200,9 mAh g$\left.{ }^{-1}\right)$, dentre as três ligas consideradas.

Novamente, a introdução de Mg na composição da liga, na condição de substituição parcial de La por $\mathrm{Mg}\left(\mathrm{La}_{0,6} \mathrm{Mg}_{0,1} \mathrm{Pr}_{0,3} \mathrm{Al}_{0,3} \mathrm{Mn}_{0,4} \mathrm{Co}_{0,5} \mathrm{Ni}_{3,8}\right)$ traduziu-se em um decréscimo na capacidade de descarga máxima obtida pelo eletrodo desta liga, correspondendo a uma redução de aproximadamente 29,3\% $\left(142,1 \mathrm{mAh} \mathrm{g}^{-1}\right)$.

Adicionalmente, a comparação do eletrodo da liga $\mathrm{La}_{0,7} \mathrm{Pr}_{0,3} \mathrm{Al}_{0,3} \mathrm{Mn}_{0,4} \mathrm{Co}_{0,5} \mathrm{Ni}_{3,8}$ com o eletrodo da liga $\mathrm{La}_{0,7} \mathrm{Mg}_{0,3} \mathrm{Al}_{0,3} \mathrm{Mn}_{0,4} \mathrm{Co}_{0,5} \mathrm{Ni}_{3,8}$, revelou que a substituição total de $\operatorname{Pr}$ por $\mathrm{Mg}$, com o teor de La mantido constante, diminuiu a capacidade de descarga máxima obtida. 


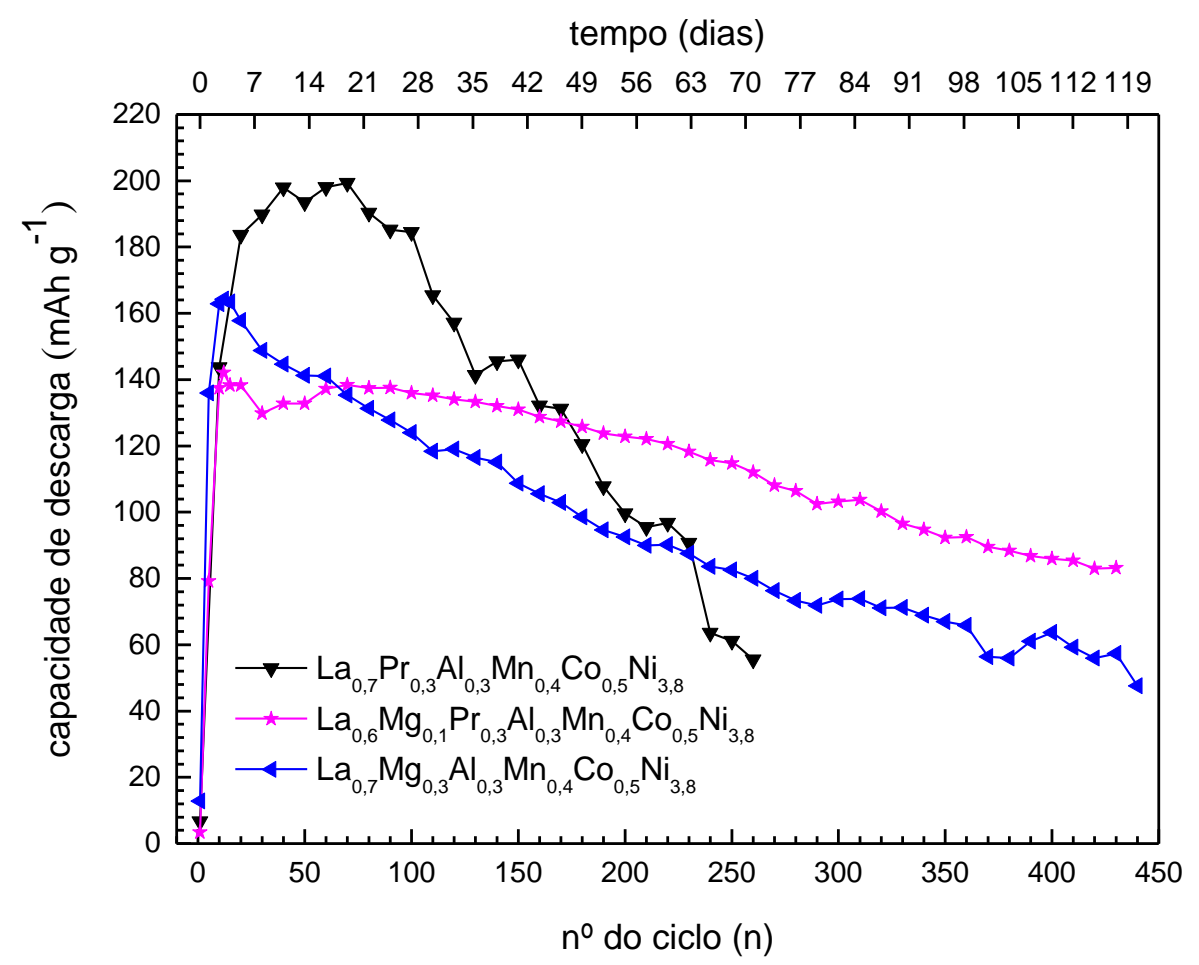

FIGURA 34 - Capacidade de descarga dos eletrodos das ligas $\mathrm{La}_{0,7} \mathrm{Pr}_{0,3} \mathrm{Al}_{0,3} \mathrm{Mn}_{0,4} \mathrm{Co}_{0,5} \mathrm{Ni}_{3,8}, \mathrm{La}_{0,6} \mathrm{Mg}_{0,1} \mathrm{Pr}_{0,3} \mathrm{Al}_{0,3} \mathrm{Mn}_{0,4} \mathrm{Co}_{0,5} \mathrm{Ni}_{3,8}$ e $\mathrm{La}_{0,7} \mathrm{Mg}_{0,3} \mathrm{Al}_{0,3} \mathrm{Mn}_{0,4} \mathrm{Co}_{0,5} \mathrm{Ni}_{3,8}$ durante os experimentos de determinação de autodescarga $\left(I_{D}=200 \mathrm{~mA} \mathrm{~g}^{-1}\right)$.

TABELA 23 - Propriedades eletroquímicas dos eletrodos das ligas $\mathrm{La}_{0,7} \mathrm{Pr}_{0,3} \mathrm{Al}_{0,3} \mathrm{Mn}_{0,4} \mathrm{Co}_{0,5} \mathrm{Ni}_{3,8}, \quad \mathrm{La}_{0,6} \mathrm{Mg}_{0,1} \mathrm{Pr}_{0,3} \mathrm{Al}_{0,3} \mathrm{Mn}_{0,4} \mathrm{Co}_{0,5} \mathrm{Ni}_{3,8}$ e $\mathrm{La}_{0,7} \mathrm{Mg}_{0,3} \mathrm{Al}_{0,3} \mathrm{Mn}_{0,4} \mathrm{Co}_{0,5} \mathrm{Ni}_{3,8}$ durante os experimentos de determinação de autodescarga $\left(I_{D}=200 \mathrm{~mA} \mathrm{~g}^{-1}\right)$.

\begin{tabular}{cccccc}
\hline \multicolumn{1}{c}{ liga } & $\begin{array}{c}\mathrm{C}_{\text {máx }} \\
\left(\mathrm{mAh} \mathrm{g}^{-1}\right)\end{array}$ & $\mathrm{Na}_{\mathrm{a}}{ }^{\mathrm{a}}$ & $\begin{array}{c}\mathrm{S}_{100} \\
(\%)\end{array}$ & $\begin{array}{c}\mathrm{S}_{220} \\
(\%)\end{array}$ & $\begin{array}{c}\mathrm{S}_{430} \\
(\%)\end{array}$ \\
\hline $\mathrm{La}_{0,7} \mathrm{Pr}_{0,3} \mathrm{Al}_{0,3} \mathrm{Mn}_{0,4} \mathrm{Co}_{0,5} \mathrm{Ni}_{3,8}$ & 200,9 & 40 & 91,8 & 48,2 & - \\
$\mathrm{La}_{0,6} \mathrm{Mg}_{0,1} \mathrm{Pr}_{0,3} \mathrm{Al}_{0,3} \mathrm{Mn}_{0,4} \mathrm{Co}_{0,5} \mathrm{Ni}_{3,8}$ & 142,1 & 12 & 95,7 & 84,9 & 58,6 \\
$\mathrm{La}_{0,7} \mathrm{Mg}_{0,3} \mathrm{Al}_{0,3} \mathrm{Mn}_{0,4} \mathrm{Co}_{0,5} \mathrm{Ni}_{3,8}$ & 164,3 & 12 & 75,5 & 54,9 & 34,9 \\
\hline
\end{tabular}

${ }^{a}$ Número de ciclos necessários para ativar os eletrodos.

Ainda com o auxílio da FIG. 34 e da TAB. 23 observou-se que, para o eletrodo da liga sem $\mathrm{Mg}\left(\mathrm{La}_{0,7} \mathrm{Pr}_{0,3} \mathrm{Al}_{0,3} \mathrm{Mn}_{0,4} \mathrm{Co}_{0,5} \mathrm{Ni}_{3,8}\right)$, foram necessários 40 ciclos de carga/descarga (aproximadamente 9 dias de operação) para sua ativação. Os eletrodos cujas ligas apresentaram $\mathrm{Mg}$ em suas composições 
( $\mathrm{La}_{0,6} \mathrm{Mg}_{0,1} \mathrm{Pr}_{0,3} \mathrm{Al}_{0,3} \mathrm{Mn}_{0,4} \mathrm{Co}_{0,5} \mathrm{Ni}_{3,8}$ e $\left.\mathrm{La}_{0,7} \mathrm{Mg}_{0,3} \mathrm{Al}_{0,3} \mathrm{Mn}_{0,4} \mathrm{Co}_{0,5} \mathrm{Ni}_{3,8}\right)$ foram ativados mais prontamente, no $12^{\circ}$ ciclo de carga/descarga (aproximadamente 3 dias de operação). Adicionalmente, pelos valores dispostos na TAB. 23, observou-se que embora apresentando o menor valor de capacidade de descarga máxima (142,1 mAh g ${ }^{-1}$ ), ao eletrodo da liga $\mathrm{La}_{0,6} \mathrm{Mg}_{0,1} \mathrm{Pr}_{0,3} \mathrm{Al}_{0,3} \mathrm{Mn}_{0,4} \mathrm{Co}_{0,5} \mathrm{Ni}_{3,8}$ foram associados os maiores valores de retenção da capacidade de descarga $\left(S_{n}\right)$ ao longo de todo o experimento de determinação da taxa de autodescarga, conferindo a maior estabilidade cíclica ao eletrodo da liga em questão. $O$ aspecto da curva de descarga do eletrodo da liga sem $\mathrm{Mg}\left(\mathrm{La}_{0,7} \mathrm{Pr}_{0,3} \mathrm{Al}_{0,3} \mathrm{Mn}_{0,4} \mathrm{Co}_{0,5} \mathrm{Ni}_{3,8}\right)$ mostrado na FIG. 34, em adição aos valores de retenção da capacidade de descarga dispostos na TAB. 23, indicaram a deterioração da capacidade de descarga do eletrodo após os 100 primeiros ciclos de carga/descarga, o que contribuiu para a redução do tempo total de operação (260 ciclos ou 72 dias). Observou-se, ainda, que a substituição total de $\operatorname{Pr}$ por $\mathrm{Mg}$, comparando a composição das ligas $\mathrm{La}_{0,7} \mathrm{Pr}_{0,3} \mathrm{Al}_{0,3} \mathrm{Mn}_{0,4} \mathrm{Co}_{0,5} \mathrm{Ni}_{3,8}$ e $\mathrm{La}_{0,7} \mathrm{Mg}_{0,3} \mathrm{Al}_{0,3} \mathrm{Mn}_{0,4} \mathrm{Co}_{0,5} \mathrm{Ni}_{3,8}$, traduziu-se na melhoria da estabilidade cíclica e menor deterioração do eletrodo, considerando as condições de operação adotadas. Para as três composições de ligas analisadas nesta fase dos estudos, verificou-se que a presença concomitante de $\mathrm{Mg}$ e $\mathrm{Pr}$ foi favorável à estabilidade cíclica do eletrodo, durante os experimentos de determinação de autodescarga.

$\mathrm{Na}$ FIG. 35 são apresentados os valores calculados para a taxa de autodescarga (SDR) dos eletrodos das ligas $\mathrm{La}_{0,7} \mathrm{Pr}_{0,3} \mathrm{Al}_{0,3} \mathrm{Mn}_{0,4} \mathrm{Co}_{0,5} \mathrm{Ni}_{3,8}$, $\mathrm{La}_{0,6} \mathrm{Mg}_{0,1} \mathrm{Pr}_{0,3} \mathrm{Al}_{0,3} \mathrm{Mn}_{0,4} \mathrm{Co}_{0,5} \mathrm{Ni}_{3,8}$ e $\mathrm{La}_{0,7} \mathrm{Mg}_{0,3} \mathrm{Al}_{0,3} \mathrm{Mn}_{0,4} \mathrm{Co}_{0,5} \mathrm{Ni}_{3,8}$ versus tempo de operação ; o eixo $x$ superior corresponde ao número de ciclos de carga/descarga.

Como observado, o eletrodo da liga sem $\mathrm{Mg}$, La $a_{0,7} \mathrm{Pr}_{0,3} \mathrm{Al}_{0,3} \mathrm{Mn}_{0,4} \mathrm{Co}_{0,5} \mathrm{Ni}_{3,8}$, apresentou, relativamente aos demais eletrodos, menores valores de autodescarga nas duas primeiras determinações (aproximadamente 26 dias de operação ou 120 ciclos). Uma vez que perdas reversíveis de capacidade por autodescarga são atribuídas à desorção do hidrogênio no eletrodo $\mathrm{MH}$ (Yang et al., 2011), pode-se inferir que, neste período de operação, contou-se com maior estabilidade dos hidretos formados pelo eletrodo da liga sem $\mathrm{Mg}$.

No sistema de ligas tipo $A B_{5}$, o platô de pressão de desorção de hidrogênio da forma $\mathrm{MH}$ aumenta gradativamente com a diminuição do volume da 
célula unitária, e, consequentemente, a estabilidade dos hidretos diminui (Zhang, W. et al., 2009). $\mathrm{Na}$ presente etapa do trabalho, as ligas $\mathrm{La}_{0,7} \mathrm{Pr}_{0,3} \mathrm{Al}_{0,3} \mathrm{Mn}_{0,4} \mathrm{Co}_{0,5} \mathrm{Ni}_{3,8}$ e $\mathrm{La}_{0,6} \mathrm{Mg}_{0,1} \mathrm{Pr}_{0,3} \mathrm{Al}_{0,3} \mathrm{Mn}_{0,4} \mathrm{Co}_{0,5} \mathrm{Ni}_{3,8}$ correspondem às substiuições de La por $\mathrm{Mg}$ nas condições $x=0,0$ e $x=0,1$, respectivamente. Para essas, o volume da célula unitária da fase $\mathrm{LaNi}_{5}$, de abundância relevante (vide TAB. 16 e FIG. 11), diminuiu de $89,6 \AA^{3}$ (liga $\mathrm{La}_{0,7} \mathrm{Pr}_{0,3} \mathrm{Al}_{0,3} \mathrm{Mn}_{0,4} \mathrm{Co}_{0,5} \mathrm{Ni}_{3,8}$ ) para 88,5 $\AA^{3}$ (liga $\mathrm{La}_{0,6} \mathrm{Mg}_{0,1} \mathrm{Pr}_{0,3} \mathrm{Al}_{0,3} \mathrm{Mn}_{0,4} \mathrm{Co}_{0,5} \mathrm{Ni}_{3,8}$ ). Presume-se que no período de operação supracitado, contou-se, portanto, com maior estabilidade dos hidretos do eletrodo da liga $\mathrm{La}_{0,7} \mathrm{Pr}_{0,3} \mathrm{Al}_{0,3} \mathrm{Mn}_{0,4} \mathrm{Co}_{0,5} \mathrm{Ni}_{3,8}$, comparativamente àquela observada para o eletrodo da liga $\mathrm{La}_{0,6} \mathrm{Mg}_{0,1} \mathrm{Pr}_{0,3} \mathrm{Al}_{0,3} \mathrm{Mn}_{0,4} \mathrm{Co}_{0,5} \mathrm{Ni}_{3,8}$.

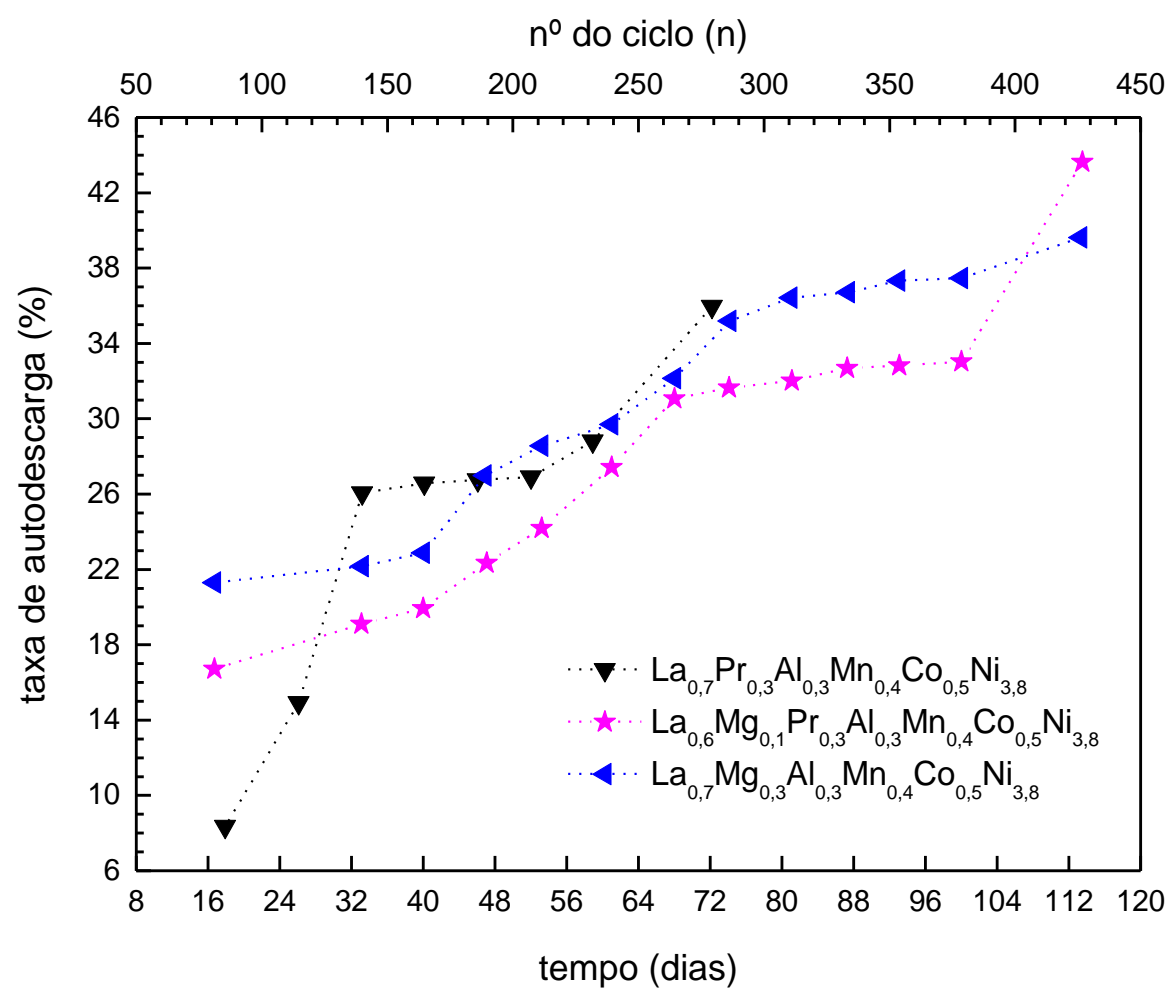

FIGURA 35 - Taxa de autodescarga dos eletrodos das ligas $\mathrm{La}_{0,7} \mathrm{Pr}_{0,3} \mathrm{Al}_{0,3} \mathrm{Mn}_{0,4}$ $\mathrm{Co}_{0,5} \mathrm{Ni}_{3,8}, \quad \mathrm{La}_{0,6} \mathrm{Mg}_{0,1} \mathrm{Pr}_{0,3} \mathrm{Al}_{0,3} \mathrm{Mn}_{0,4} \mathrm{Co}_{0,5} \mathrm{Ni}_{3,8}$ e $\mathrm{La}_{0,7} \mathrm{Mg}_{0,3} \mathrm{Al}_{0,3} \mathrm{Mn}_{0,4}$ $\mathrm{Co}_{0,5} \mathrm{Ni}_{3,8}\left(\mathrm{I}_{\mathrm{D}}=200 \mathrm{~mA} \mathrm{~g}^{-1}\right)$.

Ainda para o eletrodo da liga $\mathrm{La}_{0,7} \mathrm{Pr}_{0,3} \mathrm{Al}_{0,3} \mathrm{Mn}_{0,4} \mathrm{Co}_{0,5} \mathrm{Ni}_{3,8}$ observouse, com o auxílio da FIG. 36 (a), que no mesmo período de operação em referência, foram verificados valores elevados de retenção da capacidade de descarga $(99,1 \%$ e $79,2 \%$ para as duas primeiras medidas de SDR, respectivamente), indicando maior estabilidade cíclica para o eletrodo neste 


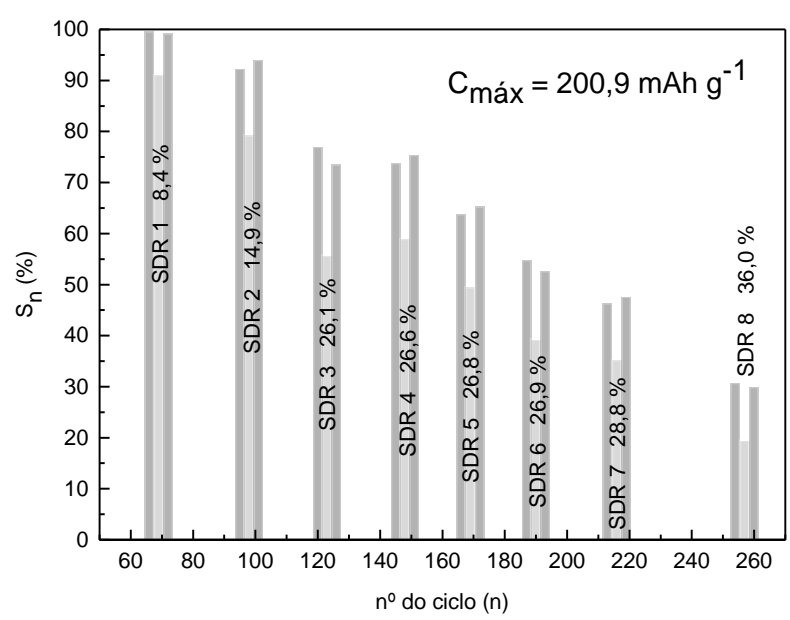

(a)

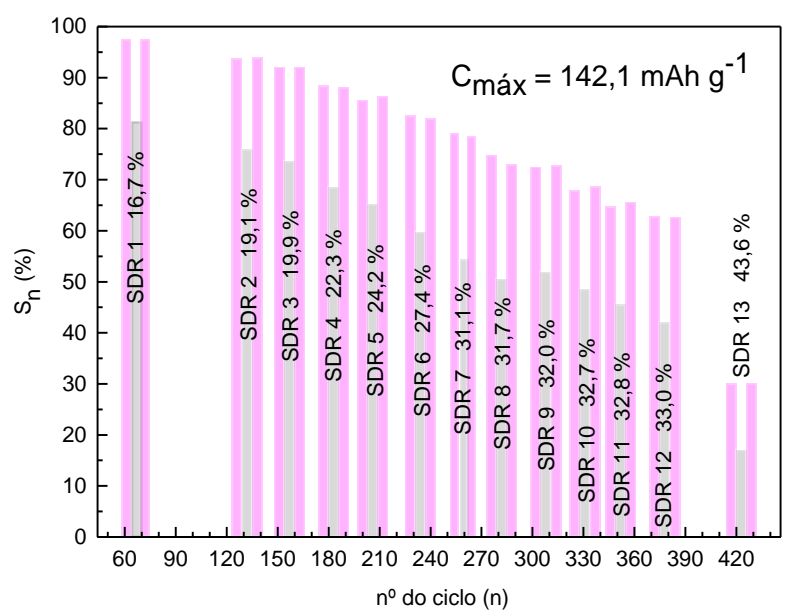

(b)

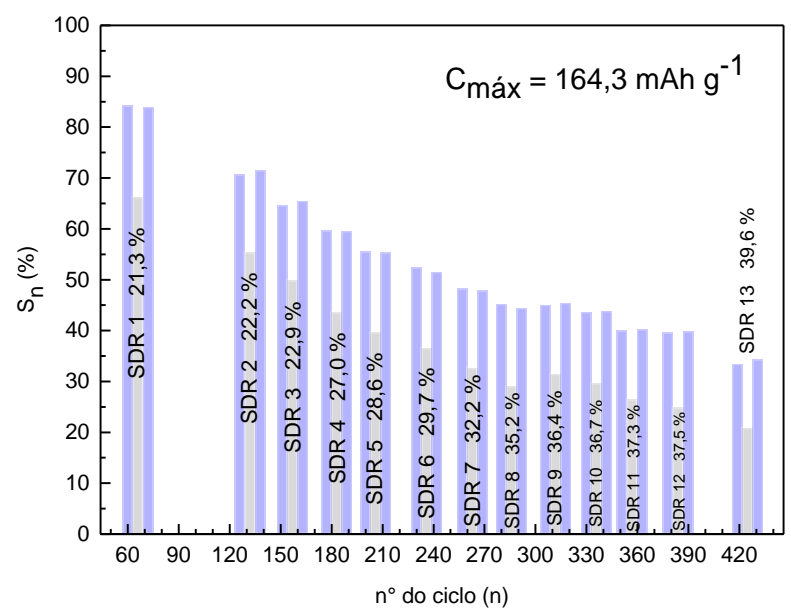

(c)

FIGURA 36 - Retenção da capacidade de descarga dos eletrodos das ligas (a) $\mathrm{La}_{0,7} \mathrm{Pr}_{0,3} \mathrm{Al}_{0,3} \mathrm{Mn}_{0,4} \mathrm{Co}_{0,5} \mathrm{Ni}_{3,8}$, (b) $\mathrm{La}_{0,6} \mathrm{Mg}_{0,1} \mathrm{Pr}_{0,3} \mathrm{Al}_{0,3} \mathrm{Mn}_{0,4}$ $\mathrm{Co}_{0,5} \mathrm{Ni}_{3,8}$ e (c) $\mathrm{La}_{0,7} \mathrm{Mg}_{0,3} \mathrm{Al}_{0,3} \mathrm{Mn}_{0,4} \mathrm{Co}_{0,5} \mathrm{Ni}_{3,8}$ durante as medidas de autodescarga indicadas $\left(I_{D}=200 \mathrm{~mA} \mathrm{~g}^{-1}\right)$. 
período. A continuidade da operação, no entanto, revelou uma queda significativa na retenção da capacidade de descarga para 0 eletrodo da liga $\mathrm{La}_{0,7} \mathrm{Pr}_{0,3} \mathrm{Al}_{0,3} \mathrm{Mn}_{0,4} \mathrm{Co}_{0,5} \mathrm{Ni}_{3,8}$, bem como o aumento nos valores de SDR, ultrapasando aqueles determinados para os demais eletrodos. Tal comportamento permite considerar que, com o prolongamento da operação segundo as condições de operação adotadas, perdas irreversíveis na capacidade devido à degradação do eletrodo $\mathrm{MH}$ da liga sem $\mathrm{Mg}$, $\mathrm{La}_{0,7} \mathrm{Pr}_{0,3} \mathrm{Al}_{0,3} \mathrm{Mn}_{0,4} \mathrm{Co}_{0,5} \mathrm{Ni}_{3,8}$, foram determinantes para a autodescarga do mesmo.

A interpretação conjunta dos valores de SDR representados na FIG. 35, e das taxas de retenção de capacidade de descarga calculados para os eletrodos das ligas $\mathrm{La}_{0,6} \mathrm{Mg}_{0,1} \mathrm{Pr}_{0,3} \mathrm{Al}_{0,3} \mathrm{Mn}_{0,4} \mathrm{Co}_{0,5} \mathrm{Ni}_{3,8} \quad$ e $\mathrm{La}_{0,7} \mathrm{Mg}_{0,3} \mathrm{Al}_{0,3} \mathrm{Mn}_{0,4} \mathrm{Co}_{0,5} \mathrm{Ni}_{3,8}$ listados na TAB. 23 - e representados na FIG. 36 (b) e (c), respectivamente - permite ainda considerar que, comparativamente, verificou-se maior estabilidade cíclica e maior estabilidade dos hidretos formados para o eletrodo da liga $\mathrm{La}_{0,6} \mathrm{Mg}_{0,1} \mathrm{Pr}_{0,3} \mathrm{Al}_{0,3} \mathrm{Mn}_{0,4} \mathrm{Co}_{0,5} \mathrm{Ni}_{3,8}$ (valores de taxa de autodescarga menores que os do eletrodo da liga $\left.\mathrm{La}_{0,7} \mathrm{Mg}_{0,3} \mathrm{Al}_{0,3} \mathrm{Mn}_{0,4} \mathrm{Co}_{0,5} \mathrm{Ni}_{3,8}\right)$ ao longo de praticamente todo o tempo de operação. Observou-se que após uma ascendência considerável (até o 260 ciclo ou primeiros 68 dias de operação), o aumento nos valores de SDR para o eletrodo da liga em referência foi mais brando, para elevar-se novamente ao final da operação. A tendência descrita foi menos pronunciada para o eletrodo da liga sem $\operatorname{Pr}, \mathrm{La}_{0,7} \mathrm{Mg}_{0,3} \mathrm{Al}_{0,3} \mathrm{Mn}_{0,4} \mathrm{Co}_{0,5} \mathrm{Ni}_{3,8}$, que, aos maiores valores de SDR, foram associados menores valores de retenção de capacidade de descarga em toda a operação realizada.

Relativamente, pode-se considerar que o processo de autodescarga do eletrodo da liga $\mathrm{La}_{0,7} \mathrm{Mg}_{0,3} \mathrm{Al}_{0,3} \mathrm{Mn}_{0,4} \mathrm{Co}_{0,5} \mathrm{Ni}_{3,8}$ ocorreu de forma mais acentuada que 0 do eletrodo da liga $\mathrm{La}_{0,6} \mathrm{Mg}_{0,1} \mathrm{Pr}_{0,3} \mathrm{Al}_{0,3} \mathrm{Mn}_{0,4} \mathrm{Co}_{0,5} \mathrm{Ni}_{3,8}$. Para este, o decaimento da capacidade de descarga foi menor ao longo de toda a operação, resultando em melhor performance no experimento de determinação de autodescarga.

Em vista dos resultados obtidos, optou-se por considerar as ligas $\mathrm{La}_{0,6} \mathrm{Mg}_{0,1} \mathrm{Pr}_{0,3} \mathrm{Al}_{0,3} \mathrm{Mn}_{0,4} \mathrm{Co}_{0,5} \mathrm{Ni}_{3,8}$ e $\mathrm{La}_{0,7} \mathrm{Mg}_{0,3} \mathrm{Al}_{0,3} \mathrm{Mn}_{0,4} \mathrm{Co}_{0,5} \mathrm{Ni}_{3,8}$ para a etapa seguinte dos estudos - avaliação da cinética eletroquímica dos eletrodos das ligas por determinação da alta taxa de descarga. 


\subsubsection{Alta taxa de descarga}

Na FIG. 37 estão representados os valores calculados para a alta taxa de descarga (HRD) dos eletrodos das ligas $\mathrm{La}_{0,6} \mathrm{Mg}_{0,1} \mathrm{Pr}_{0,3} \mathrm{Al}_{0,3} \mathrm{Mn}_{0,4} \mathrm{Co}_{0,5} \mathrm{Ni}_{3,8}$ e $\mathrm{La}_{0,7} \mathrm{Mg}_{0,3} \mathrm{Al}_{0,3} \mathrm{Mn}_{0,4} \mathrm{Co}_{0,5} \mathrm{Ni}_{3,8}$, em função da densidade de corrente de descarga aplicada $\left(I_{D}=250,300,400,500,750 \mathrm{~mA} \mathrm{~g}^{-1}\right)$; na FIG. 38 são mostrados os perfis de descarga correspondentes.

Observou-se, pela FIG. 37, que o parâmetro HRD de ambos os eletrodos decresceu com o aumento da densidade de corrente de descarga. Evidenciou-se, assim, a redução da cinética dos eletrodos com a elevação da densidade de corrente de descarga imposta.

Comparativamente, pode-se inferir que 0 eletrodo da liga $\mathrm{La}_{0,7} \mathrm{Mg}_{0,3} \mathrm{Al}_{0,3} \mathrm{Mn}_{0,4} \mathrm{Co}_{0,5} \mathrm{Ni}_{3,8}$ apresentou uma performance eletroquímica melhor do que o eletrodo da liga $\mathrm{La}_{0,6} \mathrm{Mg}_{0,1} \mathrm{Pr}_{0,3} \mathrm{Al}_{0,3} \mathrm{Mn}_{0,4} \mathrm{Co}_{0,5} \mathrm{Ni}_{3,8}$.

Observou-se, ainda, que a despeito da condição de descarga $I_{D}=750 \mathrm{~mA} \mathrm{~g}^{-1}$, onde os valores de HRD se inverteram, os demais valores deste parâmetro para eletrodo da liga sem Pr foram superiores.

A melhor cinética eletroquímica do eletrodo da liga $\mathrm{La}_{0,7} \mathrm{Mg}_{0,3} \mathrm{Al}_{0,3} \mathrm{Mn}_{0,4} \mathrm{Co}_{0,5} \mathrm{Ni}_{3,8}$ foi também percebida quando observados os menores tempos de descarga para os valores de $I_{D}$ impostos, em comparação àqueles obtidos para o eletrodo da liga $\mathrm{La}_{0,6} \mathrm{Mg}_{0,1} \mathrm{Pr}_{0,3} \mathrm{Al}_{0,3} \mathrm{Mn}_{0,4} \mathrm{Co}_{0,5} \mathrm{Ni}_{3,8}$, como pode ser verificado nos perfis de descarga apresentados na FIG. 38. A diminuição nos valores de HRD com o aumento do teor de Pr foi reportado para $x \geq 0,25 \mathrm{em}$ ligas $\mathrm{La}_{0,7-x} \mathrm{Pr}_{x} \mathrm{Mg}_{0,3} \mathrm{Ni}_{2,45} \mathrm{Co}_{0,75} \mathrm{Mn}_{0,1} \mathrm{Al}_{0,2}$ (x=0,0-0,3) (Pan et al., 2007).

No presente estudo, observou-se também que a não substituição de La por Mg parece ter auxiliado positivamente na cinética do eletrodo. 


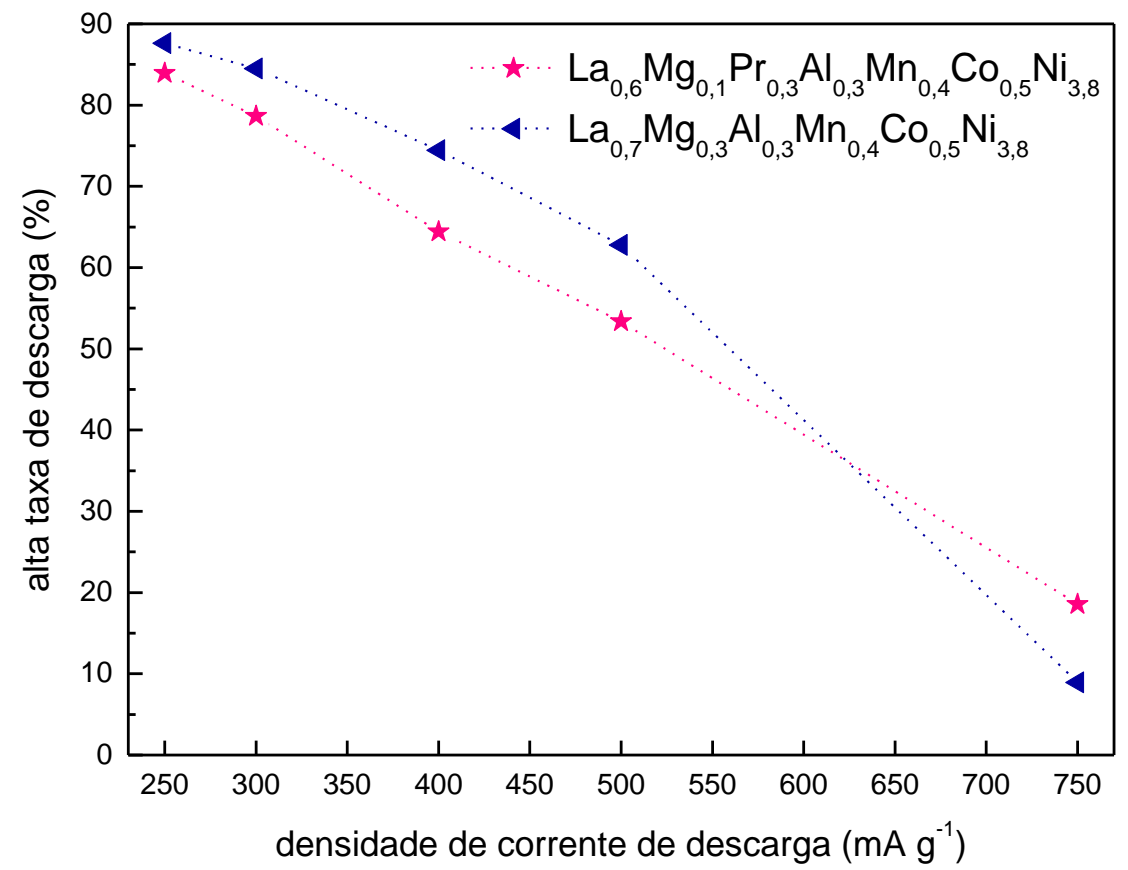

FIGURA 37 - Alta taxa de descarga dos eletrodos das ligas $\mathrm{La}_{0,6} \mathrm{Mg}_{0,1} \mathrm{Pr}_{0,3} \mathrm{Al}_{0,3} \mathrm{Mn}_{0,4} \mathrm{Co}_{0,5} \mathrm{Ni}_{3,8}$ e $\mathrm{La}_{0,7} \mathrm{Mg}_{0,3} \mathrm{Al}_{0,3} \mathrm{Mn}_{0,4} \mathrm{Co}_{0,5} \mathrm{Ni}_{3,8}$ em função da densidade de corrente de descarga $\left(I_{D}=250,300,400,500\right.$ e $\left.750 \mathrm{~mA} \mathrm{~g}^{-1}\right)$. 


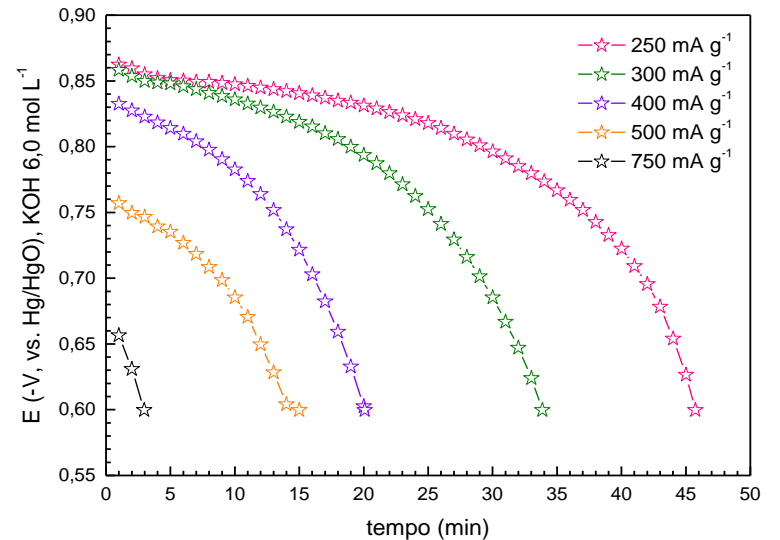

(a)

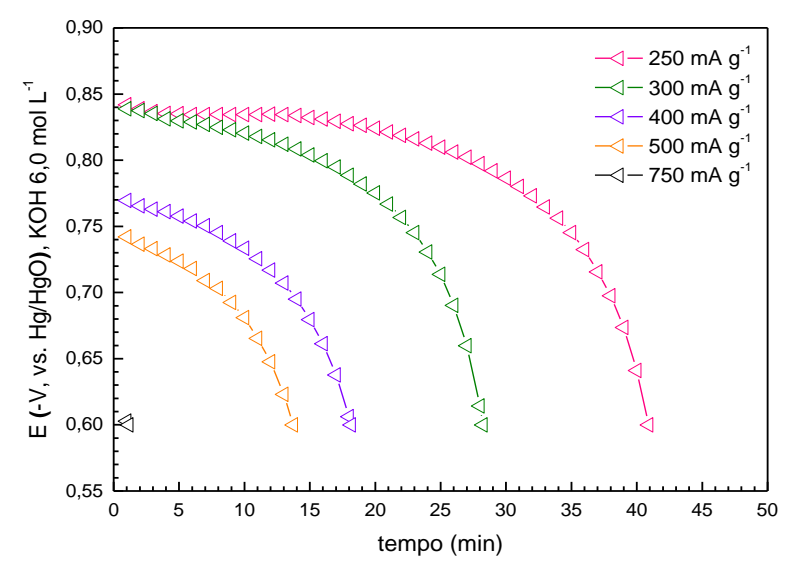

(c)

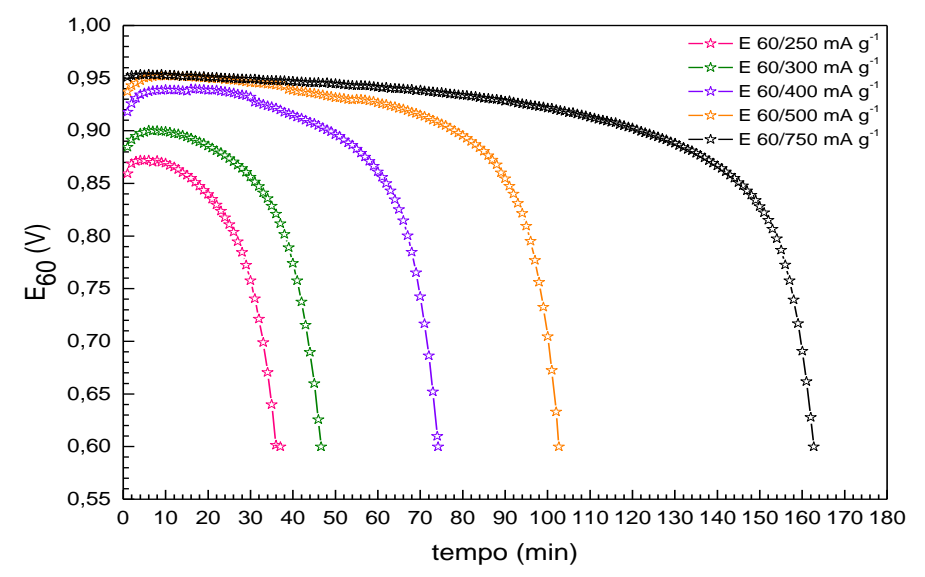

(b)

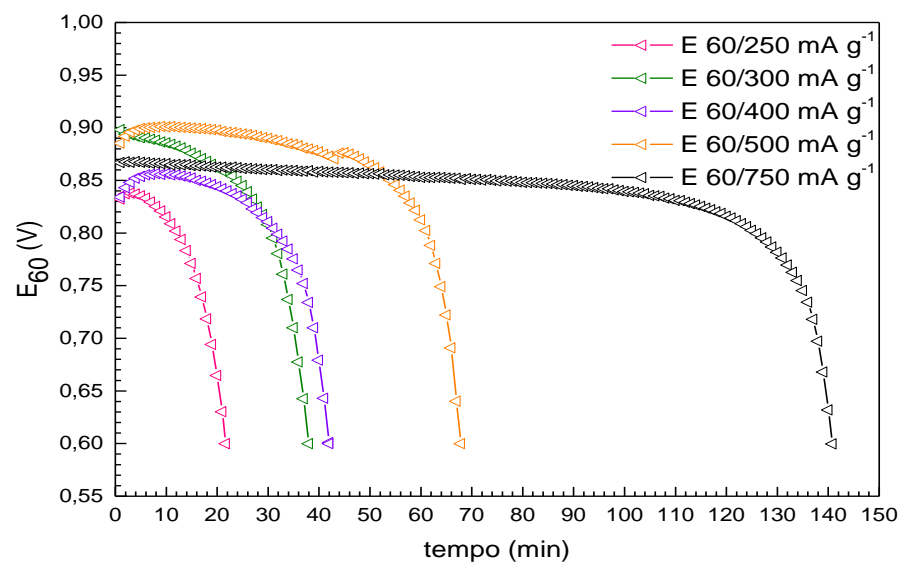

(d)

FIGURA 38 - Perfis de descarga dos eletrodos das ligas $\mathrm{La}_{0,6} \mathrm{Mg}_{0,1} \operatorname{Pr}_{0,3} \mathrm{Al}_{0,3} \mathrm{Mn}_{0,4} \mathrm{Co}_{0,5} \mathrm{Ni}_{3,8} \quad$ (a) $\mathrm{I}_{\mathrm{D}}=250-750 \mathrm{~mA} \mathrm{~g}^{-1}$ e (b) $I_{D}=60 / 250-750 \mathrm{~mA} \mathrm{~g}^{-1}$ e $\mathrm{La}_{0,7} \mathrm{Mg}_{0,3} \mathrm{Al}_{0,3} \mathrm{Mn}_{0,4} \mathrm{Co}_{0,5} \mathrm{Ni}_{3,8}$ (c) $\mathrm{I}_{\mathrm{D}}=250-750 \mathrm{~mA} \mathrm{~g}{ }^{-1}$ e (d) $\mathrm{I}_{\mathrm{D}}=60 / 250-750 \mathrm{~mA} \mathrm{~g}^{-1}$. 
Possivelmente, os maiores valores de HRD observados para o eletrodo da liga $\mathrm{La}_{0,7} \mathrm{Mg}_{0,3} \mathrm{Al}_{0,3} \mathrm{Mn}_{0,4} \mathrm{Co}_{0,5} \mathrm{Ni}_{3,8}$ estiveram associados, também, a algumas características estruturais observadas.

Na FIG. 39 está representada a abundância das fases presentes nas ligas $\mathrm{La}_{0,6} \mathrm{Mg}_{0,1} \mathrm{Pr}_{0,3} \mathrm{Al}_{0,3} \mathrm{Mn}_{0,4} \mathrm{Co}_{0,5} \mathrm{Ni}_{3,8}$ (1) e $\mathrm{La}_{0,7} \mathrm{Mg}_{0,3} \mathrm{Al}_{0,3} \mathrm{Mn}_{0,4} \mathrm{Co}_{0,5} \mathrm{Ni}_{3,8}$ (2), de acordo com os resultados obtidos pelo método de Rietveld (vide TAB. 16 para $x=0,1$ e vide TAB. 17 para $y=0,0$, respectivamente).

(1)

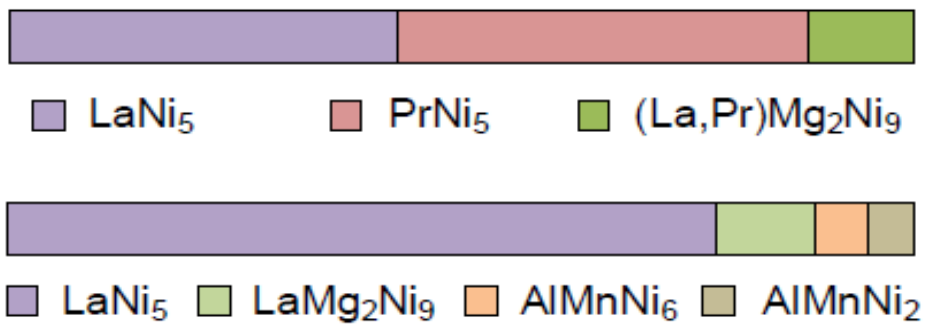

(2)

$\mathrm{LaNi}_{5} \square \mathrm{LaMg}_{2} \mathrm{Ni}_{9} \square \mathrm{AlMnNi}_{6} \square \mathrm{AlMnNi}_{2}$

FIGURA 39 - Abundância de fases nas ligas (1) $\mathrm{La}_{0,6} \mathrm{Mg}_{0,1} \mathrm{Pr}_{0,3} \mathrm{Al}_{0,3} \mathrm{Mn}_{0,4} \mathrm{Co}_{0,5} \mathrm{Ni}_{3,8}$ e (2) $\mathrm{La}_{0,7} \mathrm{Mg}_{0,3} \mathrm{Al}_{0,3} \mathrm{Mn}_{0,4} \mathrm{Co}_{0,5} \mathrm{Ni}_{3,8}$.

Comparativamente, a liga $\mathrm{La}_{0,7} \mathrm{Mg}_{0,3} \mathrm{Al}_{0,3} \mathrm{Mn}_{0,4} \mathrm{Co}_{0,5} \mathrm{Ni}_{3,8}$ pareceu deter algumas vantagens sobre a liga $\mathrm{La}_{0,6} \mathrm{Mg}_{0,1} \mathrm{Pr}_{0,3} \mathrm{Al}_{0,3} \mathrm{Mn}_{0,4} \mathrm{Co}_{0,5} \mathrm{Ni}_{3,8}$. A cinética de absorção/desorção de hidrogênio do eletrodo da liga $\mathrm{La}_{0,7} \mathrm{Mg}_{0,3} \mathrm{Al}_{0,3} \mathrm{Mn}_{0,4} \mathrm{Co}_{0,5} \mathrm{Ni}_{3,8}$ pode ter sido favorecida pela atuação catalítica que os elevados teores de $\mathrm{Ni}$ observados nas fases constituintes da referida liga exerceram (Zhang, Z. et al., 2007). A presença da fase $A I M n N i$, que exibe uma alta solubilidade em $\mathrm{KOH}$, pode ter contribuído para conservar a superficie do eletrodo da liga mais ativa, retardando as taxas de corrosão/pulverização durante o processo (Young, 2016).

Ainda, em termos gerais, é aceito que contornos de grão entre diferentes fases e a presença de microtrincas podem proporcionar um número maior de túneis para a difusão do hidrogênio (Tian et al., 2016), auxiliando seu transporte - o que pode ter ocorrido em maiores proporções no eletrodo da liga $\mathrm{La}_{0,7} \mathrm{Mg}_{0,3} \mathrm{Al}_{0,3} \mathrm{Mn}_{0,4} \mathrm{Co}_{0,5} \mathrm{Ni}_{3,8}$. 
Convém reportar que, usualmente, o parâmetro HRD de um eletrodo $\mathrm{MH}$ é determinado pelo processo de transferência de carga que ocorre na interface metal/eletrólito e/ou pelo processo de difusão do hidrogênio do interior da liga (Yan et al., 2009; Yang et al., 2011; Zhang, Y. et al., 2015).

Considerando as informações a respeito da cinética envolvida no processo de absorção/desorção do hidrogênio expostas no item 3.3.1, e a performance cinética dos dois eletrodos na presente etapa do estudo realizado, pressupõe-se que ao eletrodo da liga $\mathrm{La}_{0,7} \mathrm{Mg}_{0,3} \mathrm{Al}_{0,3} \mathrm{Mn}_{0,4} \mathrm{Co}_{0,5} \mathrm{Ni}_{3,8}$ estiveram associados maiores valores de densidade de corrente de troca e/ou de densidade de corrente limitante. Tal suposição estaria em acordo com os resultados para o parâmetro HRD obtidos, em concordância à sua dependência frente aos processos considerados. 


\section{CONCLUSÕES}

Para as composições das ligas consideradas no presente trabalho, tanto para a Série $\mathrm{Mg}\left(\mathrm{La}_{0,7-x} \mathrm{Mg}_{x} \mathrm{Pr}_{0,3} \mathrm{Al}_{0,3} \mathrm{Mn}_{0,4} \mathrm{Co}_{0,5} \mathrm{Ni}_{3,8}\right)$, quanto para a Série $\mathrm{Pr}$ $\left(\mathrm{La}_{0,7-y} \mathrm{Pr}_{y} \mathrm{Mg}_{0,3} \mathrm{Al}_{0,3} \mathrm{Mn}_{0,4} \mathrm{Co}_{0,5} \mathrm{Ni}_{3,8}\right)(x=y=0,0 ; 0,1 ; 0,3 ; 0,5 ; 0,7)$, concluiu-se que as substituições propostas não atuaram positivamente para 0 aumento da capacidade de descarga dos eletrodos correspondentes. Tanto os valores obtidos para esse parâmetro eletroquímico fundamental, como os relacionados aos demais parâmetros determinados, refletiram uma forte dependência em relação à estrutura de fases, suas abundâncias, além das modificações morfológicas observadas. Evidenciou-se, também, que a faixa de substituição adotada $(0,0$ a 0,7$)$ foi consideravelmente significativa para a deterioração da capacidade de descarga dos eletrodos.

Pontuando as afirmações anteriores, podem ser agregadas as seguintes considerações:

(a) - A substituição de La por Mg nas ligas da Série Mg resultou em uma modificação na estrutura dos grãos (equiaxial para colunar) bem mais acentuada do que a substituição de La por Pr nas ligas da Série Pr proporcionou (estrutura predominantemente dendrítica);

(b) - As fases detectadas e suas abundâncias variaram em função da concentração dos elementos de substituição nas ligas e do estado bruto de fusão das mesmas;

(c) - Os elementos envolvidos nas substituições propostas distribuiramse, preferencialmente, segundo as fases:

La e Pr: fases similares às fases de referência $\mathrm{LaNi}_{5}, \mathrm{PrNi}_{5}, \mathrm{LaMg}_{2} \mathrm{Ni}_{9}, \operatorname{PrMg}_{2} \mathrm{Ni}_{9}$; Mg: fases similares às fases de referência $\mathrm{LaMg}_{2} \mathrm{Ni}_{9}$ e $\mathrm{PrMg}_{2} \mathrm{Ni}_{9}$. 
(d) - A substituição crescente de La por Mg e de La por Pr deteriorou a capacidade de descarga dos eletrodos das ligas, acompanhando a modificação na estrutura dos grãos observada;

(e) - Os perfis de ativação e de descarga, os resultados de retenção da capacidade de descarga e, em destaque, o acréscimo nos valores de capacidade de descarga máxima dos eletrodos obtidos após o tratamento térmico das ligas (<10 \%), não justificaram sua adoção como etapa a ser incluída na execução dos estudos eletroquímicos subsequentes;

(f) - A abundância maior da fase similar à fase $\mathrm{LaNi}_{5}$ favoreceu positivamente a performance de descarga dos eletrodos das ligas, enquanto que a presença maior da fase similar à fase $\mathrm{LaMg}_{2} \mathrm{Ni}_{9}$ exerceu efeito contrário;

(g) - A densidade de corrente de descarga afetou a performance de descarga do eletrodo da liga $\mathrm{La}_{0,7} \mathrm{Pr}_{0,3} \mathrm{Al}_{0,3} \mathrm{Mn}_{0,4} \mathrm{Co}_{0,5} \mathrm{Ni}_{3,8} \quad(x=0,0)$, com valores crescentes de densidade de descarga diminuindo a capacidade de descarga máxima e aumentando a estabilidade cíclica;

(h) - A presença concomitante de $\mathrm{Mg}$ e de $\mathrm{Pr}$ - liga $\mathrm{La}_{0,6} \mathrm{Mg}_{0,1} \mathrm{Pr}_{0,3} \mathrm{Al}_{0,3} \mathrm{Mn}_{0,4} \mathrm{Co}_{0,5} \mathrm{Ni}_{3,8}(x=0,1)$ - foi favorável à estabilidade cíclica e à menor taxa de autodescarga do eletrodo da liga, indicando maior estabilidade dos hidretos formados nessa condição;

(i) - A ausência de $\mathrm{Pr}$, bem como a não substituição de La por $\mathrm{Mg}$ - liga $\mathrm{La}_{0,7} \mathrm{Mg}_{0,3} \mathrm{Al}_{0,3} \mathrm{Mn}_{0,4} \mathrm{Co}_{0,5} \mathrm{Ni}_{3,8} \quad(y=0,0)$ - favoreceram a performance cinética do eletrodo correspondente, com maiores valores de alta taxa de descarga e menores tempos de descarga associados. 


\section{SUGESTÕES PARA TRABALHOS FUTUROS}

A partir da análise dos resultados obtidos no presente trabalho, uma tendência bastante natural de sugestão repousaria na proposta de alterações pontuais nas composições das ligas consideradas, visando a melhora da performance eletroquímica dos eletrodos. Nesse entendimento, as composições que resultaram em melhor cinética de descarga e menores taxas de autodescarga obtidas, respectivamente eletrodos das ligas $\mathrm{La}_{0,7} \mathrm{Mg}_{0,3} \mathrm{Al}_{0,3} \mathrm{Mn}_{0,4} \mathrm{Co}_{0,5} \mathrm{Ni}_{3,8}(y=0,0)$ e $\mathrm{La}_{0,6} \mathrm{Mg}_{0,1} \mathrm{Pr}_{0,3} \mathrm{Al}_{0,3} \mathrm{Mn}_{0,4} \mathrm{Co}_{0,5} \mathrm{Ni}_{3,8} \quad(x=0,1)$, poderiam servir de base para outras que direcionassem à formação de superestruturas favoráveis a um aumento na absorção de hidrogênio e, consequentemente, à elevação da capacidade de descarga.

Como proposta, composições com menores teores de níquel e de algum outro componente do lado B poderiam conduzir a sistemas de ligas de composição $A B_{3,0-3,75}$. Tais sistemas possivelmente beneficiariam estruturas mais favoráveis - como um todo - a uma performance eletroquímica melhor dos eletrodos das ligas correspondentes. 


\section{REFERÊNCIAS BIBLIOGRÁFICAS}

ADZIC, G.D.; JOHNSON, J.R.; MUKERJEE, S.; McBREEN, J.; REILLY, J.J. Function of cobalt in $\mathrm{AB}_{5} \mathrm{H}_{\mathrm{x}}$ electrodes. J. Alloys Compd., v. 253-254, p. 579-582, 1997.

ADZIC, G.D.; JOHNSON, J.R.; REILLY, J.J.; McBREEN, J.; MUKERJEE, S.; SRIDHAR KUMAR, M.P.; ZHANG, W.; SRINIVASAN, S. Cerium content and cycle life of multicomponent $A B_{5}$ hydride electrodes. J. Electrochem. Soc., v. 142, n. 10, p. 3429-3433, 1995.

AMBROSIO, R.C.; TICIANELLI, E.A. Baterias de níquel-hidreto metálico, uma alternativa para as baterias de níquel-cádmio. Quim. Nova, v. 24, n. 2 , p. 243-246, 2001.

BANCZEK, E.P.; ZARPELON, L.M.C.; FARIA, R.N.; COSTA, I. Corrosion resistance and microstructure characterization of rare-earth-transition metal-aluminum-magnesium alloys. J. Alloys Compd., v. 479, n. 1-2, p. 342-347, 2009.

BARD, A.J.; FAULKNER, L.R. Electrochemical methods: fundamentals and applications. 2.ed. New York, N.Y.: Wiley, 2001.

BATTERY UNIVERSITY. What's the Best Battery?.

Disponível em: <http://batteryuniversity.com/learn/archive/whats the best battery>. Acesso em: 17 ago. 2015.

BUSCHOW, K.H.J.; MAL, H.H. van. Phase relations and hydrogen absorption in the lanthanum-nickel system. J. Less Common Met., v. 29, p. 203-210, 1972.

CASINI, J.C.S. Hidrogenação de ligas à base de terras raras para fabricação de eletrodos negativos de bateriais de níquel-hidreto metálico. 2011. Dissertacão (Mestrado) - Instituto de Pesquisas Energéticas e Nucleares, São Paulo.

CASINI, J.C.S. Influência da substituição do cobalto por estanho e cobre na microestrutura e propriedades elétricas em ligas a base de LaMgAIMnCoNi. 2015. Tese (Doutorado) - Instituto de Pesquisas Energéticas e Nucleares, São Paulo. 
CHEN, J.; DOU, S.X.; LIU, H.K. Effect of partial substitution of La with Ce, $\mathrm{Pr}$ and $\mathrm{Nd}$ on the properties of $\mathrm{LaNi}_{5}$-based alloy electrodes. J. Power Sources, v. 63, p. 267-270, 1996.

CHEN, J.; KURIYAMA, N.; TAKESHITA, H. T.; TANAKA, H.; SAKAI, T.; HARUTA, M. Hydrogen storage alloys with $\mathrm{PuNi}_{3}$ - type structure as metal hydride electrodes. Electrochem. Solid-State Lett., v. 3, n. 6, p. 249-252, 2000.

CHEN, Z.H.; LU, M.Q.; WANG, Y.L.; HU, Z.Q. Effect of Pr content in MI on the electrochemical properties of $\mathrm{MI}(\mathrm{Ni}-\mathrm{Co}-\mathrm{Mn}-\mathrm{Al})_{5}$ alloys. J. Alloys Compd., v. 231, p. 550-5852, 1995.

CHENG, L.F.; WANG, R.B.; PU, Z.H.; LI, Z.L.; HE, D.N.; XIA, B.J. Study on microstructure and electrochemical performance of $\mathrm{La}_{0.7} \mathrm{Mg}_{0.3}\left(\mathrm{Ni}_{0.9} \mathrm{Co}_{0.1}\right)_{X}$ hydrogen storage alloys. J. Power Sources, v. 185, p. 1519-1523, 2008.

CHU, H.; QIU, S.; SUN, L.; ZHANG, Y.; XU, F.; ZHU, M.; HU, W. Electrochemical hydrogen storage properties of $\mathrm{La}_{0.7} \mathrm{Mg}_{0.3} \mathrm{Ni}_{3.5^{-}}$ $\mathrm{Ti}_{0.17} \mathrm{Zr}_{0.08} \mathrm{~V}_{0.35} \mathrm{Cr}_{0.1} \mathrm{Ni}_{0.3}$ composites. Int. J. Hydrogen Energy, v. 33, p. 755-761, 2008a.

CHU, H.; ZHANG, Y.; QIU, S.; QI, Y.; SUN, L.; XU, F.; WANG, Q.; DONG, C. Electrochemical performances of cobalt-free $\mathrm{La}_{0.7} \mathrm{Mg}_{0.3} \mathrm{Ni}_{3.5-x}\left(\mathrm{MnAl}_{2}\right)_{x}$ $(x=0-0.20)$ hydrogen storage alloy electrodes. J. Alloys Compd., v. 457, p. 90-96, 2008b.

CUSCUETA, D.J.; MELNICHUK, M.; PERETTI, H.A.; SALVA, H.R.; GHILARDUCCI, A.A. Magnesium influence in the electrochemical properties of La-Ni base alloy for Ni-MH batteries. Int. J. Hydrogen Energy, v. 33, n. 13, p. 3566-3570, 2008.

DALL' ANTONIA, L.H. Caracterização eletroquímica e ótica de filmes de óxido espesso crescidos sobre ouro. 1995. Dissertação (Mestrado) Universidade de São Paulo, São Carlos.

DENYS, R.V.; YARTYS, V.A. Effect of magnesium on the crystal structure and thermodynamics of the $\mathrm{La}_{3-\mathrm{x}} \mathrm{Mg}_{\mathrm{x}} \mathrm{Ni}_{9}$ hydrides. J. Alloys Compd., v. 509S, p. S540-S548, 2011.

DONG, X.; LÜ, F.; YANG, L.; ZHANG, Y.; WANG, X. Influence of spark plasma sintering temperature on electrochemical performance of $\mathrm{La}_{0.80} \mathrm{Mg}_{0.20} \mathrm{Ni}_{3.75}$ alloy. Mater. Chem. Phys., v. 112, p. 596-602, $2008 \mathrm{a}$. 
DONG, X.; LÜ, F.; ZHANG, Y.; YANG, L.; WANG, X. Effect of La/Mg on the structure and electrochemical performance of $\mathrm{La}-\mathrm{Mg}-\mathrm{Ni}$ system hydrogen storage electrode alloy. Mater. Chem. Phys., v. 108, p. 251-256, 2008 b.

ESA - Energy Storage Association. Energy storage technologies. Disponível em: <http://energystorage.org/energy-storage/energy-storagetechnologies >. Acesso em: 17 ago.2015.

FARIA, R.N.; ZARPELON, L.M.C.; SERNA, M.M. Baterias recarregáveis introdução aos materiais e cálculos. São Paulo: Artlilber, 2014.

FENG, F.; GENG, M.; NORTHWOOD, D.O. Electrochemical behaviour of intermetallic-based metal hydrides used in Ni/metal hydride $(\mathrm{MH})$ batteries: a review. Int. J. Hydrogen Energy, v. 26, n. 7, p. 725-734, 2001.

FERREIRA, E.A. Estudo da hidrogenação para pulverização de ligas à base de terras raras com Nb para eletrodos de hidreto metálico. 2013. Tese (Doutorado) - Instituto de Pesquisas Energéticas e Nucleares, São Paulo.

FETCENKO, M. Propulsion and industrial nickel-metal hydride batteries. In: LINDEN, D.; REDDY, T.B. (Ed.). Handbook of batteries. 3.ed. New York, N.Y.: McGraw-Hill, 2002. p. 30.1-30.37.

GALDINO, G.S. Influência do Pr na microestrutura e propriedades elétricas em ligas à base de LaPrMgAIMnCoNi utilizadas em baterias de Ni-HM. 2011. Dissertação (Mestrado) - Instituto de Pesquisas Energéticas e Nucleares, São Paulo.

GAO, J.; YAN, X.L.; ZHAO, Z.Y.; CHAl, Y.J.; HOU ,D.L. Effect of annealed treatment on microstructure and cyclic stability for La-Mg-Ni hydrogen storage alloys. J. Power Sources, v. 209, p. 257-261, 2012.

GAO, Z.; LUO, Y.; LI, R.; LIN, Z.; KANG, L. Phase structures and electrochemical properties of $\mathrm{La}_{0.8-x} \mathrm{Gd}_{0.2} \mathrm{Mg}_{\mathrm{x}} \mathrm{Ni}_{3.1} \mathrm{Co}_{0.3} \mathrm{Al}_{0.1}$ hydrogen storage alloys. J. Power Sources, v. 241, p. 509-516, 2013.

HSIA, B. Materials synthesis and characterization for microsupercapacitor applications. 2013. Dissertation (partial satisfaction of the requirements for the degree of Doctor of Philosophy) - University of California, Berkeley. 
INOUE, H.; HIGUCHI, E. Electrode materials for nickel/metal hydride (Ni/MH) rechargeable batteries. In: XU, Q.; KOBAYASHI, T. (Ed.). Advanced materials for clean energy. Boca Raton: CRC, 2015. p. 201-227.

KADIR, K.; SAKAI, T.; UEHARA, I. Structural investigation and hydrogen storage capacity of $\mathrm{LaMg}_{2} \mathrm{Ni}$ and $\left(\mathrm{La}_{0.65} \mathrm{Ca}_{0.35}\right)\left(\mathrm{Mg}_{1.32} \mathrm{Ca}_{0.68}\right) \mathrm{Ni}_{9}$ of the $\mathrm{AB}_{2} \mathrm{C}_{9}$ type structure. J. Alloys Compd., v. 302, n. 1-2, p. 112-117, 2000.

KADIR, K.; SAKAI, T.; UEHARA, I. Synthesis and structure determination of a new series of hydrogen storage alloys: $\mathrm{RMg}_{2} \mathrm{Ni}_{9}$ ( $\mathrm{R}=\mathrm{La}, \mathrm{Ce}, \mathrm{Pr}, \mathrm{Nd}, \mathrm{Sm}$ and $\mathrm{Gd}$ ) built from $\mathrm{MgNi}_{2}$ Laves-type layers alternating with $\mathrm{AB}_{5}$ layers. J. Alloys Compd., v. 257, n. 1-2, p. 115-121, 1997.

KIEHNE, H.A.; RAUDSZUS, W. Feasibility study for appliances. In: KIEHNE, H.A. (Ed.). Battery technology handbook. 2.ed. New York, N.Y.: Marcel Dekker, 2003. cap. 16.

KLEPERIS, J.; WÓJCIK, G.; CZERWINSKI, A.; SKOWRONSKI, J.; KOPCZYK, M.; BELTOWSKA-BRZEZINSKA, M. Electrochemical behavior of metal hydrides. J. Solid State Electrochim., v. 5, p. 229-249, 2001.

KOHNO, T.; YOSHIDA, H.; KAWASHIMA, F.; INABA, T.; SAKAI, I.; YAMAMOTO. M.; KANDA. M. Hydrogen storage properties of new ternary system alloys: $\mathrm{La}_{2} \mathrm{MgNi}_{9}, \mathrm{La}_{5} \mathrm{Mg}_{2} \mathrm{Ni}_{23}, \mathrm{La}_{3} \mathrm{MgNi}_{14}$. J. Alloys Compd., v. 311, p. L5-L7, 2000.

LI, B.; REN, H.; ZHANG, Y.; DONG, X.; REN, J.; WANG, X. Microstructure and electrochemical performances of $\mathrm{La}_{0.7} \mathrm{Mg}_{0.3} \mathrm{Ni}_{2.55-x} \mathrm{Co}_{0.45} \mathrm{Al}_{x}(x=0-0.4)$ hydrogen storage alloys prepared by casting and rapid quenching. J. Alloys Compd., v. 425, p. 399-405, 2006.

LI, F.; YOUNG, K.; T. OUCHI, T.; FETCENKO, M.A. Annealing effects on structural and electrochemical properties of (LaPrNdZr $)_{0.83} \mathrm{Mg}_{0.17}(\mathrm{NiCoAIMn})_{3.3}$ alloy. J. Alloys Compd., v. 471, p. 371-377, 2009.

LI, M.; HAN, S.; LI, Y.; GUAN, W.; MAO, L.; HU, L. Study on the phase structure and electrochemical properties of $\mathrm{R}_{0.93} \mathrm{Mg}_{0.07} \mathrm{Ni}_{2.96} \mathrm{Co}_{0.60} \mathrm{Mn}_{0.3} 7 \mathrm{Al}_{0.17}$ hydrogen storage alloy. Electrochim. Acta, v. 51, p. 5926-5931, 2006.

LI, R.; WU, J.; ZHOU, S.; WANG, X. Effects of rare-earth content and annealing on the electrochemical properties of $\mathrm{Mm}(\mathrm{NiCoMnAl})_{5}$ hydrogen storage alloys. J. Alloys Compd., v. 363, p. 292-298, 2004. 
LI, S.; CHEN, W.; LUO, G.; HAN, X.; CHEN, D.; YANG, K.; CHEN, W. Effect of hydrogen absorption/desorption cycling on hydrogen storage properties of a LaNi ${ }_{3.8} \mathrm{Al}_{1.0} \mathrm{Mn}_{0.2}$ alloy. Int. J. Hydrogen Energy, v. 37, p. 3268-3275, 2012.

LI, Y.; HAN, D.; HAN, S.; ZHU, X.; HU, L.; ZHANG, Z.; LIU, Y. Effect of rare earth elements on electrochemical properties of $\mathrm{La}-\mathrm{Mg}-\mathrm{Ni}$-based hydrogen storage alloys. Int. J. Hydrogen Energy, v. 34, n. 3, p. 1399-1404, 2009.

LIAO, B.; LEI, Y.Q.; CHEN, L.X.; LU, G.L.; PAN, H.G.; WANG, Q.D. A study on the structure and electrochemical properties of $\mathrm{La}_{2} \mathrm{Mg}\left(\mathrm{Ni}_{0.95} \mathrm{M}_{0.05}\right)_{9}$ ( $\mathrm{M}=\mathrm{Co}, \mathrm{Mn}, \mathrm{Fe}, \mathrm{Al}, \mathrm{Cu}, \mathrm{Sn}$ ) hydrogen storage electrode alloys. J. Alloys Compd., v. 376, p. 186-195, 2004a.

LIAO, B.; LEI, Y.Q.; CHEN, L.X.; LU, G.L.; PAN, H.G.; WANG, Q.D. Effect of the $\mathrm{La} / \mathrm{Mg}$ ratio on the structure and electrochemical properties of $\mathrm{La}_{x} \mathrm{Mg}_{3-x} \mathrm{Ni}_{9}(x=1.6-2.2)$ hydrogen storage electrode alloys for nickel-metal hydride batteries. J. Power Sources, v. 129, p. 358-367, 2004b.

LIAO, B.; LEI, Y.Q.; CHEN, L.X.; LU, G.L.; PAN, H.G.; WANG, Q.D. The effect of $\mathrm{Al}$ substitution for $\mathrm{Ni}$ on the structure and electrochemical properties of $\mathrm{AB}_{3}$-type $\mathrm{La}_{2} \mathrm{Mg}\left(\mathrm{Ni}_{1-x} \mathrm{Al}_{x}\right)_{9}(x=0-0.05)$ alloys. J. Alloys Compd., v. 404-406, p. 665-668, 2005.

LIAO, B.; LEI, Y.Q.; LU, G.L.; CHEN, L.X.; PAN, H.G.; WANG, Q.D. The electrochemical properties of $\mathrm{La}_{x} \mathrm{Mg}_{3-x} \mathrm{Ni}_{9}(x=1.0-2.0)$ hydrogen storage alloys. J. Alloys Compd., v. 356-357, p. 746-749, 2003.

LIM, K.L.; LIU, Y.; ZHANG, Q.A.; LIN, K.S.; CHAN, S.L.I. Cycle stability improvement of La-Mg-Ni based alloys via composite method. J. Alloys Compd., v. 661, p. 274-281, 2016.

LIU, J.; HAN, S.; LI, Y.; YANG, S.; CHEN, X.; WU, C.; MA, C. Effect of Pr on phase structure and cycling stability of La-Mg-Ni-based alloys with $A_{2} B_{7^{-}}$ and $\mathrm{A}_{5} \mathrm{~B}_{19}$-type superlattice structures. Electrochim. Acta, v. 184, p. 257-263, 2015a.

LIU, J.; HAN, S.; LI, Y.; YANG, S.; ZHANG, L.; ZHAO, Y. Effect of AI incorporation on the degradation in discharge capacity and electrochemical kinetics of La-Mg-Ni-based alloys with $\mathrm{A}_{2} \mathrm{~B}_{7}$-type super-stacking structure. J. Alloys Compd., v. 619, p. 778-787, 2015b.

LIU, J.; HAN, S.; LI, Y.; ZHANG, J.; ZHAO, Y.; CHE, L. Effect of crystal transformation on electrochemical characteristics of La-Mg-Ni-based alloys with $\mathrm{A}_{2} \mathrm{~B}_{7}$-type super-stacking structures. Int. J. Hydrogen Energy, v. 38, p. 14903-14911, 2013. 
LIU, J.; HAN, S.; LI, Y.; ZHANG, J.; ZHAO, Y.; YANG, S.; LIU, B. Phase structures and electrochemical properties of La-Mg-Ni-based hydrogen storage alloys with superlattice structure. Int. J. Hydrogen Energy, v. 41, p. 20261-20275, 2016.

LIU, J.; LI, Y.; HAN, D.; YANG, S.; CHEN, X.; ZHANG, L.; HAN, S. Electrochemical performance and capacity degradation mechanism of single-phase La-Mg-Ni-based hydrogen storage alloys. J. Power Sources, v. 300 , p. $77-86,2015 \mathrm{c}$.

LIU, Y.; CAO, Y.; HUANG, L.; GAO, M.; PAN, H. Rare earth-Mg-Ni-based hydrogen storage alloys as negative electrode materials for $\mathrm{Ni}-\mathrm{MH}$ batteries. J. Alloys Compd., v. 509, n. 3, p. 675-686, 2011 a.

LIU, Y.; PAN, H.; GAO, M.; ZHU, Y.; LEI, Y. Hydrogen storage and electrochemical properties of the $\mathrm{La}_{0.7} \mathrm{Mg}_{0.3} \mathrm{Ni}_{3.825-} \mathrm{Co}_{0.675} \mathrm{Mn}_{x}$ hydrogen storage electrode alloys. J. Alloys Compd., v. 365, p. 246-252, 2004a.

LIU, Y.; PAN, H.; GAO, M.; LEI, Y.; WANG, Q. Degradation mechanism of the La-Mg-Ni-based metal hydride electrode $\mathrm{La}_{0.7} \mathrm{Mg}_{0.3} \mathrm{Ni}_{3.4} \mathrm{Mn}_{0.1}$. J. Electrochem. Soc., v. 152, n. 6, p. A1089-A1095, 2005 a.

LIU, Y.; PAN, H.; GAO, M.; LEI, Y.; WANG, Q. XRD study on the electrochemical hydriding/dehydriding behavior of the La-Mg-Ni-Co-type hydrogen storage alloys. J. Alloys Compd., v. 403, p. 296-304, 2005 b.

LIU, Y.; PAN, H.; GAO, M.; LI, R.; LEI, Y. Effect of Co content on the structural and electrochemical properties of the $\mathrm{La}_{0.7} \mathrm{Mg}_{0.3} \mathrm{Ni}_{3.4-x} \mathrm{Mn}_{0.1} \mathrm{Co}_{x}$ hydride alloys II. Electrochemical properties. J. Alloys Compd., v. 376, p. 304-313, 2004b.

LIU, Y.; PAN, H.; GAO, M.; LI, R.; LEI, Y. Effect of Co content on the structural and electrochemical properties of the $\mathrm{La}_{0.7} \mathrm{Mg}_{0.3} \mathrm{Ni}_{3.4-x} \mathrm{Mn}_{0.1} \mathrm{Co}_{x}$ hydride alloys I. The structure and hydrogen storage. J. Alloys Compd., v. 376, p. 296-303, 2004c.

LIU, Y.; PAN, H.; GAO, M.; MIAO, H.; LEI, Y.; WANG, Q. Function of Al on the cycling behavior of the La-Mg-Ni-Co-type alloy electrodes. Int. J. Hydrogen Energy, v. 33, n. 1, p. 124-133, 2008.

LIU, Y.; PAN, H.; GAO, M.; WANG, Q. Advanced hydrogen storage alloys for $\mathrm{Ni} / \mathrm{MH}$ rechargeable batteries. J. Mater. Chem., v. 21, n. 13, p. $4743-4755,2011 b$. 
LIU, Y.; PAN, H.; GAO, M.; ZHU, Y.; LEI, Y.; WANG, Q. The effect of Mn substitution for $\mathrm{Ni}$ on the structural and electrochemical properties of $\mathrm{La}_{0.7} \mathrm{Mg}_{0.3} \mathrm{Ni}_{2.55-x} \mathrm{Co}_{0.45} \mathrm{Mn}_{x}$ hydrogen storage electrode alloys. Int. J. Hydrogen Energy, v. 29, n. 3, p. 297-305, 2004d.

LIU, Y.; PAN, H.; LI, R.; LEI, Y. Effects of Al on cycling stability of a new rare-earth Mg-based hydrogen storage alloy. Mater. Sci. Forum, v. 475-479, p. 2457-2462, 2005c.

MA, J.; PAN, H.; CHEN, C.; WANG, Q. Effect of heat treatment on the microstructure and electrochemical properties of $A B_{5}$-type

$\mathrm{MINi}_{3,60} \mathrm{Co}_{0,85} \mathrm{Mn}_{0,40} \mathrm{Al}_{0,15}$ hydride alloy: 1.-The microstructure and $\mathrm{P}-\mathrm{C}$ isotherms. Int. J. Hydrogen Energy, v. 27, n. 1, p. 57-62, 2002.

MAL, H.H. van.; BUSCHOW, K.H.J.; MIEDEMA, A.R. Hydrogen absorption in $\mathrm{LaNi}_{5}$ and related compounds: experimental observations and their explanation. J. Less Common Met., v. 35, p. 65-76, 1974.

NOTTEN, P.H.L.; HOKKELING, P. Double-phase hydride forming compounds: a new class of highly electrocatalytic materials.

J. Electrochem. Soc., v. 128, n. 7, p. 1877-1885, 1991.

OESTERREICHER, H.; BITTNER, H. Hydride formation in $\mathrm{La}_{1-\mathrm{x}} \mathrm{Mg}_{\mathrm{x}} \mathrm{Ni}_{2}$. J. Less Common Met., v. 73, p. 339-344, 1980.

OLIVEIRA, F.C.M. Desenvolvimento de sensores eletroanalíticos utilizando eletrodos modificados com filme de bismuto. 2008. Dissertação (Mestrado) - Universidade de São Paulo, São Paulo.

OUYANG, L.Z.; CAO, Z.J.; LI, L.L.; WANG, H.; LIU, J.W.; MIN, D.; CHEN, Y.W.; XIAO, F.M.; TANG, R.H.; ZHU, M. Enhanced high-rate discharge properties of $\mathrm{La}_{11.3} \mathrm{Mg}_{6.0} \mathrm{Sm}_{7.4} \mathrm{Ni}_{61.0} \mathrm{Co}_{7.2} \mathrm{Al}_{7.1}$ with added graphene synthesized by plasma milling. Int. J. Hydrogen Energy, v. 39, p. 12765-12772, 2014.

OZAKI, T.; KANEMOTO, M.; KAKEYA, T.; KITANO, Y.; KUZUHARA, M.; WATADA, M.; TANASE, S.; SAKAI, T. J. Alloys Compd., v. 446-447, p. 620-624, 2007.

OZAKI, T.; YANG, H.B.; IWAKI, T.; TANASE, S.; SAKAI, T.; FUKUNAGA, H.; MATSUMOTO, N.; KATAYAMA, Y.; TANAKA, T.; KISHIMOTO, T.; KUZUHARA, M. Development of Mg-containing $\mathrm{MmNi}_{5}$-based alloys for lowcost and high-power Ni-MH battery. J. Alloys Compd., v. 408-412, p. 294-300, 2006. 
PAN, H.; CHEN, N.; GAO, M.; LI, R.; LEI, Y.; WANG, Q. Effects of annealing temperature on structure and the electrochemical properties of $\mathrm{La}_{0.7} \mathrm{Mg}_{0.3} \mathrm{Ni}_{2.45} \mathrm{Co}_{0.75} \mathrm{Mn}_{0.1} \mathrm{Al}_{0.2}$ hydrogen storage alloy. J. Alloys Compd., v. 397, n. 1-2, p. 306-312, 2005a.

PAN, H.; JIN, Q.; GAO, M.; LIU, Y.; LI, R.; LEI, Y. Effect of the cerium content on the structural and electrochemical properties of the $\mathrm{La}_{0.7-x} \mathrm{Ce}_{x} \mathrm{Mg}_{0.3} \mathrm{Ni}_{2.875} \mathrm{Mn}_{0.1} \mathrm{Co}_{0.525}(x=0-0.5)$ hydrogen storage alloys. J. Alloys Compd., v. 373, p. 237-245, 2004a.

PAN, H.; JIN, Q.; GAO, M.; LIU, Y.; LI, R.; LEI, Y.; WANG, Q. An electrochemical study of $\mathrm{La}_{0.4} \mathrm{Ce}_{0.3} \mathrm{Mg}_{0.3} \mathrm{Ni}_{2.975-x} \mathrm{Mn}_{x} \mathrm{Co}_{0.525}(x=0.1-0.4)$ hydrogen storage alloys. J. Alloys Compd., v. 376, p. 196-204, 2004b.

PAN, H.; LIU, Y.; GAO, M.; ZHU, Y.; LEI, Y.; WANG, Q. Structural and electrochemical properties of the $\mathrm{La}_{0.7} \mathrm{Mg}_{0.3} \mathrm{Ni}_{2.975-x} \mathrm{Co}_{0.525} \mathrm{Mn}_{x}$ hydrogen storage electrode alloys. J. Electrochem. Soc., v. 151, n. 3, p. A374-A380, 2004c.

PAN, H.; LIU, Y.; GAO, M.; LEI, Y.; WANG, Q. Electrochemical properties of the $\mathrm{La}_{0.7} \mathrm{Mg}_{0.3} \mathrm{Ni}_{2.65-x} \mathrm{Mn}_{0.1} \mathrm{Co}_{0.75} \mathrm{Al}_{x}(x=0-0.5)$ hydrogen storage alloy electrodes. J. Electrochem. Soc., v. 152, n. 2, p. A326-A332, $2005 b$.

PAN, H.; LIU, Y.; GAO, M.; ZHU, Y.; LEI, Y. The structural and electrochemical properties of $\mathrm{La}_{0.7} \mathrm{Mg}_{0.3}\left(\mathrm{Ni}_{0.85} \mathrm{Co}_{0.15}\right)_{\times}(\mathrm{x}=3.0-5.0)$ hydrogen storage alloys. Int. J. Hydrogen Energy, v. 28, n. 11, p. 1219-1228, 2003.

PAN, H.; MA, S.; SHEN, J.; TAN, J.; DENG, J.; GAO, M. Effect of the substitution of $\mathrm{Pr}$ for $\mathrm{La}$ on the microstructure and electrochemical properties of $\mathrm{La}_{0.7-x} \mathrm{Pr}_{x} \mathrm{Mg}_{0.3} \mathrm{Ni}_{2.45} \mathrm{Co}_{0.75} \mathrm{Mn}_{0.1} \mathrm{Al}_{0.2}(x=0.0-0.3)$ hydrogen storage electrode alloys. Int. J. Hydrogen Energy, v. 32, n. 14, p. 2949-2956, 2007.

PAN, H.; WU, X.; GAO, M.; CHEN, N.; YUE, Y.; LEI, Y. Structure and electrochemical properties of $\mathrm{La}_{0.7} \mathrm{Mg}_{0.3} \mathrm{Ni}_{2.45-x} \mathrm{Co}_{0.75} \mathrm{Mn}_{0.1} \mathrm{Al}_{0.2} \mathrm{~W}_{x}(x=0-0.15)$ hydrogen storage alloys. Int. J. Hydrogen Energy, v. 31, n. 4, p. 517-523, 2006.

PAN, H.; YUE, Y.; GAO, M.; WU, X.; CHEN, N.; LEI, Y.; WANG, Q. The effect of substitution of $\mathrm{Zr}$ for $\mathrm{La}$ on the electrochemical properties of $\mathrm{La}_{0.7-x} \mathrm{Zr}_{x} \mathrm{Mg}_{0.3} \mathrm{Ni}_{2.45} \mathrm{Mn}_{0.1} \mathrm{Co}_{0.75} \mathrm{Al}_{0.2}$ hydrogen storage electrode alloys. J. Alloys Compd., v. 397, p. 269-275, 2005c.

PENG, C.H.; ZHU, M. Microstructure and hydrogen storage properties of a multi-phase $\mathrm{Ml}_{0.7} \mathrm{Mg}_{0.3} \mathrm{Ni}_{3.2}$ hydrogen storage alloy. J. Alloys Compd., v. 375, n. 1-2, p. 324-329, 2004. 
REILLY, J.J. Metal hydride electrodes. In: BESENHARD, J.O. (Ed.).

Handbook of battery materials. Weinheim: Willey-VCH, 1999. cap. 7.

p. 209-230.

REILLY, J.J.; ADZIC, G.D.; JOHNSON, J.R.; VOGT, T.; MUKERJEE, S.; McBREEN, J. The correlation between composition and electrochemical properties of metal hydride electrodes. J. Alloys Compd., v. 293-295, p. 569-582, 1999.

RIIS, T.; SANDROCK, G.; ULLEBERG, Ø.; VIE, P.J.S. Hydrogen storage R\&D: priorities and gaps. In: Hydrogen production and storage - R\&D priorities and gaps, p. 19-23. Paris: OECD/IEA, 2006.

SAKAI, T.; MIYAMURA, H.; KURIYAMA, N.; KATO, A.; OGURO, K.; ISHIKAWA, H.; IWAKURA, C. The influence of small amounts of added elements on various anode performance characteristics for $\mathrm{LaNi}_{2,5} \mathrm{Co}_{2,5^{-}}$ based alloys. J. Less Common Met., v. 159, p. 127-139, 1990.

SHEN, W.; HAN, S.; LI, Y.; YANG, S.; MIAO, Q. Effect of electroplating polyaniline on electrochemical kinetics of $\mathrm{La}-\mathrm{Mg}-\mathrm{Ni}$-based hydrogen storage alloy. Appl. Surf. Sci., v. 258, p. 6316-6320, 2012.

SI, T.Z.; ZHANG, Q.A.; LIU, N. Investigation on the structure and electrochemical properties of the laser sintered $\mathrm{La}_{0.7} \mathrm{Mg}_{0.3} \mathrm{Ni}_{3.5}$ hydrogen storage alloys. Int. J. Hydrogen Energy, v. 33, p. 1729-1734, 2008.

SONG, D.; WANG, Y.; LIU, Y.; HAN, S.; JIAO, L.; YUAN, H. Effects of annealing on microstructures and electrochemical properties of $\mathrm{La}_{0.8} \mathrm{Mg}_{0.2} \mathrm{Ni}_{2.4} \mathrm{Mn}_{0.10} \mathrm{Co}_{0.55} \mathrm{Al}_{0.10}$ alloy. J. Rare Earths, v. 26, n. 3, p. 398-401, 2008.

SOUZA, E.C. Propriedades estruturais e eletroquímicas de ligas de hidreto metálico processadas por moagem de alta energia. 2006. Tese (Doutorado) - Universidade de São Paulo, São Carlos.

TANG, R.; LIU, Y.; ZHU, C.; ZHU, J.; YU, G. Effect of Mg on the hydrogen storage characteristics of $\mathrm{Ml}_{1-x} \mathrm{Mg}_{x} \mathrm{Ni}_{2.4} \mathrm{Co}_{0.6}(x=0-0.6)$ alloys. Mater. Chem. Phys., v. 95, n. 1, p. 130-134, 2006.

TIAN, X.; WEI, W.; DUAN, R.; ZHENG, X.; ZHANG, H.; TEGUS, O.; LI, X. Preparation and electrochemical properties of $\mathrm{La}_{0.70} \mathrm{Mg}_{x} \mathrm{Ni}_{2.45} \mathrm{Co}_{0.75} \mathrm{Al}_{0.30}$ (x = 0, 0.30, 0.33, 0.36, 0.39) hydrogen storage alloys. J. Alloys Compd. v. 672 , p. 104-109, 2016. 
VUCHT, J.H.N. van; KUIJPERS, F.A.; BRUNING H.C.A.M. Reversible room-temperature absorption of large quantities of hydrogen by intermetallic compounds. Philips Res. Rep., v. 25, p. 133-140, 1970.

WANG, D.; LUO, Y.; YAN, R.; ZHANG, F.; KANG, L. Phase structure and electrochemical properties of $\mathrm{La}_{0.67} \mathrm{Mg}_{0.33} \mathrm{Ni}_{3.0-x} \mathrm{Co}_{x}(x=0.0,0.25,0.5,0.75)$ hydrogen storage alloys. J. Alloys Compd., v. 413, p. 193-197, 2006.

WANG, J.; HAN, S.; LI, Y.; LIU, J.; CHE, L.; ZHANG, L.; ZHANG, J. Study on phase formation mechanism and electrochemical properties of $\mathrm{La}_{0.75-\mathrm{x}} \mathrm{Nd}_{\mathrm{x}} \mathrm{Mg}_{0.25} \mathrm{Ni}_{3.3}(\mathrm{x}=0,0.15)$ alloys prepared by powder sintering. J. Alloys Compd., v. 582, p. 552-557, 2014.

WEI, F.; LI, L.; XIANG, H.; LI, H.; WEI, F. Phase structure and electrochemical properties of $\mathrm{La}_{1.7+x} \mathrm{Mg}_{1.3-x}(\mathrm{NiCOMn})_{9.3}(x=0-0.4)$ hydrogen storage alloys. Trans. Nonferrous Met. Soc. China, v. 22, p. 1995-1999, 2012.

WILLEMS, J. J. G. Metal hydride electrodes stability of $\mathrm{LaNi}_{5}$ - related compounds. Philips J. Res., v. 39, p. 1-94, 1984. Supplement 1.

XIAO, L.; WANG, Y.; LIU, Y.; SONG, D.; JIAO, L.; YUAN, H. Influence of surface treatments on microstructure and electrochemical properties of $\mathrm{La}_{0.7} \mathrm{Mg}_{0.3} \mathrm{Ni}_{2.4} \mathrm{Co}_{0.6}$ hydrogen-storage alloy. Int. J. Hydrogen Energy, v. 33, p. 3925-3929, 2008.

YAN, H.; KONG, F.; XIONG, W.; LI, B.; LI, J. Effect of praseodymium substitution for lanthanum on structure and properties of $\mathrm{La}_{0.65-x} \mathrm{Pr}_{x} \mathrm{Nd}_{0.12} \mathrm{Mg}_{0.23} \mathrm{Ni}_{3.4} \mathrm{Al}_{0.1}(x=0.00-0.20)$ hydrogen storage alloys. J. Rare Earths, v. 27, n. 2, p. 244-249, 2009.

YANG, S.; HAN, S.; SONG, J.; LI, Y. Influences of molybdenum substitution for cobalt on the phase structure and electrochemical kinetic properties of AB5-type hydrogen storage alloys. J. Rare Earths, v. 29, n. 7; p. 692-697, 2011.

YOUNG, K. Electrochemical applications of metal hydrides. In: BADIR, F.; BASILE, A.; NEJAT VEZIROĞLU, T. (Ed.). Compendium of hydrogen energy. Cambridge, UK: WP Ltd. (imprint of Elsevier), 2016. v.3. Hydrogen energy conversion.

YOUNG, K.; NEI, J. The current status of hydrogen storage alloy development for electrochemical applications. Materials, v.6, p. 4574-4608, 2013. 
ZHANG, F.; LUO, Y.; CHEN, J.; YAN, R.; KANG, L.; CHEN, J. Effect of annealing treatment on structure and electrochemical properties of $\mathrm{La}_{0.67} \mathrm{Mg}_{0.33} \mathrm{Ni}_{2.5} \mathrm{CO}_{0.5}$ alloy electrodes. J. Power Sources, v. 150, p. 247-254, 2005.

ZHANG, F.; LUO, Y.; SUN, K.; WANG, D.; YAN, R.; KANG, L.; CHEN, J. Effect of Co content on the structure and electrochemical properties of $\mathrm{La}_{1.5} \mathrm{Mg}_{0.5} \mathrm{Ni}_{7-x} \mathrm{Co}_{x}(x=0,1.2,1.8)$ hydrogen storage alloys. J. Alloys Compd., v. 424, p. 218-224, 2006.

ZHANG, F.; LUO, Y.; WANG, D.; YAN, R.; KANG, L.; CHEN, J. Structure and electrochemical properties of $\mathrm{La}_{2-x} \mathrm{Mg}_{x} \mathrm{Ni}_{7.0}(x=0.3-0.6)$ hydrogen storage alloys. J. Alloys Compd., v. 439, p. 181-188, 2007.

ZHANG, P.; WEI, X.; LIU, Y.; ZHU, J.; ZHANG, Z.; ZHAO, T. The microstructures and electrochemical properties of non-stoichiometric low-Co $\mathrm{AB}_{5}$ alloys containing small amounts of Mg. J. Alloys Compd., v. 399, n. 1-2, p. 270-275, 2005.

ZHANG, W.; HAN, S.; HAO, J.; LI, Y.; BAI, T.; ZHANG, J. Study on kinetics and electrochemical properties of low-Co $A_{B}$-type alloys for high-power Ni/MH battery. Electrochim. Acta, v. 54, n. 4, p. 1383-1387, 2009.

ZHANG, X.; SUN, D.; YIN, W.; CHAI, Y.; ZHAO, M. Crystallographic and electrochemical characteristics of $\mathrm{La}_{0.7} \mathrm{Mg}_{0.3} \mathrm{Ni}_{3.5-x}\left(\mathrm{Al}_{0.5} \mathrm{Mo}_{0.5}\right)_{x}(x=0-0.8)$ hydrogen storage alloys. J. Power Sources, v. 154, p. 290-297, 2006.

ZHANG, Y.; CAI, Y.; LI, B.; REN, H.; HOU, Z.; ZHAO, D. Electrochemical hydrogen storage characteristics of the as-cast and annealed $\mathrm{La}_{0.8-\mathrm{x}} \mathrm{Pr}_{x} \mathrm{Mg}_{0.2} \mathrm{Ni}_{3.35} \mathrm{Al}_{0.1} \mathrm{Si}_{0.05}$ ( $\left.x=0 \sim 0.4\right)$ electrode alloys. Rare Met. Mater. Eng., v. 42, n. 10, p. 1981-1987, 2013.

ZHANG, Y.; CAI, Y.; ZHAO, C.; ZHAI, T.; ZHANG, G.; ZHAO, D. Electrochemical performances of the as-melt $\mathrm{La}_{0.75-x} \mathrm{M}_{x} \mathrm{Mg}_{0.25} \mathrm{Ni}_{3.2} \mathrm{Co}_{0.2} \mathrm{Al}_{0.1}$ $(\mathrm{M}=\mathrm{Pr}, \mathrm{Zr} ; x=0,0.2)$ alloys applied to Ni/metal hydride $(\mathrm{MH})$ battery. Int. J. Hydrogen Energy, v. 37, p. 14590-14597, 2012a.

ZHANG, Y.; HOU, Z.; LI, B.; REN, H.; ZHANG, G.; ZHAO, D. An investigation on electrochemical hydrogen storage performances of the ascast and -annealed $\mathrm{La}_{0.8-x} \mathrm{Sm}_{x} \mathrm{Mg}_{0.2} \mathrm{Ni}_{3.35} \mathrm{Al}_{0.1} \mathrm{Si}_{0.05}(x=0-0.4)$ alloys. J. Alloys Compd., v. 537, p. 175-182, 2012 b. 
ZHANG, Y.; LI, P.; YANG, T.; ZHAI, T.; YUAN, Z.; GUO, S. Effects of substituting La with $\mathrm{M}(\mathrm{M}=\mathrm{Sm}, \mathrm{Nd}, \mathrm{Pr})$ on electrochemical hydrogen storage characteristics of $A_{2} B_{7}$-type electrode alloys. Trans. Nonferrous Met. Soc.

China, v. 24, p. 4012-4022, 2014.

ZHANG, Y.; REN, H.; LI, B.; GUO, S.; WANG, Q.; WANG, X. Structures and electrochemical hydrogen storage behaviours of $\mathrm{La}_{0.75-x} \mathrm{Pr}_{\mathrm{x}} \mathrm{Mg}_{0.25} \mathrm{Ni}_{3.2} \mathrm{CO}_{0.2} \mathrm{Al}_{0.1}(\mathrm{x}=0-0.4)$ alloys prepared by melt spinning.

Int. J. Hydrogen Energy, v. 34, p. 6335-6342, 2009.

ZHANG, Y.; YANG, T.; ZHAI, T.; YUAN, Z.; ZHANG, G.; GUO, S. Effects of stoichiometric ratio $\mathrm{La} / \mathrm{Mg}$ on structures and electrochemical performances of as-cast and annealed $\mathrm{La}-\mathrm{Mg}-\mathrm{Ni}$-based $\mathrm{A}_{2} \mathrm{~B}_{7}$-type electrode alloys.

Trans. Nonferrous Met. Soc. China, v. 25, p. 1968-1977, 2015.

ZHANG, Z.; HAN, S.; LI, Y.; JING, T. Electrochemical properties of $\mathrm{Ml}_{1-x} \mathrm{Mg}_{x} \mathrm{Ni}_{3.0} \mathrm{Mn}_{0.10} \mathrm{Co}_{0.55} \mathrm{Al}_{0.10}(x=0.05-0.30)$ hydrogen storage alloys. J. Alloys Compd., v. 431, n. 1-2. p. 208-211, 2007.

ZHONG, C.; CHAO, D.; CHEN, Y.; WANG, W.; ZHU, D.; WU, C. Microstructures and electrochemical properties of $\mathrm{LaNi}_{3.8-\mathrm{x}} \mathrm{Mn}_{\mathrm{x}}$ hydrogen storage alloys. Electrochim. Acta, v. 58, p. 668-673, 2011.

ZHOU, Z.; SONG, Y.; CUI,S.; HUANG, C.; QIAN, W.; LIN, C.; ZHANG, Y.; LIN, Y. Effect of annealing treatment on structure and electrochemical performance of quenched $\mathrm{MmNi}_{4.2} \mathrm{Co}_{0.3} \mathrm{Mn}_{0.4} \mathrm{Al}_{0.3} \mathrm{Mg}_{0.03}$ hydrogen storage alloy. J. Alloys Compd., v. 501, n. 1, p. 47-53, 2010. 


\section{PRODUÇÃO TÉCNICO-CIENTÍFICA}

\section{Livro}

FARIA, R.N.; ZARPELON, L.M.C.; SERNA, M.M. Baterias recarregáveis

- introdução aos materiais e cálculos. São Paulo: Artlilber, 2014.

\section{Artigos em periódicos}

ZARPELON, L.M.C.; FARIA, R.N.; LIMA, N.B. Refinement of the structure of $\mathrm{La}_{0,7-x} \mathrm{Mg}_{x} \mathrm{Pr}_{0,3} \mathrm{Al}_{0,3} \mathrm{Mn}_{0,4} \mathrm{Co}_{0,5} \mathrm{Ni}_{3,8}$ battery alloys by Rietveld analysis of $\mathrm{X}$-ray powder diffraction data. a ser submetido em 2017.

ZARPELON, L.M.C.; BANCZEK, E.P.; SOUZA, K.P.; COSTA, I.; FARIA JUNIOR, R.N. Effects of magnesium content on structure and corrosion resistance of $\mathrm{La}-\mathrm{Mg}$-Pr-Al-Mn-Co-Ni hydrogen storage alloys. a ser submetido em 2017.

ZARPELON, L.M.C.; FARIA JUNIOR, R.N. Microstructure and electrochemical characteristics of LaPrMgAIMnCoNi hydrogen storage alloys for nickel-metal hydride batteries. Mater. Sci. Forum, v. 802, p. 421-426, 2014.

CASINI, J.C.S.; ZARPELON, L.M.C.; FERREIRA, E.A.; TAKIISHI, H.; FARIA, R.N. Hydrogenation and discharge capacity of a $\mathrm{La}_{0.7} \mathrm{Mg}_{0.3} \mathrm{Al}_{0.3} \mathrm{Mn}_{0.4} \mathrm{Co}_{0.5} \mathrm{Ni}_{3.8}$ alloy for nickel-metal hydride batteries. Mater. Sci. Forum, v. 660-661, p. 128-132, 2010.

FERREIRA, E.A.; ZARPELON, L.M.C.; CASINI, J.C.S.; TAKIISHI, H.; FARIA, R.N. The effect of high charging rates activation on the specific discharge capacity and efficiency of a negative electrode based on a LaMgAIMnCoNi alloy. Mater. Sci. Forum, v. 660-661, p. 133-138, 2010.

BANCZEK, E.P.; ZARPELON, L.M.C.; FARIA, R.N.; COSTA, I. Corrosion resistance and microstructure characterization of rare-earth-transition metal-aluminum-magnesium alloys. J. Alloys Compd., v. 479, n. 1-2, p. 342-347, 2009. 
ZARPELON, L.M.C.; GALEGO, E.; TAKIISHI, H.; FARIA JR, R.N.

Microstructure and composition of rare earth-transition metal-aluminiummagnesium alloys. Mater. Res., v. 11, p. 17-21, 2008.

\section{Trabalhos apresentados em congressos}

SOARES, E.P.; ZARPELON, L.M.C.; FARIA, R.N. The influence of Pr and Mg content on the hydrogen decrepitation of LaNi-based battery alloys. TENTH INTERNATIONAL LATIN AMERICAN CONFERENCE ON POWDER TECHNOLOGY - PTECH 2015, Nov. 8-11, 2015, Mangaratiba, RJ.

ZARPELON, L.M.C.; FARIA JUNIOR, R.N. Microstructure and electrochemical characteristics of LaPrMgAIMnCoNi hydrogen storage alloys for nickel-metal hydride batteries. NINTH INTERNATIONAL LATIN AMERICAN CONFERENCE ON POWDER TECHNOLOGY - PTECH 2013, Oct. 27-29, 2013, Campos do Jordão, SP.

CASINI, J.C.S.; ZARPELON, L.M.C.; FERREIRA, E.A.; TAKIISHI, H.; FARIA, R.N. Hydrogenation and discharge capacity of a $\mathrm{La}_{0.7} \mathrm{Mg}_{0.3} \mathrm{Al}_{0.3} \mathrm{Mn}_{0.4} \mathrm{Co}_{0.5} \mathrm{Ni}_{3.8}$ alloy for nickel-metal hydride batteries. SEVENTH INTERNATIONAL LATIN-AMERICAN CONFERENCE ON POWDER TECHNOLOGY - PTECH 2009, Nov. 8-10, 2009, Atibaia, SP.

FERREIRA, E.A.; ZARPELON, L.M.C.; CASINI, J.C.S.; TAKIISHI, H.; FARIA, R.N. The effect of high charging rates activation on the specific discharge capacity and efficiency of a negative electrode based on a LaMgAIMnCoNi alloy. SEVENTH INTERNATIONAL LATIN-AMERICAN CONFERENCE ON POWDER TECHNOLOGY - PTECH 2009, Nov. 8-10, 2009, Atibaia, SP.

ZARPELON, L. M. C.; GALEGO, E.; TAKIISHI, H.; FARIA JR, R.N. Microstructural and chemical microanalysis studies of rare earth-transition metal-aluminium-magnesium alloys. CONGRESSO BRASILEIRO DE ENGENHARIA E CIÊNCIA DOS MATERIAIS -17을 CBECIMAT, 2006, 15-19 Nov., Foz do Iguaçu. S.Paulo: Metallum, 2006. v. 1. p. 5424-5435. 